UNIVERSIDADE DE SÃO PAULO

FACULDADE DE ECONOMIA, ADMINISTRAÇÃO E CONTABILIDADE DEPARTAMENTO DE ADMINISTRAÇÃO PROGRAMA DE PÓS-GRADUAÇÃO EM ADMINISTRAÇÃO

UMA AVALIAÇÃO DO CAPITAL REGULATÓRIO NO SISTEMA BANCÁRIO

Rodrigo Barbone Gonzalez

Orientador: Prof. Dr. José Roberto Ferreia Savoia

SÃO PAULO 
Prof. Dr. João Grandino Rodas

Reitor da Universidade de São Paulo

Prof. Dr. Reinaldo Guerreiro

Diretor da Faculdade de Economia, Administração e Contabilidade

Prof. Dr. Adalberto Américo Fischmann

Chefe do Departamento de Administração

Prof. Dr. Lindolfo Galvão de Albuquerque

Coordenador do Programa de Pós-Graduação em Administração 


\title{
UMA AVALIAÇÃO DO CAPITAL REGULATÓRIO NO SISTEMA BANCÁRIO
}

\author{
Tese apresentada ao Departamento de \\ Administração da Faculdade de \\ Economia, Administração e \\ Contabilidade da Universidade de São \\ Paulo como requisito para a obtenção do \\ título de Doutor em Administração.
}

Orientador: Prof. Dr. José Roberto Ferreira Savoia

Versão Corrigida

(versão original disponível na Faculdade de Economia, Administração e Contabilidade)

\section{SÃO PAULO}




\section{Gonzalez, Rodrigo Barbone}

Uma avaliação do capital regulatório no Sistema Bancário / Rodrigo Barbone Gonzalez. -- São Paulo, 2012.

$189 \mathrm{p}$.

Tese (Doutorado) - Universidade de São Paulo, 2012

Bibliografia.

1. Basileia - Regulação 2. Bancos - Brasil 3. Risco de Crédito 4.VaR

I. Universidade de São Paulo. Faculdade de Economia, Administração de Empresas e Contabilidade

$\mathrm{CDD}-$ 
Ao Deus Pai, que graciosamente me capacita e me concede todas as coisas. 
Agradecer a todos que diretamente e indiretamente me auxiliaram nessa etapa da minha vida que convergiu para a realização desse estudo não é fácil. Sinto que devo muito e acima de tudo a Deus, a minha família, aos amigos e às instituições que me apoiaram, em especial a Faculdade de Economia, Administração e Contabilidade da Universidade de São Paulo (FEA-USP), a Columbia University, ao Banco Central do Brasil e a CAPES. Nominalmente, não posso deixar de agradecer ao meu orientador na FEA-USP Prof. Dr. José Roberto Ferreira Savoia por todo o apoio e incentivo desde o meu mestrado e por ter me enviado ao Institute for Latin American Studies (ILAS) na Columbia University e aos demais membros da minha banca de qualificação composta pelo Prof. Dr. José Roberto Securato e pelo Prof. Dr. Antonio Zoratto Sanvicente cujas recomendações foram fundamentais. Na Columbia University, ao meu co-orientador, Prof. Dr. Thomas Trebat, diretor do ILAS, e a toda sua equipe, aos valiosíssimos comentários e sugestões dos Profs. Drs. Charles Calomiris, Paul Glasserman, Irene Finel-Honigman e aos do meu amigo Prof. Fernando Sotelino. No Federal Reserve, não posso deixar de agradecer a Michael Gordy e a Mark Carey por terem me ajudado em momentos decisivos. Agradeço ainda aos colegas Lucas Leehman, Raul Segura e Gustavo Guimarães por terem despendido muitas horas preciosas de seu tempo me auxiliando com os códigos e a programação necessária para esse trabalho.

No Banco Central, sou grato ainda a Simone Miyuki pela extração dos dados, a Guilherme Yanaka pelos conselhos e aos amigos Eduardo Vieira dos Santos Paiva e Fabiano Gabriel.

Finalmente, agradeço o companheirismo e carinho de Julieta Mejía, Alessandro Di Gió, Catherine e Marcelo Hazan, Karin Vasquez, Samuel Bandeira; a Loide Bitencourth, Magdala Matesco e suas famílias e ao imenso amor de Cássio, Marilisa e toda família Barbosa. Sou grato ainda à dedicação de Maria Helena Uliani ao longo dos anos e à sabedoria do Bispo Wesley Bandeira, cujas palavras têm continuamente me guiado e amparado. Ao meu pai e minha mãe, também quero honrar e agradecer. Por todos vocês, cheguei até aqui. 
"a mão invisível era invisível porque não estava lá" 


\section{RESUMO}

Esse estudo avalia a adequação dos requerimentos absolutos de capital no Brasil para bancos pequenos e grandes separadamente e investiga os requerimentos de capital mínimo para risco de crédito nas diferentes abordagens de Basiléia, em especial o impacto da adoção dos modelos dos ratings internos (IRB) conforme o Edital BCB n. 37/11. Além disso, propõe e avalia a abordagem padronizada dos ratings centralizados, CRBA, para cálculo do Capital Mínimo Exigido (CME) em bancos pequenos e que é baseada na abordagem padronizada em vigor na Europa, mas voltada para dados disponíveis nas Centrais de Risco. A CRBA pertence à família dos modelos internos e busca contribuir com as recentes discussões sobre a reforma regulatória bancária na Europa e nos Estados Unidos. Para os três objetivos mencionados, as metodologias adotadas foram: 1) o Valuet-at-Risk (VaR) não paramétrico de Crédito (CVaR) de Carey (2002) e o paramétrico Creditrisk+ para estimar o capital econômico do Sistema Bancário; seguido da 2) estimação amostral e avaliação do capital regulatório para bancos pequenos e grandes nas abordagens IRB, Basileia 1, abordagem padrão simplificada (SSA); além da 3) avaliação da abordagem proposta nesse estudo, a CRBA. A performance de todas essas abordagens é avaliada frente a cenários de stress ad hoc e durante a Crise de 2008-2009. Os dados utilizados foram exposições de crédito aleatórias colhidas da Nova Central de Risco do Banco Central do Brasil (SCR). Os principais resultados desse estudo são: 1) sugerir um capital regulatório total (Patrimônio de Referência mais provisão) para bancos grandes de $17,5 \%$ baseado no CVaR paramétrico de $99,9 \%$ e, para pequenos, de $15,31 \%$ baseado no $\mathrm{CVaR}$ de $99 \%$; 2) sugerir que, de todas as abordagens de Basileia II, o IRB estimado conforme o Edital BCB n. 37/2011 e para as Probabilidade de Default (PDs) calculadas por matrizes de migração do SCR, é o mais conservador; 3) sugerir que a abordagem proposta seja mais sensível ao risco de crédito do que atual brasileira, especialmente no varejo, além de oferecer um nível proteção maior contra choques aleatórios de crédito. Na Crise de 2008-2009, os bancos pequenos e grandes apresentaram respostas muito distintas a choques diversos ou quando os "estados da economia" se deterioravam. Os bancos pequenos não atingem o grau de diversificação necessário para minimizar perdas extremas. Por outro lado, do ponto de vista do risco sistêmico, a falência dessas entidades tem impactos muito menores que a de conglomerados bancários de porte. Finalmente, a abordagem proposta CRBA é apresentada como uma alternativa à abordagem atual no Brasil e à abordagem padronizada (SA) nos demais países, em especial na Europa. No Brasil, a CRBA cumpriria o papel de aumentar a sensibilidade a risco de crédito do CME nos bancos pequenos criando incentivos para uma gestão de risco de crédito mais cautelosa e alinhando o nível de capital dos bancos pequenos ao seu risco efetivo. Nos demais países, a CRBA é uma alternativa à abordagem padronizada, que independe da opinião das Agências de Classificação de Risco (ACRs). A CRBA traz dois benefícios: o primeiro de ampliar o escopo dos modelos internos e eliminar a dependência regulatória na opinião das ACRs, diminuindo a oportunidade de arbitragem regulatória com ratings inflacionados e corrigindo incentivos para que as ACRs sejam apenas provedoras de opiniões isentas; e o segundo, de prover os organismos supervisores com um mecanismo de controle (tracking error) sobre a qualidade de gestão de risco dos bancos pequenos por meio das Centrais de Risco. 


\begin{abstract}
This work analyses capital requirements adequacy in Brazil both for small and big banks individually and evaluates the minimum capital requirements for credit risk in the different Basel II approaches, especially, the impacts of IRB adoption as stated on Edital BCB n.37/11. Besides, it proposes and evaluates the Centralized Standard Ratings Based Approach (CRBA) to calculate Minimum Capital Requirements (MCR) in small banks. It is inspired in the Basel II Standard Approach (SA) disseminated in Europe, but based on information from the Credit Registers. The CRBA is an internal model approach in line with recent discussions on regulatory reform in Europe and in the US. The methodology to address these three research goals is: the non-parametric credit Value-at-Risk (VaR) or CVaR of Carey(2002) and the parametric Creditrisk+ to estimate the economic capital for the banking system; to evaluate regulatory capital in small and big banks in the IRB, Basel 1 and the Simplified Standard Approach (SSA) on the sample; and to evaluate the CRBA, proposed in this study. The performance of these approaches is confronted with ad hoc stress scenarios and within the Credit Crisis of 2008-2009. The data is comprised of credit exposures available in the Brazilian Credit Register (SCR). This work main results are: 1) to suggest a total regulatory capital (capital and provision) of $17.5 \%$ to big banks based on a parametric CVaR (99.9\%) and of $15.31 \%$ to small banks based on a CVaR (99\%); 2) to suggest, based on all Basel II approaches, that the IRB, as stated on Edital BCB n.31/11 and calibrated with the probabilities of default (PD) estimated with transition matrixes from the $S C R$, is the most conservative approach; 3) to suggest that the proposed approach is more sensitive to credit risk especially in retail and is more effective against stress chocks. Small and big banks behave differently to adverse shocks. The small banks, for instance, have problems diversifying out extreme losses when the "states of the economy" deteriorate. On the other hand, considering systemic risk, the bankruptcies of these institutions are much less of a problem than the ones of a big bank. Finally, the CRBA is presented as an alternative to the current approach (SSA) in Brazil and to the Standard Approach (SA) in other countries, specifically in Europe. In Brazil, the CRBA would increase the risk sensitivity of MCR on smaller banks creating incentives to more careful risk management practices and aligning their capital and risk levels. On the other countries, the CRBA is an alternative to the Standard Approach (SA) that is not dependent on Credit Rating Agencies - CRAs' opinions and brings two additional benefits. First, it is an internal model based approach eliminating regulatory dependence on CRAs' opinions, minimizing opportunities to regulatory arbitrage with inflated ratings and allowing CRAs to be more of a trustworthy opinion provider. Second, it provides supervisors a tracking error mechanism to evaluate risk management in small banks using Credit Registers.
\end{abstract}




\section{SUMÁRIO}

1. INTRODUÇÃ

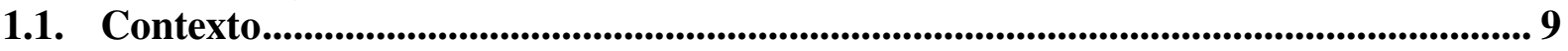

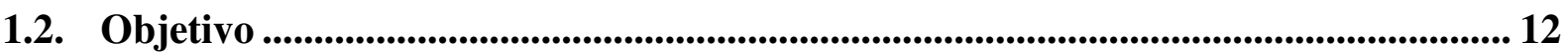

1.3. Metodologia e Limitações ........................................................................................................... 13

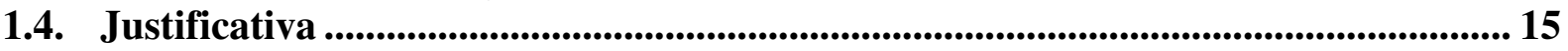

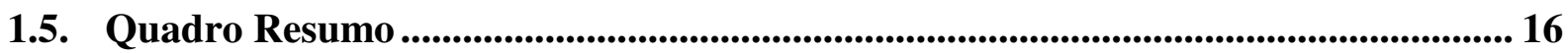

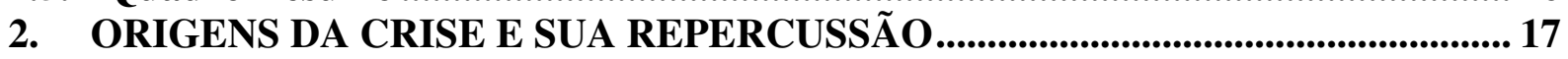

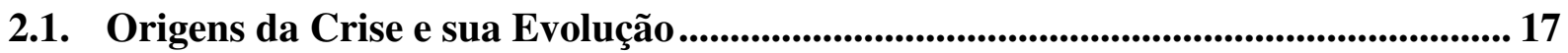

2.2. Consequências da Crise sobre a estrutura regulatória .................................................. 18

2.3. As ACRs, seu papel na crise do Subprime e a regulação concernente ..................... 23

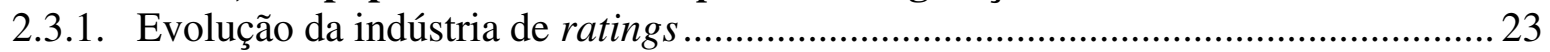

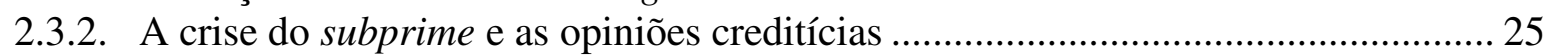

2.3.3. The Dodd-Frank Act e as Agências de Classificação de Risco (ACRs)................. 28

2.3.4. A Proposta europeia para as Agências de Classificação de Risco (ACRs) ............. 31

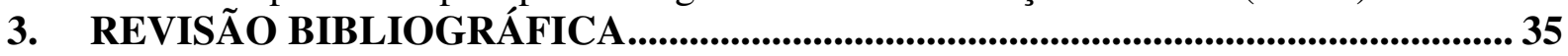

3.1. Razões para a existência de Regulação Financeira ....................................................... 35

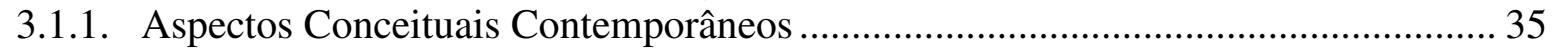

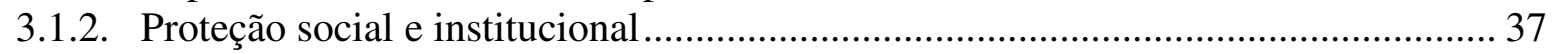

3.1.3. Regulação baseada em capital e em risco .......................................................... 38

3.2. As opiniões das ACRs e os acordos de Basileia............................................................. 40

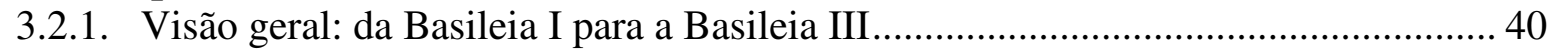

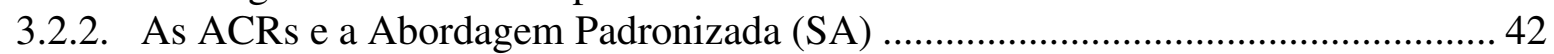

3.2.3. As ACRs e a legislação do Sistema Financeiro Nacional (SFN) ............................ 49

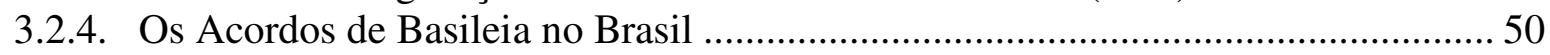

3.3. O Risco de Crédito e a Abordagem dos Ratings Internos (IRB) ............................... 57

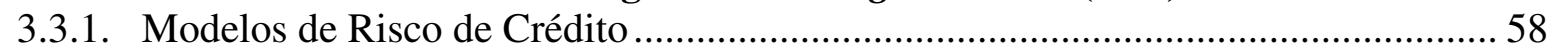

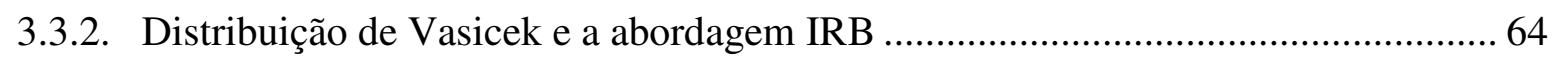

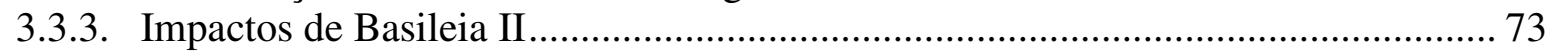

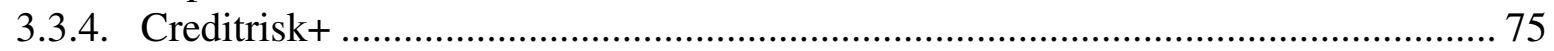

3.3.5. Modelo de Carey $(1998 ; 2001 ; 2002)$ e VaR de Crédito Não Paramétrico .............. 80

3.4. As Centrais de Risco e a Abordagem dos Ratings Centralizados............................ 84

3.4.1. As Centrais de risco: O que são e para que servem?............................................. 84

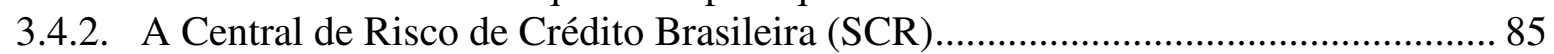

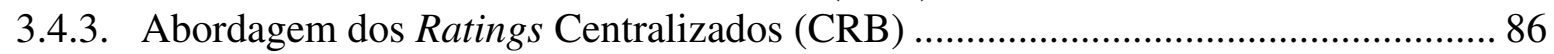

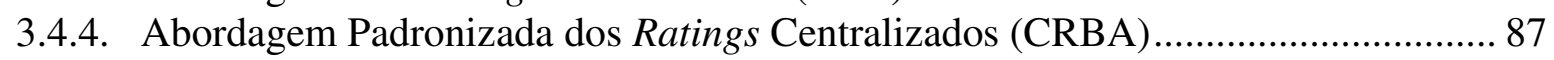

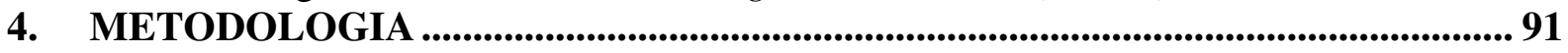

4.1. Objetivos de pesquisa .......................................................................................................... 91

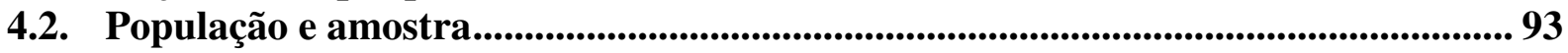

4.3. Procedimentos para estimar Requerimentos Absolutos de Capital ........................ 98

4.3.1. A Abordagem (Não Paramétrica) de Carey (2002) ................................................ 98

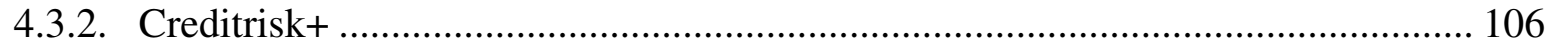

4.4. Premissas para as Abordagens de Basileia ............................................................. 108

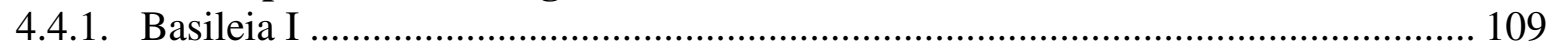

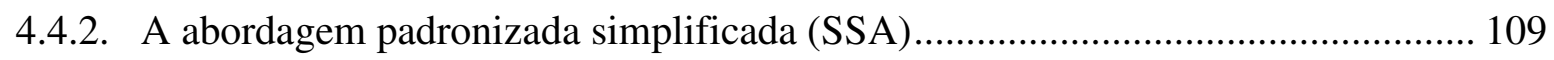

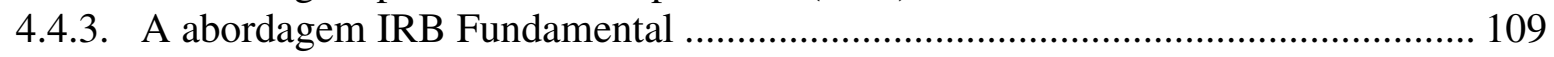

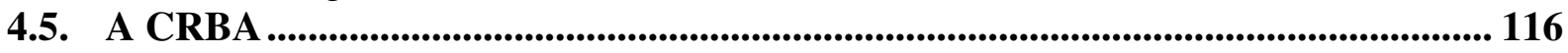

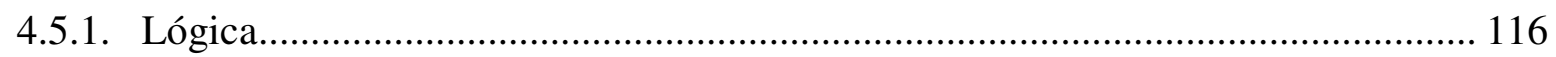




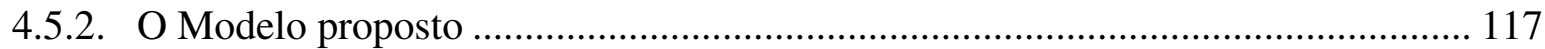

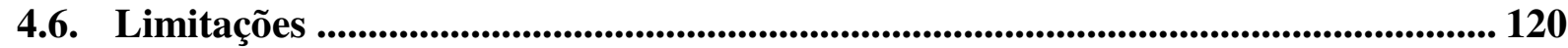

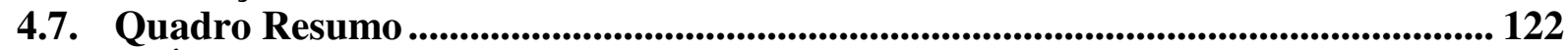

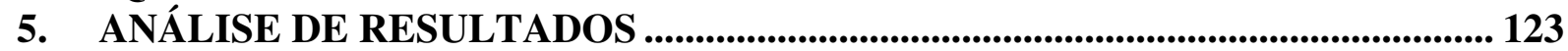

5.1. Requerimentos absolutos de Capital ............................................................................... 123

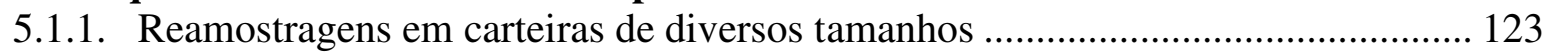

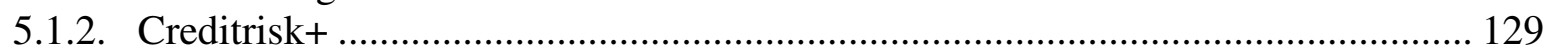

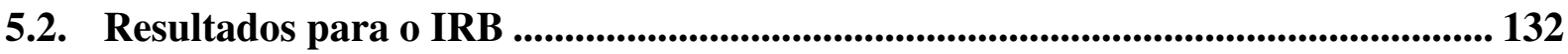

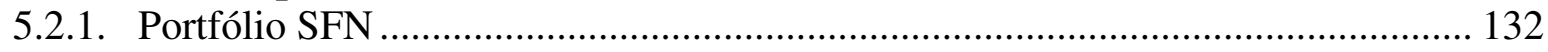

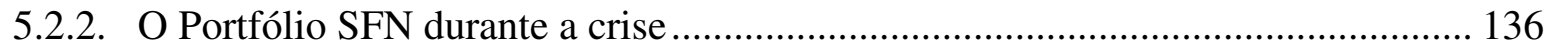

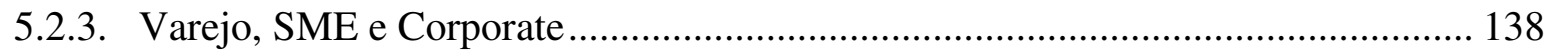

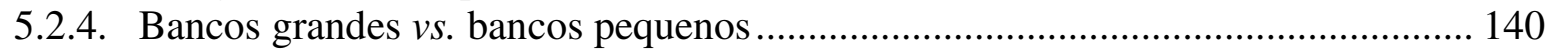

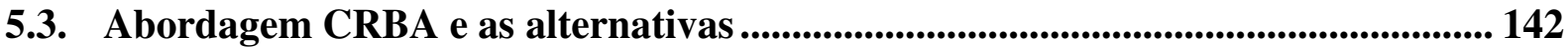

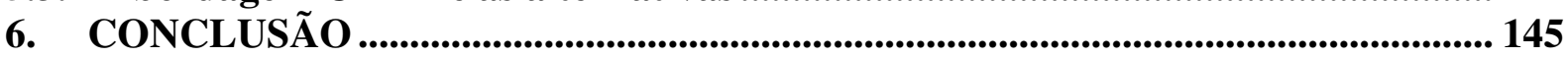

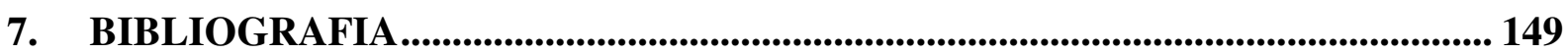

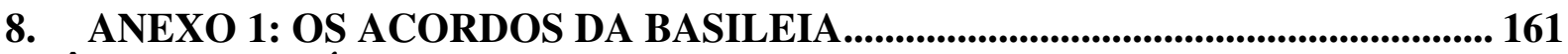

APÊNDICE A: CÓDIGOS STATA PARA OS ESTIMADORES ..................................... 164

APÊNDICE B: CÓDIGOS STATA PARA BOOTSTRAPPING ................................... 179

APÊNDICE C: CÓDIGOS STATA PARA SIMULAÇÃO DE MONTE CARLO ........ 181 


\section{LISTA DE ABREVIATURAS}

ABS: Asset-Backed Security

ACR: Agência de Classificação de Risco

APR: Ativos Ponderados pelo Risco

AMLF: Asset-Backed Commercial Paper Money Market Mutual Fund Liquidity Facility

ASRF: Asymptotic Single Risk Factor

BCB: Banco Central do Brasil

BCBS: Basel Committee in Banking Supervision

BIS: Bank for International Settlements

BCE: Banco Central Europeu

CDO: Collateralized Debt Obligation

CEBS: Committee of European Banking Supervisors

CESR: Committee of European Securities Regulators

CFA: Chartered Financial Analyst

CME: Capital Mínimo Exigido

CMN: Conselho Monetário Nacional

COREMEC: Comitê de Regulação e Fiscalização dos Mercados Financeiro, de Capitais, de Seguros, de Previdência e Capitalização

CPFF: Commercial Paper Funding Facility

CRB: Centralized Rating Based

CRBA: Abodagem Padronizada dos Ratings Centralizados, Centralized Rating Based Approach

CRC: Central de Risco de Crédito

CRD: Credit Requirements Directive

CSFB: Credit Suisse First Boston

CVA: Credit Valuation Adjustment

CVaR: Value-at-Risk (VaR) de crédito

CVM: Comissão de Valores Mobiliários

EAD: Exposição no momento do default, Exposure at Default

EESA: Emergency Economic Stabilization Act

EBA: European Banking Authority

ECAI: External Credit Assessment Institutions

ECAf: Eurosystem credit assessment framework

EIOPA: European Insurance and Occupational Pensions Authority

EL: Perda Esperada, Expected loss

ESFS: European System of Financial Supervision

ESMA: European Securities and Markets Authority

ESRB: European Systemic Risk Board

EUA: Estados Unidos da América

FD: Frequência de Default

FDIC: Federal Deposit Insurance Corporation

FDP: Frequência de distribuição de probabilidades 
FED: Federal Reserve

FMI: Fundo Monetário Internacional

FOMC: Federal Open Market Committee

FSA: Financial Services Authority

FSB: Financial Stability Board

FSF: Financial Stability Forum on Enhancing Markets and Institutional Resilience

FPR: Fatores de ponderação de Risco

GSE: Government Sponsored Enterprise

IAIS: International Association of Insurance Supervisors

ICAS: In-house credit assessment systems

IRB: Internal Rating Based ou abordagem dos ratings internos

IOSCO: International Organization of Securities Commissions

LBG: Lloyds Bank Group

LGD: Loss Given Default ou Severidade da Perda

MBS: Mortgage-Backed Securities

MMIFF: Money Market Investor Funding Facility

NRSRO: Nationally Recognized Statiscal Rating Organization

NQC: Nível de Qualidade Creditícia

OCC: Office of the Controller of the Currency

OCDE: Organização para Cooperação e Desenvolvimento Econômico

PACS: Parcela de Risco de Mercado referente à variação do preço de ações

PCAM: Parcela de Risco de Mercado referente às exposições em ouro e moedas estrangeiras

PCOM: Parcela de Risco de Mercado referente à variação do preço de mercadorias

PD: Probabilidade de Default

PDCF: Primary Dealer Credity Facility

PEPR: Parcela referente às exposições ponderadas por fatores de risco específico

PJUR: Parcela de Risco de Mercado referente à variação das taxas de juros

POPR: Parcela de Risco Operacioal

PR: Patrimônio de Referência

PRM: Parcela de Risco de Mercado

Q1: Quantitative Easing 1

Q2: Quantitative Easing 2

RBA: Risk Based Approach

RBS: Royal Bank of Scotland

SA: Standard Approach

SCR: Nova Central de Risco de Crédito do Banco Central do Brasil

SEC: Securities and Exchange Commission

SFN: Sistema Financeiro Nacional

SIFIS: Systemic Important Financial Institutions

SIV: Structured Investment Vehicles

SME: Pequenas e médias empresas ou Small and Medium Enterprises

SPE: Sociedade de Propósito Específico

SSA: Abordagem Padronizada Simplificada, Simplified Standard Approach

TAF: Term Auction Facility 
TALF: Term Asset-Backed Securities Loan Facility (TALF)

TARP: U.S. Treasury's Troubled Asset Relief Program

TL: Perda Total, Total loss

TSLF: Term Securities Lending Facility

TOP: TSLF Options Program

UL: Perda Inesperada, Unexpected loss

VaR: Value-at-Risk 


\section{LISTA DE FIGURAS}

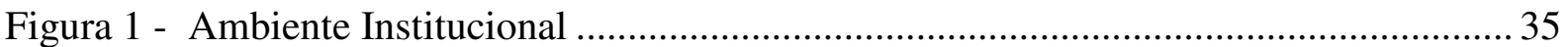

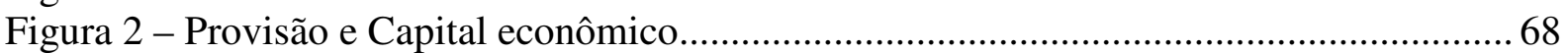

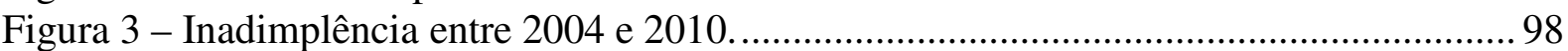

Figura 4 - f.d.p. da inadimplência para portfólios de $n=5000$ empréstimos $(B=50000) * \ldots . .101$

Figura 5 - f.d.p. da inadimplência para portfólios de $n=10000$ empréstimos $(B=50000) * \ldots 101$

Figura 6 - f.d.p. da inadimplência para portfólios de $n=50.000$ empréstimos $(B=50000) * \ldots 101$

Figura 7 - f.d.p. da inadimplência $n=300.000$ empréstimos $(B=50000)^{*}$ 101 


\section{LISTA DE QUADROS}

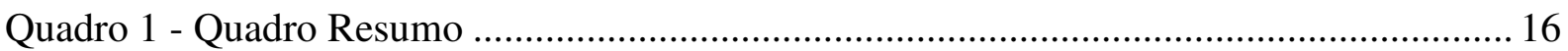

Quadro 2 - Crise e lógica das reformas regulatórias ................................................................ 22

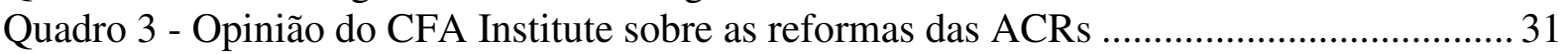

Quadro 4 - As abordagens da Basileia II e o Risco de Crédito ............................................... 40

Quadro 5 - APRs para risco de crédito na Abordagem Padronizada de Basileia II................. 42

Quadro 6 - Capital Mínimo Exigido (CME) e K(\%) em diversas classes de exposição de US\$ 1 milhão de Basileia I a II.5 ..................................................................................... 46

Quadro 7 - Bancos IRB desde dezembro de 2010 .............................................................. 47

Quadro 8 - Capital Requerido no banking book para o exemplo da securitização de US\$1

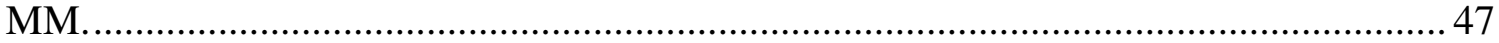

Quadro 9 - Capital Requerido no trading book para o exemplo da securitização de US\$1 MM.

48

Quadro 10 - Fórmula do Patrimônio de Referencia Exigido (PRE) introduzido em 2007 no

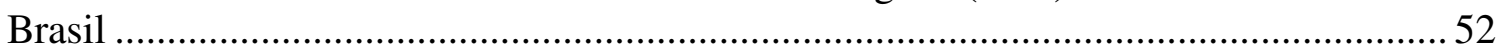

Quadro 11 - Abordagem padronizada simplificada ou abordagem padronizada brasileira ..... 53

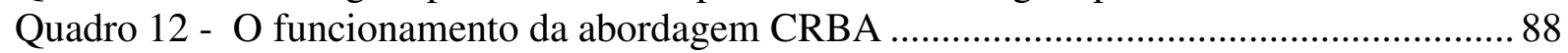

Quadro 13 - Dados extraídos do SCR para a amostra aleatória de exposições de crédito....... 93

Quadro 14 - Categorias da Fiscalização do Banco Central do Brasil ..................................... 94

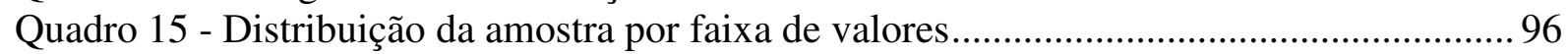

Quadro 16 - FPRs para o Modelo Proposto ........................................................................... 118

Quadro 17 - Comparação de FDs nas 3 principais agências de Rating (Corporate) - 10 anos de

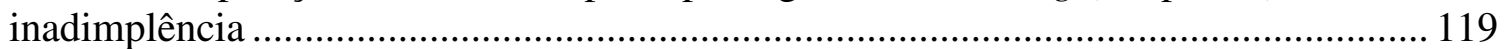

Quadro 18 - Quadro Resumo ............................................................................................ 122

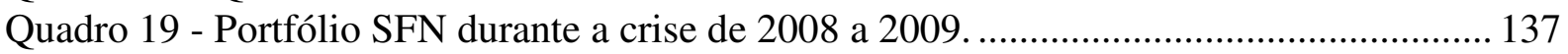

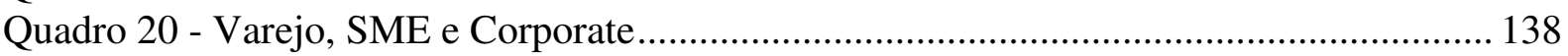

Quadro 21 - Bancos Grandes vs. Bancos Pequenos............................................................ 140

Quadro 22 - Bancos Pequenos nas abordagens alternativas ............................................... 143

Quadro 23 - CVaR - Modelo de Carey (2002) para Bancos Pequenos na crise e Credirisk+ 144

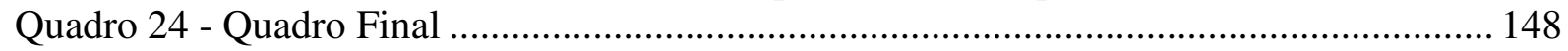




\section{LISTA DE TABELAS}

Tabela 1 - APRs na Basileia I

Tabela 2 - APRs disponíveis na abordagem padronizada (Basileia II) para securitização no Banking Book.

Tabela 3 - Cargas usada na Abordagem Padronizada da Basileia II.5 - Trading Book.......... 44

Tabela 4 - Tabela RBA representando os APRs usados na Basileia II abordagem IRB.......... 45

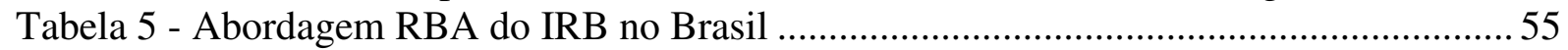

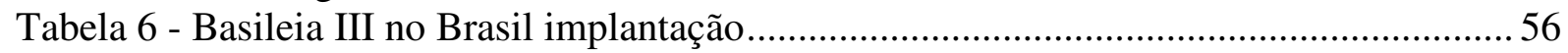

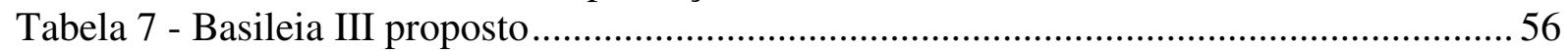

Tabela 8 - Perda Total (VAR), EL e UL ou K(\%) para varejo (LGD=75\%) ........................... 71

Tabela 9 - Sensibilidade de VaR a PD e r na Fórmula do IRB .............................................. 72

Tabela 10 - Impacto percentual no CME da Adoção das abordagens IRB em relação a Basileia

I...

Tabela 11 - PD média para diversas classes de ativo $(\%)$........................................................ 75

Tabela 12 - Oito membros da subamostra de bancos grandes (dados de dezembro de 2010).95

Tabela 13 - Inadimplência amostral média no período com e sem ponderação ...................... 96

Tabela 14 - Inadimplência amostral no Varejo, SME e Corporate (06/2004 a 12/2010)........ 97

Tabela 15 - Inadimplência amostral na crise (12/2008 a 06/2010) ........................................ 98

Tabela 16 - Sensibilizando B para portfólios de $n=500$ exposições ....................................... 99

Tabela 17 - Quantis para reamostragem da inadimplência .................................................... 101

Tabela 18 - PDs estimadas por matrizes de migração para o SFN .................................... 111

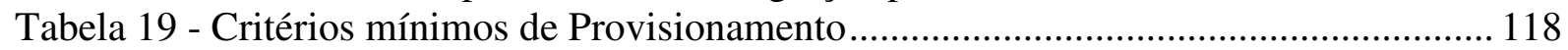

Tabela 20 - Fatores FPR da CRBA e CRBAc................................................................... 119

Tabela 21 - Perdas Totais - Carteiras de 300.000 exposições - Todo o SFN entre 2004-2010

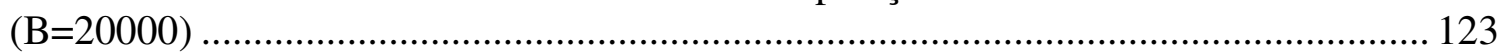

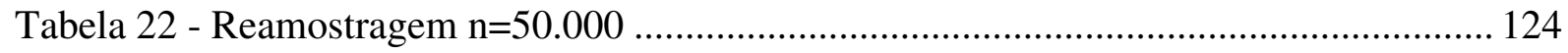

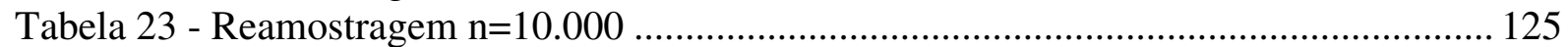

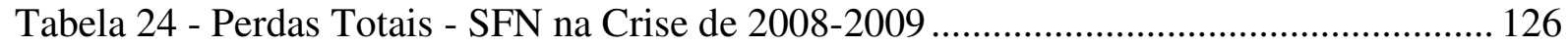

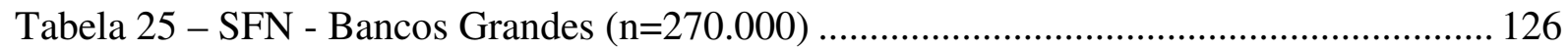

Tabela 26 - Bancos com carteiras formadas por empréstimos de bancos grandes $\quad(n=50000)$

Tabela 27 - Bancos com carteiras formadas por empréstimos de bancos Pequenos $(n=50.000)$

Tabela 28 - Bancos pequenos na Crise $(\mathrm{n}=10.000)$

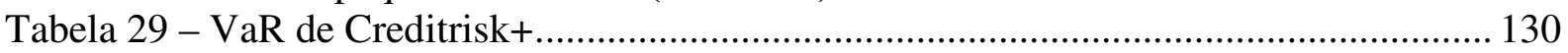

Tabela 30 - Perdas Esperadas (EL) e Provisão Mínima para o Portfólio SFN Período total 133

Tabela 31 - VaR e CME para o portólio do SFN em todos os períodos ................................ 134

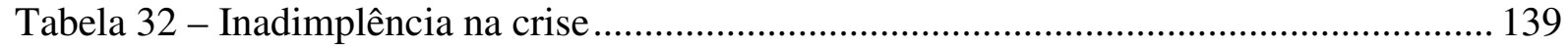

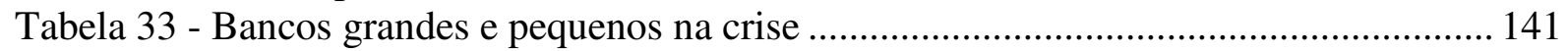




\section{INTRODUÇÃO}

\subsection{Contexto}

A crise bancária de 2008, iniciada nos Estados Unidos da América (EUA) e com forte repercussão em todos os demais países, também conhecida como Crise do Subprime, Meltdown ou como a Grande Crise Global de Crédito de 2008 e 2009 (EICHENGREEN, 2010), é reconhecidamente a mais importante crise financeira desde de 1930. Suas consequências são econômicas (deflação, desemprego e o aumento do endividamento público), financeiras (com destaque para a reestruturação do setor bancário), institucionais e legais (em que pese toda a reforma do aparato regulatório e do conjunto normativo).

Nos EUA, após um ano de polêmicas, o Congresso e o Senado aprovaram o The Dodd-Frank Wall Street Reform and Consumer Protection Act, Dodd-Frank Act, a nova lei de reforma do sistema financeiro, contendo, não apenas profunda revisão normativa, mas também aparato institucional completamente novo para a regulação do sistema financeiro americano. $\mathrm{O}$ ato de mais de 2.300 páginas se apresenta com a seguinte finalidade: “[...] para promover [...] a responsabilização e a transparência, dar fim ao 'too big to fail', proteger o contribuinte americano de novos resgates [ao sistema financeiro][...]" (USA, 2010a), deixando claro que os custos sociais, econômicos e políticos da crise tornaram o status quo do atual modelo insustentável.

No restante do mundo, os Estados, por meio do Tesouro Nacional, dos Bancos Centrais ou das agências com finalidade similar a estas instituições, saíram em socorro do seu sistema bancário ao custo do incremento do endividamento público.

Vários países não possuíam recursos para arcar com esses custos e precisaram do apoio de instituições multilaterais, que, por sua vez, também estavam despreparadas para uma crise dessa magnitude ou que nunca oficialmente foram reconhecidas como emprestadores de última instância, como o Fundo Monetário Internacional (FMI) e o Banco Central Europeu (BCE). A receita para evitar ou apaziguar a crise soberana em países como Islândia, Hungria, Grécia, Irlanda e Portugal passou por combinações da atuação entre FMI, BCE, Federal Reserve (FED), Banco da Inglaterra e ainda fundos soberanos, com destaque para o fundo 
chinês e o dos Emirados Árabes Unidos. Nas palavras do então premiê francês e presidente do G-20, Nicolas Sarkosy, o mundo está à procura de um novo Breton Woods.

No Reino Unido, onde dois dos maiores bancos - Lloyds Banking Group e Royal Bank of Scotland - tiveram de ser nacionalizados, o Financial Services Authority (FSA), sob o comando de Lord Turner, sugeriu mudanças ainda mais profundas no sistema financeiro, envolvendo maiores impostos, remuneração de executivos, liquidez mínima exigida e forte fiscalização sobre o shadow banking (agentes da desintermediação financeira) e empresas não financeiras que participam ativamente do mercado de derivativos.

O restante da União Europeia passa por reformas regulatórias e institucionais ainda mais dramáticas, já que a crise atingiu em cheio um sistema financeiro que ainda não tinha identidade como um conjunto de instituições integradas. De certa forma, a reforma do póscrise implica na própria criação do aparato regulatório da União Europeia. Em janeiro de 2011, por exemplo, é oficialmente criado o European System of Financial Supervision (ESFS) composto pelo European Banking Authority (EBA), o European Securities and Markets Authority (ESMA), o European Insurance and Occupational Pensions Authority (EIOPA) e o European Systemic Risk Board (ESRB). No entanto, a eficiência e a independência política desses organismos será decisiva e ainda está por ser testada.

Se, por um lado, na União Europeia, a extensão das reformas é maior do que a observada na Inglaterra e nos EUA, por outro lado, o seu ritmo de implantação é extremamente moroso, porque a criação desses aparatos também indiretamente implicou e implica na discussão de aspectos ainda mais fundamentais, como a inexistência de um federalismo fiscal e a própria extensão com que um federalismo é desejado.

Nesse contexto, o comitê da Basileia, por meio do Financial Stability Board (FSB), no qual tem assento os presidentes de bancos centrais das vinte economias mais expressivas do mundo, G20, aprovou em novembro de 2010, um novo pacote de normas para o sistema bancário mundial, contendo propostas de fortes reformas macro e microprudenciais, tanto imediatas (Basileia II.5), quanto de médio e longo prazo (Basileia III).

As crises do sistema bancário sempre foram o estopim de reformas estruturais e normativas do sistema financeiro. Por exemplo: a Lei Glass-Steagall foi uma resposta à crise de 1929 nos EUA; o primeiro acordo da Basileia foi uma reação à crise bancária dos anos 1980, desencadeada por créditos ruins a países latino-americanos em poder de bancos americanos e 
europeus; o segundo acordo - Basileia II - foi uma resposta às crises russa e asiática de 1997 e 1998, que culminaram na criação da exigência de instrumentos de maior controle de risco de mercado, de maiores poderes para a autoridade supervisora (Pilar 2) e exigências de transparência (Pilar 3) - (Anexo I); da mesma forma, o Dodd-Frank Act, a Reforma Bancária Inglesa e Basileia III traduzem o aprendizado da última crise e representam as respostas normativas e institucionais às falhas do modelo existente.

Um dos principais aspectos revelados na crise e que tem inspirado reformas regulatórias expressivas é a excessiva dependência regulatória e do sistema financeiro como um todo nas opiniões das Agências de Classificação de Risco (ACRs). Essa dependência afeta, por exemplo, o BCE, que se via em 2011 impedido de prestar socorros de liquidez a bancos portugueses e gregos caso ocorresse rebaixamento do rating dos títulos soberanos de Portugal e da Grécia. Ela afeta também a liquidez de títulos lastreados em hipotecas de alto risco, na medida em que, para diversas instituições financeiras, como fundos de pensão, a sua aquisição dependia de um rating elevado. Além disso, afeta o capital regulatório de virtualmente todos os bancos nos países que adotaram a abordagem padronizada de Basileia II.

A gravidade das perdas decorrentes da crise, a captura dos reguladores, supervisores, do sistema financeiro em geral e a preocupação com a própria qualidade dos ratings têm influenciado reformas regulatórias distintas como o Dodd-Frank Act, a nova proposta do Parlamento Europeu e mudanças no cálculo do capital regulatório, isto é, Basileia II.5 e Basileia III. Além disso, o Financial Stability Forum on Enhancing Markets and Institutional Resilience (FSF) sugeriu aos países do G-7 que individualmente revissem seu aparato normativo no sentido de mitigar a dependência regulatória do sistema financeiro em relação à opinião das ACRs. ${ }^{1}$

O Brasil acatou à referida sugestão do FSF. Entretanto, os impactos foram mínimos, principalmente porque o Capital Mínimo Exigido (CME) não era sensibilizado por nenhum tipo de rating à época (COREMEC, 2010). Em maio de 2011, após a ratificação de Basileia III pelos países membros do G-20, o Banco Central do Brasil lança o Edital Público N.37 (BCB, 2011b) criando os novos parâmetros para o cálculo do CME na abordagem dos ratings internos (IRB). Esse será o primeiro modelo de capital regulatório sensível à classificação de

\footnotetext{
${ }^{1} \mathrm{O}$ relatório especificamente menciona que esse tipo de regulação cria um "selo de aprovação" tácito que é indesejável (Cf. COREMEC, 2010).
} 
risco específica do tomador e da operação no Brasil. Sabe-se que ele, a princípio, não considerará as opiniões das ACRs, mas apenas ratings gerados por modelos internos dos bancos.

\subsection{Objetivo}

Quer-se aqui avaliar o impacto da adoção de diferentes abordagens de Basileia II sobre o CME para risco de crédito no Brasil. Além disso, propõe-se uma abordagem padronizada alternativa para bancos pequenos, baseada nas categorias da Resolução CMN n. 2.682/99 (CMN, 1999) no espírito do Comunicado BCB n. 12.746 de 9.12.2004 e da preferência do regulador brasileiro pelos ratings internos. $\mathrm{O}$ trabalho pode ser subdivido em três objetivos mais específicos:

1- Estimar o capital econômico para carteiras de empréstimos representativas do SFN entre 2004 e 2010 e adotá-lo como proxy para perdas totais de crédito e, consequentemente, para o requerimento absoluto de capital desejável no Brasil (Cf. CAREY, 2002);

2- Avaliar o impacto da implantação do modelo IRB Fundamental em distintos cenários de stress vis-à-vis à abordagem atual brasileira;

3- Propor e testar uma metodologia de cálculo de Capital Mínimo Exigido (CME) para risco de crédito sensível a ratings (internos) centralizados, ou seja, registrados em Centrais de Risco como a Nova Central de Risco de Crédito do Banco Central do Brasil (SCR). Esse modelo é denominado Centralized Standard Risk Based Approach (CRBA) e apresentado na página 87.

A abordagem IRB para risco de crédito do item 2, se adequadamente calibrada, é factível apenas para bancos grandes. Alternativamente, esse trabalho propõe a CRBA (item 3) para bancos pequenos. Esta abordagem visa aproximar a proposta brasileira dos objetivos pretendidos pela Abordagem Padronizada (SA) de Basileia II, de tornar o nível de capital mínimo dos bancos pequenos mais próximo de seu capital econômico; e também dos objetivos do Joint Forum, de minimizar o uso das opiniões das ACRs. 


\subsection{Metodologia e Limitações}

Primeiramente, faz-se uma análise crítica da abordagem padronizada (SA) de Basileia II, baseada em ratings externos, e das propostas de reformulação do sistema financeiro mundial em relação à opinião das ACRs ora em discussão. A revisão bibliográfica ainda contempla os distintos modelos internos de mensuração de risco de crédito para portfólios Value-at-Risk (VaR) de Crédito ou (CVaR) incluindo a cópula de Vasicek, que fundamenta o IRB, utilizada no item 2; Creditrisk+ e o modelo de Carey(2002).

A parte empírica desse estudo contém exposições aleatórias de crédito colhidas do SCR entre 2004 e 2010 e que representavam $\mathrm{R} \$ 14,5$ bilhões cerca de 1,5\% da carteira ativa média do Sistema Bancário no período. As exposições de crédito dos bancos de desenvolvimento e da Caixa Econômica Federal não foram incluídas. A amostra é usada para:

1) estimar o capital econômico (item 1) por:

- modelo de Carey (2002), que é uma abordagem não paramétrica baseada em Reamostragem e Simulação de Monte Carlo;

- Creditrisk+, uma abordagem paramétrica bastante conveniente desenvolvida por Credit Suisse First Boston (CSFB, 1997) e que não exige hipóteses sobre a correlação das probabilidades de default (PDs);

2) avaliar a performance do VaR no IRB fundamental - VaR_IRB - (item 2) por:

- análise descritiva de VaR_IRB, perda esperada (EL), CME e provisão mínima nos cenários base e de stress 1 e 2;

- avaliação descritiva de VaR_IRB, EL, CME e provisão mínima na Crise de 2008-2009 em bancos pequenos e grandes;

- avaliação descritiva de VaR_IRB, Perda EL, CME e provisão mínima para as carteiras teóricas de Basileia II: varejo, pequenas e médias empresas (SME) e corporate;

3) avaliar a performance da CRBA (item 3): 
- por meio de quatro modelos distintos: com fatores de ponderação (FPRs) iguais aos da abordagem padronizada (SA) para as exposições corporate (CRBA_CP); com os mesmos FPRs da abordagem SA para o portfólio total (CRBA); para fatores de ponderação mais conservadores nos moldes da SA para exposições corporate (CRBAc_CP) e para o portfólio total (CRBAc);

- comparar a performance desses quatro modelos frente ao capital econômico estimado em (1) e os principais resultados de (2) para bancos pequenos;

Esse trabalho pode ser genericamente descrito como um exercício de CVaR para avaliar os atuais requerimentos mínimos de capital e as perdas esperadas e totais do Sistema Bancário Brasileiro vis-à-vis ao seu capital econômico. Além disso, avalia-se o impacto sobre o CME da implantação do IRB Fundamental e dos modelos propostos.

Para o item 1, todas as simulações visam reproduzir ao máximo o sistema bancário brasileiro entre 2004 e 2010, o que torna seu estudo apropriado para uma validação dos modelos sobre o sistema bancário como um todo e não sobre qualquer banco em particular. A maioria das análises versa sobre o Portfólio SFN, que se comporta como um banco que reproduz as decisões de investimento disponíveis no SFN nos sete anos de análise, mas não uma determinada política de crédito.

Por restrição dos dados, o comportamento de todos os portfólios simulados criados nessa tese é sempre condicionado às condições econômico-financeiras do ciclo compreendido entre 2004 e 2010. Uma restrição desse modelo é que nenhum banco pode ter uma estratégia de diversificação melhor ou pior que a do SFN. Para Carey (2002), cada portfólio simulado pode ser interpretado como uma realização do SFN, e o quantil à direita representa a probabilidade do SFN como um todo colapsar. Esta restrição está presente em todos os modelos paramétricos ${ }^{2}$, incluindo Creditrisk+, também utilizado em (1).

Uma limitação importante desse estudo é que os ratings e as PDs são sempre calibrados com as categorias de risco da Resolução do CMN No. 2.682 de 21.12.1999 (CMN, 1999). Essas classificações refletem muito a discricionariedade dos modelos internos e das práticas de gestão dos bancos. As PDs aqui utilizadas para calibrar o IRB Fundamental foram calculadas conforme Yanaka (2009) por matrizes de migração para dados populacionais do SCR em todo o Sistema Bancário. Acredita-se que elas sejam robustas além de terem sido agrupadas para as

\footnotetext{
2 “all-or-nothing condition" (CAREY, 2002).
} 
mesmas modalidades de crédito do SCR dos dados amostrais. No entanto, elas refletem apenas as cinco categorias de não default da Resolução CMN n. 2.682/99 (CMN, 1999) que são, na prática, insuficientes para esse fim. Além disso, para as matrizes de migração foram usados quatro anos de dados, quando o recomendável pelo Basel Committee in Banking Supervision (2006a) é de ao menos cinco anos.

\subsection{Justificativa}

A adoção tardia do Basileia II, no Brasil, pode ter um reflexo (involuntário) bastante positivo. Após a crise financeira de 2008-2009, o acordo de Basileia II passou a ser questionado justamente no seu ponto mais fundamental: a inadequação do capital regulatório para proteger a economia de crises no sistema bancário. Um aspecto em análise é a excessiva dependência do CME aos riscos estimados por modelos de ratings internos de bancos e externos de ACRs.

No Brasil, os bancos seguem a SSA, uma abordagem que pode ser situada entre Basileia I e a abordagem SA, e que não considera o risco específico do tomador, apenas a qualidade da garantia. Ainda que o SFN como um todo tenha demonstrado solidez durante a crise, os bancos pequenos se mostraram fragilizados, sugerindo que uma proposta que incentive um comportamento mais conservador seja desejável. A abordagem proposta, teoricamente, tem condições de produzir esses incentivos, especialmente se acompanhada de maior fiscalização.

Embora as perdas de crédito possam ter impactos diferentes sobre bancos pequenos e grandes, elas nunca foram estimadas de modo independente no Brasil. Na realidade, até onde se sabe, em nenhuma parte o risco de crédito é estimado separadamente com foco na adequação do CME do modo adotado neste trabalho. 


\subsection{Quadro Resumo}

O Quadro 1 sintetiza esse trabalho, sua metodologia e resultados.

Quadro 1 - Quadro Resumo

\begin{tabular}{|c|c|c|c|}
\hline $\begin{array}{l}\text { Pergunta } \\
\text { Problema }\end{array}$ & $\begin{array}{c}\text { Objetivo do } \\
\text { Trabalho }\end{array}$ & Metodologia & Resultados \\
\hline \multirow{3}{*}{$\begin{array}{c}\text { Quais as } \\
\text { consequências } \\
\text { sobre o } \\
\text { capital } \\
\text { regulatório } \\
\text { para risco de } \\
\text { crédito da } \\
\text { adoção de } \\
\text { diferentes } \\
\text { abordagens } \\
\text { de Basileia } \\
\text { II? }\end{array}$} & $\begin{array}{l}\text { 1) Estimar o } \\
\text { capital econômico } \\
\text { para um portfólio } \\
\text { que representa o } \\
\text { SFN. Para Carey } \\
\text { (2002), esse é o } \\
\text { requerimento } \\
\text { absoluto de } \\
\text { capital. }\end{array}$ & $\begin{array}{l}\text { 1.1) Estimar o VaR de } \\
\text { Crédito (CVaR) por } \\
\text { modelo de Carey } \\
\text { (2002) para bancos } \\
\text { pequenos e grandes } \\
\\
\text { 1.2) Estimar CVaR } \\
\text { paramétrico por } \\
\text { Creditrisk+ }\end{array}$ & $\begin{array}{l}\text { 1. Baseado nos quantis da distribuição não } \\
\text { paramétrica de CVaR para bancos pequenos } \\
\text { na crise de 2008-2009, o capital econômico } \\
\text { seria de 9,05\% (95\%). } \\
\text { 2. Para o CVaR paramétrico de Creditrisk+, } \\
\text { tem-se no quantil de } 99,9 \%, 17,5 \% \text { (com } \\
\text { provisão) ou um CME de 11,5\%. Para } \\
\text { CVaR(95\%), 13,55\% e CME de 7,55\%. } \\
\text { Ambos os CMEs próximos à exigência } \\
\text { regulatória atual, isto é, entre 8.25\% e 11\%. } \\
\text { Um intervalo de confiança (bootstrap) de } \\
\text { 99,9\% para CME mais provisão mínima } \\
\text { exigida (PME) na abordagem atual } \\
\text { apresentou valores entre [13,32\%:14,82\%], } \\
\text { situando CReq na zona de } 95 \% \text { a } 97.5 \% \text { de } \\
\text { Creditrisk+. }\end{array}$ \\
\hline & $\begin{array}{l}\text { 2) Avaliar a } \\
\text { performance do } \\
\text { IRB Fundamental } \\
\text { frente a } \\
\text { abordagem atual } \\
\text { (SSA) em dois } \\
\text { cenários de stress }\end{array}$ & $\begin{array}{l}\text { 2.1) Avaliar na } \\
\text { amostra a Provisão } \\
\text { Mínima e o CME nos } \\
\text { cenários-base nas } \\
\text { abordagens atual e } \\
\text { IRB, durante a crise, e } \\
\text { sob stress } 1 \text { e stress2 } \\
\text { para: bancos pequenos } \\
\text { e grandes; e para } \\
\text { 2.2) as carteiras } \\
\text { teóricas de Basileia II: } \\
\text { varejo, atacado r } \\
\text { pequenas e médias } \\
\text { empresas (PME). }\end{array}$ & $\begin{array}{l}\text { 1. Durante a crise, o aumento da } \\
\text { inadimplência em bancos pequenos foi de } \\
56,16 \% \text { e nos grandes de } 28,93 \% \text {. No } \\
\text { entanto, apenas bancos pequenos tiveram } \\
\text { perdas médias superiores à PME. O IRB } \\
\text { Fundamental é mais conservador que todas } \\
\text { as demais abordagens e subsiste ao choque } \\
\text { aleatório mais severo stress } 2 \text {. Na } \\
\text { abordagem atual, o exigível mínimo não } \\
\text { subsiste stress2. } \\
\text { 2. O Varejo mostrou-se mais arriscado que } \\
\text { SME e o atacado. O IRB ajuda a corrigir } \\
\text { essa distorção reforçada pela abordagem } \\
\text { atual. }\end{array}$ \\
\hline & $\begin{array}{l}\text { 3) Avaliar a } \\
\text { proposição da } \\
\text { Abordagem } \\
\text { Padronizada dos } \\
\text { Ratings } \\
\text { Centralizados } \\
\text { (CRBA) }\end{array}$ & $\begin{array}{l}\text { 3.1) Avaliar o CME } \\
\text { para as diversas } \\
\text { CRBAs propostas em } \\
\text { bancos pequenos } \\
\text { frente a abordagem } \\
\text { atual e o IRB. }\end{array}$ & $\begin{array}{c}\text { 1. CRBAc para bancos pequenos é a } \\
\text { abordagem mais conservadora dentre as } \\
\text { quatro propostas para CME e representa } \\
\text { uma meia distância entre a abordagem } \\
\text { brasileira atual (SSA) e o IRB. Além disso, } \\
\text { é mais sensível ao risco de crédito } \\
\text { principalmente no Varejo e resiste ao } \\
\text { critério de stress2. }\end{array}$ \\
\hline
\end{tabular}




\section{ORIGENS DA CRISE E SUA REPERCUSSÃO}

\subsection{Origens da Crise e sua Evolução}

Os primeiros sintomas da crise financeira mundial de 2008-2009 são sentidos no verão de 2007 por meio de registros de perdas com ativos lastreados em hipotecas - Mortgage Backed Securities (MBS). O FED e o BCE fizeram injeções de liquidez expressivas à época, mas, em setembro de 2007, o banco Northern Rock faliu. Tratava-se da primeira falência bancária registrada no Reino Unido em cem anos (FRENCH et al, 2010).

O banco americano Bear Stearns foi o próximo a falir, em março de 2008, por uma falta de liquidez aguda no mercado interbancário após ter registrado perdas expressivas com os mesmos MBSs. O FED conteve essa crise negociando um resgate por parte do banco J.P. Morgan com garantias do próprio FED.

Em setembro de 2008, duas empresas cujas atividades financeiras de fomento ao setor imobiliário por meio de criação, venda e especulação com MBSs estavam tecnicamente falidas, Fannie Mae e Freddie Mac, foram socorridas pelo Federal Housing Finance Agency e reestatizadas. O estopim da crise foi a falência do tradicional banco de investimento estadunidense Lehman Brothers, fundado em 1850, do exato mesmo modo que Bear Stearns.

A gigante seguradora American International Group (AIG), importante contraparte desse banco e de outras entidades financeiras por haver emitido centenas de bilhões de dólares em derivativos de crédito, Credit Default Swaps (CDS), veio na esteira. Algumas das mais importantes instituições financeiras do mundo - como Citigroup e Merrill Lynch (EUA), Royal Bank of Scotland (RBS) e Lloyds (Reino Unido), Swiss Re e UBS (Suíça) e Société Générale (França) - declararam ter tido perdas elevadas em seus balanços, o que agravou ainda mais o clima de desconfiança.

Aparentemente, foi nesse momento que as autoridades americanas se deram conta do tamanho do problema e o secretário do Tesouro Hank Paulson anunciou o Troubled Asset Relief Program (TARP), um socorro de liquidez que consistia na compra de US\$ 700 bilhões de MBSs (FRENCH et al, 2010). Em outubro de 2008, a Alemanha, a França, a Áustria, os 
Países Baixos e a Itália anunciaram pacotes que somaram US\$ 1,58 trilhão em ajuda ao seus sistemas financeiros. O PIB da Zona do Euro teve uma queda de 1,5\% no quarto trimestre de 2008, em relação ao trimestre anterior, sua maior contração na breve história do bloco.

\subsection{Consequências da Crise sobre a estrutura regulatória}

A extensão dos impactos da crise revelou a interdependência dos mercados e a falta de capacidade dos bancos, dos governos e dos instrumentos multilaterais de mensurarem riscos, protegerem seus sistemas financeiros e lidarem com crises globais, respectivamente. Os bancos centrais foram conduzidos a injetar liquidez no mercado interbancário para evitar um efeito dominó. O IMF (2008) registra que as perdas decorrentes de hipotecas do mercado imobiliário subprime já contabilizavam US\$ 1,4 trilhão e o valor total dos créditos subprime (alto risco) chegava a US\$12,3 trilhões, o que corresponde a 89\% do PIB americano.

Em abril de 2009, o G-20, reunido em Londres, anunciou conjuntamente a injeção de US\$ 1 trilhão na economia mundial de maneira a combater a crise financeira global. Além dos impactos financeiros, a crise do Subprime traz à tona a necessidade de reformular o aparato financeiro multilateral de modo a refletir, não só o novo grau de interconexão entre os mercados, mas também as novas relações de poder em um mundo que mudou drasticamente desde 1945. As reformas normativas e institucionais não são incomuns nacionalmente desde 1988 têm sido realizadas coordenadamente pelo G-10 e, desde 2008, pelo G-20. No entanto, pela primeira vez desde 1945, são propostas reformas drásticas nos próprios organismos multilaterais, como o FMI e o Banco Mundial.

Para Eichengreen (2010), os principais contornos da reforma regulatória até 2010 foram:

- Nos EUA, a criação de padrões mais rígidos para a subscrição de hipotecas, circunscrição da negociação de instrumentos derivativos às bolsas e a restrição às transações com capital proprietário em instituições seguradas pelo FDIC;

- Na Inglaterra, a questão da remuneração de executivos mereceu destaque, especialmente os bônus e demais instrumentos que criavam "incentivos perversos". Vale ressaltar que o FSA criou multas severas e efetivamente as 
aplicou a instituições em que encontrou evidências de risco moral, além de perseguir e processar membros do conselho e diretoria de diversos bancos.

- $\quad$ Na França e na Alemanha, o destaque foi dado às instituições consideradas pouco reguladas como Hedge Funds e empresas de Private Equity (Shadow banking).

\section{Arbitragem Regulatória}

Novamente, o fato dessas reformas terem tomado características distintas denuncia a falta de coordenação internacional, especialmente ao se considerar que os principais bancos operam internacionalmente, beneficiam-se de oportunidades de arbitragem regulatória e possuem poder de lobby em seus países de origem (EICHENGREEN, 2010).

A arbitragem regulatória é um dos problemas centrais na reestruturação do sistema financeiro e dos marcos regulatórios internacionais e o maior impedimento a uma reforma multilateral. Porém, também existe arbitragem regulatória no interior dos países e até dentro de um mesmo conglomerado financeiro. Dentro dos EUA, um exemplo típico é a realocação de atividades entre empresas afiliadas, mas que estão sujeitas a reguladores diferentes, como a transferência de risco de crédito para seguradoras ou SPEs (Ibidem). Como tratado na próxima seção, a oportunidade de arbitragem regulatória com as opiniões das ACRs e entre o banking book e o trading book ${ }^{3}$ contribuiu muito para a crise e é um dos principais motivos das reformas regulatórias na Europa, EUA e o principal motivo de Basileia II.5.

Sempre que normas mais restritivas ou práticas de supervisão mais intensivas aumentam o custo dos negócios (consistentemente, já que certas atividades têm maiores custos sociais), cria-se um incentivo para a realocação de riscos para jurisdições mais permissivas, o que aumenta o custo dessas atividades para toda a sociedade, inclusive para os demais países. Como os custos sociais de uma falência no setor financeiro são muito mais elevados, cria-se uma situação insustentável em que o governo é forçado a intervir e o contribuinte a arcar com as consequências em um movimento cíclico de risco moral (Ibidem).

\footnotetext{
${ }^{3} \mathrm{O}$ trading book é formado pelos títulos com intenção de negociação e o banking book com os ativos para os quais não há intenção de negociação.
} 
Outro exemplo: antes da crise, o FDIC possuía autoridade para intervir imediatamente nas instituições depositárias sobre sua esfera de atuação (os segurados) e, assim, impedir que uma crise de liquidez se disseminasse. Porém, o FDIC não tinha autoridade para fazer o mesmo em bancos grandes e complexos, as holdings, nem nas seguradoras, nem em outras instituições financeiras.

Ainda que o Dodd-Frank Act tenha dado essa autoridade ao regulador federal em junho de 2010, diferentes práticas no que diz respeito ao direito dos credores no Reino Unido e nos Estados Unidos, teriam, de igual modo, criado entraves caso a quebra do Lehman Brothers tivesse ocorrido em 2010 [...] [A] cooperação internacional para a reforma regulatória é o ponto nevrálgico do problema e, na medida em que se torna impraticável, é necessário que um organismo regulador supranacional intermedeie o problema. (Ibidem).

A cooperação regulatória internacional, como sugerido pelos organismos multilaterais, não é ponto pacífico entre os pesquisadores. Uma corrente alternativa defende que as especificidades dos sistemas financeiros - principalmente, sua maior orientação para o sistema bancário ou para o mercado de capitais, o grau de participação dos bancos estatais na economia, a primazia de Internet Banking e a interferência da Lei Islâmica em determinados mercados - determinam a existência de aparatos normativos e regulatórios particulares e que respeitem essa diversidade.

Os pesquisadores que defendem essa linha invocam usualmente a falha do Comitê da Basileia em conter a crise atual e a de 1997/1998, a despeito do modelo conciliador ter sido assinado em virtualmente todos os países. Para eles, a adoção de um modelo único pode tornar o sistema financeiro ainda mais frágil. Entretanto, um argumento presente no discurso de ambas as linhas de pesquisa e no Financial Stability Board (FSB) em si é de que a procura por um consenso geralmente leva a uma espécie de mínimo denominador comum até aqui insuficiente para prevenir crises. Esta é a principal crítica ao acordo global mais recente (Basileia III) finalizado em novembro de 2010 e que tem uma agenda de implementação de 2013 a 2019 (Ibid.).

No entender de Eichengreen (2010), a cooperação internacional regulatória tem sido o caminho trilhado pelos países, ainda que na base de mínimos denominadores comuns, suscetíveis a lobbys dos mais diversos tipos e em passos vagarosos. A criação do Financial Stability Board, em 1999, seria uma prova disso. No Comitê, composto por 24 bancos centrais e outras agências reguladoras, e que já em 1999 contava com a presença da International Association of Insurance Supervisors e da International Organization of Securities Regulators, o foco central era o risco sistêmico e eram debatidos aspectos como atuação de 
off-shores, fluxo internacional de recursos via mercado de capitais e Hedge Funds. O único problema do fórum internacional é que ele é nada mais que um grupo de discussão e “[...] assim como o Papa, o FSB não tem exércitos [...]” (Ibid., p. 112).

Consequentemente, no sentido de dar autoridade ao novo acordo de capitais, o grupo dos 20 (ou, mais precisamente, dos 22, já que a Espanha e a Holanda também integraram o painel) foi chamado a assumir os compromissos relacionados ao Basileia III. Tanto em 2012, quanto naquela ocasião, esses países não têm mandato sobre os demais, não havendo garantias de que as deliberações do grupo serão aceitas pelos outros países e nem mesmo de que os países signatários se empenharão nos esforços regulatórios.

Evidentemente, não existe nenhum organismo que efetivamente represente todos os países no que tange à regulação internacional, o que "[...] existe é falta de consequências para os países que não possuem políticas regulatórias adequadas [...]” (Ibid., p. 113).

No entender de Barry Eichengreen, nem mesmo o FMI teria representatividade como fórum para responder por questões financeiras e de arbitragem regulatória. A sugestão do autor e de Benjamin Friedman e Edward Glaeser é a criação do World Financial Organization (WFO), com mecanismo de funcionamento similar ao da Organização Mundial do Comércio (OMC), em que todos os países membros, virtualmente todos que desejam participar do mercado financeiro internacional, teriam obrigações genéricas a cumprir com relação à fiscalização, práticas regulatórias, exigências de capital etc. O descumprimento dessas obrigações permitiria aos demais países membros restringir ou impedir a atuação das instituições financeiras do país ofensor em seu território.

Finalmente, o Quadro 2 é uma tentativa de compilar de modo compreensivo constatações da última crise e as principais propostas e marcos regulatórios dela decorrentes. 
Quadro 2 - Crise e lógica das reformas regulatórias

\begin{tabular}{|c|c|c|c|}
\hline Constatações da Crise & Exemplo & Contexto & Proposta Regulatórias \\
\hline $\begin{array}{l}\text { Solvência e Liquidez demandam } \\
\text { tratamento regulatório diferenciado } \\
\text { e específico. }\end{array}$ & $\begin{array}{l}\text { Bear Sterns e } \\
\text { Lehman } \\
\text { Brothers }\end{array}$ & Basileia III & Requerimento Mínimo de Liquidez \\
\hline $\begin{array}{l}\text { A incapacidade de carregamento de } \\
\text { exposições na ausência de liquidez. }\end{array}$ & $\begin{array}{l}\text { Bear Sterns e } \\
\text { Lehman } \\
\text { Brothers }\end{array}$ & Basileia III & $\begin{array}{c}\text { Requerimento Mínimo de Captações } \\
\text { estáveis (NSFR) }\end{array}$ \\
\hline $\begin{array}{l}\text { O risco de contraparte está } \\
\text { subdimensionado. }\end{array}$ & AIG & Basileia II.5 & $\begin{array}{l}\text { Fatores de Ponderação de Riscos } \\
\text { (FPRs) mais elevados. }\end{array}$ \\
\hline $\begin{array}{l}\text { Os instrumentos híbridos de capital } \\
\text { e dívida (Patrimonio de Referencia } \\
\text { - PR2) são pouco eficazes para } \\
\text { proteção contra perdas. }\end{array}$ & RBS e Lloyds & Basileia III & $\begin{array}{l}\text { Instrumentos híbridos que podiam } \\
\text { compor até } 6 \% \text { do CME são } \\
\text { reduzidos a } 2 \% \text {. O Patrimônio de } \\
\text { Referência Nível } 1 \text { (PR1) deve ser o } \\
\text { principal colchão contra perdas. }\end{array}$ \\
\hline $\begin{array}{l}\text { Política de Dividendos e bônus } \\
\text { irresponsáveis. }\end{array}$ & RBS & $\begin{array}{l}\text { Basileia III / } \\
\text { Vickers } \\
\text { Commission }\end{array}$ & $\begin{array}{l}\text { O pagamento só pode ocorrer se o } \\
\text { nível mínimo de capital exceder o } \\
\text { colchão de conservação, isto é,acima } \\
\text { de } 8 \% \text { em } 2013 \text { e de } 10,5 \% \text { a partir } \\
\text { de } 2019 .\end{array}$ \\
\hline $\begin{array}{l}\text { Prociclicidade do capital } \\
\text { regulatório. }\end{array}$ & Geral & Basileia III & $\begin{array}{l}\text { Capital Contra-cíclico. Maior em } \\
\text { períodos de expansão econômica e } \\
\text { menor na retração. }\end{array}$ \\
\hline $\begin{array}{c}\text { O risco sistemático trazido por } \\
\text { instituições financeiras } \\
\text { sistemicamente importantes } \\
\text { (SIFIS) é substantivamente maior e } \\
\text { mais onerosos para os cofres } \\
\text { públicos. }\end{array}$ & $\begin{array}{l}\text { RBS, Lloyds, } \\
\text { Citibank }\end{array}$ & Basileia III & Colchão de 0,5 a $2,0 \%$ para as SIFIs \\
\hline Shadow Banking & $\begin{array}{l}\text { Crise dos } \\
\text { Fundos } \\
\text { Monetários }\end{array}$ & $\begin{array}{l}\text { Dodd-Frank / } \\
\text { Vickers e } \\
\text { Lavoisier } \\
\text { Report }\end{array}$ & $\begin{array}{l}\text { Reguladores Sistêmicos são em geral } \\
\text { propostos. }\end{array}$ \\
\hline Derivativos desconhecidos & AIG & $\begin{array}{l}\text { Dodd-Frank / } \\
\text { Vickers }\end{array}$ & $\begin{array}{l}\text { "Todos" os derivativos de entidades } \\
\text { de tamanho relevante devem passar } \\
\text { por bolsas. }\end{array}$ \\
\hline $\begin{array}{c}\text { Arbitragem regulatória com } \\
\text { opiniões das ACRs }\end{array}$ & Geral & $\begin{array}{l}\text { Basileia II.5 / } \\
\text { Dodd-Frank }\end{array}$ & $\begin{array}{c}\text { Possibilidade de conflitos de } \\
\text { interesse é minimizada }\end{array}$ \\
\hline Testamento (“Living wills”) & $\begin{array}{l}\text { Lehman } \\
\text { Brothers }\end{array}$ & $\begin{array}{l}\text { Dodd-Frank / } \\
\text { Vickers }\end{array}$ & $\begin{array}{c}\text { Regulação que visa agilizar os } \\
\text { processos de reestruturação } \\
\text { decorrentes de falências com ou sem } \\
\text { intervenção do regulador. }\end{array}$ \\
\hline Too-big-to-fail e proteção social & Geral & $\begin{array}{l}\text { Dodd-Frank / } \\
\text { Vickers }\end{array}$ & $\begin{array}{c}\text { Limitação de investimentos com } \\
\text { capital próprio ("proprietary } \\
\text { trading”), por meio de Volcker Rule } \\
\text { ou Vickers. }\end{array}$ \\
\hline $\begin{array}{l}\text { Reforma dos organismos } \\
\text { multilaterais }\end{array}$ & $\begin{array}{c}\text { Crises } \\
\text { Soberanas }\end{array}$ & $\begin{array}{l}\text { Proposta de } \\
\text { Sarcozy } \\
\text { quando } \\
\text { presidente do } \\
\text { G-20 }\end{array}$ & Novo Breton Woods \\
\hline
\end{tabular}


O item em negrito merece especial atenção nesse trabalho e justifica o desenvolvimento da Abordagem dos Ratings Centralizados (CRBA) prospota nesse trabalho.

\subsection{As ACRs, seu papel na crise do Subprime e a regulação concernente}

\subsubsection{Evolução da indústria de ratings}

O primeiro manual de ratings foi publicado por John Moody, em 1909. A agencia Moody's foi seguida por Poor's Publishing Company, em 1916, Standard Statistics Company, em 1922, e Fitch Publishing Company, em 1924. As opiniões creditícias produzidas por essas agências (principalmente sobre títulos do setor ferroviário) eram vendidas aos investidores em manuais extensos (WHITE, 2010).

Para White (2010, p. 213), após o crash de 1930 nos EUA:

[...] os reguladores do setor bancário estavam comprometidos em encorajar os bancos a investirem apenas em títulos seguros [...] [e emitiram diversas normas sobre o assunto, culminando num decreto de 1936 que efetivamente] proibiu os bancos de investirem em 'ativos especulativos' assim identificados em "manuais' de rating reconhecidos [...]

Essa nova regulação impedia que os bancos utilizassem qualquer tipo de julgamento que não o das agências de rating que produziam os manuais reconhecidos. Nas décadas seguintes, os reguladores do setor de seguros seguiram um caminho similar e passaram a exigir um requerimento mínimo de capital (CME) baseado nos ratings obtidos pelas empresas em que investiam. Os fundos de pensão seguiram uma estratégia similar na década de 1970. Paralelamente, a indústria de ratings foi ficando mais concentrada.

Em 1975, a U.S. Securities and Exchange Commission (SEC) criou a designação Nationally Recognized Statistical Rating Organization (NRSRO) e com ela uma barreira à entrada de novas agências desse tipo. A reestruturação dessa indústria acabou por tornar as NRSROs no final do milênio (quando o mercado de mortgage backed securities (MBS) ou títulos lastreados em hipotecas estava a ponto de decolar nos EUA e globalmente) novamente nas três grandes: Fitch, Moody's, and Standard and Poor's (ALTMAN et al, 2010).

Durante os 25 anos da criação da categoria NRSRO pela SEC, apenas quatro novas empresas foram certificadas: Duff \& Phelps, em 1982; McCarthy, Crisanti \& Maffei, em 1983; IBCA, em 1991; e ThomsonBankWatch, em 1992. Entretanto, fusões entre estes novos entrantes e a Fitch também fizeram com que, em 2000, as NRSROs voltassem a ser as três grandes 
agências internacionais (WHITE, 2010). Um critério para designação de uma NRSRO nunca foi oficialmente estabelecido até 2010.

O modelo de negócios da indústria começou a mudar o paradigma de "o investidor paga" para o de "o emissor paga" no início da década de 1970. White (2010) aponta os seguintes motivos:

- o problema do free rider no uso dos manuais de rating. Supostamente, o uso indiscriminado das copiadoras impôs o receio de que os investidores de modo geral obteriam cópias dos manuais de seus amigos comprometendo suas vendas;

- a percepção de que o negócio das agências de rating era, na verdade, de duas vias, como o das revistas e jornais, possibilitando que a receita viesse de dois lados do mercado: os que queriam a informação (investidores) e os que dependiam de sua divulgação (emissores);

- a percepção de que a regulação sobre os investidores institucionais tornava os emissores reféns desse serviço ao demandar uma opinião por parte de uma ou mais agências de rating quando da aquisição de um título por parte dos investidores regulados;

A mudança para o modelo em que o emissor paga (ou é o principal pagador) abriu a porta para diversos conflitos de interesse na contratação das ACRs pelas partes por elas avaliadas, em especial o risco moral (moral hazard), abundantemente estudado pela literatura (e.g. SY, 2009; COVITZ; HARRISON, 2003; ALTMAN et al, 2010; CANTOR; PARKER, 1994; HULL; WHITE, 2009).

No mercado de títulos empresariais ou governamentais, a preocupação das ACRs com sua reputação ajudou a minimizar esses conflitos de interesse durante as três décadas que se seguiram à implantação desse novo modelo de negócios (ALTMAN et al, 2010; WHITE, 2010).

Por outro lado, no segmento de produtos estruturados, o modelo não resistiu à pressão. Neste segmento, as margens são comparativamente muito mais elevadas, o responsável pela emissão emite muitas opiniões de natureza similar em um curto período de tempo, tornando a captura da ACR muito mais fácil. "O testemunho de ex-funcionários de NRSROs na Câmara dos Deputados em 2009 ajudou a esclarecer a natureza da promiscuidade entre os emissores e as Agências de Rating (ALTMAN et al, 2010)".

Esse padrão de regulação centrado em ratings externos foi seguido pelo Japão e pela União Europeia (Basel Committee in Banking Supervision, 2009), mas generalizado com a adoção de Basileia II. 


\subsubsection{A crise do subprime e as opiniões creditícias}

A crise financeira de 2007-09 gerou preocupação considerável acerca dos incentivos distorcidos oferecidos aos principais participantes do mercado financeiro, e a extensão com que contribuíram para a crise. Certamente, há alguns que acreditam que a crise foi de muitas maneiras uma crise da avaliação (classificação de risco) de crédito. Títulos e valores mobiliários que emergiram da securitização, principalmente os lastreados em hipotecas imobiliárias, representaram US\$ 11 trilhões que precisaram ser absorvidos pela dívida soberana americana. (Thakor, 2010, p. 2).

Calomiris (2009a) identifica dois tipos de falhas em relação às opiniões creditícias: ratings inflacionados e de baixa qualidade, definidos respectivamente como:

[...] uma subestimação intencional da probabilidade de default (PD) em instrumentos de dívida; e ratings de baixa qualidade, resultando em medidas viesadas sobre o valor dos ativos e de suas garantias subjacentes. O colapso do subprime revelou os dois problemas ao extremo [...] [Para o autor, os ratings de baixa qualidade são ainda mais problemáticos que os inflacionados]. Pressupostos tais como o de que os preços dos imóveis nos EUA não podem cair parecem bastante inadequados. (CALOMIRIS, 2009a).

No mercado de hipotecas residenciais de baixa qualidade creditícia (Subprime residential mortgage - RSMB) e outros instrumentos lastreados em hipotecas (Asset Backed Securities ABS), existe um viés claro em favor dos emissores (ADMATI et al, 2010). Dados apresentados pelo IMF (2009, p. 89-93) confirmam esse ponto. O Gráfico 1 mostra que 90\% das emissões do tipo AAA foram rebaixadas em 2008 e mais da metade delas abaixo do nível B.

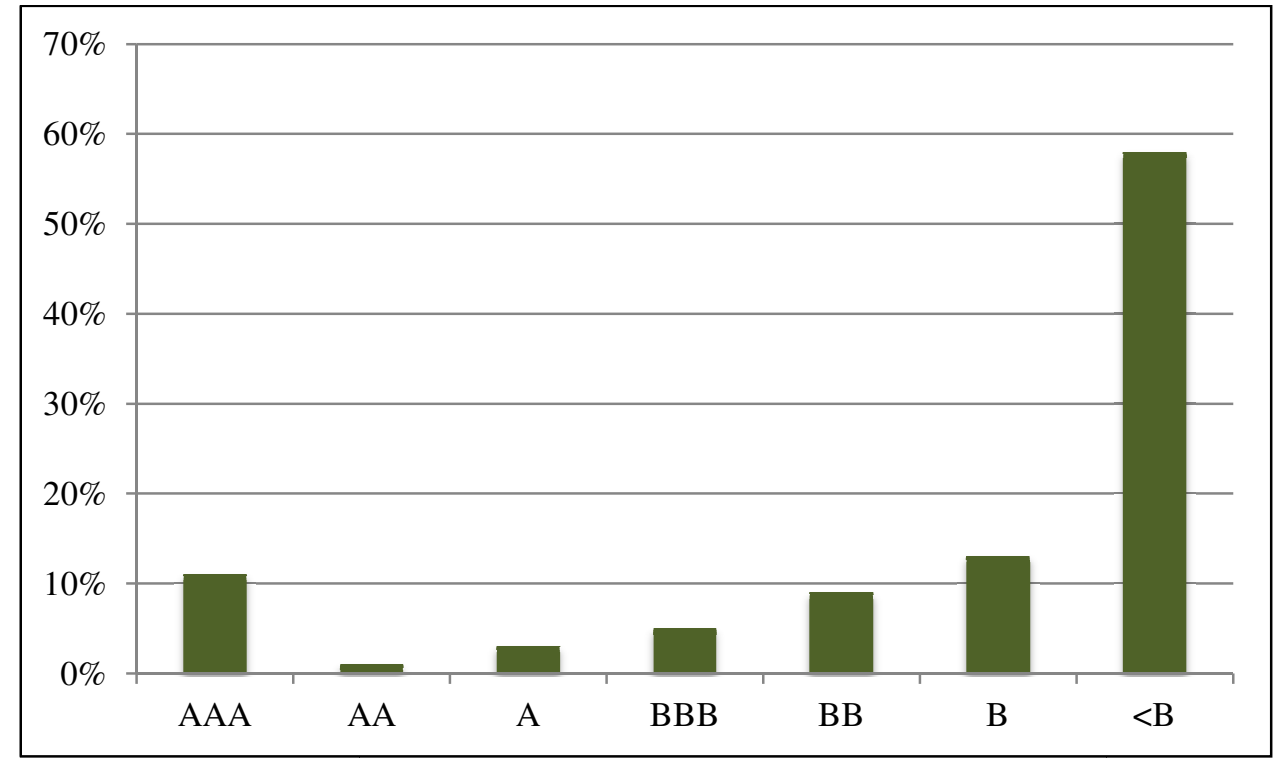

Gráfico 1 - O que aconteceu com os AAAs?

FONTE: IMF, 2009, p. 93.

Outro problema central é que uma oportunidade de arbitragem é criada na negociação desses produtos. De modo geral, os investidores identificam que os riscos desse tipo de produto são 
superiores ao de um título corporativo AAA e, por isso mesmo, os yields dos ABSs e dos ABSs de CDOs são superiores aos dos corporativos, apesar do benefício de granularidade (ou diversificação) oferecido nesses produtos. (HULL; WHITE, 2009; CALOMIRIS, 2009b).

\section{Conflitos de interesse no uso de opiniões das ACRs: algumas evidências}

Hull e White (2009) demonstraram que as classificações AAA concedidas pelas agências aos ABSs de hipotecas residenciais não eram totalmente incoerentes e geravam estimativas de probabilidades de default similares aos AAAs de debêntures de cinco anos, quando os autores replicavam os mesmos pressupostos. No entanto, os pressupostos de capacidade de recuperação (LGD) eram bem pouco conservadores e não consideravam a possibilidade de stress no valor dos imóveis.

Além disso, a fórmula das agências, em geral, uma cópula Gaussiana de fator único exatamente igual à fórmula de risco de crédito da Basileia II, assumia que a correlação entre os defaults era não superior a 5\%, enquanto Basileia II impunha 15\% para as hipotecas. O impacto disso é que o modelo bancário gerava para a carteira hipotecária uma estimativa de perda duas vezes maiores em média. Se os modelos das ACRs seguissem essa premissa, as Sociedades de Propósito Específico (SPEs) gerariam ABSs AAA não superiores a 40\% de seus passivos. De fato, acontecia que em média $82 \%$ deles eram chancelados como AAAs (HULL;WHITE, 2009).

Deve-se considerar porém que, mesmo seguindo os mesmos pressupostos das agências, Hull e White (2009) identificam que os ratings AAA concedidos aos produtos ressecuritizados a partir de hipotecas BBB eram incoerentes com os próprios parâmetros declarados pelas ACRs.

Coval et al (2009) também destrincham o modelo das ACRs para produtos securitizados constatando que eles são muito sensíveis à (1) capacidade de recuperação do valor das hipotecas, (2) à correlação entre os defaults e (3) ao impacto dos "estados da economia" nos fluxos de caixa das SPEs. Como as incertezas sobre os parâmetros do modelo são muito grandes e seus impactos elevados, eles testam uma abordagem bayesiana para os mesmos parâmetros. O resultado é uma quantidade de AAAs muito menor por SPE. 
Para Altman et al (2010), as estimativas de Probabilidade de Default (PD) e Severidade da Perda (Loss given default - LGD) geradas para os produtos securitizados é controversa. Se comparados aos riscos das debêntures, os riscos envolvidos na securitização são bem maiores do que o explicitado pelas agências, porque os títulos de securitização, na realidade, representam opções compostas e as ACRs não estão comprometidas em avaliar a volatilidade do colateral subjacente.

Em pesquisa realizada pelo Chartered Financial Analyst (CFA) Institute com 5.000 membros, mais de dois terços deles responderam que não tomam decisões baseados nas opiniões das ACRs e consideram que elas perderam credibilidade com a precificação dos produtos de securitização. Além disso, $80 \%$ responderam que as ACRs são reacionárias e manifestam opiniões já conhecidas pelo mercado (DANNHAUSER, 2011).

Em relação à securitização, Calomiris (2009b) observa que o emissor (issuer side) não é necessariamente quem mais se beneficia de ratings inflacionados; o investidor (buy side), que é restringido pelos reguladores do sistema financeiro, é quem mais se beneficia do lucro adicional gerado por esse tipo de ativo.

\footnotetext{
Ratings que minimizam o risco ajudam o investidor institucional porque eles [...] incrementam a lucratividade ajustada pelo risco aos olhos de investidores finais menos sofisticados (fundos mútuos, bancos, acionistas de seguradoras, pensionistas ou detentores de apólices) ao fazer com que ativos do tipo AAA tenham performance de AA. (CALOMIRIS, 2009a ).
}

Em suma, os investidores de alguma forma restringidos por ratings são atraídos pela lucratividade e por uma maior alavancagem, já que o capital regulatório exigido para essa exposição é menor do que o exigido para a aquisição de debêntures com risco de crédito efetivamente comparável.

Além disso, investidores institucionais, em especial fundos de pensão americanos, restringidos de adquirir ativos de maior risco, ficam autorizados a adquirir esses títulos de securitização. Adelino (2009) avalia ABSs residenciais (RMBS) emitidos entre 2003 e 2006 e testa se os yields dos RMBS continham na emissão informação superior sobre a qualidade dos ativos subjacentes não refletida nos ratings. Ele conclui que esses spreads previam tanto futuros downgrades, quanto defaults, mesmo quando a informação contida nos ratings é levada em consideração. Esse fenômeno foi observado em todas as classes de ativos, exceto os AAAs, o que, para ele, sugere que os investidores dessa classe eram, na média, menos informados sobre a qualidade dos ativos subjacentes contidas nessas emissões do que os compradores dos ativos de maior risco. 
Altman et al (2010) sugerem que reformas regulatórias envolvendo agências de risco devem levar em consideração três aspectos:

1- redução da dependência regulatória nas opiniões das Agências de Classificação de Risco (ACRs);

2- transparência e qualidade da informação fornecida pelas ACRs (e.g. a inclusão de PDs, LGDs, testes de estresse e avisos (disclaimers) sobre riscos de liquidez e de mercado;

3- redução de conflitos de interesse, especialmente os incentivos distorcidos envolvidos no modelo de negócio em que o emissor paga.

\subsubsection{The Dodd-Frank Act e as Agências de Classificação de Risco (ACRs)}

O novo marco regulatório americano, The Dodd-Frank Wall Street Reform and Consumer Protection Act, The Dodd-Frank Act (USA, 2010a), considera esses três aspectos em maior ou menor profundidade e, em especial, exige ou habilita a SEC a exigir:

- a melhoria dos controles internos nas Nationally Recognized Statistical Rating Organizations (NRSROs), incluindo a completa separação entre os departamentos comercial e de rating e a criação de um departamento de compliance independente (Seção 932a);

- que metade do comitê executivo não seja formado por membros da agência ou empresas afiliadas (Seção 932t);

- a criação de poderes para suspender ou revogar o direito das NRSROs de emitir opiniões sobre determinados produtos, multar e penalizar as agências (Seção 932a);

- a criação de quarentena e outros tipos de cláusulas de look-back quando os analistas deixam as NRSROs para juntarem-se a empresas clientes (Seção 932a).

Além disso:

- torna a SEC responsável por treinar e certificar os analistas de NRSROs;

- torna os dados do primeiro rating públicos, bem como a metodologia utilizada, limitações e explicações sobre a volatilidade dos ratings (Seção 932 a);

- torna certas estatísticas públicas, em especial a PD e a LGD, bem como seus pressupostos e análise de sensibilidade do rating obtido à luz de mudanças nos referidos pressupostos (Seção 932s);

- torna qualquer informação obtida por meio de due dilligence pública; 
- estuda a criação de uma associação profissional para analistas de agências de rating criando padrões de conduta para a profissão, código de ética e para supervisionar a profissão de modo geral (Seção 939e);

- estuda a criação de uma terminologia única para ser adotada em toda a indústria requerendo correspondência quantitativa entre ratings e PDs esperadas tanto em situações normais quanto em cenários de estresse predefinido (Seção 939); ${ }^{4}$

- estuda a criação de um sistema de intermediação entre as NRSROs e os emissores de produtos securitizados por meio de uma organização pública ou privada (Franken Amendment - Seção 939F). ${ }^{5}$

O Franken Amendment propõe um processo para impedir que os emissores da securitização barganhem o primeiro rating. Uma organização independente recolheria uma taxa dos emissores e associaria a solicitação de opinião creditícia a uma NRSRO aleatoriamente ou com base em algum critério estatístico de precisão em suas estimativas.

Altman et al (2010) reconhecem os méritos desse sistema para a minimização de conflitos de interesse, especialmente se a SEC ou outra organização independente (a ser escolhida) adotar métricas de acurácia na estimação ou tracking error para selecionar as ACRs. Calomiris (2009b; 2010) propõe uma metodologia de tracking error para o setor e critica veementemente a falta de incentivos do modelo atual na produção de ratings de qualidade.

Também merece destaque a isenção de responsabilidade civil ou Fair Disclosure (FD) que tornou, nos EUA, as NRSROs (civilmente) responsáveis pelos seus relatórios, assim como auditores e analistas de investimento (Seção 939B).

Quanto ao modelo de negócios da indústria emissor paga vs. investidor paga, o Dodd-Frank Act demanda que o Office of the Controller General (OCC) dê uma resposta final sobre qual o modelo a ser adotado nos EUA (Seção 939F).

Finalmente, o Dodd-Frank Act requer a "[...] remoção de referências à terminologia das Agências de Rating das leis federais e estaduais [...]". A título de exemplo, a expressão "não investment grade" deverá ser substituída por "não apresenta altos padrões creditícios". Os reguladores de todas as agências supervisoras devem desenvolver seu próprios padrões e escalas de capacidade creditícia, além de revisar a nomenclatura usada nas regras e leis centradas em ratings (USA, 2010a, Seção 939a).

\footnotetext{
${ }^{4}$ A SEC deve apresentar uma proposta em um ano.

${ }^{5}$ A SEC deve apresentar uma proposta em dois anos.
} 
Esse último aspecto do código atende a uma sugestão do Joint Forum (BCBS, 2009). Este é formado pelo Basel Committee on Banking Supervision (BCBS), pela International Organization of Securities Commissions (IOSCO), e pela International Association of Insurance Supervisors (IAIS) que se reuniu para sugerir justamente a redução da dependência regulatória em ratings externos. As conclusões foram apresentadas no relatório Stocktaking on the use of Credit Ratings. Em resposta ao documento, diversos países, inclusive o Brasil, iniciaram um processo de levantamento e revisão da legislação financeira dependente de ratings (COREMEC, 2010)

Vale ressaltar que o Congresso Americano, sob influência da IOSCO, já havia passado o Credit Rating Agency (CRA) Reform Act de 2006. Esta lei instruía a SEC a criar critérios claros para a aquisição do selo de NRSRO e requeria da SEC maior transparência em assuntos relacionados às NRSROs. Ele também deu poderes à SEC para fiscalizar o setor, mas não para interferir em suas metodologias ou modelo de negócio (WHITE, 2010).

Para Utzig (2010) e White (2010), esta lei visava principalmente mitigar as barreiras à entrada que a própria SEC impôs, produzindo resultados muito positivos, como a promoção da competição no setor. O número de NRSROs aumentou para dez, incluindo três internacionais.

O Quadro 3, extraído do relatório Comparison of Dodd-Frank Act with IWG and CFA Institute Views, apresenta a visão do Certified Financial Assossiation (CFA) Institute e do Investor's Working Group - IWG. O IWG é uma comissão independente formada pelo Council of Institutional Investors e membros do CFA para tratar das reformas regulatórias nos EUA. 
Quadro 3 - Opinião do CFA Institute sobre as reformas das ACRs

\begin{tabular}{|l|l|l|}
\hline \multicolumn{1}{|c|}{ Dodd-Frank Act } & \multicolumn{1}{|c|}{ Investors' Working Group } & \multicolumn{1}{c|}{ Visão do CFA Institute } \\
\hline $\begin{array}{l}\text { Cria o Office of Credit Ratings } \\
\text { (OCR) dentro da SEC. O OCR } \\
\text { supervisiona as NRSROs para } \\
\text { promover acurácia em ratings de } \\
\text { crédito e limitar conflitos de } \\
\text { interesse. }\end{array}$ & $\begin{array}{l}\text { Concorda que é necesário aumentar } \\
\text { a supervisão da SEC sobre as } \\
\text { NRSROs; aumentar a } \\
\text { responsabilização das NRSROs por } \\
\text { falta de due diligence; reduzir } \\
\text { dependência regulatória nas } \\
\text { NRSROs. }\end{array}$ & $\begin{array}{l}\text { NRSRos precisam ser } \\
\text { responsabilizadas por negligência } \\
\text { ou fraude. }\end{array}$ \\
\hline $\begin{array}{l}\text { Determina a remoção de } \\
\text { referências estatutórias a ratings de } \\
\text { crédito. }\end{array}$ & $\begin{array}{l}\text { Concorda que devem gerenciar } \\
\text { conflitos de interesse e estudar } \\
\text { outros modelos de negócios. }\end{array}$ & $\begin{array}{l}\text { Concorda com a remoção das } \\
\text { referências a ratings da legislação. }\end{array}$ \\
\hline $\begin{array}{l}\text { NRSROs devem criar controles } \\
\text { internos sobre suas metodologias. }\end{array}$ & $\begin{array}{l}\text { Devem gerenciar conflitos de } \\
\text { interesse e estudar outros modelos } \\
\text { de negócios. }\end{array}$ & $\begin{array}{l}\text { Concorda com controles internos } \\
\text { que previnam a gestão de conflitos } \\
\text { de interesse. }\end{array}$ \\
\hline $\begin{array}{l}\text { Dá poderes à SEC de multar as } \\
\text { ACRs e de suspender ou revogar a } \\
\text { licença das ACRs para atuar em } \\
\text { determinas classes de ativos por } \\
\text { certo período. }\end{array}$ & $\begin{array}{l}\text { Aumentar a responsabilização das } \\
\text { NRSROs por falta de due } \\
\text { diligence; }\end{array}$ & $\begin{array}{l}\text { Concorda que as NRSROs } \\
\text { precisam ser responsabilizadas por } \\
\text { negligência. }\end{array}$ \\
\hline $\begin{array}{l}\text { Impõe novos requerimentos sobre } \\
\text { transparência tanto da performance, } \\
\text { quanto da metodologia das ACRs. }\end{array}$ & & $\begin{array}{l}\text { Concorda com maior transparência } \\
\text { sobre as metodologias e } \\
\text { performance das NRSROs. }\end{array}$ \\
\hline
\end{tabular}

FONTE: CFA Institute, 2010, p. 8.

O Dodd-Frank Act enfatiza a disciplina de mercado nas NRSROs demandando maior transparência, governança e responsabilização (enforcement). Ainda que a implementação do Franken Amendment tenha sido postergada, sua existência reconhece que o regulador americano está comprometido em reduzir os conflitos de interesse na indústria de ratings ainda que para isso tenha que modificar o modelo de negócio das agências. Por outro lado, a nova lei não reduz efetivamente a dependência regulatória na opinião das ACRs. A mudança de nomenclatura ou até mesmo das escalas não altera a dependência histórica que a regulação bancária e, de modo geral, a de todo o sistema financeiro, depositou na opinião das agências, especialmente para o cálculo do CME, como tratado mais adiante.

\subsubsection{A Proposta europeia para as Agências de Classificação de Risco (ACRs)}

O grupo das 20 maiores economias do mundo (G-20), o FSA, o Financial Stability Board (FSB), o FMI e a Organização para a Cooperação e Desenvolvimento Econômico (OCDE) apresentaram propostas para melhorar o nível de qualidade, ética e competição na indústria de ratings (e.g. SY, 2009; IMF, 2009). De modo geral, todas essas propostas combinavam recomendações sobre como modificar o modelo de negócio das ACRs e a estrutura normativa 
e de supervisão, mas falhavam em dirimir a dependência excessiva da regulação bancária em opiniões creditícias externas.

Em abril de 2009, o Parlamento Europeu aprovou a Regulação (EC) No. 1060/2009 do Parlamento Europeu e do Council on Credit Rating Agencies: um conjunto de normas que tratava principalmente de aprimorar a transparência e o nível de governança corporativa na indústria (EUROPEAN PARLIAMENT, 2009). Assim como o Dodd-Frank Act, nos EUA, a regulamentação europeia, sob influência da IOSCO, determinava a criação de um departamento de compliance, exigia a presença de membros independentes no comitê executivo das agências, a separação do departamento comercial e de ratings, e criava as cláusulas de quarentena e look-back quando da contratação de ex-funcionários das ACRs por outras entidades.

O Committee of European Securities Regulators (CESR) também proibiu que as ACRs oferecessem serviços de consultoria para as entidades que avaliava, além de requerer transparência na divulgação de sua metodologia e dos pressupostos utilizados em todas as opiniões creditícias por elas emitidas (UTZIG, 2010).

As falências da Enron e da Worldcom geraram diversas preocupações com relação ao risco moral na indústria de ratings. Em 2004, o Code of Conduct Fundamentals for Credit Rating Agencies foi publicado pela IOSCO, sugerindo regras para assegurar a qualidade e integridade nos processos de rating, incluindo sua monitoração, recomendações sobre controles internos e independência dos analistas. Embora nos EUA o código tenha influenciado diretamente o Credit Rating Agency Reform Act de 2006, na Europa nenhuma regulação foi implementada antes do início da Crise de 2007-2009 (Ibidem).

Segundo Utzig (2010), a necessidade de uma reforma regulatória foi amplamente discutida, mas o CESR recomendou à Comissão Europeia que tomasse o caminho da autorregulação. Consequentemente, as ACRs se comprometeram a seguir o código da IOSCO e a informar anualmente a CESR sob seus esforços em implementar o código. As autoridades nacionais dentro da Zona do Euro ficaram também responsáveis pela fiscalização das agências sob coordenação da CESR.

Não obstante, em janeiro de 2007, as três grandes agências de rating receberam o status de External Credit Assessment Institutions (ECAIs). A designação foi criada sob a Capital Requirements Directive (CRD), que implantou o Basileia II na União Europeia, para certificar 
as ACRs que poderiam fornecer opiniões sobre idoneidade creditícia para os bancos que adotaram a abordagem padronizada (UTZIG, 2010; EUROPEAN PARLIAMENT, DIRECTIVE 49, de 4 de julho de 2006).

Em janeiro de 2011, foi criado o European Security Markets Authority (ESMA) também com poderes para registrar, supervisionar e cancelar o registro das agências. Além disso, é esperada uma nova regulação para o setor em 2012. Para subsidiar a votação da nova lei, a Comissão Europeia emitiu, em setembro de 2010, um edital público ou European Commission Consultative Paper sugerindo:

- maior transparência e competição entre as Agências de Rating, incluindo a obrigatoriedade do emissor tornar pública toda a informação disponibilizada à ACR por ele escolhida e facilitando os ratings espontâneos e não solicitados;

- a criação de uma ACR pública europeia para competir com as do setor privado (modelo de utilidade pública);

- o desenvolvimento de uma nova terminologia para as escalas de rating para reduzir a dependência em ratings;

- meios de reduzir conflitos de interesse inerentes ao modelo de negócio do "emissor paga", o que inclui estudos sobre os seguintes modelos: "investidor ou assinante paga"; "investidor e emissor pagam"; uma entidade intermediária paga ("trading venue paga") ou o "governo contrata";

- a introdução de implicações legais e responsabilização das agências (EUROPEAN COMMISSION, 2010, p. 24).

A disciplina de mercado e competição marcaram o tom do European Commission Consultative Paper. Em especial, propostas controversas, como modificar o modelo de negócio para o investidor paga ou modelos derivados e um modelo de utilidade pública, são apresentados.

Como mencionado anteriormente, o problema do free-rider foi um dos principais motivos da mudança do modelo de negócio das agências de investidor paga (buy-side pays) para o de emissor paga, no início da década de 1970. Ainda mais importante, o investidor institucional que é restringido pelos ratings (buy side) é exatamente a parte mais interessada em ratings inflacionados (e.g. CALOMIRIS, 2009a; SY, 2009; IMF, 2009, p. 89-93; ECB, 2009).

O modelo de utilidade pública também apresenta sérios problemas, conforme sugerido no European Commission (2010, p. 27): “[...] o modelo de 'utilidade pública/governo' tem 
desvantagens: ele não é livre de conflitos de interesse (governos são entidades avaliadas [pelas agências]); pode afetar negativamente o mercado financeiro e é uma proposta cara e que envolve o uso de recursos do contribuinte."

A primeira minuta da nova lei a ser votada pelo Parlamento Europeu foi apresentada em abril de 2011 e está sendo formulada pelo congressista Wolf Klinz do Committee of Economic and Monetary Affairs sugerindo até aqui principalmente:

- a obrigatoriedade de dois ratings para os produtos de securitização. O primeiro por meio de uma ECAI escolhida pelo emissor e o segundo por uma agência diferente escolhida pela ESMA, levando em consideração o "mérito das agências e sua performance histórica" (EUROPEAN PARLIAMENT, 2010, p. 6);

- a criação da European Credit Rating Foundation (ECRaf) totalmente independente para competir com as empresas do setor privado (modelo de utilidade pública);

- responsabilização civil das CRAs.

Em suma: na Europa, após a Regulação (EC) No. 1060/2009 (EUROPEAN PARLIAMENT, 2009), e nos EUA, após o Credit Rating Reform Act de 2006, houve progresso material no sentido de demandar das NRSROs e ECAIs melhores controles internos e maior transparência. Mas a redução da dependência da regulação nas opiniões das agências não foi adequadamente dirimida em nenhuma delas. $\mathrm{O} B C E$ chamou a atenção para esse fato em resposta à European Commission (2010) e sugeriu o crescente uso dos ratings internos em oposição aos ratings externos, em especial no que tange ao modelo de Abordagem Padronizada adotado na Zona do Euro (EC, 2011). Saliente-se que a abordagem CRBA desenvolvida nessa tese atende essa sugestão do BCE (Ver seção 3.4 para a proposta desse estudo). 


\section{REVISÃO BIBLIOGRÁFICA}

\subsection{Razões para a existência de Regulação Financeira}

A regulamentação é tratada por diversos autores em perspectivas econômicas, sociais e políticas brevemente apresentadas adiante.

\subsubsection{Aspectos Conceituais Contemporâneos}

Uma forma simples de apresentar a regulação financeira envolvendo todas as entidades no sistema bancário é apresentada por Barth- et al (2006) como um grande problema de agente e principal entre os elos apresentados na Figura 1.

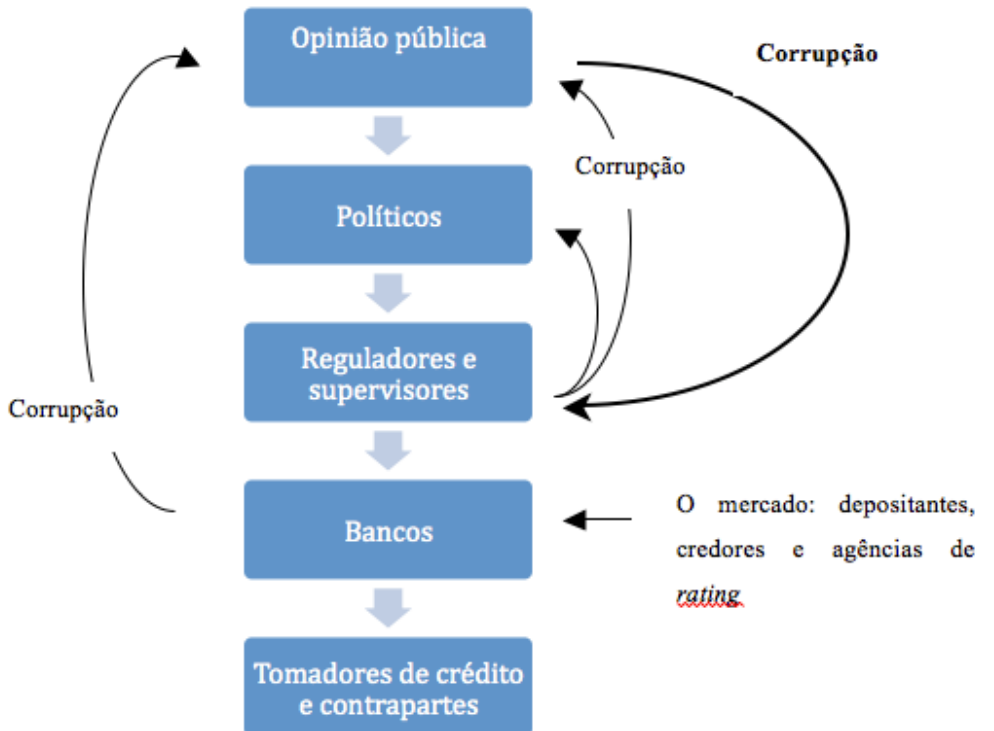

Figura 1 - Ambiente Institucional

FONTE: BARTH et al., 2006, p. 6.

Em todos os elos da Figura 1, é possível observar um problema entre agente e principal, centrado na assimetria informacional. Entre bancos e tomadores de crédito, por exemplo, existe uma relação em que o banco precisa induzir o tomador a comportar-se responsavelmente e honrar suas dívidas. Como o tomador dispõe de mais informações sobre 
suas próprias atividades e riscos do que o banco, a solução desse dilema será arbitrada com empréstimos de curta duração e exigência de colaterais. Na mesma figura, no elo acima, uma situação similar é observada.

Os reguladores e supervisores precisam criar regras e procedimentos que forcem os bancos a atuar de forma conservadora e responsável, mas estes detêm informações superiores às dos reguladores, bem como daquelas disponíveis aos depositantes, credores, pequenos acionistas e agências de rating. O problema segue no próximo elo, em que políticos tentarão influenciar a ação do organismo regulador a seu favor e serão minados pela falta de conhecimento técnico específico dos supervisores. No topo da cadeia, está a própria opinião pública que deseja influenciar os políticos no sentido de protegerem seus interesses, mas não tem informações suficientes para controlar seus representantes.

Quando os políticos e o setor público de modo mais amplo agem em favor do interesse da sociedade (Teoria do interesse público), contribuem para acelerar o desenvolvimento econômico, prevenir crises e promover a competição. Contudo, quando agem por seus próprios interesses, acabam, de fato, capturados pelos interesses dos banqueiros, dos maus pagadores e de outros entes (Teoria da captura). "A habilidade da sociedade de monitorar e controlar seus políticos tem fortes implicações para a escolha das práticas de regulamentação e supervisão bancária e, portanto, sobre a performance do sistema bancário e da prosperidade da nação." (Ibidem).

Para Barth et al (2004), a Teoria do interesse público aplicada à regulação bancária sustenta que os mercados financeiros são imperfeitos e os governos regulamentam os bancos para aumentar sua eficiência e minimizar falhas de mercado. Como ficou evidente após 1929, as crises bancárias são caras e produzem a redução do crescimento econômico e piora da distribuição de renda, devendo ser evitadas ao máximo.

$\mathrm{Na}$ Teoria da captura, os mercados também são imperfeitos, mas a regulação emerge naturalmente da interação entre os diversos agentes privados: credores, acionistas, devedores e bancos. A Teoria da captura aposta na disciplina de mercado e na maior transparência como os fatores-chave para o desenvolvimento de uma regulação de mercado eficaz e menos sujeita à corrupção.

Observe-se que ambas as teorias partem do pressuposto de que existem imperfeições de mercado e ambas refutam o laissez-faire. Se não houvesse custos de transação, se os governos 
maximizassem a riqueza social e se os direitos de propriedade fossem autorreforçáveis, os mercados naturalmente alcançariam a eficiência sem necessidade de mecanismos de governança públicos ou privados (Idem, 2006).

Qualquer que seja o arcabouço teórico adotado, fica evidente que aumentar o poder da autoridade supervisora só faz sentido se os mecanismos de controle sobre as instituições políticas minimizarem a captura política e regulatória, prevenirem o executivo de usar seus poderes para ganhos próprios e obrigarem os supervisores a agirem em nome dos interesses da nação (Idem, 2001).

Os resultados encontrados por Barth et al (2006) e trabalhos anteriores dos mesmos autores indicam que aumentar os requerimentos de capital (Pilar 1) e reforçar os poderes dos supervisores (Pilar 2) contribui negativamente para fomentar o desenvolvimento econômico, aumentar a eficiência dos bancos, reduzir a corrupção nos empréstimos ou diminuir a fragilidade do sistema financeiro. Dos três pilares, apenas a disciplina de mercado e o aumento da transparência se mostraram eficazes (Pilar 3). Nos trabalhos empíricos crosscountry realizados para o setor bancário, foram encontrados indícios de captura política e regulatória (e.g. BARTH et al, 2001; 2004; 2006).

Para certos autores, como Viscusi et al (2005), o processo de regulação deveria passar por uma fase de aumento do controle governamental até que a sociedade tivesse instituições mais sólidas e um mercado mais desenvolvido e capaz de exercer maior controle. A etapa de desregulamentação deveria ser posterior. Barth et al (2006) encontraram evidências de que, justamente nos países com instituições políticas e legais mais frágeis, o aumento do poder da supervisão foi mais nefasto.

\subsubsection{Proteção social e institucional}

Se a razão para existência de regulação e fiscalização pode ser descrita como conjuntos de normas, acordos e aparatos institucionais de supervisão que emergem da necessidade de minimizar conflitos de interesse entre diversos agentes, a sua justificativa mais usual é a promoção de uma rede de proteção.

A intermediação financeira em si é calcada na transformação de passivos de curto prazo em ativos financeiros de prazo mais longo. Esse problema de descasamento cria o risco de 
liquidez inerente de modo geral a toda atividade de financiamento. No setor bancário, esse risco, bem como o de crédito e o de mercado, cujo equilíbrio permite a solvência do banco, é assumido pelo depositante em última instância.

A proteção do depositante é o motivo original da existência da regulação e advém historicamente da própria necessidade de se estimular a intermediação financeira e consequentemente do desenvolvimento econômico (FREIXAS; ROCHET, 1997; BARTH et $a l, 2004)$. A contrapartida da proteção ao depositante por meio de seguro de depósito na maior parte dos países é a imposição de normas aos bancos, sendo a restrição específica de alavancagem ou o requerimento de capital mínimo, a mais importante (FREIXAS; ROCHET, 1997).

\subsubsection{Regulação baseada em capital e em risco}

Após a Crise de 1929, o regulador americano adicionou, às restrições de capital, a restrição à assunção de risco por parte dos bancos, originalmente proibindo os ativos de risco e mais adiante condicionando-os ao capital. Essa decisão, como descrito no segundo capítulo, está intimamente ligada ao desenvolvimento dos modelos de mensuração de risco da própria indústria de ratings e do setor bancário. Blum (2005) destaca que as decisões ótimas de alocação de ativos por uma instituição financeira após a adoção desse tipo de regulação mudam significativamente.

A liberalização financeira dos anos 1970 e 1980, associada ao excesso de liquidez dos petrodólares e à irresponsabilidade generalizada tanto de bancos, quanto dos governos latinoamericanos na assunção de risco de crédito, levou às crises bancárias dos anos 1980 na América Latina. Além das enormes perdas incorridas pelo setor bancário, os países diretamente envolvidos no resgate do seu próprio sistema financeiro tomaram um passo na direção de homogeneizar a regulação bancária internacional.

Desse esforço, nasceu o primeiro acordo da Basileia, em 1988. O Comitê de Supervisão Bancária da Basileia (Basel Committee in Banking Supervision - BCBS), existente desde 1974 como fórum de supervisores, ficou responsável pela elaboração do acordo, consagrando um modelo de regulação bancária de capital mínimo sensível a risco. 
No primeiro acordo, de 1988, o saldo de certas famílias de ativos eram ponderadas por risco e a razão entre o Capital (Patrimônio de Referência) e o total dos ativos ponderados pelo risco (APRs) conforme os fatores da Tabela 1 deveria observar um valor mínimo de $8 \%$ chamado de "Cooke Ratio”, “Capital Ratio” ou, no Brasil, o Índice de Basileia (YANAKA, 2009).

Tabela 1 - APRs na Basileia I

\begin{tabular}{|l|c|}
\hline \multicolumn{1}{|c|}{ Exemplo de Ativo } & APR \\
\hline Operações de Crédito em geral & $100 \%$ \\
\hline Crédito Imobiliário (residencial) sem garantia & $50 \%$ \\
\hline Bancos da OCDE & $20 \%$ \\
\hline Títulos públicos de países da OCDE & $0 \%$ \\
\hline
\end{tabular}

FONTE: YANAKA, 2009, p. 16.

Entre os acordos de Basileia I e II, um adendo ( $C f$. Basel Committee in Banking Supervision, 1996) incorporou o risco de mercado e criou o tratamento diferenciado do trading e do banking book. As versões posteriores do acordo, Basileia II e III, incorporariam o risco operacional e de liquidez, respectivamente, e criariam abordagens distintas em ordem crescente de complexidade em relação à capacidade de mensuração do risco, a saber: a abordagem padronizada simplificada - SSA, a abordagem padronizada (baseada em ratings externos) - SA, a abordagem baseada nos modelos internos (IRB) básica e a IRB avançada (Quadro 4).

No que tange ao risco de crédito, o cálculo do requerimento de capital ou Capital Mínimo Exigido (CME) deixa de ser baseado nas grandes famílias de risco para ser baseado nas exposições em si, em que, para cada operação, existe um CME específico que leva em consideração a classificação de risco do tomador, sua garantia, seu prazo, a diversificação do portfólio, a capacidade de recuperação de perdas etc.

Para Carey (2002), o nível adequado dos requerimentos absolutos de capital é aquele que é tão conservador por longos ciclos de negócios que, em qualquer momento, é capaz de enfrentar um período de estresse (ou choque adverso) repentino de severidade predeterminada pelo regulador sem que essas perdas de crédito consumam a totalidade do seu colchão de capital $^{6}$..

\footnotetext{
${ }^{6}$ Para o autor, esse colchão deve ser formado de ações ordinárias. Os instrumentos híbridos de capital e dívida não possuem as propriedades desejadas do capital regulatório.
} 
Quadro 4 - As abordagens da Basileia II e o Risco de Crédito

\begin{tabular}{|c|c|}
\hline Abordagens & Sensibilidade a risco de crédito em relação ao Acordo de Basileia I \\
\hline $\begin{array}{c}\text { Abordagem } \\
\text { Padronizada } \\
\text { Simplificada } \\
\text { (SSA) }\end{array}$ & $\begin{array}{c}\text { Inclusão dos mitigadores de risco, ou seja, fatores de ponderação (APRs) diferenciados de } \\
\text { acordo com a natureza da garantia e a criação de um fator de 75\% para a Carteira de } \\
\text { Varejo. }\end{array}$ \\
\hline $\begin{array}{c}\text { Abordagem } \\
\text { Padronizada } \\
\text { (SA) }\end{array}$ & $\begin{array}{c}\text { Além da sensibilização à garantia e à granularidade descritas acima, é sensível à } \\
\text { classificação de risco do tomador medida pelo rating externo da operação ou do devedor } \\
\text { concedido por uma ACR certificada para isso (e.g. ECAIs na Europa). Conforme a } \\
\text { classificação obtida junto à ACR, a operação pode receber fatores de ponderação de 0\% a } \\
\text { 150\%. }\end{array}$ \\
\hline $\begin{array}{c}\text { Abordagem dos } \\
\text { modelos } \\
\text { internos (IRB) } \\
\text { básica }\end{array}$ & $\begin{array}{c}\text { O capital regulatório é sensível à classificação de risco ou rating interno da operação. Os } \\
\text { fatores de ponderação da SA dão lugar à probabilidade de default (PD) estimada pela IF. O } \\
\text { capital regulatório é função da PD, da garantia, do prazo, da diversificação do portfólio e da } \\
\text { capacidade de recuperação de perdas do banco (RR) e a severidade da perda (LGD). No } \\
\text { entanto, apenas a PD e a LGD do Varejo são estimadas diretamente pelo banco. Os demais } \\
\text { parâmetros da operação, correlação entre os ativos (R) e a maturidade (M), influenciam o } \\
\text { CME, mas são estimados pela Supervisão Bancária. }\end{array}$ \\
$\begin{array}{c}\text { Abordagem dos } \\
\text { modelos } \\
\text { internos (IRB) } \\
\text { avançada }\end{array}$ & $\begin{array}{c}\text { Similar à anterior. Contudo, todos os parâmetros são estimadas internamente pelo } \\
\text { banco. }\end{array}$ \\
\hline
\end{tabular}

FONTE: Elaborado pelo autor com base em BCBS (2005a; 1988; 2006)

A abordagem SSA e em muitos casos Basileia I foram a opção dos países emergentes, especialmente os latino-americanos. Uma combinação entre SA e IRB está presente na maioria dos países desenvolvidos.

\subsection{As opiniões das ACRs e os acordos de Basileia}

No segundo capítulo, foi explorada a relação entre as opiniões creditícias e a crise de 20082009, bem como a evolução da dependência regulatória nelas. Nesta seção, trata-se com detalhes do impacto dessas opiniões no cálculo do CME nos acordos da Basileia.

\subsubsection{Visão geral: da Basileia I para a Basileia III}

No primeiro Acordo da Basileia, todos os empréstimos eram equivalentes no que tange à sua contribuição para o capital regulatório. Os ativos ponderados pelo risco (APRs) eram de $100 \%$ para todos os empréstimos. Os ratings internos dos bancos eram usados para inferir exclusivamente as perdas esperadas e para o cálculo da provisão para devedores duvidosos.

A Basileia I não admitia o uso de ratings externos para a determinação dos requerimentos de capital e também não levava em consideração a sofisticação no gerenciamento do risco ou a 
capacidade de recuperação de perdas dos bancos. Conceitualmente, todas as exposições de crédito eram capazes de gerar a mesma perda inesperada, a despeito de sua natureza, classificação ou colateral. No final da década de 1980, esse modelo pareceu suficientemente robusto para coibir a assunção irresponsável de riscos por parte dos maiores bancos e prevenir experiências traumáticas, como a crise das dívidas soberanas na América Latina (GONZALEZ et al, 2011).

Na década de 1990, com o crescimento explosivo dos mercados de ações, ficava evidente que os requerimentos de capital também deveriam contemplar o risco de mercado levando à criação da emenda de risco de mercado, Amendment to the capital accord to incorporate market risks (BCBS, 2006a) e a intenção de negociação determinava se certo título estava no trading ou no banking book.

As crises da Ásia e da Rússia (1997-1998) revelaram ainda a necessidade de modelos de gerenciamento de risco mais eficientes, maior transparência e uma supervisão mais orientada à gestão de risco. Outra vez, os membros, dessa vez do G-20, se reuniam para discutir um novo arcabouço regulatório e o segundo Acordo da Basileia foi criado.

No contexto de Basileia II, o requerimento mínimo de capital (Pilar 1) deveria não apenas proteger o banco e os depositantes dos riscos de crédito e de mercado, mas também do operacional. Adicionalmente, foram estabelecidos princípios gerais de gestão interna de risco (Pilar 2) e demandas para aprimorar a transparência e a disciplina de mercado de modo mais amplo (Pilar 3).

Por outro lado, havia um consenso de que as instituições mais sofisticadas, que fazem elevados investimentos em gestão de risco, e as menos sofisticadas não podiam ser tratadas da mesma maneira. Criava-se um prêmio para a qualidade de gestão e para os investimentos de certos bancos (hoje conhecidos como Instituições Financeiras Sistemicamente Importantes SIFIS) e esse prêmio tomava a forma de uma maior alavancagem.

Se os bancos mais sofisticados estavam a ponto de utilizar os seus modelos internos de risco, internal rating based (IRB), para estimar o capital regulatório necessário a fazer frente a perdas, o que fazer com os demais bancos? A abordagem padronizada (SA) e a abordagem simplificada padronizada (SSA) da Basileia II foram criadas exatamente para atender às 
necessidades dos bancos menos sofisticados. Consequentemente, a categoria de $\mathrm{FPR}^{7}$ de $100 \%$ utilizada para a carteira de empréstimos dava lugar a uma gama de FPRs entre $20 \%$ e $150 \%$, dependendo do rating externo ou do colateral da operação (Quadro 5).

Quadro 5 - APRs para risco de crédito na Abordagem Padronizada de Basileia II

\begin{tabular}{|c|c|c|c|c|c|c|c|}
\hline \multirow{2}{*}{\multicolumn{2}{|c|}{ Exposição de Crédito }} & \multicolumn{6}{|c|}{ Ratings concedidos por NRSROs ou ECAIs } \\
\hline & & $\begin{array}{c}\text { AAA / } \\
\text { AA- }\end{array}$ & $\mathrm{A}+/ \mathrm{A}-$ & $\begin{array}{c}\text { BBB+ / } \\
\text { BBB- }\end{array}$ & $\mathrm{BB}+/ \mathrm{B}-$ & B- /e inf & N/A \\
\hline \multicolumn{2}{|c|}{ Soberano } & $0 \%$ & $20 \%$ & $50 \%$ & $100 \%$ & $150 \%$ & $100 \%$ \\
\hline \multirow{3}{*}{ Bancos } & Opção 1 & $20 \%$ & $50 \%$ & $100 \%$ & $100 \%$ & $150 \%$ & $100 \%$ \\
\hline & Opção 1 & $20 \%$ & $50 \%$ & $50 \%$ & $100 \%$ & $150 \%$ & $50 \%$ \\
\hline & Curto prazo & $20 \%$ & $20 \%$ & $20 \%$ & $50 \%$ & $150 \%$ & $20 \%$ \\
\hline \multicolumn{2}{|c|}{ Corporate } & $20 \%$ & $50 \%$ & $100 \%$ & $100 \%$ & $150 \%$ & $100 \%$ \\
\hline \multirow{3}{*}{ Varejo } & $\begin{array}{l}\text { Hipoteca } \\
\text { residencial }\end{array}$ & & & & & & $35 \%$ \\
\hline & $\begin{array}{l}\text { Hipoteca } \\
\text { comercial }\end{array}$ & & & & & & $100 \%$ \\
\hline & Outros & & & & & & $75 \%$ \\
\hline
\end{tabular}

FONTE: BCBS, 2001, p. 10 (Adaptado).

Adicionalmente, Basileia II.5, uma revisão do acordo de Basileia II para o risco de mercado, que entrou em vigor a partir de 30 de dezembro de 2010, impôs FPRs mais elevados para atividades como securitização, negociação de títulos à vista e derivativos, risco de contrapartes, além de impor, no contexto do IRB, uma estimação de risco mais conservadora para o VaR em stress, sVaR.

\subsubsection{As ACRs e a Abordagem Padronizada (SA)}

As opiniões sobre idoneidade creditícia começaram a influenciar os requerimentos mínimos de capital de maneira generalizada em todo o mundo após 2004, com a adoção da abordagem padronizada da Basileia II. Os ratings externos, como demonstrado no Quadro 5, tornaram-se mitigadores de risco de crédito, assim como os colaterais, permitindo o uso de APRs menores e reduzindo os requerimentos de capital para exposições de atacado, soberano e bancos. É válido observar que as exposições ao risco de crédito são ponderadas por fatores

\footnotetext{
${ }^{7}$ Neste texto, as expressões APR e Fator de Ponderação de Risco (FPR) são usados como substitutos perfeitos. O termo FPR foi adotado no Brasil em 2007, quando a SSA foi adotada.
} 
significativamente menores quando a exposição é classificada como Investment Grade ou melhor (BBB ou superior). As exposições devem ser comparadas com a coluna NA, sem classificação, similar ao FPR existente em Basileia I e usada na SA para exposições sem garantia ou ratings externos. Vale ressaltar que os Fatores de Ponderação do Quadro 5 dizem respeito às posições ativas para as quais o banco não tem intenção de negociação (banking book). Quando a intenção não existe, as exposições são classificadas na carteira de negociação (trading book). Nesse caso, o capital regulatório é estimado de outro modo.

$\mathrm{Na}$ abordagem padronizada, os bancos devem escolher entre duas alternativas: escolher uma ECAI que classificasse o máximo possível de clientes com quem ele opera ou contratar duas ou mais ECAIs. Neste caso, ele diminui a probabilidade de deparar-se com exposições não classificadas e sujeitas a um APR de 100\%, mas fica obrigado a sempre utilizar o pior rating. Qualquer que seja a opção inicial do banco e a ECAI por ele escolhida, não é possível alterála sem o aval do supervisor (BCBS, 2006, p. 28)

\section{Exemplo}

No contexto de Basileia I (Acordo de 1988), uma hipoteca residencial de US\$ 1 milhão ou uma exposição de securitização lastreada em uma hipoteca de mesmo risco requereria um capital regulatório de US\$39.200 (assumindo um índice de Basileia de 8\%, APR de 50\% e provisão para devedores duvidosos - PDD - de $2 \%)^{8}$. A mesma operação em um banco que adota a abordagem padronizada de Basileia II demanda um capital regulatório um pouco menor, US\$27.440 (APR de 35\%).

Todavia, deve-se ponderar que uma exposição de securitização classe sênior lastreada em ativos subjacentes do exato mesmo risco da operação anterior (mas que pelo suposto benefício da granularidade) recebeu rating AAA demandaria US\$16.000 (APR de 20\% - Tabela 2) no

\footnotetext{
${ }^{8}$ Basileia I (Cf. BCBS, 1988) não reconhecia os benefícios da granularidade eventualmente trazidos pela securitização. Tanto uma exposição em hipoteca, quanto uma exposição lastreada em uma hipoteca estavam sujeitas a um APR de $50 \%$.
} 
banking book ${ }^{9}$, e por volta de US\$ 2.500 no trading book ${ }^{10}$. Sob Basileia II.5, a carga regulatória desta última modalidade seria elevada para $\mathrm{R} \$ 16.000$ (1.6\% - Tabela 3 - APR de $20 \%)$.

Tabela 2 - APRs disponíveis na abordagem padronizada (Basileia II) para securitização no Banking Book.

\begin{tabular}{|c|c|c|c|c|c|}
\hline \multirow{2}{*}{$\begin{array}{c}\text { Ponderação de } \\
\text { Risco }\end{array}$} & \multicolumn{5}{|c|}{ Opinião de idoneidade creditícia } \\
\cline { 2 - 6 } & $\begin{array}{c}\text { AAA / } \\
\text { AA- }\end{array}$ & $\begin{array}{c}\text { A+ / } \\
\text { A- }\end{array}$ & $\begin{array}{c}\text { BBB+ / } \\
\text { BBB- }\end{array}$ & $\begin{array}{c}\text { BB+ / } \\
\text { BB- }\end{array}$ & $\begin{array}{c}\text { B+ / } \\
\text { inferiores }\end{array}$ \\
\hline APR & $20 \%$ & $50 \%$ & $100 \%$ & $350 \%$ & Dedução \\
\hline
\end{tabular}

FONTE: BCBS, 2006, p. 12.

Tabela 3 - Cargas usada na Abordagem Padronizada da Basileia II.5 - Trading Book

\begin{tabular}{|l|c|c|c|c|c|}
\hline \multirow{2}{*}{ Rating Externo } & \multicolumn{5}{|c|}{ Cargas regulatórias na Abordagem Padronizada } \\
\cline { 2 - 6 } & $\begin{array}{c}\text { AAA to } \\
\text { AA- A- } \\
\text { 1/P-1 }\end{array}$ & $\begin{array}{c}\text { A+ to A- } \\
\text { A-2/P-2 }\end{array}$ & $\begin{array}{c}\text { BBB+ to } \\
\text { BBB- } \\
\text { A-3/P-3 }\end{array}$ & $\begin{array}{c}\text { BB+ to } \\
\text { BB- }\end{array}$ & $\begin{array}{c}\text { Abaixo de BB- } \\
\text { ou A-3/P-3 ou } \\
\text { sem } \text { rating }\end{array}$ \\
\hline $\begin{array}{l}\text { Exposição em } \\
\text { Securitização }\end{array}$ & $1,6 \%$ & $4 \%$ & $8 \%$ & $28 \%$ & Dedução \\
\hline $\begin{array}{l}\text { Exposição em } \\
\text { Resecuritização }\end{array}$ & $3,2 \%$ & $8 \%$ & $18 \%$ & $52 \%$ & Dedução \\
\hline
\end{tabular}

FONTE: BCBS, 2010e, p. 6.

Se o banco seguisse a abordagem IRB de Basileia II, como um investidor e não como um originador, e adquirisse o mesmo ativo de securitização, ele aplicaria o Rating Based Approach (RBA) e a carga regulatória seria de US\$5.600 ${ }^{11}$ (APR de 7\% - Tabela 4) no banking book. No trading book, esse número seria internamente calibrado por uma abordagem VaR usando uma janela mínima de 10 dias. Implicitamente, existe um prêmio por se utilizar o IRB.

\footnotetext{
${ }^{9}$ A operação descrita representa a compra de Asset-backed Security (ABS) cujo colateral é uma hipoteca, isto é, um tipo de Credit Debt Obligation (CDO). O risco de uma exposição sênior em um ABS é supostamente menor que o de investir em uma única hipoteca, porque o pool traz um benefício de diversificação e as classes subordinadas absorvem as primeiras perdas.

${ }^{10}$ Está sendo assumido o mínimo capital regulatório devido, isto é, 0,25\%, disponível apenas para ativos qualificados e que não impõem cargas adicionais pela Maturity Ladder por estarem a menos de 6 meses do vencimento. O exemplo foi criado para refletir a maior arbitragem regulatória disponível pela legislação. Detalhes sobre os pressupostos podem ser encontrados em BCBS (2006, p. 167-171). Também foi assumido um risco nulo de contraparte que seria facilmente conseguido, por exemplo com um derivativo de crédito como um Credit Default Swap. (Cf. BCBS 2006, p. 258).

${ }^{11} \mathrm{~A}$ PD não é utilizada nas exposições de securitização.
} 
No IRB, o rating externo precisa ser utilizado quando disponível na securitização: o ratingsbased approach (RBA). No entanto, ainda que a opinião creditícia seja a mesma e produzida pela mesma ACR, a Tabela utilizada é a 4, muito menos conservadora que a Tabela 2 da abordagem padronizada. Os requerimentos de capital são maiores na abordagem padronizada do que no IRB no banking e no trading book.

Tabela 4 - Tabela RBA representando os APRs usados na Basileia II abordagem IRB

\begin{tabular}{|c|c|c|c|}
\hline $\begin{array}{l}\text { Ratings Externos de } \\
\text { curto e longo prazo }\end{array}$ & $\begin{array}{c}\text { APR para uma } \\
\text { exposição senior } \\
\text { granular }\end{array}$ & $\begin{array}{c}\text { APR para uma } \\
\text { exposição não senior } \\
\text { granular }\end{array}$ & $\begin{array}{c}\text { APR para uma } \\
\text { exposição não } \\
\text { granular }\end{array}$ \\
\hline AAA/A1/P1 & $7 \%$ & $12 \%$ & $20 \%$ \\
\hline AA & $8 \%$ & $15 \%$ & $25 \%$ \\
\hline $\mathrm{A}+$ & $10 \%$ & $18 \%$ & \multirow{3}{*}{$35 \%$} \\
\hline $\mathrm{A} / \mathrm{A} 2 / \mathrm{P} 2$ & $12 \%$ & $20 \%$ & \\
\hline A- & $20 \%$ & $35 \%$ & \\
\hline $\mathrm{BBB}+$ & $35 \%$ & \multicolumn{2}{|c|}{$50 \%$} \\
\hline $\mathrm{BBB} / \mathrm{A} 3 / \mathrm{P} 3$ & $60 \%$ & \multicolumn{2}{|c|}{$75 \%$} \\
\hline BBB- & \multicolumn{3}{|c|}{$100 \%$} \\
\hline $\mathrm{BB}+$ & \multicolumn{3}{|c|}{$250 \%$} \\
\hline $\mathrm{BB}$ & \multicolumn{3}{|c|}{$425 \%$} \\
\hline BB- & \multicolumn{3}{|c|}{$650 \%$} \\
\hline $\begin{array}{c}\text { Abaixo de BB- ou sem } \\
\text { rating }\end{array}$ & \multicolumn{3}{|c|}{ Dedução } \\
\hline
\end{tabular}

FONTE: BCBS, 2006a, p. 135-136 (Adaptado).

O Quadro 6 sumariza o exemplo. Ele apresenta uma comparação dos APRs e do capital mínimo exigido (CME) para exposições corporate com rating AAA e exposições de securitização AAA de US\$ 1 milhão nos três acordos da Basileia. Observe-se que é praticamente impossível para um ente externo ao banco (inclusive o supervisor) calcular os requerimentos de capital para um banco que segue a abordagem IRB (HALDANE, 2011).

A Basileia II.5 introduziu uma Tabela RBA para o trading book das instituições que seguem o IRB eliminando a possibilidade de arbitragem regulatória entre o trading book e o banking book para exposições de securitização. Um banco que segue o IRB teria de constituir um APR de 7\% (US\$ 5.600 - Tabela 4) no banking book ou Value-at-Risk (VaR) no trading book. Porém, como pode ser observado durante a crise de 2008-2009, poucos bancos o faziam, pois o banking book demandava uma carga regulatória muito maior. 
Quadro 6 - Capital Mínimo Exigido (CME) e K(\%) em diversas classes de exposição de US\$ 1 milhão de Basileia I a II.5

\begin{tabular}{|c|c|c|c|c|c|c|c|c|}
\hline & \multicolumn{2}{|c|}{$\begin{array}{c}\text { Basileia I - } \\
\text { Acordo de 1988* }\end{array}$} & \multicolumn{2}{|c|}{$\begin{array}{l}\text { Basileia II - } \\
\text { Abordagem } \\
\text { Padronizada }\end{array}$} & \multicolumn{2}{|c|}{$\begin{array}{c}\text { Basel II - } \\
\text { Abordagem IRB }\end{array}$} & \multicolumn{2}{|c|}{$\begin{array}{c}\text { Basel II.5 - IRB/ } \\
\text { Standard } \\
\text { Approach (SA) }\end{array}$} \\
\hline & $\begin{array}{l}\mathrm{K}(\%) / \\
\text { APR }\end{array}$ & $\begin{array}{l}\text { US\$ } \\
\text { CME }\end{array}$ & $\begin{array}{l}\mathrm{K}(\%) / \\
\text { APR }\end{array}$ & $\begin{array}{l}\text { US\$ } \\
\text { CME }\end{array}$ & $\begin{array}{l}\mathrm{K}(\%) / \\
\mathrm{APR}\end{array}$ & $\begin{array}{l}\text { US\$ } \\
\text { CME }\end{array}$ & $\begin{array}{l}\text { K IRB/ } \\
\text { SA }\end{array}$ & $\begin{array}{l}\text { US\$ } \\
\text { CME }\end{array}$ \\
\hline \multicolumn{9}{|c|}{ Exposição Corporate AAA } \\
\hline $\begin{array}{l}\text { Empréstimo com } \\
\text { ou sem garantia }\end{array}$ & $\begin{array}{l}8 \% / \\
100 \%\end{array}$ & 78.400 & $\begin{array}{c}1,6 \% / \\
20 \%\end{array}$ & 15.680 & C.I** & C.I** & $\begin{array}{l}\text { C.I**/ } \\
1,6 \%\end{array}$ & $\begin{array}{l}\text { C.I. } * * / \\
15.680\end{array}$ \\
\hline $\begin{array}{l}\text { Debênture no } \\
\text { banking book }\end{array}$ & $\begin{array}{c}8 \% / \\
100 \%\end{array}$ & 78.400 & $\begin{array}{c}1,6 \% / \\
20 \%\end{array}$ & 15.680 & C.I** & C.I** & $\begin{array}{c}\text { C.I.**/ } \\
1,6 \%\end{array}$ & $\begin{array}{l}\text { C.I. } * * / \\
15.680\end{array}$ \\
\hline $\begin{array}{l}\text { Debênture no } \\
\text { trading book* }\end{array}$ & $\begin{array}{l}8 \% / \\
100 \%\end{array}$ & 78.400 & $\begin{array}{l}>\text { que } \\
0,25 \%\end{array}$ & 2.500 & $\mathbf{V a R} * *$ & $\mathbf{n} / \mathbf{a}$ & $\underset{* * *}{3 \mathbf{x V a R}}$ & $\underset{* * *}{3 \mathbf{x V a R}}$ \\
\hline \multicolumn{9}{|c|}{$\begin{array}{l}\text { Hipoteca (sem rating) e classes sênior de securitização lastreadas em hipotecas residenciais com rating } \\
\text { AAA (RMBS) }\end{array}$} \\
\hline $\begin{array}{c}\text { Hipoteca } \\
\text { residencial (risco } \\
\text { de } 1 \text { famiília) }\end{array}$ & $\begin{array}{l}4 \% / \\
50 \%\end{array}$ & 39.200 & $\begin{array}{l}2.8 \% 1 \\
35 \%\end{array}$ & 27.440 & C.I.** & C.I** & $\begin{array}{l}\text { C.I.**/ } \\
2,8 \%\end{array}$ & $\begin{array}{l}\text { C.I. } * * / \\
27.440\end{array}$ \\
\hline $\begin{array}{l}\text { Securitização no } \\
\text { banking book } \\
\text { (pool) }\end{array}$ & $\begin{array}{l}4 \% / \\
50 \%\end{array}$ & 39.200 & $\begin{array}{l}1.6 \% / \\
20 \%\end{array}$ & 16.000 & $\begin{array}{l}0.56 \% / \\
7 \%\end{array}$ & 5,600 & $\begin{array}{l}0.56 \% \\
/ 1.6 \%\end{array}$ & $\begin{array}{l}5,600 / \\
16.000\end{array}$ \\
\hline $\begin{array}{l}\text { Securitização } \\
\text { no trading book } \\
\text { (pool) }\end{array}$ & $\begin{array}{l}\mathbf{4 \%} / \\
\mathbf{5 0 \%}\end{array}$ & 39.200 & $\begin{array}{l}>\text { que } \\
0.25 \%\end{array}$ & 2.500 & VaR* & $\mathbf{V a R}^{*}$ & $\begin{array}{l}0.56 \% \\
/ 1.6 \%\end{array}$ & $\begin{array}{l}5.600 / \\
16.000\end{array}$ \\
\hline \multicolumn{9}{|c|}{$\begin{array}{l}\text { * O trading book foi introduzido pelo BCBS (1996) na emenda de risco de mercado. Não fazendo } \\
\text { parte do Acordo de } 1988 \text {. } \\
\text { ** C.I significa parâmetros calibrados internamente. O VaR também é calibrado internamente. } \\
\text { *** Na Basileia II.5, em vigor desde dezembro de } 2010 \text {, a estimação do VaR para requerimento mínimo de } \\
\text { capital tornou-se mais conservadora. Surgiu um fator que multiplica o VaR por pelo menos } 3 \text { e um } \\
\text { compenente de stressed VaR (sVAR). }\end{array}$} \\
\hline
\end{tabular}

Desde dezembro de 2010, os bancos que seguem o IRB não se beneficiam com o uso do trading book. Uma carga de capital de $0,56 \%$ passa a ser exigida e equivale a $7 \%$ (Tabela 4 ) dos $8 \%$ do índice de Basileia do banking book. Na abordagem padronizada da Basileia II.5, o uso do trading book para a securitização também ficou vetado e os bancos tiveram de utilizar os mesmos US\$ 16.000 (Tabela 3 - 1,6\%) que usariam no banking book em oposição aos 0,25\% da tabela de risco de mercado, usados antes da crise (Quadro 7) . 
Quadro 7 - Bancos IRB desde dezembro de 2010

\begin{tabular}{|c|c|c|c|c|c|}
\hline \multirow[t]{2}{*}{ Rating Externo } & \multicolumn{3}{|c|}{ Exposição à securitização } & \multicolumn{2}{|c|}{$\begin{array}{c}\text { Exposição à } \\
\text { ressecuritização }\end{array}$} \\
\hline & $\begin{array}{l}\text { Senior } \\
\text { Granular }\end{array}$ & $\begin{array}{l}\text { Não senior } \\
\text { Granular }\end{array}$ & $\begin{array}{l}\text { Não } \\
\text { granular }\end{array}$ & Senior & Não Senior \\
\hline AAA/A-1/P-1 & $0,56 \%$ & $0,96 \%$ & $1,60 \%$ & $1,60 \%$ & $2,40 \%$ \\
\hline AA & $0,64 \%$ & $1,20 \%$ & $2,00 \%$ & $2,00 \%$ & $3,20 \%$ \\
\hline $\mathrm{A}+$ & $0,80 \%$ & $1,44 \%$ & \multirow{3}{*}{$2,80 \%$} & $2,80 \%$ & $4,00 \%$ \\
\hline $\mathrm{A} / \mathrm{A}-2 / \mathrm{P}-2$ & $0,96 \%$ & $1,60 \%$ & & $3,20 \%$ & $5,20 \%$ \\
\hline A- & $1,60 \%$ & $2,80 \%$ & & $4,80 \%$ & $8,00 \%$ \\
\hline $\mathrm{BBB}+$ & $2,80 \%$ & \multicolumn{2}{|c|}{$4,00 \%$} & $8,00 \%$ & $12,00 \%$ \\
\hline $\mathrm{BBB} / \mathrm{A}-3 / \mathrm{P}-3$ & $4,80 \%$ & \multicolumn{2}{|c|}{$6,00 \%$} & $12,00 \%$ & $18,00 \%$ \\
\hline BBB- & \multicolumn{3}{|c|}{$8,00 \%$} & $16,00 \%$ & $28,00 \%$ \\
\hline$\overline{\mathrm{BB}+}$ & \multicolumn{3}{|c|}{$20 \%$} & $24,00 \%$ & $40,00 \%$ \\
\hline$\overline{\mathrm{BB}}$ & \multicolumn{3}{|c|}{$34 \%$} & $40,00 \%$ & $52,00 \%$ \\
\hline BB- & \multicolumn{3}{|c|}{$52 \%$} & $60,00 \%$ & $68,00 \%$ \\
\hline $\begin{array}{l}\text { Abaixo de BB-/ } \\
\text { Abaixo de A-3/P- } \\
3\end{array}$ & \multicolumn{5}{|c|}{ Dedução } \\
\hline
\end{tabular}

FONTE: BCBS, 2009, p. 7.

As Basileias II.5 e III (até aqui) não modificam FPRs do banking book. O maior rigor em relação às exposições ativas de risco trazido por Basileia II.5 está apenas no trading book. (Ver Quadros 8 e 9). Segundo o Basel Committee in Banking Supervision (2011), essas mudanças (genericamente chamadas de Basileia II.5) tiveram efeito a partir de 31 de dezembro de 2010 (BCBS, 2009b) e novas mudanças entraram em vigor em 31 de dezembro de 2011 (BCBS, 2011).

Quadro 8 - Capital Requerido no banking book para o exemplo da securitização de US\$1 MM.

\begin{tabular}{|c|c|c|c|}
\hline - Basiléia I & & & 39.200 \\
\hline Basiléia II - Standard Approach & & 15.680 & \\
\hline Basiléia III - Standard Approach & & 15.680 & \\
\hline Basiléia II - IRB (RBA) & 5.488 & & \\
\hline Basiléia III - IRB & 5.488 & & \\
\hline
\end{tabular}


Quadro 9 - Capital Requerido no trading book para o exemplo da securitização de US\$1 MM.

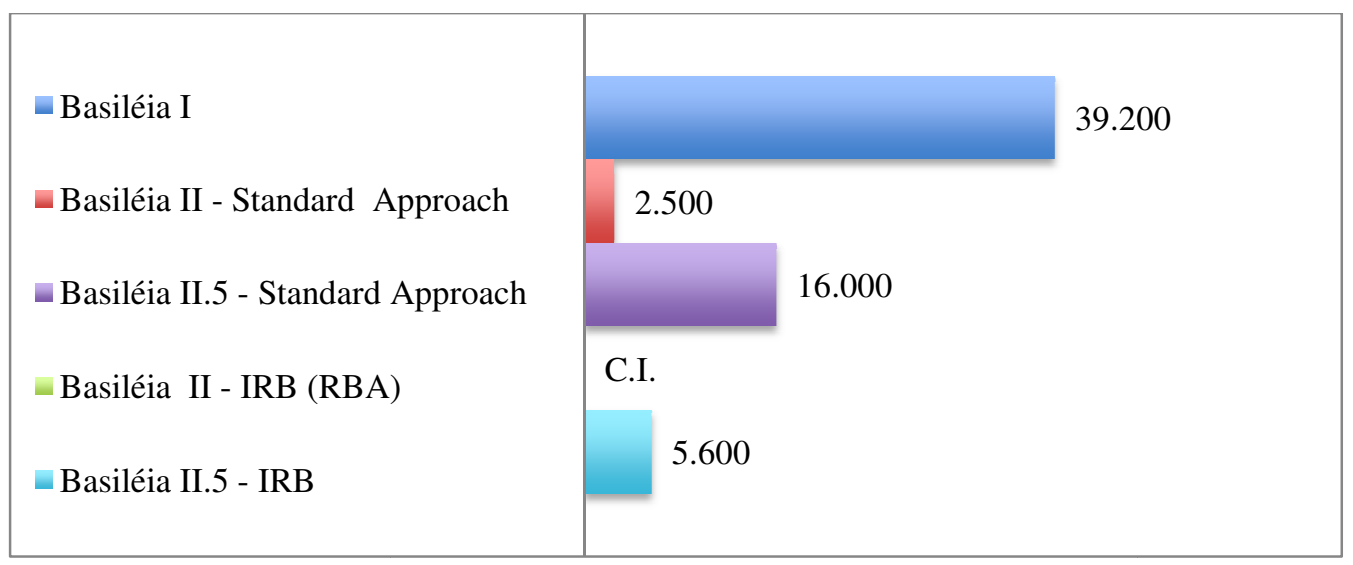

Sob Basileia I, todos os empréstimos eram tratados do mesmo modo e não havia oportunidade de arbitragem entre títulos e empréstimos ou entre o trading e o banking book. Basileia II não apenas permitiu CMEs menores com base na informação de terceiros (rating externo), mas também criou um abismo entre o capital regulatório devido por bancos sofisticados (usuários do IRB) e não sofisticados, permitindo que os bancos maiores (sistemicamente importantes) e, por isso, qualificados para o IRB, operassem com um nível de alavancagem maior.

Como se pode observar, a orientação do capital regulatório ao uso de ratings externos, introduzida no contexto de Basileia II, não é modificada no contexto de Basileia II.5 e III. A despeito do Comitê da Basileia ter feito pesadas críticas à dependência excessiva da regulação bancária da informação provida pelas agências (e.g. Basel Committee in Banking Supervision, 2009a), o novo acordo não diminui a dependência na informação externa.

As reformas que entraram em vigor antes de 2013 (Basileia II.5) visaram fortalecer o trading book e, em especial, dirimir o excessivo incentivo à arbitragem regulatória na securitização ao optar pelo trading book (o que era feito irrestritamente, ainda que certos produtos não atendessem a critérios de liquidez nem tivessem sido adquiridos exclusivamente para negociação).

Vale ressaltar que a resposta regulatória por parte do G-20 para a crise de 2008-2009 vai no sentido absolutamente oposto ao tomado em Basileia II em diversos aspectos, merecendo destaque o tratamento dado aos bancos sistemicamente importantes, que passaram a observar um colchão de capital conforme o seu tamanho. (Ver Anexo 1). 


\section{Quais eram as deficiências do primeiro acordo?}

Basileia I para o risco de crédito era insensível de duas maneiras: primeiramente, o capital regulatório era insensível ao risco de default específico do tomador de crédito; em segundo lugar, era omisso em relação à existência de colateral possivelmente incentivando os bancos a assumirem riscos mais elevados em exposições não garantidas.

Note-se que a abordagem padronizada atende os dois pontos acima ao reconhecer tanto colaterais, quanto opiniões creditícias para sensibilizar o $\mathrm{CME}$ a risco de crédito. A abordagem padronizada simplificada (SSA) adotada no Brasil atende apenas o segundo, o que será explicitado nas duas próximas seções.

Esse ponto é fundamental nessa tese, pois sua proposta visa suprir essa deficiência sem recorrer às opiniões das ACRs.

\subsubsection{As ACRs e a legislação do Sistema Financeiro Nacional (SFN)}

De acordo com um estudo elaborado em junho de 2009 pelo Joint Forum - formado pelo BCBS, o International Organization of Securities Commissions, e o International Association of Insurance Supervisors - BCBS (2009a) Stocktaking on the use of Credit Ratings as classificações de risco são usadas na regulação do sistema financeiro para cinco propósitos principais $^{12}$ (COREMEC, 2010):

i) determinação de requisitos de capital para instituições sujeitas à regulação prudencial;

ii) identificação ou classificação de ativos ou instituições, normalmente associados a investimentos elegíveis ou a limite de concentração em ativos;

iii) oferta pública de títulos resultantes de operações de securitização;

iv) requisito de transparência; e

v) exigência de apresentação de prospecto.

O Comitê de Regulação e Fiscalização dos Mercados Financeiro, de Capitais, de Seguros, de Previdência e Capitalização (COREMEC), atendendo solicitação do Joint Fórum, realizou um

\footnotetext{
12 No âmbito internacional, o levantamento envolveu as seguintes jurisdições: Alemanha, Austrália, Bélgica, Canadá, Espanha, EUA, França, Holanda, Itália, Japão, Reino Unido e Suíça.
} 
extenso estudo ( $C f$. COREMEC, 2010) sobre o uso da opinião creditícia gerada pelas ACRs no Brasil. O Comitê concluiu que as categorias II e IV são as mais comuns. Especialmente no setor previdenciário e securitário no sentido de restringir os instrumentos em que as entidades fiscalizadas podem investir e, no mercado de capitais, a título de requisito de transparência.

O uso de rating para determinação de requerimentos de capital é admitido apenas pela SUSEP, desde janeiro de 2011, para a obtenção dos fatores de risco de crédito dos resseguradores estrangeiros.

No setor bancário brasileiro, o uso de ratings externos para determinação de requisitos de capital é vedado, lembrando que, no corpo de documentos que tratam da adoção de Basileia II no Brasil, o Comunicado BCB n. 12.746 de 9 de dezembro de 2004 especificamente menciona que não serão admitidos relatórios de rating elaborados por ACRs para esse fim. $\mathrm{O}$ Comunicado BCB n. 18.365, de 22 de abril de 2009 admite o uso dos referidos relatórios de forma apenas acessória na elaboração do rating interno dos bancos e no caso deles serem utilizados, a Carta-Circular n. 3.419, de 10 de dezembro de 2009 determina que o rating de referência seja explicitado no relatório mensal enviado ao Sistema de Classificação de Crédito do Banco Central do Brasil (SCR).

O Banco Central do Brasil, por sua vez, admite ou exige o uso de rating externo apenas em operações com contraparte no exterior ou quando existem garantias no exterior. No último caso, a garantia, se título soberano, deve possuir no mínimo rating $\mathrm{A}$, conforme Resoluções CMN No. 3.633, de 3 de novembro de 2008 (CMN, 2008) e n. 3.691, de 23 de março de 2009. Nesses casos, os empréstimos externos (incluindo títulos) de maneira mais ampla também podem ser avaliados pelos critérios usuais da Resolução CMN n. 2.682 de 21 de dezembro de 1999 (CMN, 1999) ou devem possuir rating mínimo A, emitido por ao menos duas Agências de Classificação de Risco (Circular BCB No. 3.415, de 16 de outubro de 2008).

\subsubsection{Os Acordos de Basileia no Brasil}

Basileia I foi implantada no Brasil tardiamente pela Resolução CMN n. 2.099 de 17 de agosto de 1994 (CMN, 1994, anexo IV), que criava originalmente exigências de capital para 
cobertura de risco de crédito e um índice de Basileia de 8\%, progressivamente elevado para 10\% e 11\% a partir da Resolução CMN n. 2.784, de 27 de novembro de 1997 (CMN, 1997).

A adoção de Basileia II no Brasil acontece oficialmente em junho de 2008, a partir da Resolução CMN n. 3.490, de 29.08.2007 (CMN, 2007). No entanto, como mencionado, o Comunicado n. 12.746 de 9.12.2004 já antecipava o teor da opção brasileira no que se refere ao uso das opiniões das agências de rating (grifos meus):

I - o Banco Central do Brasil não utilizará ratings divulgados pelas agências externas de classificação de risco de crédito para fins de apuração do requerimento de capitalII deverá ser aplicada à maioria das instituições financeiras a abordagem padrão simplificada, que consiste em um aprimoramento da abordagem atual mediante a incorporação de elementos que, a exemplo dos instrumentos específicos para mitigação de risco de crédito, possibilitem uma melhor adequação do requerimento de capital às características das exposições, considerando as demandas do Banco Central do Brasil relativamente à suas atribuições de órgão supervisor e a melhor alocação de recursos pelas instituições financeiras menores, com a consequente revisão dos fatores de ponderação de risco de crédito determinados pela tabela anexa à Resolução 2.099, de 17 de agosto de 1994

III - às instituições de maior porte, com atuação internacional e participação significativa no SFN, será facultada a utilização de abordagem avançada, com base em sistema interno de classificação de risco, após período de transição, a ser estabelecido pelo Banco Central do Brasil, em que deverá ser adotada a abordagem padrão simplificada e, posteriormente, a abordagem fundamental (ou básica) de classificação interna de riscos.

Em outras palavras, o Comunicado n. 12.746/04 especificamente rejeita a abordagem padronizada de Basileia II e antecipa elaborar um aprimoramento da abordagem atual, isto é, a abordagem padrão simplificada (SSA), que incorpora mitigadores de crédito e o FPR de $75 \%$ do Varejo, mas não ratings externos.

A Resolução do CMN n. 3.490 de 29.08.2007 (CMN, 2007) colocou em vigor a fórmula exposta no Quadro 10 para a estimação da Patrimônio de Referência Exigido (PRE), revogando a anterior Resolução CMN n. 2.099 de 17.08.1994 (CMN). 
Quadro 10 - Fórmula do Patrimônio de Referencia Exigido (PRE) introduzido em 2007 no Brasil

$$
P R E=P_{E P R}+P_{C A M}+P_{J U R}+P_{C O M}+P_{A C S}+P_{O P R}
$$

em que:

PEPR = parcela referente às exposições ponderadas pelo fator de ponderação de risco a elas atribuído;

PCAM = parcela referente ao risco das exposições em ouro, em moeda estrangeira e em operações sujeitas à variação cambial;

$$
\text { PJUR }=\sum_{i=1}^{n} \text { PJURi }
$$

parcela referente ao risco das operações sujeitas à variação $i=1$ de taxas de juros e classificadas na carteira de negociação, na forma da Resolução no 3.464, de 26 de junho de 2007, onde $\mathrm{n}=$ número das diferentes parcelas relativas ao risco das operações sujeitas à variação de taxas de juros e classificadas na carteira de negociação;

PCOM = parcela referente ao risco das operações sujeitas à variação do preço de mercadorias (commodities);

PACS = parcela referente ao risco das operações sujeitas à variação do preço de ações e classificadas na carteira de negociação, na forma da Resolução no 3.464, de 2007;

POPR $=$ parcela referente ao risco operacional.

FONTE: CMN, 2007.

A Circular BCB n. 3.360 de 12.09.2007 efetivamente criou os novos fatores de ponderação (FPRs) para a parcela PEPR de risco de crédito da SSA e as Circulares BCB No. 3.361 a 3.369 as demais parcelas.

\subsubsection{1. $\quad$ Abordagem Padronizada Simplificada (SSA) Brasileira}

A alternativa adotada no Brasil foi a de "tropicalizar" a SSA, que é um desdobramento de Basileia I, em que o risco de crédito não é sensível a ratings, como nas demais abordagens de Basileia II. A SSA para risco de crédito no banking book é muito similar à Basileia I trazendo um $\mathrm{FPR}^{13}$ de $100 \%$ para todas as exposições de crédito (não garantidas).

\footnotetext{
13 Conforme mencionado anteriormente, as expressões FPR e APR estão sendo usadas como perfeitos
} substitutos. A expressão FPR é adotada na Resolução CMN No. 3.490 de 29.08.2007 (CMN, 2007) como 
O uso do colateral, contudo, permite o uso de mitigadores de risco, que são FPRs menores do que $100 \%$ no banking book e $75 \%$ para as de Varejo (Quadro 11).

Quadro 11 - Abordagem padronizada simplificada ou abordagem padronizada brasileira

\begin{tabular}{|c|c|c|c|}
\hline \multicolumn{2}{|l|}{ Exposições ativas } & \multicolumn{2}{|c|}{ Mitigadores de Risco (Colaterais) } \\
\hline Tipo & APR & Mitigadores de Risco & APR \\
\hline Itens que representam caixa & $0 \%$ & $\begin{array}{l}\text { Garantia do Tesouro Nacional ou } \\
\text { Banco Central do Brasil }\end{array}$ & $0 \%$ \\
\hline Investimentos em ouro & $0 \%$ & $\begin{array}{l}\text { Garantia de Organismos } \\
\text { Multilaterais reconhecidos }\end{array}$ & $0 \%$ \\
\hline $\begin{array}{l}\text { Títulos públicos do Tesouro Nacional } \\
\text { ou Banco Central do Brasil }\end{array}$ & $0 \%$ & Cash Collateral & $0 \%$ \\
\hline Depósitos em moeda local & $20 \%$ & $\begin{array}{l}\text { Garantias de instituições } \\
\text { financeiras no Brasil }\end{array}$ & $50 \%$ \\
\hline \multicolumn{2}{|l|}{ Exposições de crédito } & $\begin{array}{l}\text { Garantias de instituições } \\
\text { financeiras de países que não } \\
\text { apresentaram default nos últimos } \\
5 \text { anos. }\end{array}$ & $50 \%$ \\
\hline Exposições a bancos & $50 \%$ & $\begin{array}{l}\text { Certificados de Depósito (CDBs) } \\
\text { ou outros títulos emitidos por } \\
\text { instituições financeiras. }\end{array}$ & $50 \%$ \\
\hline $\begin{array}{l}\text { Exposições a outros bancos centrais e } \\
\text { títulos soberanos }\end{array}$ & $50 \%$ & Derivativos de Crédito & $50 \%$ \\
\hline $\begin{array}{l}\text { Exposições com colateral em } \\
\text { propriedades de maneira geral }\end{array}$ & $50 \%$ & \multicolumn{2}{|c|}{$\begin{array}{l}\text { Propriedade comercial ou residencial cujo } \\
\text { valor }\end{array}$} \\
\hline Exposições de Varejo (sem garantia) & $75 \%$ & $\begin{array}{l}\text { - represente mais do que } 200 \% \\
\text { da exposição }\end{array}$ & $35 \%$ \\
\hline Outros empréstimos & $100 \%$ & $\begin{array}{l}\text { - represente entre } 125 \% \text { e } \\
200 \% \text { da exposição. }\end{array}$ & $50 \%$ \\
\hline Outras exposições & $100 \%$ & $\begin{array}{l}\text { - represente menos de } 125 \% \text { da } \\
\text { exposição }\end{array}$ & $100 \%$ \\
\hline
\end{tabular}

FONTE: Circular BCB n. 3.360 de 12.09.2007.

A título de exemplo, na atual abordagem brasileira, uma exposição corporate de $\mathrm{R} \$ 1$ milhão requer um capital regulatório de $\mathrm{R} \$ 107.800$ (supondo índice de Basileia de 11\%, FPR de 100\% e Provisão Mínima de 2\%). Se a mesma exposição tiver uma garantia (no mínimo no valor total da exposição) de outra instituição financeira ou um derivativo de crédito, a carga seria de R \$ 53.900 (APR de 50\% - comparando as colunas da direita e da esquerda do Quadro 11). Se a exposição fosse garantida na sua totalidade por um organismo multilateral de alto nível como o Banco Mundial, não haveria carga (FPR de 0\%). 
Apenas os maiores bancos brasileiros participarão do processo de certificação para utilizar a abordagem IRB. Todos os bancos pequenos e médios continuarão a utilizar essa abordagem.

\subsubsection{A abordagem IRB no Brasil: implantação e RBA}

Desde 2007, o teor do IRB vem sendo antecipado pelo Banco Central do Brasil. As orientações sobre como calibrar os parâmetros e as categorias a serem criadas foram progressivamente sugeridas e apresentadas, em especial pelo Comunicado 18.365, de 22 abril de 2009.

Em 18 de fevereiro de 2011, o Banco Central do Brasil colocou em audiência pública o Edital de No. 37 apresentando a minuta de Circular que finamente disporá sobre a abordagem IRB contida no documento International Convergence of Capital Measurement and Capital Standards: a Revised Framework, revisão apresentada em junho de 2006 (Cf. Basel Committee in Banking Supervision, 2006a).

Embora adotando o texto original na maioria dos aspectos, vale ressaltar que quando faz menção ao RBA, a minuta apenas admite o uso do método de classificação interna e ainda menciona (Art. 130 item II):

$\S 1$ o O processo de classificação interna da abordagem RBA deve permitir a segregação das exposições em, no mínimo, onze Níveis de Qualidade Creditícia de Longo Prazo (NQL) e três Níveis de Qualidade Creditícia de Curto Prazo (NQC).

§ 2o A classificação interna no âmbito da abordagem RBA deve ser comparada com classificações externas, quando estas existirem, com vistas à identificação de eventuais discrepâncias.

Finalmente, para a abordagem RBA, a minuta apresenta a Tabela 5 em substituição à tabela original de Basileia II apresentada anteriormente e totalmente orientada para ratings internos. 
Tabela 5 - Abordagem RBA do IRB no Brasil

\begin{tabular}{|c|c|c|c|}
\hline Classificação Interna & $\begin{array}{l}\text { Ponderação } \\
\text { de risco para } \\
\text { exposição de } \\
\text { maior } \\
\text { senioridade e } \\
\text { com ativos } \\
\text { subjacentes } \\
\text { granulares }\end{array}$ & $\begin{array}{l}\text { Ponderação } \\
\text { de risco para } \\
\text { exposição de } \\
\text { menor } \\
\text { senioridade e } \\
\text { com ativos } \\
\text { subjacentes } \\
\text { granulares }\end{array}$ & $\begin{array}{l}\text { Ponderação } \\
\text { de risco para } \\
\text { exposição } \\
\text { cujo } \\
\text { conjunto de } \\
\text { ativos } \\
\text { subjacentes é } \\
\text { não granular }\end{array}$ \\
\hline NQL1 & $7 \%$ & $12 \%$ & $20 \%$ \\
\hline NQL2 & $8 \%$ & $15 \%$ & $25 \%$ \\
\hline NQL3 & $10 \%$ & $18 \%$ & $35 \%$ \\
\hline NQL4 & $12 \%$ & $20 \%$ & $35 \%$ \\
\hline NQL5 & $20 \%$ & $35 \%$ & $35 \%$ \\
\hline NQL6 & $35 \%$ & $50 \%$ & $50 \%$ \\
\hline NQL7 & $60 \%$ & $75 \%$ & $75 \%$ \\
\hline NQL8 & $100 \%$ & $100 \%$ & $100 \%$ \\
\hline NQL9 & $250 \%$ & $250 \%$ & $250 \%$ \\
\hline NQL10 & $425 \%$ & $425 \%$ & $425 \%$ \\
\hline NQL11 & $650 \%$ & $650 \%$ & $650 \%$ \\
\hline $\begin{array}{c}\text { Abaixo de NQL11/não } \\
\text { classificadas }\end{array}$ & $909 \%$ & $909 \%$ & $909 \%$ \\
\hline
\end{tabular}

FONTE: BCB, 2011b

\subsubsection{Basileia III no Brasil: primeiras impressões}

Em 17 de fevereiro de 2011, o BCB emitiu o Comunicado n. 20.615 que antecipava os impactos da aceitação de Basileia III no Brasil. Novamente, um aspecto primordial e diferenciado da abordagem brasileira é:

Em particular, o tratamento proposto para o ajuste de avaliação do crédito - Credit Valuation Adjustment - (CVA) deverá ser adaptado, mantida a decisão de não utilizar classificações realizadas por agências externas de classificação de risco de crédito para apuração do PRE, divulgada no Comunicado no 12.746, de 9 de dezembro de 2004.

O CVA é um mecanismo que aumenta o requerimento de capital quando o risco percebido da contraparte aumenta (calculado com dados de mercado, em especial a variação das taxas de Credit Default Swaps - CDS).

Com respeito ao parâmetro mínimo para o capital regulamentar, já que o Brasil parte de um índice de Basileia mais elevado, o calendário de implantação seguirá a Tabela 6. Cumpre observar as diferenças em relação à Tabela 7 de Basileia III proposta pelo Comitê da Basileia. 
Tabela 6 - Basileia III no Brasil implantação

\begin{tabular}{|c|c|c|c|c|c|c|c|}
\hline $\begin{array}{c}\text { Parâmetro dividido } \\
\text { pelo APR }\end{array}$ & $\begin{array}{c}\text { Em 1o. } \\
\text { De } \\
\text { Janeiro } \\
\text { de } \\
2013 \\
\end{array}$ & $\begin{array}{c}\text { Em 1o. } \\
\text { De } \\
\text { Janeiro } \\
\text { de } \\
2014 \\
\end{array}$ & $\begin{array}{c}\text { Em 1o. } \\
\text { De } \\
\text { Janeiro } \\
\text { de } \\
2015 \\
\end{array}$ & $\begin{array}{c}\text { Em 1o. } \\
\text { De } \\
\text { Janeiro } \\
\text { de } \\
2016 \\
\end{array}$ & $\begin{array}{c}\text { Em 1o. } \\
\text { De } \\
\text { Janeiro } \\
\text { de } \\
2017 \\
\end{array}$ & $\begin{array}{c}\text { Em 1o. } \\
\text { De } \\
\text { Janeiro } \\
\text { de } \\
2018 \\
\end{array}$ & $\begin{array}{c}\text { Em 1o. } \\
\text { De } \\
\text { Janeiro } \\
\text { de } \\
2019 \\
\end{array}$ \\
\hline Capital Principal & $4,50 \%$ & $4,50 \%$ & $4,50 \%$ & $4,50 \%$ & $4,50 \%$ & $4,50 \%$ & $4,50 \%$ \\
\hline Nível I & $5,50 \%$ & $5,50 \%$ & $6,00 \%$ & $6,00 \%$ & $6,00 \%$ & $6,00 \%$ & $6,00 \%$ \\
\hline PR & $11 \%$ & $11 \%$ & $11 \%$ & $9,875 \%$ & $9,250 \%$ & $8,625 \%$ & $8,000 \%$ \\
\hline Capital de Conservação & & & & $0,625 \%$ & $1,250 \%$ & $1,875 \%$ & $2,500 \%$ \\
\hline $\begin{array}{c}\text { PR + Capital de } \\
\text { Conservação }\end{array}$ & $11,0 \%$ & $11,0 \%$ & $11,0 \%$ & $10,5 \%$ & $10,5 \%$ & $10,5 \%$ & $10,5 \%$ \\
\hline Capital Contra-cíclico & & $\begin{array}{c}\text { Até } \\
0,625 \%\end{array}$ & $\begin{array}{c}\text { Até } \\
1,25 \%\end{array}$ & $\begin{array}{c}\text { Até } \\
1,875 \%\end{array}$ & Até $2,5 \%$ & Até $2,5 \%$ & Até $2,5 \%$ \\
\hline
\end{tabular}

FONTE: Comunicado No. 20.615 de 7.2.2011

Tabela 7 - Basileia III proposto

\begin{tabular}{|c|c|c|c|c|c|c|c|}
\hline $\begin{array}{c}\text { Parâmetro dividido } \\
\text { pelo APR }\end{array}$ & $\begin{array}{c}\text { Em } 10 . \\
\text { De } \\
\text { Janeiro } \\
\text { de } \\
2013\end{array}$ & $\begin{array}{c}\text { Em 1o. } \\
\text { De } \\
\text { Janeiro } \\
\text { de } \\
2014\end{array}$ & $\begin{array}{c}\text { Em 1o. } \\
\text { De } \\
\text { Janeiro } \\
\text { de } \\
2015\end{array}$ & $\begin{array}{c}\text { Em 1o. } \\
\text { De } \\
\text { Janeiro } \\
\text { de } \\
2016\end{array}$ & $\begin{array}{c}\text { Em 1o. } \\
\text { De } \\
\text { Janeiro } \\
\text { de } \\
2017\end{array}$ & $\begin{array}{c}\text { Em } 10 . \\
\text { De } \\
\text { Janeiro } \\
\text { de } \\
2018\end{array}$ & $\begin{array}{c}\text { Em 1o. } \\
\text { De } \\
\text { Janeiro } \\
\text { de } \\
2019\end{array}$ \\
\hline Capital Principal & $3,50 \%$ & $4,00 \%$ & $4,50 \%$ & $4,50 \%$ & $4,50 \%$ & $4,50 \%$ & $4,50 \%$ \\
\hline Nível I & $4,50 \%$ & $5,50 \%$ & $6,00 \%$ & $6,00 \%$ & $6,00 \%$ & $6,00 \%$ & $6,00 \%$ \\
\hline PR & $8,00 \%$ & $8,00 \%$ & $8,00 \%$ & $8,00 \%$ & $8,00 \%$ & $8,00 \%$ & $8,00 \%$ \\
\hline Capital de Conservação & & & & $0,625 \%$ & $1,250 \%$ & $1,875 \%$ & $2,500 \%$ \\
\hline $\begin{array}{c}\text { PR + Capital de } \\
\text { Conservação }\end{array}$ & $8,0 \%$ & $8,0 \%$ & $8,0 \%$ & $8,625 \%$ & $9,250 \%$ & $9,875 \%$ & $10,5 \%$ \\
\hline Capital Contra-cíclico & & $\begin{array}{c}\text { Até } \\
0,625 \%\end{array}$ & $\begin{array}{c}\text { Até } \\
1,25 \%\end{array}$ & $\begin{array}{c}\text { Até } \\
1,875 \%\end{array}$ & Até $2,5 \%$ & Até $2,5 \%$ & Até $2,5 \%$ \\
\hline
\end{tabular}

FONTE: BCBS, 2010.

Com respeito ao risco de mercado, a chamada Basileia II.5, tratada anteriormente neste capítulo, que reforçou os requerimentos de capital para o trading book, foi introduzida no Brasil pela Circular No. 3.498, de 28 de junho de 2010.

Embora, no Brasil, o IRB ainda não exista, todos os bancos calculam suas exposições por VaR ou Maturity Ladder. A regulamentação determinou assim que o VaR passasse a ser calculado de modo mais conservador (como demandado desde dezembro de 2010 para todas as instituições que seguem o IRB), com o acréscimo de um multiplicador que cresce 
progressivamente até março de 2012 ou é divulgado diariamente pelo BCB (PJUR 1), somado a um fator de stress adicional (SVaR) que é introduzido progressivamente até junho de 2012. A volatilidade padrão para essa última componente é fornecida na referida circular.

\subsection{O Risco de Crédito e a Abordagem dos Ratings Internos (IRB)}

As abordagens padronizada e IRB são muito diferentes entre si tanto do ponto de vista da complexidade envolvida no cálculo do $\mathrm{CME}$, quanto do grau de liberdade que os bancos desfrutam na eleição dos modelos a serem por eles utilizados e sua calibragem tanto para risco de crédito, quanto para risco de mercado e operacional (YANAKA, 2009).

Como ilustrado na seção anterior, a SSA usa fatores de ponderação para o cálculo da parcela de risco de crédito. Para o risco de mercado, as parcelas são estimadas por VaR ou Maturity Ladder e, no Brasil, os parâmetros são dados pela Supervisão Bancária, inclusive com referências divulgadas diariamente pelo BCB. Para o risco operacional, uma abordagem simplificada está disponível e é baseada em percentagens sobre o resultado da intermediação financeira e receita de serviços.

Para Yanaka (2009), as abordagens IRB são mais flexíveis para risco de mercado e operacional do que para risco de crédito. Para o risco de mercado, por exemplo, a abordagem VaR é imperativa, mas o banco elege como estimá-lo (modelo paramétrico, histórico etc.) e também como estabelece as correlações entre os diversos fatores de risco (juros, câmbio, ações etc.). Para o risco operacional, diversas alternativas são oferecidas (e.g. CRUZ, 2004). No entanto, para o risco de crédito, uma fórmula geral é apresentada e deve ser observada por todos os bancos. A fórmula é a rigor imposta pela Supervisão e igual no mundo todo $(C f$. Basel Committee in Banking Supervision, 2006), mas existem diversas orientações sobre como estimar seus parâmetros e sua calibragem final é do banco.

Esta seção trata dos modelos de risco de crédito, em especial do que deu origem à fórmula do IRB, seu funcionamento e evidências encontradas até aqui sobre o impacto da vertente de risco de crédito sobre o CME na adoção de Basileia II no Brasil e no mundo. 


\subsubsection{Modelos de Risco de Crédito}

\subsubsection{Risco de crédito: definição}

A literatura apresenta diversas definições de risco de crédito, dependendo de sua finalidade. Para Yanaka (2009), duas delas merecem destaque, em que pese a maior adequação da primeira ao risco de crédito observado no trading book, títulos com intenção de negociação, e a segunda ao risco observado no banking book.

A primeira é que o risco de crédito é o risco de mudança do valor de uma carteira devido a mudanças inesperadas na qualidade de crédito do emissor ou parceiro comercial (McNEIL et $a l, 2005)$.

Na segunda,

[...] define-se o risco de crédito como a possibilidade de ocorrência de perdas associadas ao não cumprimento pelo tomador ou contraparte de suas respectivas obrigações financeiras nos termos pactuados, à desvalorização de contrato de crédito decorrente da deterioração na classificação de risco do tomador, à redução de ganhos ou remunerações, às vantagens concedidas na renegociação e aos custos de recuperação. (CMN, 2009b, Art. 2)

Na primeira definição, o risco de crédito está refletido na desvalorização dos ativos, muito embora ela também reflita outros riscos. Na segunda definição, o risco de crédito é medido por um modelo que, em geral, considera as perdas esperadas quando da inadimplência ou default.

Em ambos os casos, o evento de interesse é a inadimplência e o acordo de Basileia II uniformizou a definição de inadimplência (Basel Committee in Banking Supervision, 2006a, $\S 452)$ da seguinte maneira:

Considera-se que houve inadimplência quando, com relação a um tomador em particular, um (ou ambos) os eventos a seguir acontece:

- o banco considera improvável que o tomador irá honrar integralmente suas obrigações junto ao grupo bancário, sem que o banco tenha que recorrer a renegociações ou as garantias;

- o tomador está em atraso há mais de 90 dias em qualquer obrigação material de crédito junto ao grupo bancário. (grifo meu) 
Obviamente, os modelos tratam da inadimplência probabilística (PD) e baseada em dados históricos. A inadimplência ou o atraso são backward-looking, pois só são conhecidos ex-post e são influenciados por variáveis não controladas pelos bancos, mas a variável risco de crédito desejada é forward-looking assim como todas as demais componentes que compõem a taxa de juros de uma operação de crédito (COSTA; BLUM, 2008). Como acredita-se que as variáveis explicativas (cadastrais e macroeconômicas) usualmente usadas pelos bancos em seus modelos internos para estimar o risco de crédito e classificá-los em categorias de risco sejam consistentes ao longo do tempo, as estimativas feitas por estes modelos com dados atuais de seus clientes são supostas estimativas não viesadas da PD forward-looking por faixa de risco.

A PD pode ser estimada de três maneiras:

1- como uma média de longo prazo das Frequências de Default (e.g. YANAKA, 2009);

2- econometricamente, em geral por probit ou logit contendo variáveis explicativas cadastrais e macroeconômicas (e.g. SILVA et al, 2010);

3- com dados de mercado, ou seja, por meio dos spreads observados em um título com risco de crédito.

Uma alternativa quando esses dados não estão disponíveis é assumir como PD a inadimplência observada ou a carteira em atraso a 60 ou 90 dias (e.g. ANTÃO; LACERDA, 2011; VASQUEZ et al, 2011). Costa e Blum (2008) demonstram que uma variável contendo a carteira classificada de $\mathrm{E}$ a $\mathrm{H}$ sobre a carteira ativa para uma certa modalidade é um estimador forward-looking mais eficiente do que a inadimplência passada. Nesse caso, as categorias de $\mathrm{E}$ a $\mathrm{H}$ representam que o banco considera improvável o recebimento, de acordo com a primeira definição de BCBS (2006a, §452) da definição de Basileia II apresentado acima.

Yanaka (2009) discorda que esse critério seja efetivamente forward-looking com dados brasileiros, já que, para diversos bancos, os critérios usados para classificar uma exposição nas faixas de risco da Resolução CMN n. 2.682/99 (CMN, 1999) restringem-se apenas à exigência mínima de atraso. Além disso, o chamado elemento forward-looking dessa medida reflete também as discrepâncias entre os modelos internos dos bancos e, em diversos casos, seu próprio interesse em usar a provisão sobre devedores duvidosos (PDD) para direcionar o lucro contábil. 
Outro problema presente tanto na medida típica de inadimplência, quanto na proposta de Costa e Blum (2008) é o efeito denominador. A carteira ativa do banco é dinâmica, mas o usuário externo da informação contábil não é capaz de acompanhar o mesmo grupo de devedores e apurar seu desempenho. Assim, sempre que a carteira do banco está em expansão, subestima-se a inadimplência. Por outro lado, se ocorrer, por exemplo, uma cessão de créditos em curso normal, superestima-se esse valor. Qualquer medida de inadimplência que se adote deve considerar esse fato. $\mathrm{O}$ controle desse efeito precisa ser feito por matrizes de migração (YANAKA; HOLLAND, 2010), especialmente quando envolve um período de expansão da carteira de crédito como o brasileiro entre 2005 e 2008 (SILVA et al, 2010).

A severidade da perda ou perda dado o default (LGD) também é atribuída no início da operação. Ela é estimada considerando todos os esforços de recuperação em operações similares da mesma faixa de risco e que possuem garantias similares ${ }^{14}$. $\mathrm{O}$ risco de crédito de cada exposição no modelo do IRB é calculado considerando que esta exposição ou família de exposições é parte de um portfólio.

\subsubsection{Modelos de Risco de Crédito para Portfólios}

\section{Value at Risk (VaR)}

Para Allen et al (2004), o VaR é a perda potencial (ou máxima) para um determinado horizonte de tempo e um nível de confiança unicaudal, usualmente os quantis de $95 \%$ ou 99\%. O modelo originalmente criado para mensurar o risco de mercado foi rapidamente disseminado para o cálculo de risco de crédito e operacional.

Para o cálculo do risco de mercado, o VaR é apurado histórica e parametricamente para a variação de preço de um ativo específico ou de uma família agrupada pelos vencimentos. No entanto, para o risco de crédito, o estimador sempre representa a probabilidade de inadimplência de uma carteira.

\footnotetext{
${ }^{14}$ A estimação da LGD é, na verdade, bastante sofisticada, já que ela deve ser calculada livre de todos os custos de recuperação diretos e indiretos e trazendo todos os recebimentos (oriundos do esforço de recuperação) ao valor da data de default com uma taxa de desconto apropriada. Além disso, a LGD devida é a de downturn, estimada em condições de stress. (BCBS, 2005).
} 
Outra diferença marcante entre $\mathrm{VaR}$ de crédito $(\mathrm{CVaR})$ e o de mercado é que o horizonte de curto prazo (1 dia) é incoerente e possivelmente impossível de ser calculado, dando lugar ao horizonte de 1 ano. O nível de confiança também é mais conservador, usualmente 99,9\%, já que uma perda expressiva no portfólio de crédito pode levar à insolvência com maior facilidade. Análoga e intuitivamente, essa perda é usualmente interpretada como a pior perda esperada por inadimplência do portfólio em 1.000 anos (YANAKA, 2009).

Dada a dificuldade de encontrar dados para essa estimação histórica, a abordagem usual é a estimação paramétrica com forte peso para o tratamento da correlação entre os eventos de inadimplência ou aos fatores de risco sistêmico subjacentes.

A fórmula do IRB advém de um desses modelos paramétricos em que a perda potencial ou total vem de uma solução analítica para o cálculo do VaR.

\section{Creditmetrics}

Existem basicamente dois tipos de modelos de risco de crédito na literatura: os modelos estruturais e os reduzidos (ELIZALDE, 2005, p. 4). Os modelos estruturais utilizam a evolução de variáveis representativas da firma como seus ativos e passivos para determinar endogeneamente o momento do default. O modelo de Merton (1974) é o precursor dessa família de modelos. Mas os da forma reduzida ou de intensidade não consideram a relação entre default e a situação financeira da firma de maneira explícita. Nesta família de modelos, a inadimplência é o primeiro salto de um conjunto de variáveis exógenas inferidas do mercado ou estimadas com dados históricos.

Merton (1974) usa o modelo de precificação de opções de Black e Scholes (1973) para estimar a probabilidade de default de uma empresa. A inadimplência acontece quando o valor da dívida excede o valor dos ativos no momento de honrá-las.

Suponha-se que os $n$ ativos de uma firma no momento $t, \mathrm{~A}_{\mathrm{n}, \mathrm{t}}$, sigam um processo de difusão browniano do tipo (ELIZALDE, 2005):

(1) $\frac{d A_{n, t}}{A_{n, t}}=\mu_{n} d t+\sigma_{n} d W_{n, t}$ 
em que:

$\mu_{\mathrm{n}}=$ retorno total esperado em cada um dos $\mathrm{n}$ ativos

$\sigma_{\mathrm{n}}=$ volatilidade instantânea dos ativos

$\mathrm{W}_{\mathrm{n}, \mathrm{t}}=$ processo de Wiener

A estrutura de capital dessa firma é composta por ações e uma dívida do tipo zero-coupon bond com maturidade $T$ e valor de face $D_{n}$ em que $A_{n, t}$ é simplesmente a soma de $D_{n}$ e seu capital a valores de mercado. Sob essas condições, o capital representa uma opção de compra sobre os ativos da empresa com data de exercício $\mathrm{T}$ e valor de exercício $\mathrm{D}_{\mathrm{n}}$. A probabilidade de default em um momento $\mathrm{t}<\mathrm{T}$ da firma não honrar suas dívidas em $\mathrm{T}$ é dada por:

(2) $\quad p_{n, t, T}=P\left[A_{n, t, T}<D_{n} \mid A_{n, t}\right]$

Merton (1974) demonstra, a partir do Lema de Ito, que o processo de difusão (1) no momento $\mathrm{T}$, sob a condição de neutralidade ao risco, pode ser escrito como:

$$
A_{n, T}=A_{n, t} e^{\left\{\left(\mu_{n}-\frac{\sigma_{n}^{2}}{2}\right)(T-t)+\sigma_{n} \sqrt{T-t} X_{n, t, T}\right\}}
$$

$$
\ln \left(A_{n, T}\right)=\ln \left(A_{n, t}\right)+\left(\mu_{n}-\frac{\sigma_{n}^{2}}{2}\right)(T-t)+\sigma_{n} \sqrt{T-t} X_{n, t, T}
$$

onde $\mathrm{X}_{\mathrm{n}, \mathrm{t}, \mathrm{T}}$ tem (por definição do processo browniano) distribuição normal padrão $\Phi($.$) .$

(4) $\quad X_{n, t, T}=\Phi\left(\frac{W_{n, T}-W_{n, t}}{\sqrt{T-t}}\right)$

A restrição de Merton (1974) pode ser então escrita como:

$$
A_{n, t}<D_{n} \Leftrightarrow X_{n, t, T}<K_{n, t, T}
$$

em que $\mathrm{K}_{\mathrm{n}, \mathrm{t}, \mathrm{T}}$ é o valor de exercício de uma opção de compra (ELIZALDE, 2005): 
(6)

$$
K_{n, t, T}=\frac{\ln D_{n}-\ln A_{n, t}-\left(\mu_{n}-\frac{\sigma_{n}^{2}}{2}\right)}{\sigma_{n} \sqrt{T-t}}
$$

Consequentemente, a probabilidade de default (PD) de um firma condicionada ao valor de seus ativos pode ser reescrita como:

$$
p_{n, t, T}=\Phi\left(K_{n, t, T}\right)
$$

Porém, para aferir a PD e as possíveis perdas de crédito em um portfólio, é preciso conhecer mais do que as probabilidades individuais de inadimplência de cada uma das firmas que comporão o portfólio. É fundamental conhecer também a correlação entre essas probabilidades de default ou entre as variáveis aleatórias $X_{n, t}$ (ELIZALDE, 2005):

$$
\operatorname{corr}\left(X_{n, t}, X_{m, t}\right)=\rho_{n, m, t} \text { para } n \neq m
$$

Como, na prática, é muito difícil observar essas correlações ${ }^{15}$, modelos de risco de crédito estruturais como CreditMetrics adotam fatores de risco (em geral variáveis macroeconômicas e setoriais) que consideram um vetor de variáveis sistemáticas $\mathrm{Y}$ comuns a todas as firmas. Trata-se de reconhecer que $\mathrm{X}$ contém tanto elementos sistemáticos quanto idiossincráticos. CreditMetrics, por exemplo, define (GORDY, 2000):

$$
X_{i}=w_{i} Y+\eta_{i} Z_{i}
$$

em que:

$\mathrm{X}_{i}=$ variável aleatória que representa o risco do tomador i (isto é do conjunto de seus $n$ ativos) $\mathrm{Y}=$ matriz de variáveis que representam o risco sistemático

\footnotetext{
${ }^{15}$ Note-se que, decorrente do Modelo de Merton (1974), a correlação entre os defaults não precisa ser calculada diretamente, pois ela é perfeitamente expressa na correlação do valor dos ativos das firmas. Essa é uma propriedade muito utilizada na calibração das correlações, embora largamente questionada e limitada ao atacado (CSFB, 1997).
} 
$\mathrm{w}_{i}=$ matriz que contém os fatores de ponderação que refletem a sensibilidade do tomador $\mathrm{i}$ aos fatores de risco Y.

$\mathrm{Z}_{i}=$ variável aleatória que representa o risco idiossincrático do tomador i. Esta variável é i.i.d $\operatorname{com} \mathrm{N}(0,1)$.

$\eta_{i}=$ fator de ponderação que representa a sensibilidade do tomador i à $Z_{i}$

Quando $\mathrm{X}_{i}$ cai abaixo de um nível de corte preestabelecido $\mathrm{C}_{\zeta i}$ em que $\zeta$ é um rating que representa uma família de devedores a que i pertence, o default acontece. Saliente-se que $\mathrm{X}_{\mathrm{i}}$ incondicional não é i.i.d, mas $\mathrm{X}_{i} \mid \mathrm{Y}$ sim. A condição de inadimplência pode ser escrita a partir de $\mathrm{Z}_{i}$ como:

(10) $Z_{i}<\frac{C_{5(i)}-Y w_{i}}{\eta_{i}}$

e a probabilidade de default de $\mathrm{X}_{i} \mid \mathrm{Y}$ :

$$
P_{i}(X \mid Y)=\Phi\left(\frac{C_{\zeta(i)}-Y w_{i}}{\eta_{i}}\right)
$$

Os principais modelos estruturais disponíveis no mercado e usualmente usados para estimação de VaR de Crédito ou CVaR são KMV e CreditMetrics. O primeiro, que leva o nome da consultoria que lhe deu origem, parte de uma aplicação mais explícita do modelo de precificação de opções. O segundo, sintetizado anteriormente, foi desenvolvido por J.P. Morgan. Para o ECB (2007), este último é o predileto entre os reguladores da Zona do Euro.

Dentre os modelos da forma reduzida, merece destaque Creditrisk+, que é usado nesse trabalho na forma simplificada $(C f$. CSFB, 1997) como referencial para o capital econômico, apresentado no item 3.3.4.

\subsubsection{Distribuição de Vasicek e a abordagem IRB}

Vasicek (2002) demonstra que os modelos baseados em fatores de risco sistemático, sob certas condições, podem ser generalizados para um modelo de carteira denominado 
Asymptotic Single Risk Factor (ASRF). Se a inadimplência ou os eventos de crédito fossem independentes, seria possível demonstrar que a distribuição de perdas da carteira convergiria para normal à medida que o número de exposições aumenta.

Mas, os defaults são correlacionados por fatores de risco subjacentes. O autor encontra, entretanto, uma solução analítica para as perdas observadas em um portfólio quando existe um único fator de risco sistemático. A distribuição de perdas para esse caso específico tem uma cauda pesada a direita, mas forma definida e que é derivada em Vasicek (1987) e apresentada abaixo. Essa distribuição é mais conhecida como distribuição de Vasicek e tem a seguinte função densidade de probabilidade, f.d.p. (12):

$$
f(x ; p, \rho)=\sqrt{\frac{1-p}{p}} \exp \left(\frac{-1}{2 \rho}\left(\sqrt{1-\rho} N^{-1}(x)-N^{-1}(p)\right)^{2}+\frac{1}{2}\left(N^{-1}(x)\right)^{2}\right)
$$

e a função de massa (13)

$$
F(x, p, \rho)=\Phi\left(\sqrt{\frac{1-\rho}{\rho}} N^{-1}(x)-\sqrt{\frac{1}{\rho}} N^{-1}(p)\right)
$$

Em que p é a probabilidade média de default (PD) da categoria a que o devedor X pertence, $\rho$ a correlação entre os ativos da economia e x a PD incondicional do devedor X.

A condição, no entanto, é que exista um fator de risco sistemático Y escalar e que o risco do tomador $\mathrm{X}_{\mathrm{i}}$ no portfólio possa ser representado por uma função linear do fator de risco sistemático Y ("estado da economia") e de um fator idiossincrático $\mathrm{Z}_{\mathrm{i}}$ (risco idiossincrático de "i”) conforme a equação abaixo:

$$
X_{i}=\sqrt{\rho} Y+\sqrt{1-\rho} Z_{i}
$$

onde $\mathrm{Y}$ escalar e $\mathrm{Z}_{i}$ são variáveis mutuamente independentes com distribuição normal padrão. $Y \sqrt{ } \rho$ representa a exposição da firma ao fator de risco sistemático e $Z_{i} \sqrt{ }(1-\rho)$ ao risco 
idiossincrático. Como os trabalhos de Vasicek (1987;2002) partem de Merton (1974), $\rho$ representa a correlação entre os "n" ativos das firmas.

Note-se que (14) é um caso particular de (9) em que w e Y são escalares.

Quando o fator único (ASRF) é conhecido, a probabilidade condicional de default pode então ser deduzida da seguinte forma (VASICEK, 2002):

$$
\begin{aligned}
& P\left(X_{i}<\gamma\right)=P\left(\sqrt{\rho} Y+\sqrt{1-\rho} Z_{i}\right) \\
= & P\left(Z_{i}<\frac{\gamma-\sqrt{\rho} Y}{\sqrt{1-\rho}}\right) \\
= & P\left(Z_{i}<\frac{N^{-1}(P D)-\sqrt{\rho} Y}{\sqrt{1-\rho}}\right) \\
= & N\left(\frac{N^{-1}(P D)-\sqrt{\rho} Y}{\sqrt{1-\rho}}\right)
\end{aligned}
$$

em que $\gamma=C_{\zeta \mathrm{i}}$ representa um ponto de corte para o risco do tomador $i$ por exemplo, a PD média da categoria de risco. $\log o, \gamma=\mathrm{N}^{-1}(\mathrm{PD})$ e $\mathrm{Y} \sim \mathrm{N}(0,1)$ assumirão um $p$-value que representa um estado da economia para $i$.

Escrevendo em função das perdas,

(16) $P(\mid Y)=P\left[L_{i}=1 \mid Y\right]=P[\leq X=\gamma]=N\left(\frac{N^{-1}(P D)-Y \sqrt{\rho}}{\sqrt{1-\rho}}\right)$

e para o portfólio (17):

(17) $L=\frac{1}{n} \sum_{i=1}^{n} L_{i}$

em que: 
$\mathrm{L}=$ perda probabilística do portfólio a que $i$ pertence

$\mathrm{L}_{\mathrm{i}}=$ variável binária que assume o valor de zero quando não há inadimplência e um quando há

Contudo, Vasicek (2002) teve que impor pressupostos adicionais para encontrar a solução analítica acima:

1- A correlação entre defaults é a mesma para quaisquer duas firmas ou devedores

$$
\operatorname{corr}\left(X_{n, t}, X_{m, t}\right)=\rho_{n, m, t}=\rho_{t}
$$

2- A PD para cada firma é previamente conhecida

3- O numero de empréstimo de um portfólio qualquer tende ao infinito.

A Fórmula para a perda total de crédito do IRB parte deste modelo em que a probabilidade de perdas associada a Y é 99,9\% (Fórmula 19). Intuitivamente, $\mathrm{Y}$ equivale a um cenário específico em que a inadimplência pode ser cerca de 3,29 vezes maior que a esperada. Quer dizer, CVaR na condição Y, de todos os possíveis "estados da economia", representa a perda máxima associada ao improvável e extremo quantil de 99,9\% da distribuição de Vasicek.

$$
P L \leq X=\gamma]=L G D \cdot N\left(\frac{N^{-1}(P D)-\sqrt{R} N^{-1}(0,999)}{\sqrt{1-R}}\right)
$$

Como a equação foi escrita em função das perdas $L$, a severidade de perda, $L G D=(1-R R)$, é incluída para reconhecer a taxa de recuperação (RR) do crédito após o default.

Gordy (2003) demonstra que um modelo ASRF, como o de Vasicek (2002) só é portfólio independente (LIY i.i.d) quando a dependência entre as exposições é determinada por um único fator de risco sistemático escalar e a carteira é composta por um grande número de exposições. Somente quando as duas condições são satisfeitas, o pressuposto de portfólio independência existente na fórmula IRB é válido. Violações do segundo pressuposto, ou seja, a granularidade infinita do portfólio, podem ser admitidas. Na verdade, para portfólios com mais de 5.000 exposições, o impacto no VaR é desprezível e Vasicek (2002) chega a propor um ajuste na sua fórmula para a granularidade finita. 
Por outro lado, se o pressuposto de que existe um único risco sistemático $\mathrm{Y}$ escalar for violado, a solução analítica de Vasicek (2002) será viesada, já que todo o risco remanescente é suposto idiossincrático e diversificável. Observe-se que esse pressuposto é conceitualmente muito forte na medida em que impõe a todos os devedores um único ciclo de negócios (GORDY, 2003).

Esse tipo de modelo não captura fenômenos setoriais ou regionais que podem ser bastante significativos. "[Para um banco com operações internacionais], por exemplo, eventos na França não contribuem nada para a inadimplência de tomadores franceses." (GORDY, 2003, p. 222). Assim, se houver bolsões de risco significativos [no portfólio], calibrar um modelo desse tipo para um fator internacional único pode na verdade subestimar a exigência de capital (Ibidem).

Finalmente, a fórmula geral (19) trata da perda total (CVaR) representada na Figura 2 e subdividida conceitualmente como perda esperada - EL e inesperada - UL (Figura 2).

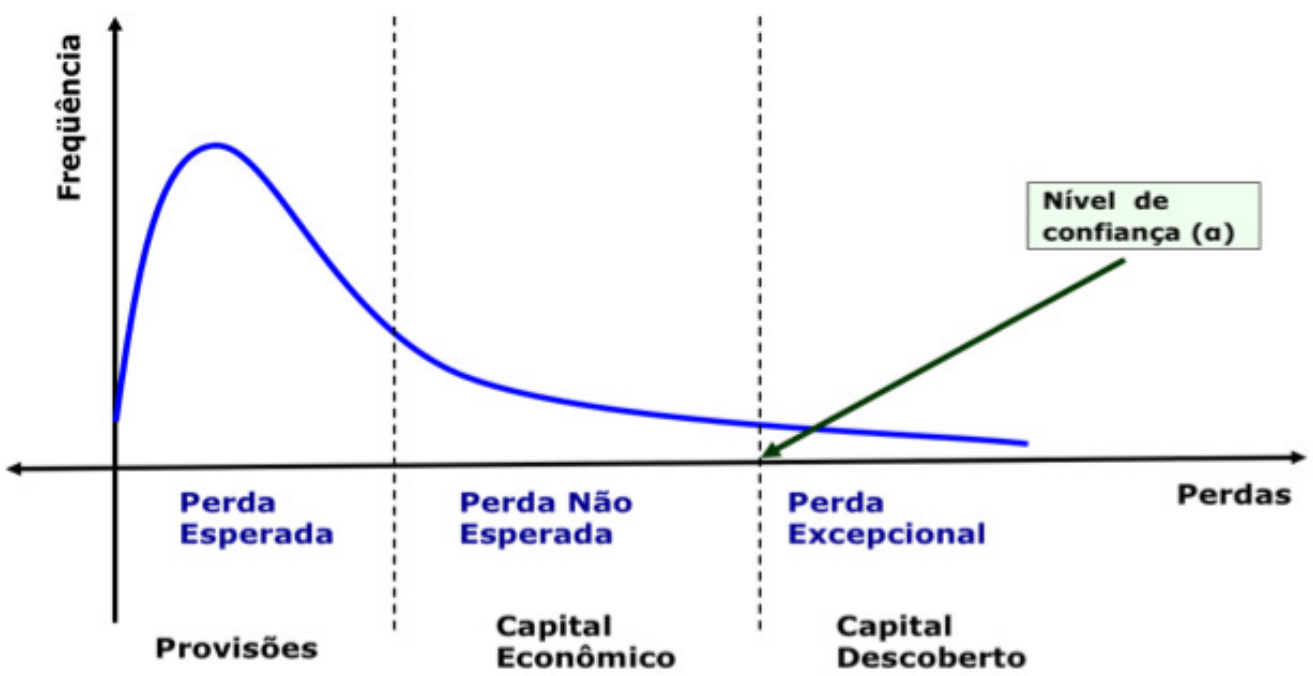

Figura 2 - Provisão e Capital econômico

EL é a esperança matemática da Perda Total, associada a Provisão (Fórmula 20), e o CME assume o valor de UL que é a diferença entre a perda total (TL) e EL (Fórmula 21). 


$$
E L(\%)=P D . L G D
$$

$$
E L(\$)=P D . L G D . E A D
$$

$$
\begin{gathered}
K(\%)=C \operatorname{VaR}(\%)-E L(\%) \\
K(\%)=L G D \cdot N\left(\frac{N^{-1}(P D)-\sqrt{R} N^{-1}(0,999)}{\sqrt{1-R}}\right)-E L(\%) \\
K(\%)=L G D \cdot N\left(\frac{N^{-1}(P D)-\sqrt{R} N^{-1}(0,999)}{\sqrt{1-R}}\right)-P D . L G D \\
K(\%)=L G D \cdot\left[N\left(\frac{N^{-1}(P D)-\sqrt{R} N^{-1}(0,999)}{\sqrt{1-R}}\right)-P D\right]
\end{gathered}
$$

Com $\mathrm{R}=\rho=$ correlação da Basileia, isto é, a correlação entre os “[...] ativos da economia [...]" (Cf. MERTON, 1974), definida pelo Comitê ou pelos reguladores.

O CME (21) ainda é ajustado por um multiplicador de 1,06.

Neste texto, sempre adota-se a expressão VaR ou CVaR como representativa da perda total (TL) e CME ou K(\%) de UL, isto é CVaR (-) EL.

De modo geral, pode-se dividir o modelo do IRB em duas grandes famílias: o sistema IRB e a fórmula (21). O sistema IRB, remarque-se, diz respeito à classificação das exposições consistentemente em faixas de risco (ao menos 11) e à atribuição de PDs e LGDs a essa exposição. A validação desses modelos pela Supervisão é feita no contexto do Pilar 2 (YANAKA, 2009). Portanto, o sistema IRB é sancionado nacionalmente pelo regulador e apenas a fórmula IRB demonstrada acima é igual no mundo todo.

Segundo o BCBS (2006 a), o IRB pressupõe que as exposições a risco de crédito no banking book sejam classificadas em cinco diferentes categorias: atacado (corporate), soberano, bancos (interbancário), varejo e participações acionárias (equity) com fórmulas ligeiramente diferentes. 
O atacado ainda é subdividido em duas categorias: empréstimos especializados (SL) e pequenas e médias empresas (SME) com faturamento anual inferior a cinquenta milhões de Euros. O varejo também é dividido em empréstimos qualificados (QRRE) e habitacionais.

A correlação $\mathrm{R}$ é chave para o modelo e aumenta significativamente o K. O valor de $\mathrm{R}$ é diferente nas classes de ativo do IRB conforme BCBS (2006a) - Fórmula (22).

$$
\begin{aligned}
& \left.R_{\text {Atacaddcorporate }}=0,12 . \mid \frac{1-e^{-50 P D}}{1-e^{-50}}\right\rfloor+0,24 .\left\lfloor 1-\frac{1-e^{-50 P D}}{1-e^{-50}}\right\rfloor \\
& R_{S M E}=0,12 \cdot\left[\frac{1-e^{-50 P D}}{1-e^{-50}}\right]+0,24 .\left[1-\frac{1-e^{-50 P D}}{1-e^{-50}}\right]-0,04 .\left\lfloor\frac{S-5}{45}\right] \\
& R_{\text {varejo }}=0,03 .\left[\frac{1-e^{-35 P D}}{1-e^{-35}}\right]+0,16 .\left[1-\frac{1-e^{-35 P D}}{1-e^{-35}}\right]
\end{aligned}
$$

Verifique-se que, nas três classes, R é decrescente em relação à PD. No varejo, a correlação é menor, já que a inadimplência depende mais do risco idiossincrático do que do risco sistemático. As exposições a pequenas e médias empresas apresentam um valor intermediário. O S representa o faturamento medido em milhões de euros e deve ser maior do que 5 e menor do que 50. Exposições a pessoas jurídicas superiores a 50 milhões são consideradas de atacado e abaixo de 5 milhões de varejo (BCBS, 2006a)

O R de soberano e de bancos é igual ao corporate e o $\mathrm{R}$ do varejo (crédito imobiliário) é fixo, independente da PD, e igual a 0,15. Para o varejo (qualificado rotativo), o número é 0,04.

Para o cálculo do $\mathrm{K}$ das exposições corporate superiores a um ano, existe ainda um fator de ajuste de maturidade que é multiplicado a K conforme a equação 23.

$$
F_{\text {Maturidade }}=\frac{1+(M-2,5) \cdot b}{1-1,5 \cdot b}, \text { com } b=[0,11852-0,05478 \cdot \ln (P D)]^{2}
$$

em que $\mathrm{M}$ é a maturidade efetiva em anos da operação de crédito, com $1<\mathrm{M}<5$.

A Tabela 8 apresenta alguns valores extraídos da fórmula de varejo a título de exemplo. Para uma PD de $2 \%$ e LGD de $75 \%$, a EL é $1,50 \%$ e o CME de $7,73 \%$. O fator de $11 \%$ usado no 
Brasil para o atacado equivale a um portfólio com PD média de 12\%, comprável à categoria D da Resolução CMN n. 2.682/99 (YANAKA, 2009).

Tabela 8 - Perda Total (VAR), EL e UL ou K(\%) para varejo (LGD=75\%)

\begin{tabular}{|c|c|c|c|}
\hline & & $\mathrm{K}(\%)=\mathrm{VAR}-$ & \\
$\mathrm{PD}$ & $\mathrm{EL}$ & $\mathrm{EL}$ & VAR \\
$0,03 \%$ & $0,02 \%$ & $0,59 \%$ & $0,62 \%$ \\
$0,05 \%$ & $0,04 \%$ & $0,88 \%$ & $0,92 \%$ \\
$0,10 \%$ & $0,08 \%$ & $1,49 \%$ & $1,56 \%$ \\
$0,20 \%$ & $0,15 \%$ & $2,43 \%$ & $2,58 \%$ \\
$0,30 \%$ & $0,23 \%$ & $3,17 \%$ & $3,40 \%$ \\
$0,50 \%$ & $0,38 \%$ & $4,31 \%$ & $4,69 \%$ \\
$0,70 \%$ & $0,53 \%$ & $5,17 \%$ & $5,69 \%$ \\
$1,00 \%$ & $0,75 \%$ & $6,10 \%$ & $6,85 \%$ \\
$2,00 \%$ & $1,50 \%$ & $7,73 \%$ & $9,23 \%$ \\
$3,00 \%$ & $2,25 \%$ & $8,37 \%$ & $10,62 \%$ \\
$4,00 \%$ & $3,00 \%$ & $8,67 \%$ & $11,67 \%$ \\
$5,00 \%$ & $3,75 \%$ & $8,86 \%$ & $12,61 \%$ \\
$7,00 \%$ & $5,25 \%$ & $9,23 \%$ & $14,48 \%$ \\
$10,00 \%$ & $7,50 \%$ & $10,07 \%$ & $17,57 \%$ \\
$15,00 \%$ & $11,25 \%$ & $11,81 \%$ & $23,06 \%$ \\
\hline
\end{tabular}

FONTE: Elaborado pelo Autor com base na Fórmula IRB de Varejo

Finalmente, para saber o CME do risco de crédito é imperativo saber a PD por faixa de risco e a sua capacidade de recuperação, expresso em LGDs menores ou maiores. O Gráfico 2 ilustra o enorme impacto de LGD sobre o CME.

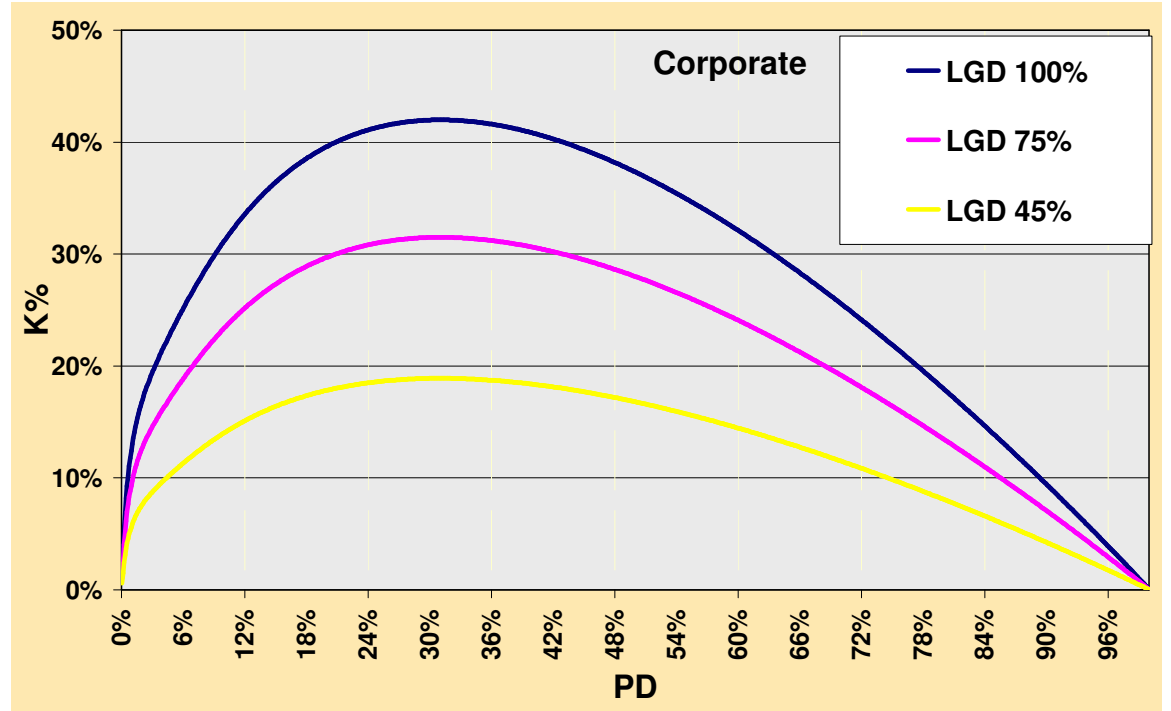

Gráfico 2 - Impacto da LGD sobre o K(\%)

FONTE: YANAKA, 2009. 
A distribuição de Vasicek tem apenas dois parâmetros $\rho=\mathrm{R}$ e $p=\mathrm{PD}$. No Gráficos 3, sensibiliza-se PD e R a partir da função densidade de probabilidade de Vasicek.

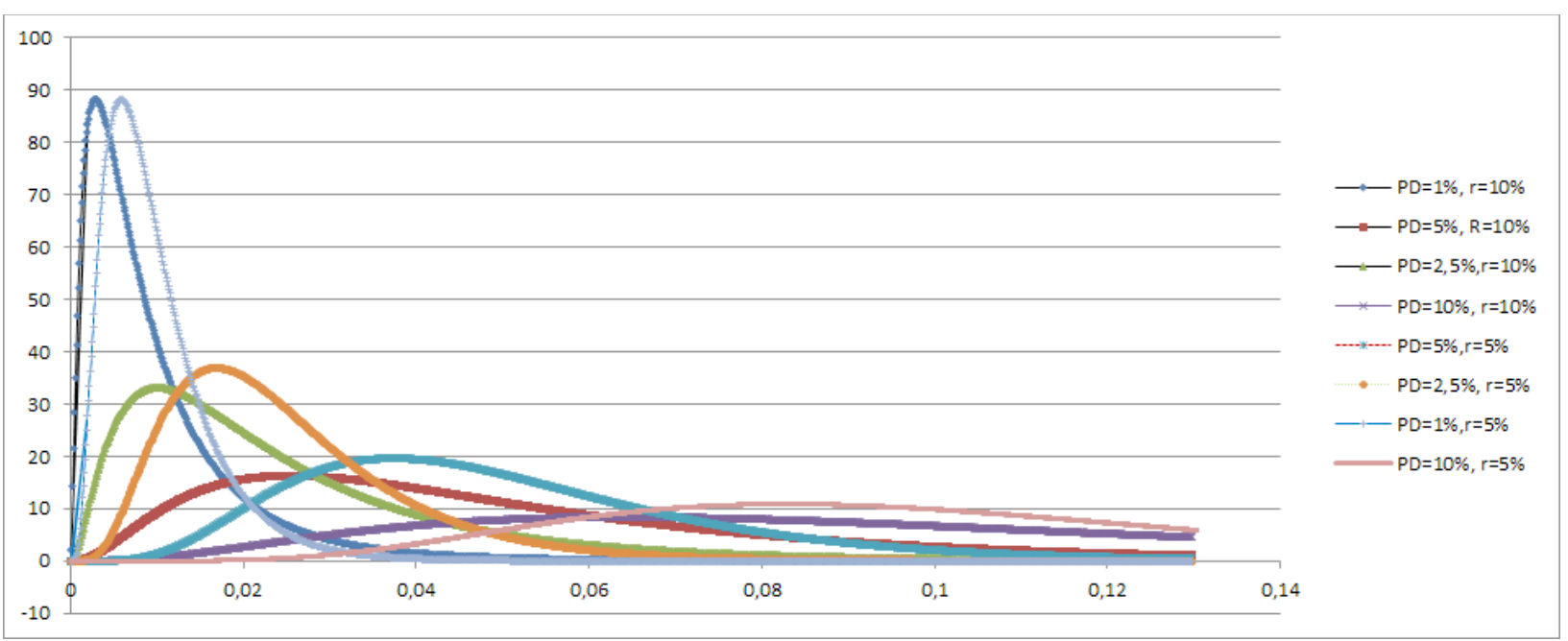

Gráfico 3 - Sensibilidade da Fórmula do IRB a PD e R

Quer-se aqui observar (Gráfico 3) como o incremento das PDs aumenta a assimetria e reduz a curtose da curva. Em outras palavras, um incremento de PD provoca um deslocamento para a direita na curva e um deslocamento menos que proporcional na cauda. Já o incremento de $\mathrm{R}$ gera uma redução da assimetria (um deslocamento para a esquerda), mas cria caudas bem mais pesadas (Tabela 9).

Tabela 9 - Sensibilidade de VaR a PD e r na Fórmula do IRB

\begin{tabular}{|c|c|c|}
\hline PD & $\mathbf{R}$ & $\mathbf{V a R}$ \\
\hline $1,0 \%$ & $5,0 \%$ & $4,7 \%$ \\
$1,0 \%$ & $10,0 \%$ & $7,7 \%$ \\
$2,5 \%$ & $5,0 \%$ & $9,6 \%$ \\
$1,0 \%$ & $15,0 \%$ & $11,0 \%$ \\
$1,0 \%$ & $20,0 \%$ & $14,6 \%$ \\
$2,5 \%$ & $10,0 \%$ & $15,0 \%$ \\
$5,0 \%$ & $5,0 \%$ & $16,4 \%$ \\
$1,0 \%$ & $25,0 \%$ & $18,4 \%$ \\
$2,5 \%$ & $15,0 \%$ & $20,4 \%$ \\
$1,0 \%$ & $30,0 \%$ & $22,4 \%$ \\
$5,0 \%$ & $10,0 \%$ & $24,1 \%$ \\
$2,5 \%$ & $20,0 \%$ & $25,9 \%$ \\
$5,0 \%$ & $25,0 \%$ & $45,4 \%$ \\
$10,0 \%$ & $15,0 \%$ & $46,3 \%$ \\
$5,0 \%$ & $30,0 \%$ & $52,3 \%$ \\
$10,0 \%$ & $20,0 \%$ & $54,5 \%$ \\
$10,0 \%$ & $25,0 \%$ & $62,0 \%$ \\
$10,0 \%$ & $30,0 \%$ & $68,8 \%$ \\
\hline
\end{tabular}




\subsubsection{Impactos de Basileia II}

\subsubsection{Impactos da Abordagem Padronizada (SA) sobre CME}

Roy (2005) conduz um estudo para o BCE para avaliar os impactos da adoção da SA na Zona do Euro. O autor optou por simular o portfólio de um banco médio hipotético para cada país da Zona do Euro. O portfólio desses bancos é gerado com exposições de tamanhos aleatórios para emissores (países, bancos e empresas) com ratings sorteados de uma base externa contendo apenas empresas com ratings. $\mathrm{O}$ autor busca testar se o capital regulatório gerado por esse portfólio é significativamente diferente do que seria observado em Basileia I e se é sensível à escolha da ECAI que representará o banco.

O autor conclui que, no cenário de 2004, com $70 \%$ das exposições corporate sem ratings, na média e apenas para vertente de risco de crédito, um banco europeu economizaria entre $6 \mathrm{e}$ $15 \%$ em capital regulatório em relação a Basileia I. Entre eleger apenas Moody’s como sua ECAI e contratar todas as demais haveria, este segundo caso traria uma economia adicional de no mínimo $6 \%$ em capital regulatório.

Se todas as exposições desse banco fossem efetivamente cobertas pela ECAI escolhida ou uma combinação delas, a economia em 2004 seria de 9\% em capital regulatório (um cenário cada vez mais provável dada a expansão das ACRs e o incentivo dado por esses bancos de oferecer melhores taxas de juros para empresas com rating da agência por eles escolhida).

Observe-se que, na época em que o autor realizou o estudo, o capital regulatório no contexto da abordagem padronizada não era sensibilizado pela opinião das ACRs para os produtos de securitização. Reiterando: o impacto seria potencialmente muito superior, já que a revisão do acordo de 2006, tornou-se o padrão internacional, tanto para bancos que seguem a abordagem padronizada, quanto para bancos que seguem o IRB (usando a RBA para a securitização).

\subsubsection{Impactos do IRB sobre o CME}

Os possíveis impactos da adoção de uma abordagem IRB começaram a ser estimados pelo Comitê da Basileia por meio do Quantitative Impact Study 3 (QIS 3) e, em 2006, pelo QIS 5 
(Basel Committee in Banking Supervision, 2006b). O QIS 3 revelou que a adoção do modelo traria uma queda média nos requerimentos de capital de 6\% (YANAKA, 2009). Em consequência, um fator de ajuste de 1,06 foi incorporado e os resultados apresentados no QIS 5 já contavam com ele.

Para o QIS 5, uma amostra de 356 bancos de 32 países foi utilizada. Os órgãos supervisores encaminharam um modelo de estudo de impacto para esses bancos e solicitaram o preenchimento do mesmo, remetendo a informação ao BIS. O resultado desse exercício é apresentado na Tabela 10 para os países membros do G-10 em duas categorias: Grupo 1 para bancos internacionalmente ativos com PR Nível I superior a 3 bilhões de euros e Grupo 2 para os demais. Da mesma forma, para os 18 países membros do Committee of European Banking Supervisors (na verdade, 11, já que 8 países também pertenciam ao G-10) e para os demais. Os grandes bancos brasileiros que participaram do estudo faziam parte da categoria "Outros Não G10 Grupo 2", já que os bancos internacionais com atuação no Brasil à época consolidaram dados com suas matrizes (YANAKA, 2009, p. 37).

Tabela 10 - Impacto percentual no $\mathrm{CME}^{16}$ da Adoção das abordagens IRB em relação a Basileia I

\begin{tabular}{|l|c|c|}
\hline Grupo & $\begin{array}{l}\text { IRB } \\
\text { Fundamental }\end{array}$ & $\begin{array}{l}\text { IRB } \\
\text { Avançada }\end{array}$ \\
\hline G10 - Grupo 1 & $-1,3$ & $-7,1$ \\
\hline G10 - Grupo 2 & $-12,3$ & $-26,7$ \\
\hline CEBS - Grupo 1 & $-3,2$ & $-8,3$ \\
\hline CEBS - Grupo 2 & $-16,6$ & $-26,6$ \\
\hline Outros - não G-10 Grupo 1 & $-16,2$ & $-29,0$ \\
\hline Outros - não G-10 Grupo 2 & 11,4 & $-1,0$ \\
\hline
\end{tabular}

FONTE: BCBS, 2006b, p. 9.

Nos países do G-10 e CEBS - Grupo 1 há uma ligeira redução no CME e nos demais do grupo 2 (bancos menos prováveis de aderir ao IRB), acentuada redução.

Note-se que o grupo a que pertence o Brasil foi o único que apresentou aumento no CME e a razão encontra-se ao comparar as PDs deste grupo com a dos demais países na Tabela 11.

\footnotetext{
${ }^{16}$ CME para Risco de Crédito, Mercado e Operacional.
} 
Tabela 11 - PD média para diversas classes de ativo (\%)

\begin{tabular}{|l|c|c|c|}
\hline Grupo & Corporate & SME & Varejo \\
\hline G10 - Grupo 1 & 0,99 & 2,10 & 3,45 \\
\hline G10 - Grupo 2 & 0,89 & 2,19 & 2,09 \\
\hline CEBS - Grupo 1 & 1,04 & 2,20 & 4,33 \\
\hline CEBS - Grupo 2 & 0,83 & 2,16 & 2,32 \\
\hline Outros - não G-10 Grupo 1 & 0,85 & 1,61 & 2,77 \\
\hline Outros - não G-10 Grupo 2 & 1,47 & 4,31 & 11,66 \\
\hline
\end{tabular}

FONTE: BCBS, 2006b, p. 9.

Carneiro et al (2005) utilizou dados da Central de Risco (CRC) do Banco Central do Brasil para estimar a adoção do modelo numa amostra de 107 bancos. Seus resultados para CME de crédito apontaram para uma redução do CME. Para Yanaka (2009), a razão disso está no fato daquele trabalho adotar uma LGD de 45\%. Esta LGD é sugerida pelo BCBS (2006a), mas não é compatível com a realidade brasileira, especialmente ao se considerar o custo elevado do registro e da recuperação das garantias no Brasil. Ao replicar o estudo para os oito maiores bancos brasileiros (excluindo BNDES e Caixa Econômica Federal) e com uma LGD de 75\%, o resultado encontrado por Yanaka e Holland (2010) foi um aumento do CME se comparado ao da abordagem atual.

\subsubsection{Creditrisk+}

Creditrisk+ foi desenvolvido por Credit Suisse Financial Services, uma subsidiária do banco suíço Credit Suisse First Boston (CSFB) em 1997 (CSFB, 1997). O modelo, que pertence à forma reduzida e que é inspirado nas abordagens atuariais, tornou-se um dos mais utilizados para a estimação de perdas de crédito pela indústria bancária e pelos reguladores dos países em desenvolvimento, porque impõe menos pressupostos e possui um solução analítica conveniente (AVESANI et al, 2006; CSFB , 1997. SCHETCHMAN et al., 2006).

Em Creditrisk+, a função geradora dos defaults segue uma distribuição Poisson e as perdas sistemáticas (Y) seguem uma distribuição Gamma (SCHECHTMAN et al, 2004). O modelo não impõe implicitamente uma correlação entre os defaults previamente conhecida. Ao invés disso, os episódios de default são supostos independentes e a correlação entre eles está implicitamente expressa em seu desvio-padrão (CSFB , 1997). 
Estimar o desvio-padrão da Frequência de Default $(\mathrm{FD})^{17}$ é mais fácil do que a correlação propriamente dita, pois não demanda séries temporais muito longas, o que é desejável para Organismos de Supervisão Bancária que adotaram Centrais de Risco apenas recentemente (SCHECHTMAN et al, 2004). Além disso, o CSFB (1997) e Wilde (2000) sugerem um método simplificado (conservador) quando esse desvio-padrão não pode ser adequadamente estimado.

Gordy (2000) demonstra que uma versão reduzida de CreditMetrics (default-mode) e Creditrisk+ são equivalentes.

O modelo de CreditMetrics é conhecido pelos econometristas como um probit ordenado. Os eventos de crédito são causados por variáveis latentes não observáveis. Essas variáveis latentes dependem de "fatores de risco" externos. A dependência nos mesmos fatores de risco cria a correlação entre eventos de crédito de tomadores diversos. CreditRisk+ é baseado em modelos da indústria de seguros. Ao invés de uma variável latente, cada devedor tem uma probabilidade de default. Essa probabilidade não é constante ao longo do tempo, mas aumenta ou diminui em resposta aos (mesmos) fatores de risco sistêmicos que operam como pano de fundo. Se dois devedores são sensíveis ao mesmo conjunto de variáveis latentes, a sua probabilidade de default deve mover-se de modo similar. São precisamente esses movimentos coordenados que geram a correlação entre os defaults. Creditmetrics e Creditrisk+ servem essencialmente à mesma função, porém são construídas de forma diferente (GORDY, 2000).

Escrevendo o modelo na notação já adotada nesse texto (Fórmula 9) e em Schechtman et al (2004) tem-se:

$$
\begin{aligned}
& X_{i}=w_{i} Y+\eta_{i} Z_{i} \\
& \mathrm{Y}_{\mathrm{k}} \sim \operatorname{Gamma}(\alpha, \beta) \\
& \mathrm{E}\left(\mathrm{Y}_{\mathrm{k}}\right)=\alpha \beta=1 \\
& \sigma^{2}\left(\mathrm{Y}_{\mathrm{k}}\right)=\beta \\
& \mathrm{D}_{i k} \mid \mathrm{Y}_{k} \sim \text { Poisson com intensidade } p\left(\mathrm{Y}_{\mathrm{i}}\right)
\end{aligned}
$$

em que:

$\mathrm{X}_{i}=$ matriz de variáveis aleatórias que representam o risco dos tomadores $i$

$\mathrm{Y}_{k}=$ matriz de variáveis latentes que representam a exposição aos setores $(C f$. Creditrisk+) ou o risco sistemático ( $C f$. Creditmetrics)

$\mathrm{w}_{i k}=$ matriz que contém os fatores de ponderação que ajustam a sensibilidade do tomador $i$ aos $k$ setores representados por $\mathrm{Y}_{\mathrm{k}}$ ou fatores latentes de risco ( $C f$. Creditmetrics)

\footnotetext{
${ }^{17}$ FD foi propositadamente utilizada em lugar de PD. Nesse texto, usa-se a expressão de modo consistente com o BCBS (2006a). PD é utilizada apenas quando relacionada a um rating. Como explicitado, uma média de longo prazo de FDs de uma mesma categoria de risco (e.g. estimada por matrizes de migração) é um estimador adequado de PD.
} 
$\mathrm{D}_{i}=$ Variável de Bernoulli que assume 0 para não default e 1 para default.

$\mathrm{P}\left(\mathrm{Y}_{i k}\right)=$ probabilidade de $\mathrm{D}_{i k}=1 / \mathrm{Y}_{k}$

$\mathrm{FD}_{\mathrm{ik}}=p\left(\mathrm{Y}_{i k}\right)$

Para Gordy (2000), a correlação entre defaults em Creditrisk+ é inteiramente dirigida por um vetor $\mathrm{K}$ de fatores de risco (setores) $\mathrm{Y}_{\mathrm{k}}=\left(\mathrm{Y}_{1}, \mathrm{Y}_{2}, \mathrm{Y}_{3} \ldots \mathrm{Y}_{\mathrm{k}}\right)$. Condicionado a $\mathrm{Y}_{\mathrm{k}}$, os defaults de cada indivíduo $i, \mathrm{D}_{i}$, são variáveis de Bernoulli i.i.d. A probabilidade condicional $p_{i}(\mathrm{Y})$ de que um empréstimo esteja em default é função de um rating $\zeta$ dessa exposição $i$ que representa a realização dos fatores de risco $\mathrm{Y}_{i k}$ e do seu vetor de ponderação $\mathrm{w}_{i k}$, isto é, $p_{i}(\mathrm{Y})$.

$$
p_{i}(Y)=\overline{p_{\varsigma i}}\left(\sum_{k=1}^{K} Y_{i k} w_{i k}\right)
$$

onde

$p_{\zeta i}=$ probabilidade incondicional de default (PD) de um tomador $i$ pertencente a uma classe de risco $\zeta$.

$\mathrm{Y}_{\mathrm{k}}$ é sempre positivo com média 1 e a sua função é ajustar a PD média. O somatório da equação (25) é sempre 1 para cada $i$, mas a wY para um certo tomador pode torná-lo mais ou menos exposto aos k setores, tornando $p_{i}(\mathrm{Y})$ ou $\mathrm{PD}_{\mathrm{i}}$ mais sensível do que as incondicionais $p_{\zeta i}$ ou $\mathrm{PD}_{\zeta}$. Remarque-se que isso equivale a sensibilizar o tomador $i$ aos fatores de risco sistemático de Creditmetrics. Além disso, a grosso modo, para cada $i$, sua $\mathrm{PD}_{\mathrm{i}}$ é uma média ponderada por $\mathrm{w}_{\mathrm{k}}$. Ao atribuir um rating a um tomador ou operação e alocá-lo a um ou vários setores, Creditrisk+ está fazendo o que Creditmetrics faria. No entanto, $\sigma(\mathrm{Y})=\beta$ ou o desviopadrão do default faz o papel da correlação entre os ativos (GORDY, 2000).

Creditrisk+ calcula primeiramente a função geradora de defaults e não a distribuição de defaults.

A função geradora de probabilidade (f.g.p.) $\mathrm{F}_{\mathrm{k}}(\mathrm{z})$ de uma variável discreta $\mathrm{k}$ é função de uma variável auxiliar $\mathrm{z}$ de modo que a probabilidade de $\mathrm{k}=\mathrm{n}$ seja dada pelo coeficiente de $\mathrm{z}^{\mathrm{n}}$ na expansão polinomial de $\mathrm{F}_{\mathrm{k}}(\mathrm{z})$. Duas propriedades importantes decorrem disso (Ibid.):

1) Para Ks ortogonais, a f.g.p da soma de $\mathrm{k}_{1}+\mathrm{k}_{2}+\ldots$ equivale ao produto dessas f.g.ps 


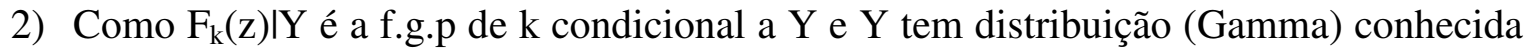
- G(Y), a f.g.p incondicional desejada, pode ser integrada :

(26) $\quad F_{K}(z)=\int_{Y} F_{K}(z \mid Y) d G(Y)$

A função geradora condicional a Y para o tomador $i$ é a de uma variável de Bernoulli (Ibid.):

$$
F_{i}(z \mid Y)=\left(1-p_{i}(Y)+p_{i}(Y) z\right)=1+p_{i}(Y)(z-1)
$$

Da propriedade 1) para uma carteira, obtém-se:

(28) $F(z \mid Y)=\prod_{i} F_{i}(z \mid Y)$

Mas resolver (28) com base em (29) e (30) de forma analítica não é trivial. O CSFB (1997) sugere que a distribuição de Poisson seja usada sobre a equação 29 e justifica da seguinte forma (notação ajustada):

De (27) vem,

$$
F_{i}(z \mid Y)=G(z \mid Y)=\left(1-p_{i}(Y)+p_{i}(Y) z\right)=1+p_{i}(Y)(z-1)
$$

que é equivalente a:

(30) $\mathrm{G}(\mathrm{z} \mid \mathrm{Y})=\exp [\ln (\mathrm{G}(\mathrm{z} \mid \mathrm{Y}))]=\exp \left[\ln \left(1+\mathrm{p}_{\mathrm{i}}(\mathrm{Y})(\mathrm{z}-1)\right]\right.$

Se $p_{i}(Y)$ ou $\mathrm{PD}_{\mathrm{i}}$ são muito pequenos, $\mathrm{a}=\mathrm{p}_{i}(\mathrm{Y})(\mathrm{z}-1)$ também será. Da expansão de Taylor vem (AVESANI et al, 2006):

(31) $\ln (1+a)=a-\frac{a^{2}}{2}+\frac{a^{3}}{3}+\ldots$ 
Como $\mathrm{PD}_{i}$ é muito pequeno, os termos de ordem dois e superiores são negligenciáveis levando a:

$$
\ln \left[\left(1+\mathrm{p}_{i}(\mathrm{Y})(\mathrm{z}-1)\right] \cong \mathrm{p}(\mathrm{Y})(\mathrm{z}-1)=\mathrm{PD}_{i}(\mathrm{z}-1)\right.
$$

$\mathrm{e}$

$$
\mathrm{G}(\mathrm{z} \mid \mathrm{Y})=\exp \left[\mathrm{PD}_{i}(\mathrm{z}-1)\right]
$$

Uma nova expansão de Taylor na região de $\mathrm{PD}_{\mathrm{i}}=0$ leva a:

(33) $G(z \mid Y)=\exp \left[P_{i}(z-1)\right]=\exp \left(-P_{i}\right) \sum_{x=0}^{\infty} \frac{P D_{i}^{x}}{x !} z^{x}$

O último termo é a p.g.f de uma distribuição de Poisson com intensidade PD (AVESANI et al., 2006). Em outras palavras, se a probabilidade de default é muito pequena, a aproximação da distribuição de Poisson para uma distribuição de Bernoulli da variável de default $\mathrm{D}_{\mathrm{i}}$ é adequada.

Por sua vez, para o portfólio (28) pode-se escrever:

(34) $\mathrm{F}(\mathrm{z} \mid \mathrm{Y})=\prod_{\mathrm{i}} \mathrm{F}_{\mathrm{i}}(\mathrm{z} \mid \mathrm{Y}) \cong \prod_{\mathrm{i}} \exp \left[\mathrm{PD}_{\mathrm{i}}(\mathrm{z}-1)\right]$

A equação 34 é então integrada em Y de modo a obter uma solução analítica para a p.g.f incondicional que será da forma (35). O CSFB (1997) propõe o uso do algoritmo recursivo de Panjer para resolução dessa passagem.

$$
\mathrm{F}_{\mathrm{K}}(\mathrm{z})=\prod_{\mathrm{k}=1}^{\mathrm{K}}\left(\frac{1-\delta_{\mathrm{k}}}{1-\delta_{\mathrm{k}} \mathrm{z}}\right)^{1 / \sigma_{\mathrm{k}}^{2}}
$$

(35) com

$$
\delta_{\mathrm{k}} \equiv \frac{\sigma_{\mathrm{k}}^{2} \mu_{\mathrm{k}}}{1+\sigma_{\mathrm{k}}^{2} \mu_{\mathrm{k}}}
$$

$\mathrm{e}$ 


$$
\mu_{\mathrm{k}} \equiv \sum_{\mathrm{i}} \mathrm{w}_{\mathrm{ik}} \overline{\mathrm{p}}_{\varsigma(\mathrm{i})}
$$

Avesani et al (2006) demonstram que, em decorrência da aproximação de Poisson, todos os VaR estimados por esses modelos estão superestimados e este viés é tanto maior quanto maiores forem as PDs. Por outro lado, a aproximação de Poisson e da distribuição de Gamma para $\mathrm{Y}$ permitem que $\mathrm{PD}_{i}$ seja aleatória e incorpore o desvio-padrão de $\mathrm{PD}_{k}$. Se $\mathrm{PD}$ for determinística, uma solução por transformação de Fourier (FFT) permite o cálculo de CVaR quando default é uma variável de Bernoulli, mas o efeito sistemático que se deseja incorporar com o desvio-padrão das PDs é perdido.

Um problema computacional importante do uso de Creditrisk+ é que o algoritmo de Panjer é viesado para portfólios muito grandes. Duas soluções para esse problema foram propostas: a de Melchiori (2004) de utilizar transformação inversa de Fourier (IFFT) e a de Gordy (2003) por saddlepoint (AVESANI et al, 2006).

Esse trabalho utiliza Creditrisk+ para estimar o capital econômico em um portfólio de referência que representa o Sistema Bancário.

\subsubsection{Modelo de Carey $(1998 ; 2001 ; 2002)$ e VaR de Crédito Não Paramétrico}

Carey (1998) sugere um modelo para estimar perdas de crédito, condicionado a apenas as características do portfólio utilizando reamostragem. $\mathrm{O}$ autor propõe o primeiro (e, até onde se sabe, o único) método não paramétrico para estimação de um VaR de Crédito. Trata-se de construir milhares de portfólios simulados com exposições de crédito aleatórias obedecendo objetivos de diversificação ou limites variados. Se todas as possíveis estratégias de diversificação com todas as exposições de crédito pudessem ser reproduzidas em simulações, a distribuição de perdas gerada por esse procedimento seria a distribuição de perdas não condicionada (SCHECHTMAN, 2006a). Na prática, é impossível simular todas essas alternativas e a distribuição de perdas é sempre condicionada, no mínimo, ao período usado para a estimação.

Carey (1998) conduz diversos exercícios de simulação e conclui que: 
- o aumento da perda esperada (pela inclusão de ativos de pior qualidade) gera distribuições com caudas mais gordas (intensidade de $\mathrm{PD}_{i}$ sobre $\mathrm{CVaR}$ );

- mantendo constante a qualidade do portfólio, o aumento do tamanho do portfólio leva a caudas mais leves (efeito diversificação sobre CVaR);

- O estado da economia é o fator sistemático mais importante na estimação. Ao usar janelas de estimação recessivas e menores, tantos as perdas esperadas, quanto as inesperadas aumentam muito.

Quando a discussão sobre o uso de uma fórmula IRB que aproximasse o capital econômico do regulatório começa a emergir no Basel Committee in Banking Supervision (2001), Carey (2002) propõe o uso do procedimento para a escolha do nível absoluto de requerimento de capital: "A reamostragem de um cenário de stress para a estimação da distribuição de perdas de crédito de um portfólio deveria ser a base para estimar o nível apropriado de alocação de capital econômico para fazer frente a perdas de crédito."

Para o autor, a hipótese de independência de defaults (implícita no procedimento de Monte Carlo) é mais realista do que assumir que a exposição a cada fator de risco sistemático é previamente conhecida e pode ser medida sem erros. Os defaults são independentes, porque a f.d.p. empírica incorporou as variáveis latentes para um período passado (CAREY, 2002). Ao usar cenários de stress, tanto as caudas, quanto as esperanças da perda total devem refletir condições extremas de risco sistemático sobre o portfólio.

Uma forma conveniente de descrever Carey (2002) a partir da notação de Gordy (2000) usada na fórmula (9) é,

$$
X_{i}=w_{i} Y+\eta_{i} Z_{i}
$$

$$
\begin{aligned}
& \text { com } \\
& w Y \sim \Theta(\text { desconhecida }) \\
& X \mid w Y \sim B(n, p) \\
& Z \sim \Psi(\text { desconhecida })
\end{aligned}
$$

em que $p$ é a inadimplência observada no portfólio criado por reamostragem e $n$ o número total de exposições $i$. 
De (36) vem que XlwY, assim como Z, são não observáveis e nenhuma forma funcional precisou ser imposta ex-ante. Em tese, $\mathrm{X}$ incondicional é a única variável observável ex-post e terá apenas uma distribuição empírica fruto do exercício de reamostragem.

Ao contrário, de Creditmetrics, Creditrisk+ e demais modelos paramétricos, o risco sistemático Y não pode ser integrado, o que não é um problema, já que a abordagem de Carey (2002) é usada apenas para validar requerimentos absolutos de capital com base em perdas observáveis no passado. Note-se que os pressupostos de Creditmetrics (09) foram relaxados significativamente.

Em (09),

w era conhecido ex-ante e Z n.i.i.d (0,1) e consequentemente

$\mathrm{XI}$ w, $\mathrm{Y} \sim$ n.i.i.d $(0,1)$,

Três hipóteses fundamentais de (09) e da Fórmula de Vasicek - caso particular em que w é escalar - podem ser relaxadas por meio de (36). Elas são (SCHECHTMAN, 2006a):

1) a de que os fatores $w_{i}$ são perfeitamente correlacionados

2) a de que bancos e reguladores podem estimar $w$ para cada tomador $i$ individualmente

3) a de que PDs incondicionais de longo prazo podem ser estimadas.

Existem pressupostos muito fortes nos procedimentos de $\mathrm{CVaR}$ paramétrico, em especial a excessiva dependência dos modelos nos fatores de risco Y ou na correlação de defaults (muito difícil de ser estimada pela falta de dados históricos) e da independência das exposições de crédito dado Y, supostamente verdadeiras apenas para carteiras grandes e granulares. Ao contrário da abordagem paramétrica da fórmula IRB, nesse modelo a sensibilidade da exposição aos estados da economia é suposta desconhecida ex-ante. (CAREY, 2002).

A lógica de Carey (2002) é de que a formação do portfólio pode ser modelada como retiradas independentes de um pool de tomadores representativo do mercado de crédito. Implicitamente, todas as estratégias de diversificação que um banco ou o próprio sistema bancário possa fazer são equivalentes ex-ante, mas algumas dessas carteiras apresentarão perdas superiores ex-post. 
Para Carey (2002):

[...] essa hipótese de independência garante que qualquer quantil das distribuições de perda geradas por um processo de reamostragem de carteiras possa ser interpretado não somente como o requerimento necessário para um banco se manter solvente, mas também como o percentual necessário para o regulador atingir uma determinada taxa de solvência bancária [consistente com a probabilidade conjunta do SFN se manter solvente].

Schechtman (2006b) é da mesma opinião. Dois estudos que merecem destaque são Majnoni e Powell (2005) e Schechtman (2006b), especialmente porque se assemelham mais ao objetivo deste trabalho. Os autores usam dados da Central de Risco (CRC) para exposições Corporate e, por meio de portfólios hipotéticos gerados por reamostragem, criam uma abordagem VaR não paramétrica para a carteira corporate no Brasil. Majnoni e Powell (2005) estimam desse modo ULs de 10,5\% para esta carteira, isto é, adequadas aos $11 \%$ requeridos por Basileia I à época para exposições de atacado.

Porém, Carey (2002) aponta três fraquezas nesse tipo de procedimento e, em especial, no seu estudo:

1) Viés do Sobrevivente.

2) A limitação temporal. No caso do autor, de 1986 a 1992, o que, na realidade, não reflete todas as possíveis realizações de perdas decorrentes do risco sistemático Y.

3) A limitação de estratégias de diversificação. Na verdade, as perdas observadas nas caudas refletem decisões de gestores que escolhem ativos aleatoriamente apenas observando limites de concentração impostos pelo autor.

A segunda limitação é digna de nota, porque implica que o X observado não é incondicional como desejado ou como estimado por modelos internos nas abordagens de CVaR paramétrico. Ocorre que o $\mathrm{X}$ observado no mínimo é condicional aos $t$ períodos de análise que não contêm todos os possíveis "estados da economia" de Y. Ou seja, XlwY é observável, e não $\mathrm{X}$. É sempre subjetivo se $\mathrm{XlwY}$ converge para $\mathrm{X}$, porque $t$ não tende ao infinito e, na prática, as observações de perdas de crédito (por inadimplência) são escassas. Para Carey (1998), se t for suficientemente grande em um dado exercício de reamonstragem, X é o quantil de interesse da função densidade de probabilidade desse exercício.

Dupoy (2007) chega a afirmar que encontra $X$ incondicional, porque observa Xlt1, Xlt2 ... Xlt5 e logo, com uma reamostragem envolvendo todos os anos, X. Mas é difícil supor que 
todas as realizações de wY ou os possíveis "estados da economia" foram observadas em cinco anos.

Carey (2002), Schechtman (2006b) e Majnoni e Powell (2005) não estão preocupados em estimar X de um portfólio e ficam satisfeitos em observar apenas XIY em um período de stress real ou simulado, desde que essa referência seja suficientemente conservadora aos olhos do regulador. Para eles, esse deve ser o referencial do requerimento absoluto de capital.

\subsection{As Centrais de Risco e a Abordagem dos Ratings Centralizados}

Esse tópico mostra como as Centrais de Risco podem ser usadas para o monitoramento de risco de crédito e propõe uma abordagem padronizada para o cálculo do CME baseada em dados contidos nesses bureaus públicos.

\subsubsection{As Centrais de risco: O que são e para que servem?}

As Centrais (Públicas) de Risco de Crédito contêm dados sobre o comportamento dos devedores do sistema financeiro (SHECHTMAN, 2006a). Elas são predominantes na América Latina, possivelmente pela escassez de bureaus de crédito (com dados privados). Porém, a compulsoriedade das IFs de alimentar as Centrais torna sua abrangência superior à dos bureaus (MILLER, 2003).

Trucharte (2004) salienta três usos principais para as centrais de risco:

1- elas monitoram o risco de crédito no sistema financeiro. Tanto do ponto de vista da supervisão bancária, quanto do de bancos, que individualmente utilizam as centrais para melhor dimensionar o risco específico de um tomador tendo em vista o total de suas exposições;

2- elas disciplinam os tomadores de crédito e minimizam o risco moral; e

3- demandam transparência e encorajam a competição entre os agentes do sistema financeiro.

Jappelli e Pagano (2001) encontram evidências de que as Centrais tanto públicas, quanto privadas aumentam o volume dos empréstimos e minimizam o risco de crédito. Miller (2003) demonstra que as Centrais têm efeito positivo no acesso ao crédito. As principais contribuições das centrais, todavia, dizem respeito ao seu potencial para minimizar o risco 
moral e a assimetria informacional entre bancos sobre o comportamento de sua clientela, o que tem efeito positivo sobre a concorrência e sobre a solidez do sistema financeiro (TRUCHARTE, 2004).

O Banco Mundial realizou uma pesquisa entre 1999 e 2003 sobre bureaus de crédito (privados) e centrais de crédito (públicos). Miller (2003) registra que 44 países possuíam bureaus e 41 centrais (alguns ambos). Os principais atributos das centrais foram:

- $\quad$ a obrigatoriedade de todas as instituições que concedem crédito reportarem dados sobre exposições de crédito;

- $\quad$ gestão do Banco Central;

- $\quad$ informações detalhadas sobre a inadimplência e o volume de exposições de crédito;

- $\quad$ alto nível de confidencialidade e isenção de custo na consulta para as instituições participantes;

O survey ainda apontou que em todos os países a informação era usada pela supervisão para monitorar a qualidade de crédito dos bancos e de sua evolução.

As propostas de Trucharte (2004) e Majnoni e Powell (2005) embora de naturezas distintas, são de usar as Centrais como instrumento-chave de validação e acompanhamento de Basileia II, sobretudo em países emergentes, onde outras fontes de dado podem ser inexistentes.

\subsubsection{A Central de Risco de Crédito Brasileira (SCR)}

A primeira Central de Risco Brasileira (CRC) foi criada em 1997 para "[...] prover dados sobre o montante de débitos e a responsabilidade por garantias para a Diretoria de Fiscalização do Banco Central do Brasil”. A partir de 2002, a antiga central foi substituída pelo Sistema de Informações de Risco de Crédito (SCR), cujo foco deixou de ser as informações agregadas e passou a ser as operações ou exposições em si mesmo (YANAKA, 2009, p. 46).

A antiga Central, CRC, continha dados detalhados apenas das exposições superiores a $\mathrm{R} \$ 50$ mil, mas atualmente contém todas as exposições superiores a $\mathrm{R} \$ 5.000$ e muitas de valor inferior. As principais informações disponíveis dizem respeito a atrasos, carteira ativa, prejuízos, porte do cliente, linhas de crédito, classificação de risco e tipo de operação e garantia. O SCR é alimentado mensalmente com dados individuais por parte de todas as IFs 
obrigatoriamente para exposições de valor superior a $\mathrm{R} \$ 5.000$ (Doc. 3020) e voluntariamente para valores inferiores. Dados consolidados (Doc. 3030) para todas as exposições de crédito também são devidos mensalmente.

O cliente bancário inicialmente autoriza as instituições financeiras a consultarem suas informações de crédito, em geral, durante o preenchimento do cadastro para abertura da conta corrente.

Espera-se para junho de 2012, a plena substituição do SCR pelo SCR2, que reduzirá o limite mínimo para a remessa obrigatória de informação individualizada por cliente dos atuais $\mathrm{R} \$ 5$ mil para R\$ 1 mil, além de algumas melhorias, em especial, no tratamento da cessão de crédito etc (MEIRELLES, 2011).

\subsubsection{Abordagem dos Ratings Centralizados (CRB)}

Majnoni e Powell (2005) usam dados das Centrais de Risco brasileira, argentina e mexicana para testar as consequências do uso da abordagem IRB, utilizando também a abordagem de Carey (2002). Os autores concluíram que as curvas baseadas em distribuições empíricas e consequentemente o capital regulatório estimado desse modo para a Argentina e para o México deveriam ser muito superiores aos $8 \%$ sugeridos pelo Comitê da Basileia e representados pela curva paramétrica de Basileia II.

Para remediar esse problema e ainda o da falta de preparo dos países latino-americanos para o IRB, os autores desenvolveram a abordagem de ratings centralizados (Centralized Rating Based - CRB), posteriormente sugerida pelo Banco Interamericano de Desenvolvimento (BID) como uma solução alternativa ao IRB nesses países.

Majnoni e Powell (2005) sugerem uma escala com valores mínimos e máximos de PDs calibrados pelo regulador em sete categorias. Os bancos deveriam usar uma PD média de cada categoria para estimar o capital regulatório.

Uma vantagem dessa abordagem é que a PD advém do modelo interno do banco, mas é reajustado para um limite central ao ser classificado nas categorias de risco do regulador. Além disso, a supervisão tem o ferramental básico para comparar os resultados gerados por um dado banco com os de todos os demais e possui um sistema natural de tracking error em 
suas Centrais de Risco. Esta abordagem era especialmente bem-vinda em países como o Brasil e Argentina que já possuíam uma central de risco de crédito e um sistema de classificação de risco com uma escala padronizada para o provisionamento, mas onde a penetração das agências de rating era pequena (MAJNONI; POWELL, 2005).

Os ratings centralizados são uma alternativa estudada nesse trabalho para o Brasil. Por sua similaridade conceitual a CRB, optou-se por denominá-lo Abordagem Padronizada dos Ratings Centralizados (Centralized Stantandardized Ratings Based Approach - CRBA). No entanto, a proposta desse estudo não é uma alternativa ao IRB e sim à Abordagem Padronizada de Basileia II.

Alguns benefícios da abordagem proposta são:

- a eliminação da dependência regulatória nas opiniões das ACRs para o cálculo do CME;

- penetração total e não apenas às exposições de corporate, soberano e bancos;

- Maior controle da supervisão sobre os modelos internos por meio das Centrais de Risco que têm condições de acompanhar (tracking error) a performance dessas carteiras.

$\mathrm{Na}$ verdade, algumas Centrais são, inclusive, reconhecidas como provedores de dados complementares aos das ECAIs. O ECB (2011) aponta que existem três nessa condição: o do Banque de France, o do Banco de España e o do Bundesbank.

\subsubsection{Abordagem Padronizada dos Ratings Centralizados (CRBA)}

O Quadro 12 apresenta as FPRs sugeridas para a abordagem CRBA (um dos objetivos deste trabalho) em comparação com as da Abordagem Padronizada. 
Quadro 12 - O funcionamento da abordagem CRBA

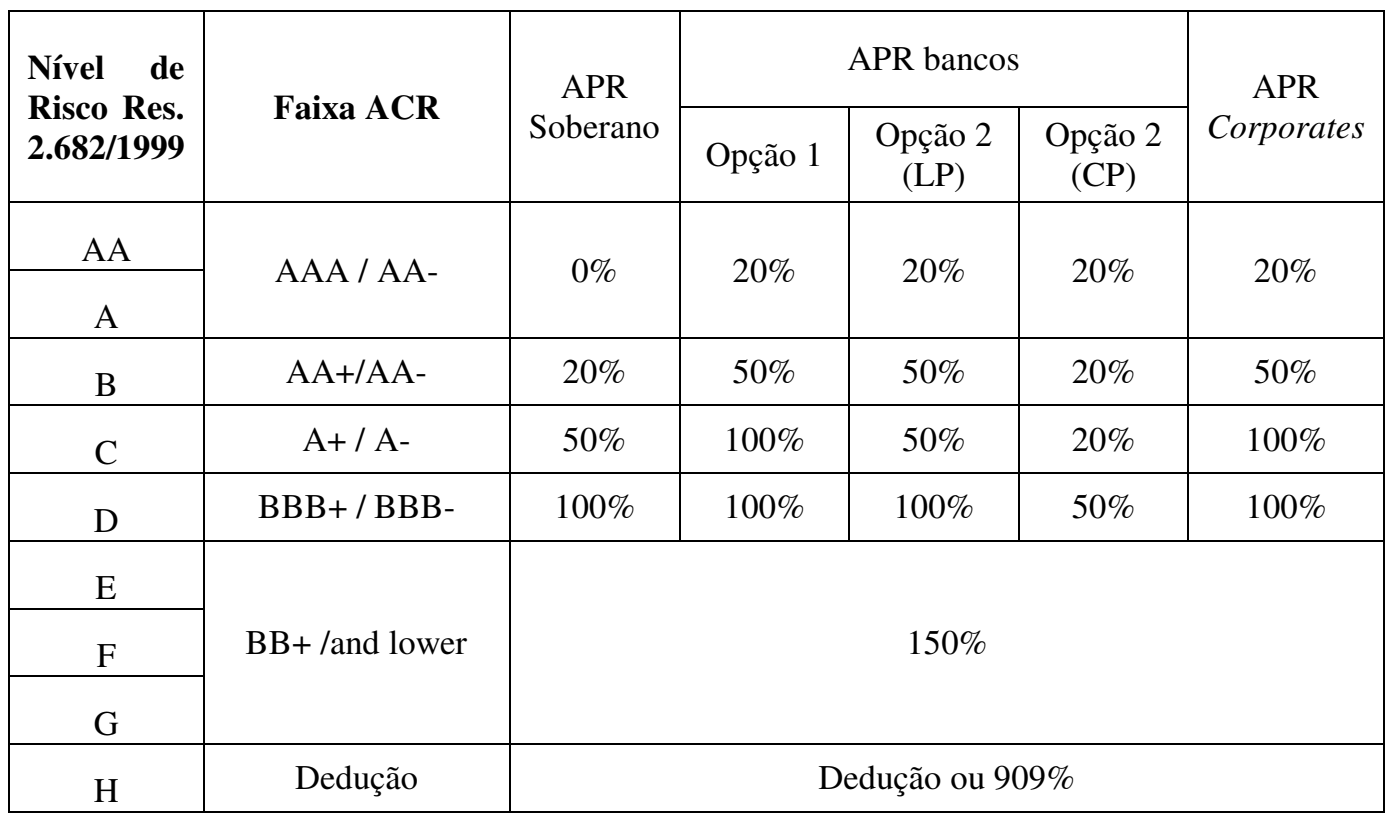

Embora similar à SA na forma, a CRBA é diferente em um ponto fundamental. Na SA, a opinião creditícia vinha da ACR e, na CRBA, a opinião vem do banco. Na essência, a CRBA é um modelo interno bastante simplificado e que tende a corrigir um problema ainda existente na abordagem atual: a insensibilidade ao risco de crédito do tomador. Além disso, a proposta mitiga os problemas de conflitos de interesse remanescentes e que são teoricamente indissociáveis da abordagem SA. No Brasil, isso é particularmente relevante, porque incentiva a assunção de maior risco de crédito para um mesmo nível de capital regulatório, sobretudo no caso dos bancos pequenos onde o capital é mais caro, criando, por hipótese, um círculo vicioso.

Se se desejasse elencar as oportunidades de arbitragem regulatória no Brasil em duas categorias, elas seriam:

1) incentivo à criação de uma clientela de risco, já que o CME é insensível na SSA; 
2) incentivo ao subprovisionamento, já que a Resolução CMN n. 2682/99 penaliza operações de maior risco.

Uma consequência indesejável da CRBA é que se pode agravar este segundo tipo de arbitragem regulatória com ratings inflacionados. De certa forma, essa arbitragem está presente com o uso das provisões mínimas da Resolução CMN n. 2.682/99 (CMN, 1999) sempre que a classificação mínima é adotada e revisada apenas por atrasos, ou quando uma garantia é suposta muito melhor do que efetivamente é, levando a uma classificação mais alta (apesar de atrasos).

Os grandes benefícios da CRBA é que ela impede a arbitragem regulatória do tipo (1) e, de certa forma, permite o controle do tipo (2) por meio das Centrais de Risco. As matrizes de risco calculadas pelas Centrais de Risco mensalmente banco a banco permitem saber se as frequências de default excedem um limite predefinido pelo regulador ou se são mais elevadas do que às dos demais bancos com portfólios de risco similar.

O tracking error pode ser realizado, por exemplo, com uma nova faixa de classificação, não ligada a atraso e utilizada apenas para reportar o rating interno do banco.

Vale ressaltar que, na Inglaterra e nos EUA, esse tipo de mecanismo de controle é inexistente (CALOMIRIS, 2009a). Mas, na maioria dos países da Europa Continental, existem centrais de risco (MULLER, 2003), o que torna esse modelo teoricamente viável. A possibilidade de usar as Centrais de Risco de modo complementar para o cálculo do CME também foi mencionado no documento EC (2010).

Sobre esse ponto, a carta resposta do BCE à proposta de Bruxelas foi de que as Centrais ou os in-house credit assessment systems (ICASs) pudessem ter papel crescente divulgando dados sobre exposições não cobertas pelas ECAIs. Por outro lado, EP (2011) não considera a hipótese de as Centrais competirem ou substituírem as ACRs por considerar que uma nota por parte de um órgão oficial teria o valor de uma chancela indesejável politicamente sobre um determinado tomador de crédito. O BCE era contrário a que as ICASs se tornassem alternativas às ACRs e oferecessem opiniões creditícias, ou uma referência que pudesse ser entendida dessa forma.

Como explicitado, a proposta deste trabalho não vai nesse sentido. A nota ou classificação de risco é do banco, mas o regulador se encarrega de acompanhar confidencialmente a 
performance de seu modelo interno tanto pela supervisão indireta (por exemplo, com o uso de matrizes de migração), quanto pela fiscalização in loco. A informação para o acompanhamento da inadimplência das carteiras mensalmente fica no Banco Central e não (exclusivamente) no banco.

A metodologia detalhada para a calibração dessa abordagem é explicitada no capítulo seguinte, seção 4.5 . 


\section{METODOLOGIA}

\subsection{Objetivos de pesquisa}

O estudo parte da contextualização das crises financeiras e a necessidade de regulação dos sistemas financeiros para então conceituar os riscos envolvidos na intermediação. Destaca as estruturas regulatórias e as diversas modelagens propostas para mitigar e mensurar o risco de crédito.

São propostos três objetivos primários:

1- Verificar qual o capital econômico, isto é, o requerimento absoluto de capital para as carteiras de crédito bancárias no Brasil baseado na metodologia de CVaR não paramétrico de Carey (2002) e o paramétrico Creditrisk+.

2- Avaliar o CME nas seguintes abordagens de Basileia: a extinta Basileia I, a SSA (em vigor) e o IRB Fundamental (em fase de certificação para bancos grandes).

3- Avaliar a abordagem proposta, a CRBA, em diversas especificações e como uma alternativa à SSA especialmente para bancos pequenos e médios.

Neste trabalho, procura-se apresentar resultados mais detalhados sobre o risco de crédito dos bancos pequenos e médios brasileiros e estimativas de seu capital econômico pelo modelo de Carey (2002).

O efeito das perdas de crédito sobre eles é avaliado tanto do ponto de vista do efeito de choques aleatórios sobre carteiras pequenas (com menor potencial de diversificação), quanto da qualidade de crédito disponível a esses bancos. O primeiro efeito é medido simulando carteiras pequenas com todas as exposições de crédito disponíveis na população de devedores do Sistema Bancário. No segundo, mais realista, o exercício de simulação de Monte Carlo é repetido construindo portfólios apenas com exposições de crédito disponíveis nas carteiras desses bancos no período de análise.

Ao realizar esses dois procedimentos, quer-se controlar o experimento para o efeito do tamanho da carteira (ganho de diversificação) e da qualidade da carteira. Por hipótese, o universo de devedores ou empréstimos disponíveis para bancos pequenos e grandes não é o mesmo. Os bancos grandes escolhem melhor (ou primeiro) sua clientela e os pequenos competem por nichos não capturados pelos grandes. Busca-se também saber se a qualidade de 
crédito em carteiras de bancos grandes é substancialmente superior ou se existe apenas um efeito diversificação que explica sua menor inadimplência.

Com foco no segundo objetivo desta tese, apresenta-se uma estimativa dos requerimentos de capital nas diversas abordagens existentes de Basileia para um banco ou para o próprio SFN cuja carteira é o portfólio-base que é a amostra completa deste estudo e para certos substratos de interesse como varejo, corporate e SME, além de bancos pequenos e grandes. Essas estimativas amostrais de capital regulatório e provisão mínima nas abordagens de Basileia I, Basileia II SSA e IRB podem ser convenientemente comparadas entre si, com o requerimento absoluto de capital mínimo em vigor no Brasil, com o requerimento mínimo "médio" (aqui estimado apenas para a vertente de risco de crédito) e com os resultados dos exercícios de simulação (objetivo 1) tanto no período completo de estudo, quanto ao longo da crise de 2008-2009. Adicionalmente, propõem-se dois cenários de stress apresentados mais adiante para complementar essa análise.

Finalmente, propõe-se o terceiro objetivo de avaliar a abordagem CRBA apresentada conceitualmente na seção anterior.

Vale ressaltar que este é o primeiro estudo de que se tem notícia realizado com dados do SCR para o varejo com exposições abaixo de $\mathrm{R} \$ 5.000,00$. A maioria dos trabalhos empíricos sobre crédito bancário no Brasil versa sobre o atacado e.g. Schechtman (2006b), Majnoni e Powell (2005). Um raro contra exemplo é o de Silva et al (2010), que estima correlações de default no varejo bancário brasileiro usando dados do SCR com a limitação típica de que suas conclusões se aplicam à carteiras de valor superior a $\mathrm{R} \$ 5.000,00$.

Em cada simulação de Monte Carlo, para cada um dos 20 mil portfólios reamostrados, há uma estimativa de cada modelo alternativo com e sem stress (Ver Apêndice para o código em Stata completo e comentado). ${ }^{18}$

Na sequência, apresentam-se os dados utilizados, as premissas adotadas para cada abordagem e as limitações envolvidas nos três objetivos apresentados.

\footnotetext{
18 Esse código é computacionalmente pesado. Pode ser reproduzido em um computador doméstico apenas para um número pequeno de simulações. Para a simulação mais pesada, foram utilizados os servidores da Columbia University e da City University of New York. Os servidores eram de última geração, mas o código mais pesado levou cerca de um mês para ser processado, razão pela qual o código do Apêndice B foi preferido.
} 
A pesquisa utilizou reamostragem e simulações de Monte Carlo para estimar requerimentos de capital e avaliar a robustez das diversas abordagens e carteiras de Basileia II em proteger o sistema financeiro dos choques aleatórios stress 1 e 2. Foi dada especial atenção ao modelo IRB Fundamental a ser adotado no Brasil com os parâmetros do Edital Público do BCB n. 37/11. De modo geral, buscou-se saber como o CME e a provisão mínima exigida (PME) pela resolução CMN n. 2682/99 (CMN, 1999) se comportariam com base na amostra desse estudo e durante a crise de 2008-2009.

Para tanto, os bancos pequenos e grandes são tratados de modo independente, já que se procura avaliar qual requerimento de capital seria adequado a esses dois grupos e se a abordagem proposta CRBA seria uma alternativa mais adequada para bancos pequenos e médios em relação às demais. Avaliam-se ainda os portfólios de varejo, atacado e pequenas e médias empresas (SME) do setor bancário de modo independente.

\subsection{População e amostra}

Os dados são os do SCR, 50.000 exposições de crédito anônimas e aleatórias para as datasbase de julho e dezembro de 2004 a 2010. Trata-se de sete anos e uma amostra aleatória inicial de pouco mais de 700.000 exposições de crédito do SFN menos as dos bancos de desenvolvimento e da Caixa Economia Federal. ${ }^{19}$

Os dados coletados são os do Quadro 13.

Quadro 13 - Dados extraídos do SCR para a amostra aleatória de exposições de crédito

\begin{tabular}{|l|c|l|}
\hline \multicolumn{1}{|c|}{ Campo } & Variável & \multicolumn{1}{c|}{ Detalhes do Campo } \\
\hline MM_REF & data & Data Base \\
\hline ID_IF & top10 & Identifica se banco é grande ou pequeno \\
\hline TP_CLI_RES_DS & PF & Identificador PF ou PJ \\
\hline PORTE_CLI_DS & ------------- & Porte do cliente \\
\hline MOD_OPER_RES_DS & Type & Modalidade da Operação (Específico) \\
\hline DET_MOD_OP_RES_DS & ------------- & Modalidade da operação (Genérico) \\
\hline CA & ca & Carteira Ativa ou Tamanho da exposição \\
\hline CAVencida90 & CAVencida90 & Montante da Carteira ativa em atraso superior a 90 dias \\
\hline ClassCli/ClassOpe & rating & Classificação do Cliente nas categorias AA a H \\
\hline PREJ & $--------------~$ & Montante da Carteira Ativa em prejuízo \\
\hline
\end{tabular}

FONTE: BCB. Nova Central de Risco (SCR). Documento 3020.

\footnotetext{
${ }^{19} \mathrm{O}$ perfil de inadimplência desses dois bancos públicos e suas matrizes de migração são muito distintas das observadas nos demais bancos.
} 
O Departamento de Fiscalização do Banco Central do Brasil consolida as Modalidades de Operação do SCR em oito categorias mais genéricas e que são convenientes para a formação de pools de devedores com risco comparável em matrizes de migração. Essas categorias são utilizadas para a estimação da Frequências de Default (FD) e podem ser usadas para uma estimação simplificada da Probabilidade de Default (PD) ( $C f$. Yanaka, 2009). As oito categorias estão subdivididas em quatro de pessoa física e quatro de pessoa jurídica conforme o Quadro 14.

Quadro 14 - Categorias Fiscalização do Banco Central do Brasil

\begin{tabular}{|l|l|}
\hline PF & Consumo \\
\hline PF & Investimento e Aquisição de bens \\
\hline PF & Rural e Financiamento Rural \\
\hline PF & Outros \\
\hline PJ & Capital de Giro \\
\hline PJ & Investimento e Financiamento \\
\hline PJ & Atividades Especializadas \\
\hline PJ & Outros \\
\hline
\end{tabular}

As 700.000 exposições são filtradas para o Consolidado Bancário I e II. Após os ajustes, a amostra de trabalho foi de 675.206 exposições. Ela foi gerada com uma variável de controle top10 que informa se determinada exposição de crédito, é proveniente de um dos sete maiores conglomerados privados do Brasil e do Banco do Brasil - oito bancos grandes - ou se pertence aos demais, considerados nesse estudo, como bancos pequenos e médios.

Os bancos grandes são os da Tabela 12, abaixo, a saber, os oito maiores (salvo CEF e BNDES) em relação ao tamanho da carteira de crédito ao longo dos 7 anos do estudo. Em número de exposições na amostra, cerca de $83,94 \%$ pertenciam a esses bancos. Em saldo médio ao longo dos sete anos, estas exposições representaram R \$ 10,7 de R \$ 14,18 bilhões $(75,5 \%)$. 
Tabela 12 - Oito membros da subamostra de bancos grandes (dados de dezembro de 2010)

\begin{tabular}{|c|c|c|c|c|c|}
\hline Consolidado Bancário & Ativo Total & $\begin{array}{l}\text { Operações de } \\
\text { Crédito e } \\
\text { Arrendamento }\end{array}$ & Patrimônio Liq & $\begin{array}{l}\text { Índice de } \\
\text { Basileia }\end{array}$ & $\begin{array}{l}\text { Índice de } \\
\text { Imobilização }\end{array}$ \\
\hline BB & 779.303 .944 & 334.193 .046 & 50.495 .589 & 14,7 & 20,99 \\
\hline ITAÚ & 720.313 .868 & 233.687 .162 & 61.802 .220 & 15,8 & 37,32 \\
\hline BRADESCO & 562.601 .430 & 197.231 .554 & 48.218 .521 & 15,1 & 49,71 \\
\hline SANTANDER & 376.062 .156 & 142.020 .354 & 65.322 .455 & 28,4 & 39,65 \\
\hline VOTORANTIM & 110.741 .218 & 51.966 .708 & 8.388 .935 & 13,1 & 1,4 \\
\hline HSBC & 124.686 .081 & 40.217 .164 & 7.790 .649 & 13,2 & 36,69 \\
\hline SAFRA & 76.297 .016 & 30.855 .447 & 5.613 .741 & 14,1 & 24,04 \\
\hline CITIBANK & 54.406 .014 & 10.830 .053 & 5.394 .184 & 13,8 & 14,45 \\
\hline
\end{tabular}

FONTE: Relatório Top50 do BCB (dezembro de 2010)

Os dados da Tabela 12 indicam que a carteira de crédito mais expressiva em dezembro de 2010 era a do Banco do Brasil e representava (em saldo) 27\% do universo de interesse desse estudo. Na média dos últimos sete anos, ele também foi o mais expressivo.

Ocorreram fusões durante o período, notadamente, entre o grupo dos maiores com destaque para $\mathrm{ABN}$ e Santander e Itaú e Unibanco. Como as exposições são colhidas por CNPJ e depois reagrupadas no conglomerado financeiro, a expansão de um conglomerado financeiro não prejudica a representatividade do estudo. No caso específico destas maiores, todos os CNPJs dos atuais membros foram considerados no grupo de grandes desde julho de 2004.

Ao total, 160 bancos fizeram parte da amostra. Vale ressaltar que ela não só é aleatória, mas o universo de IFs do estudo também é dinâmico. A cada semestre, o universo bancário é reconstruído e são retiradas exposições aleatoriamente de todos os CNPJs bancários. O banco que foi individualmente mais representativo contribuiu para a amostra com 187.821 exposições, o menos representativo com 1 . Ao permitir que o universo flutuasse de tamanho, procurou-se minimizar o viés do sobrevivente. Assim, fica claro que exposições de bancos que, por exemplo, faliram durante estes sete anos estão incluídas na amostra até o momento em que, por efetivo cancelamento, estas IFs deixaram de enviar dados ao SCR.

O Quadro 15 apresenta a distribuição da amostra por faixa de valores. 
Quadro 15 - Distribuição da amostra por faixa de valores

\begin{tabular}{|c|c|c|c|c|c|}
\hline Faixa de Valor & $\begin{array}{l}\mathbf{P F} / \\
\mathbf{P J} \\
\mathrm{PF}\end{array}$ & $\begin{array}{l}\text { Número de } \\
\text { exposições }\end{array}$ & $\begin{array}{c}\text { Saldo } \\
\text { amostral (R\$ } \\
\text { MM) }\end{array}$ & $\begin{array}{c}\text { Saldo Total no } \\
\text { SFN Média } \\
\text { (2004/06-2010/12) } \\
\text { R\$ MM }\end{array}$ & $\begin{array}{c}\text { Representatividade } \\
\text { da amostra em } \\
\text { saldo } \\
033 \%\end{array}$ \\
\hline até R\$5 mil & $\mathrm{PF}$ & 334.651 & $444,7(2,9 \%)$ & $133.202(13,95 \%)$ & $0,33 \%$ \\
\hline De R\$ 5 a R\$ 50 mil & $\mathrm{PF}$ & 273688 & $3.337(21,83 \%)$ & $202.724(21,22 \%)$ & $1,65 \%$ \\
\hline Acima de $\mathrm{R} \$ 50 \mathrm{mil}$ & $\mathrm{PF}$ & 12427 & $1.615(10,5 \%)$ & $90.019(9,42 \%)$ & $1,79 \%$ \\
\hline Até R\$ 100 mil & PJ & 9760 & $1.158(7,57 \%)$ & $91.583(9,58 \%)$ & $1,26 \%$ \\
\hline De $\mathrm{R} \$ 100 \mathrm{M}$ a $\mathrm{R} \$ 10 \mathrm{MM}$ & PJ & 6564 & $5.214(34,11 \%)$ & $214.926(22,50 \%)$ & $2,43 \%$ \\
\hline Acima de R\$ 10 MM & PJ & 129 & $3.516(23 \%)$ & $222.855(23,32 \%)$ & $1,58 \%$ \\
\hline
\end{tabular}

FONTE: BCB. Sistema Gerenciador de Séries Temporais (Média de 2004 a 2010)

Um mínimo de 1,5\% do montante médio para o período de estudo das operações de crédito do SFN está representado na amostra, salvo pela modalidade inferior a R \$5.000,00 que está subdimensionada.

O subdimensionamento nesse substrato ocorre porque até 2012 as IFs não eram obrigadas a reportar essa informação. Na medida em que as IFs se preparavam para o SCR2, esse dado tornou-se cada vez mais usual. ${ }^{20} \mathrm{O}$ SCR2 em fase de implantação reduz o valor de corte para R\$ 1.000,00. Optou-se por não eliminar esse substrato, que representa cerca de $14 \%$ em saldo médio do universo de interesse e a maior parte das exposições do sistema bancário em número de operações. Optou-se ainda por reponderá-lo para que a inadimplência e todos os demais indicadores aqui calculados refletissem melhor a realidade do SFN.

A Tabela 13 demonstra o impacto de reponderar a amostra desse estudo

Tabela 13 - Inadimplência amostral média no período com e sem ponderação

\begin{tabular}{|l|l|}
\hline Amostra sem nenhum ajuste & $3,91 \%$ \\
Apenas com os ativos > R \$5 mil & $3,81 \%$ \\
\hline Amostra reponderada & $4,18 \%$ \\
\hline
\end{tabular}

Sem nenhum ajuste, a inadimplência amostral é de 3,91\%. Ao reponderá-la na frequência para compensar o fato de que os dados estão subamostrados na faixa de valor iinferior a $\mathrm{R} \$ 5.000$,

\footnotetext{
${ }^{20}$ Uma consequência indesejável disso é que podem existir bancos que efetivamente contribuíram mais que outros no substrato abaixo de R \$ 5.000,00 na população do SCR, porque seus sistemas estavam mais aptos. Não há motivos para crer que as suas carteiras sejam qualitativamente superiores às dos demais. Investigou-se a inadimplência nesse substrato frente ao consolidado para dados abaixo de R\$ 5.000 e os dados amostrais convergem para o populacional. Esse substrato também contém as operações residuais que inicialmente eram superiores a $\mathrm{R} \$ 5.000$.
} 
chega-se a 4,18\%. ${ }^{21}$ A inadimplência de $4,18 \%$ é o melhor estimador amostral disponível dado as limitações de dados públicos e converge para a média populacional desse estudo (não pública). Verifique-se que estudos que usavam apenas dados do SCR Doc. 3020 sem reponderá-los com os dados agregados do Doc. 3030, na prática, podem ter subestimado a inadimplência em cerca de 10\% (YANAKA, 2009). Isso decorre do fato de que a carteira ativa de varejo na faixa abaixo de $\mathrm{R} \$ 5$ mil apresenta um perfil muito mais arriscado do que o do restante do varejo. O principal motivo para isso são as modalidades de consumo ligadas à pessoa física, em especial cartão de crédito e cheque especial.

Ficou claro na revisão bibliográfica que dois critérios de inadimplência eram utilizados: Atraso superior a 90 dias (variável inadimplência ou dloss ${ }^{22}$ ) e exposições classificadas de E a H - variável subprime sugerida por Costa e Blum (2008) ou tloss. A variável tloss está mais relacionada ao conceito de perda econômica do que de inadimplência. A principal diferença é que a "[...] perda econômica usa a deterioração da qualidade do banking book" como proxy para o default. Uma estimação feita pelo Banco da Inglaterra aponta que a perda econômica, em geral, estava 70\% acima da inadimplência [...] (JACKSON, 2001). Para Basileia II, tloss e dloss são igualmente importantes porque as duas desencadeiam o default, a que ocorrer primeiro. Adota-se aqui o mesmo critério.

Para o agrupamento geral do IRB nas famílias de Varejo, Corporate e SME, os dados são os das Tabelas 14 (para o período completo) e 15 (para o período da crise).

Tabela 14 - Inadimplência amostral no Varejo, SME e Corporate (06/2004 a 12/2010)

\begin{tabular}{|c|c|c|c|}
\hline & $\begin{array}{c}\text { Inadimplência } \\
\text { (dloss) }\end{array}$ & $\begin{array}{c}\text { Subprime } \\
\text { (tloss) }\end{array}$ & $\begin{array}{c}\text { Saldo Médio } \\
\text { (R\$) }\end{array}$ \\
\hline Varejo & $5,58 \%$ & $8,55 \%$ & $\mathrm{R} \$ 10.999$ \\
\hline SME & $2,98 \%$ & $5,41 \%$ & $\mathrm{R} \$ 1.200 .324$ \\
\hline Corporate & $1,74 \%$ & $2,22 \%$ & $\mathrm{R} \$ 14.421 .928$ \\
\hline
\end{tabular}

\footnotetext{
${ }^{21} \mathrm{O}$ critério para reponderar a amostra por frequência (fweights) não precisou ser codificado. Stata 11.2 possuía uma função interna para isso. O procedimento computacional de Stata 11.2 equivale a replicar as exposições na base de dados até que a frequência amostral se aproxime da populacional. Os estimadores da média e variância adotados não estão viesados em decorrência dessa replicação (CAREY, 2001).

${ }^{22}$ Conforme observado anteriormente, todo o crédito do SFN teve forte crescimento no período, razão principal pela qual a inadimplência típica é geralmente subdimensionada. As frequentes cessões e securitizações também podem viesar o número para baixo. Números mais robustos são baseados em matrizes de migração, mas eles também não controlavam as cessões de crédito até 2011 (MEIRELLES, 2011). O mesmo vale para os dados da Figura 3. Além disso, a inadimplência da Figura 3 não segue o critério de arrasto.
} 
Tabela 15 - Inadimplência amostral na crise (12/2008 a 06/2010)

\begin{tabular}{|c|c|c|}
\cline { 2 - 3 } \multicolumn{1}{c|}{} & $\begin{array}{c}\text { Inadimplência } \\
\text { (dloss) }\end{array}$ & $\begin{array}{c}\text { Subprime } \\
\text { (tloss) }\end{array}$ \\
\hline Varejo & $6,68 \%$ & $9,67 \%$ \\
\hline SME & $4,90 \%$ & $6,65 \%$ \\
\hline Corporate & $3,89 \%$ & $3,62 \%$ \\
\hline
\end{tabular}

Para as próximas sessões, um dos critérios de período de stress é o dos efeitos da Crise de 2008-2009 no Brasil. O pico da crise é sentido em setembro de 2009 (Figura 3). Em dezembro de 2008, a inadimplência começa a se elevar e, em junho de 2010, retorna para a média de 2004 a 2010. Assim, elegem-se quatro datas-base como representativas do período de crise no Brasil: 12/2008, 06/2009,12/2009 e 06/2010

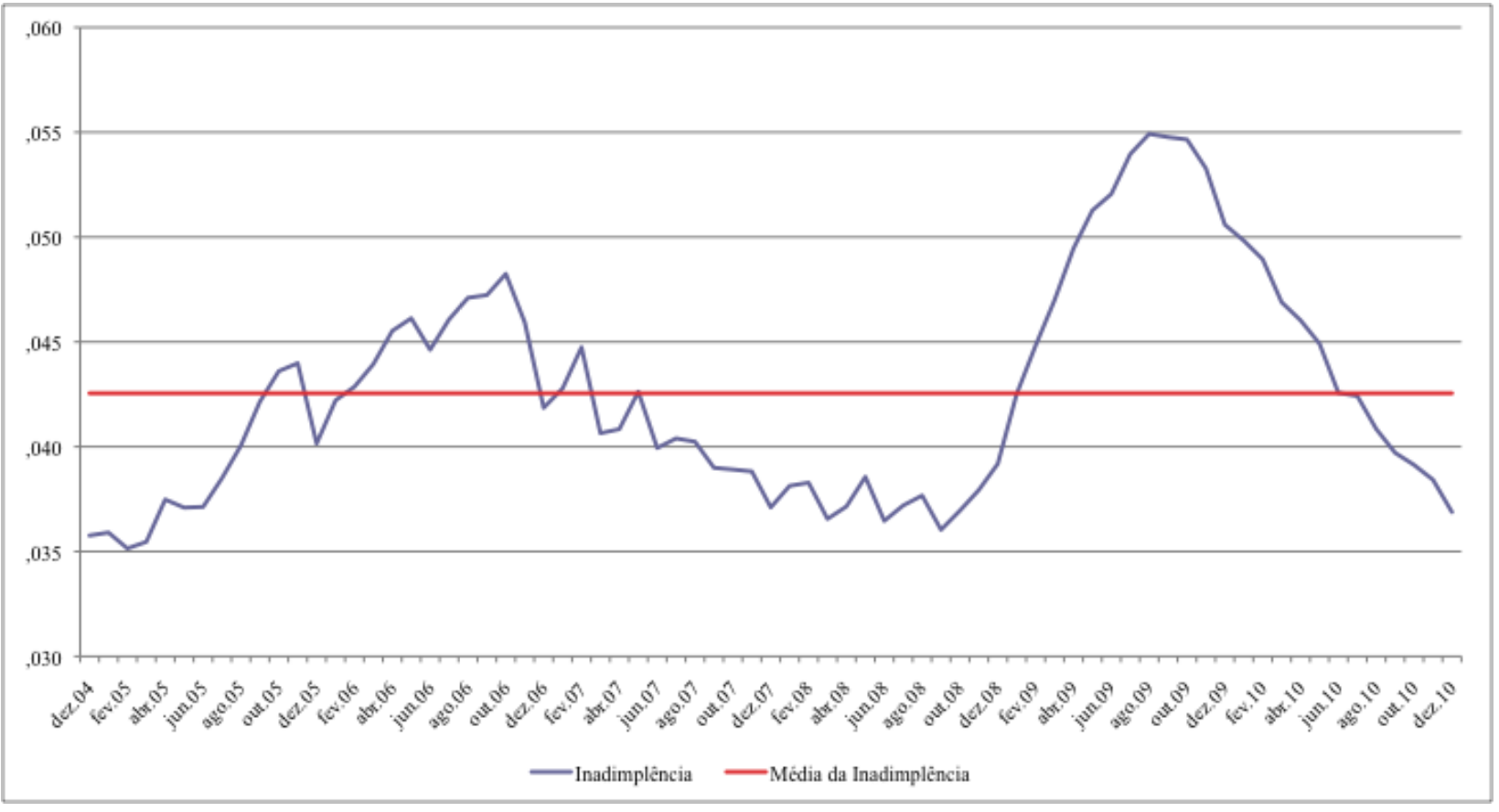

Figura 3 - Inadimplência entre 2004 e 2010.

FONTE: BCB

\subsection{Procedimentos para estimar Requerimentos Absolutos de Capital}

\subsubsection{A Abordagem (Não Paramétrica) de Carey (2002)}

À semelhança de Majnoni e Powell (2005), Dupoy (2007) e Schechtman (2006b) estima-se um CVaR não paramétrico para a carteira de crédito de bancos brasileiros. Entretanto, 
pretende-se sofisticar um pouco mais esses trabalhos, na medida em que o primeiro objetivo desse trabalho (Quadro 1) é obter uma estimativa de capital econômico para bancos grandes e pequenos baseado nos quantis de interesse da perda dado o default.

O procedimento utilizado é a reamostragem (com repetição) para formar carteiras hipotéticas aleatórias. A distribuição empírica de perdas para um conjunto muito grande de carteiras simuladas gera uma freqüência de perdas para o Sistema Bancário. Assim como em Carey (2002), busca-se estimar os quantis à direita dessa função densidade de probabilidade (f.d.p), porque eles representam as piores realizações da inadimplência bancária em portfólios bancários similares aos reais. Outro ponto que aproxima os resultados desse estudo da realidade é que, em oposição à Carey, a amostra desse estudo é de exposições de crédito que efetivamente pertenceram ao portfólio dos bancos.

A respeito da reamostragem com repetição adotada, Carey (2001, p. 208) ressalta que, embora possa parecer lógico que um devedor ou operação de crédito seja único, o que tornaria ilógico sorteá-lo mais de uma vez no mesmo portfólio, a amostragem com repetição segue sendo a mais adequada, pois sempre haverá devedores bons e ruins na economia. Para os fins desse trabalho, a população de devedores é infinita, mas a amostra não. Manter a repetição preserva a independência das subamostras (EFRON ,1981).

No entanto, o modelo de reamostragem de Carey é, na verdade, um tanto subjetivo em dois aspectos: a quantidade B (de bootstrap) de repetições, isto é, o número B de carteiras simuladas que representam todas as estratégias de diversificação de um portofólio, e o seu tamanho " $n$ ". Procura-se sensibilizar os dois para maior robustez.

A Tabela 16 apresenta diversos Bs para uma carteira de $n=500$ exposições reamostradas.

Tabela 16 - Sensibilizando B para portfólios de $\mathbf{n = 5 0 0}$ exposições

\begin{tabular}{|l|c|c|c|c|c|c|c|c|c|}
\hline & Média & $\mathrm{DP}$ & $\mathrm{As}$ & $\mathrm{Ku}$ & $95,0 \%$ & $97,5 \%$ & $99,0 \%$ & $99,50 \%$ & $99,90 \%$ \\
\hline $\begin{array}{l}\text { Reamostragem } \\
\mathrm{B}=5.000\end{array}$ & $4,55 \%$ & $5,69 \%$ & 6,84 & 63,21 & $10,12 \%$ & $15,83 \%$ & $26,96 \%$ & $51,61 \%$ & $66,67 \%$ \\
\hline $\begin{array}{l}\text { Reamostragem } \\
\mathrm{B}=10.000\end{array}$ & $4,43 \%$ & $5,1 \%$ & 6,96 & 69,80 & $9,85 \%$ & $15,15 \%$ & $24,07 \%$ & $43,02 \%$ & $66,08 \%$ \\
\hline $\begin{array}{l}\text { Reamostragem } \\
\mathrm{B}=50.000\end{array}$ & $4,40 \%$ & $5,08 \%$ & 7,17 & 73,99 & $9,65 \%$ & $14,60 \%$ & $23,63 \%$ & $42,80 \%$ & $65,88 \%$ \\
\hline
\end{tabular}

$\mathrm{O}$ aumento de $\mathrm{B}$ acima de 50.000 repetições tem impactos marginais em todos os quantis. Schechtman et al (2004), Majnoni e Powell (2005) e Carey (2002) adotam 20.000. De fato, 
para portfólios maiores (com mais do que 5.000 exposições), a diferença entre assumir $\mathrm{B}=$ 20.000 ou 50.000 é praticamente nula.

Os quantis da Tabela $16^{23}$ representam a inadimplência nos portfólios reamostrados. Para uma carteira com $n=500$ empréstimos, reamostrada $B=50.000$ vezes, em média em $5 \%$ dos casos a inadimplência da carteira excederia 9,65\%.

Na sequência, sensibiliza-se o tamanho da carteira. Esse ponto é o mais delicado nesse procedimento não paramétrico, porque idealmente almeja-se um referencial CVaR para capital econômico baseado nas perdas de crédito para uma carteira do exato tamanho da carteira de interesse. Mas, ocorre que sempre se está sujeito a Lei dos Grandes Números quando os portfólios aumentam de tamanho dado que a população da amostra de trabalho é finita.

As Figuras 4 a 7 abaixo apresentam a f.d.p da inadimplência para o portfólio de 5 mil exposições de crédito, em média R \$ 200MM; o de 10 mil, R\$ 408MM; o de 50 mil, R\$ 1.052 MM; o de 300 mil, R\$ 12.000 MM e o de 650 mil, cerca de R\$15.000 MM. A Tabela 17 traz os quantis de interesse.

\footnotetext{
${ }^{23}$ A amostra não foi reponderada nesse exemplo.
} 


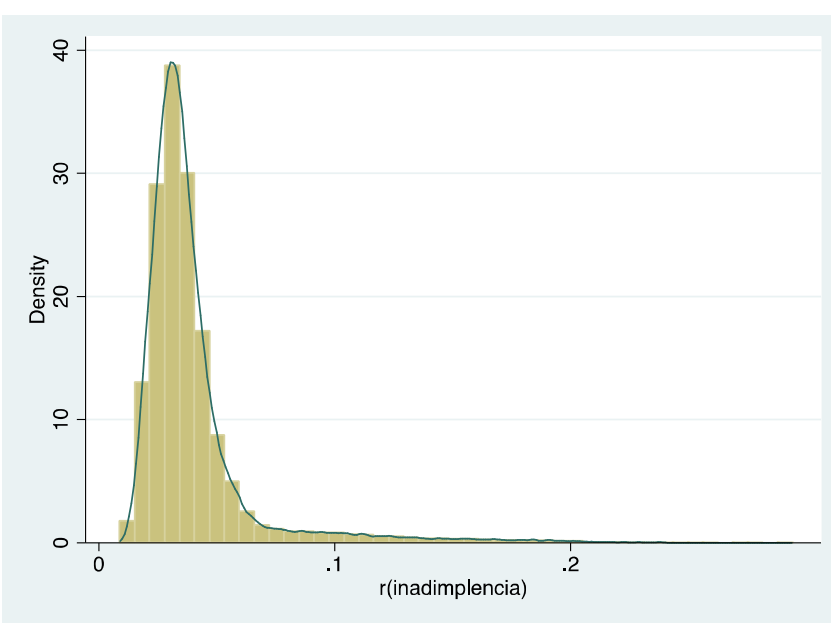

Figura 4 - f.d.p. da inadimplência para portfólios de $n=5000$ empréstimos $(B=50000) *$

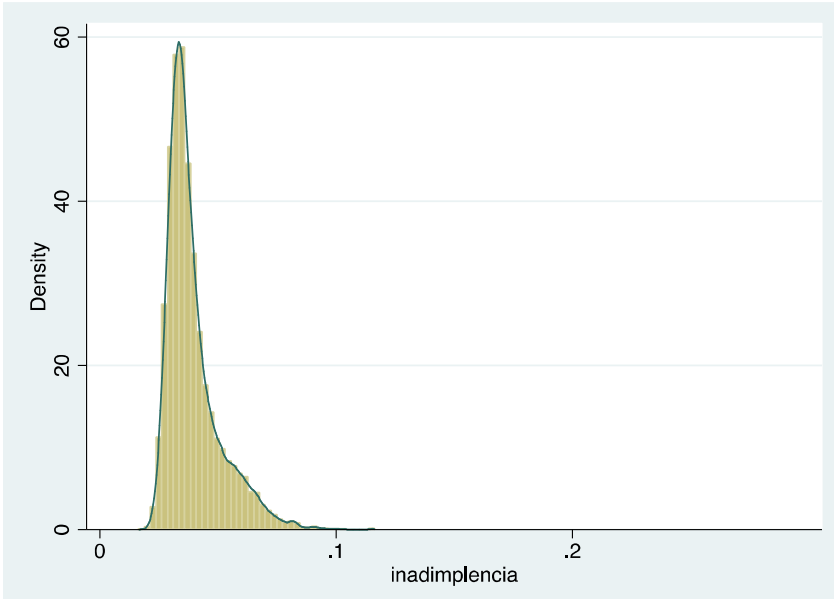

Figura 6 - f.d.p. da inadimplência para portfólios de $n=50.000$ empréstimos $(B=50000) *$

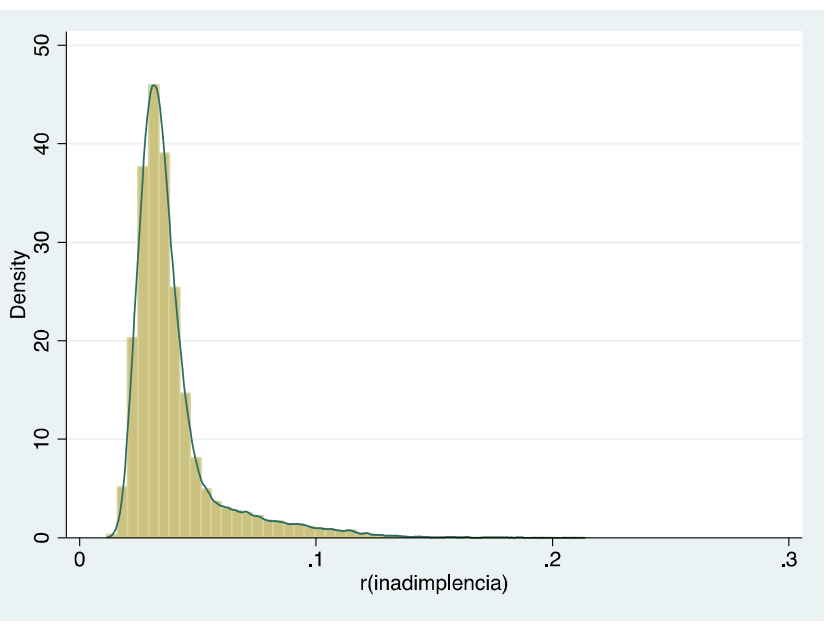

Figura 5 - f.d.p. da inadimplência para portfólios de $n=10000$ empréstimos $(B=50000) *$

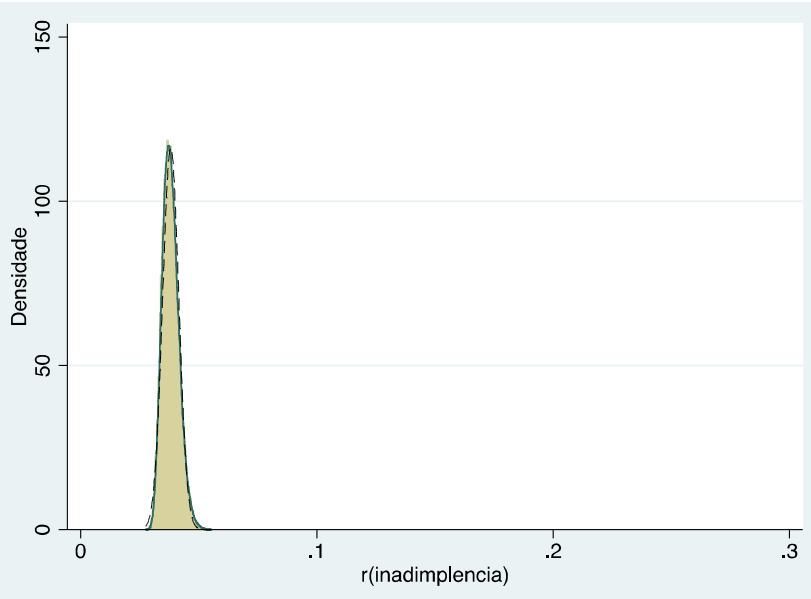

Figura 7 - f.d.p. da inadimplência $n=300.000$ empréstimos $(B=50000) *$

*o eixo das ordenadas foi ajustado para maior comparabilidade entre todas. A Figura 7 está bem próxima de um distribuiçãoo normal. Note-se na Tabela 17 a assimetria (As) próxima de zero e a curtose (Ku) próxima de 3.

Tabela 17 - Quantis para reamostragem da inadimplência

\begin{tabular}{|l|c|c|c|c|c|c|c|c|c|}
\hline & Média & DP & As & Ku & $\mathbf{9 5 , 0 \%}$ & $\mathbf{9 7 , 5 \%}$ & $\mathbf{9 9 , 0 \%}$ & $\mathbf{9 9 , 5 0 \%}$ & $\mathbf{9 9 , 9 0 \%}$ \\
\hline Carteira $\mathrm{n}=500$ & $4,40 \%$ & $5,08 \%$ & 7,17 & 73,99 & $9,65 \%$ & $14,60 \%$ & $23,63 \%$ & $42,80 \%$ & $65,88 \%$ \\
\hline Carteira $\mathrm{n}=5000$ & $3,98 \%$ & $2,55 \%$ & 3,56 & 19,09 & $8,72 \%$ & $12,21 \%$ & $16,34 \%$ & $18,49 \%$ & $21,61 \%$ \\
\hline Carteira $\mathrm{n}=10000$ & $3,90 \%$ & $1,86 \%$ & 2,60 & 11,85 & $7,98 \%$ & $9,68 \%$ & $11,43 \%$ & $12,44 \%$ & $15,65 \%$ \\
\hline Carteira $\mathrm{n}=50000$ & $3,94 \%$ & $1,14 \%$ & 1,9 & 6,15 & $6,35 \%$ & $6,93 \%$ & $7,77 \%$ & $8,27 \%$ & $9,54 \%$ \\
\hline Carteira $\mathrm{n}=300000$ & $3,91 \%$ & $0,34 \%$ & 0,47 & 3,27 & $4,42 \%$ & $4,56 \%$ & $4,73 \%$ & $4,85 \%$ & $5,09 \%$ \\
\hline Carteira $\mathrm{n}=650000$ & $3,92 \%$ & $0,31 \%$ & 0,46 & 3,29 & $4,47 \%$ & $4,6 \%$ & $4,75 \%$ & $4,86 \%$ & $5,10 \%$ \\
\hline
\end{tabular}


Deve-se analisar que a reamostragem da carteira praticamente completa se assemelha a uma normal. É natural observar que a inadimplência diminua em todos os quantis devido a ganhos de diversificação obtidos por carteiras maiores (CAREY, 1998). No entanto, é necessário saber se isso é de fato o que se está medindo, porque um outro problema se descortina no pano de fundo.

Uma interpretação comum das Figuras 6 e, especialmente da Figura 7, é que, condicionados ao fatores de risco latentes no ciclo econômico, as perdas de crédito são normais, independentes e identicamente distribuidas (n.i.i.d.) como desejável na aplicação dos modelos paramétricos de CVaR. Poder-se-ia ainda assumir que o resultado dos portfólios grandes, como os maiores que $\mathrm{R} \$ 12$ bilhões das Figuras 6 e 7, está condicionado ao risco sistemático (normalmente distribuido) e que o idiossincrático é diversificável. Para os bancos pequenos, a mesma condição não é observada, porque eles não possuem a granularidade necessária, ou a propriedade ARSF de Vasicek (Cf. GORDY, 2000), para que suas perdas reflitam apenas o fator de risco sistemático latente. Ou seja, a inadimplência nas carteiras menores (Figuras 5 a 6) é dominada pelo risco idiossincrático.

Embora ideal, parece pouco factível que o risco sistemático possa ser totalmente diversificado em uma carteira maior que $\mathrm{R} \$ 12$ bilhões, mas não em carteiras menores. A limitação que deseja-se salientar é que a amostra de estudo é o universo disponível para as simulações de Monte Carlo. Ainda que as carteiras sejam reamostradas com repetição, o desvio-padrão deste exercício será mínimo quando toda a amostra é reamostrada, porque esse banco é o universo e contém todos os empréstimos da economia (CAREY, 2001). Ele tornou-se "perfeitamente diversificado" por força da lei dos grandes números e porque a amostra de trabalho é finita, não porque qualquer portfólio de $\mathrm{R} \$ 12$ bilhões ou maior o seja.

A aleatoriedade do modelo de Carey (2002) decorre de dois fatores: de B ser grande o bastante para que todas as estratégias felizes e infelizes sejam computadas e do número $\mathrm{n}$ de empréstimos da carteira ser pequeno em relação ao universo $\mathrm{N}$ de todos os devedores da economia. Note-se que para B muito grande, o desvio-padrão já não se reduz mais (Tabela 13). O desvio remanescente representa o segundo fator e tem o sentido econômico de que existe um componente de aleatoriedade capaz de gerar realizações de inadimplência extremas em portfólios, decorrentes de estratégias infelizes. Esse último efeito não é igual para portfólios grandes e pequenos (Tabela 14). A inadimplência média deve convegir para a 
populacional (ou N) apenas por força de B se a correlação entre os defaults não for expressiva ou (igualmente) se todas as variáveis latentes forem conjuntamente normalmente distribuídas.

Contudo, como o universo de devedores é finito, a oportunidade de resultados infelizes é cada vez mais limitada à medida que $\mathrm{n}$ se aproxima de $\mathrm{N}$ populacional. Além disso, o efeito das variáveis latentes ou da correlação entre os defaults não é desprezível e n torna-se relevante (GORDY, 2003). Como mencionado, Gordy (2003) demonstra que apenas para n muito grande, o risco idiossincrático é diversificável condicionado ao risco sistemático Y e este pode ser expresso como um único fator.

No modelo de Carey (2002), a propriedade de Gordy (2003) pode ser observada, como desejado, mas apenas quando $\mathrm{N}$ é muito maior do que $\mathrm{n}$. Do contrário, o efeito observado não é o ganho de diversificação, ou granularidade de Gordy (2003), e sim apenas a Lei dos Grandes Números em ação e possivelmente desprovida de sentido econômico.

Existe certa subjetividade em se saber o modelo de Carey mede acuradamente o ganho de diversificação do banco grande. Se N (populacional ou da amostra completa) tendesse ao infinito, então os aumentos de n mediriam exclusivamente os ganhos de diversificação, já que a inadimplência em todos os quantis da curva seria condicionada apenas a n e não a N.

Essa explicação não está clara em Carey (1998; 2002). No entanto, o modelo é irremediavelmente dependente de se encontrar um $\mathrm{n}$ de trabalho que seja pequeno o bastante em relação a $\mathrm{N}$ (disponível) de tal modo que o aumento de $\mathrm{n}$ não represente mais do que o ganho de diversificação. Carey (2001) não omite essa subjetividade e sugere que N seja no mínimo 5 ou 6 vezes maior do que n ou "a distribuição empírica deve colapsar para a média".

Carey (2001) relata que, em certos casos, devido à restrição de $\mathrm{N}$, adota o procedimento de replicar devedores. Para o autor, a replicação preserva a razão populacional e não viesa os resultados. Ela tem o objetivo de corrigir sua insuficiência amostral.

Na sequência, impõem-se restrições ao exercício de Simulação para que cada portfólio represente o SFN em todas as simulações. Essas simulações serão feitas sem repetição por facilidade computacional, uma vez que programar esse procedimento com repetição levaria a criação de milhares de matrizes intermediárias, o que aumentaria o tempo de simulação. $\mathrm{O}$ código completo para esse exercício foi disponibilizado no Apêndice B. Para amostras do 
tamanho das desse estudo, os resultados para simulações com e sem repetição são negligenciáveis (SCHECHTMAN, 2006a).

O código utilizado neste trabalho permite que cada simulação seja usada para o cálculo de todas as variáveis de interesse desse estudo. Ainda que o quantil da inadimplência possa eventualmente parecer não representativo como proxy do capital econômico dado o alto grau de subjetividade do modelo de Carey, cada simulação realizada é usada para recriar um portfólio que representa uma carteira do sistema bancário brasileiro.

A amostra é aleatória. Todos as variáveis dessa tese são calculadas sobre cada um desses portfólios e são bastante precisos, já que o código desenvolvido calcula todos os estimadores (por exemplo o CME no IRB) em cada portfólio para todos os devedores individualmente. Esse indicador é então consolidado para cada um dos B portfólios desprezando as matrizes intermediárias. Pode-se demonstrar que um estimador qualquer desse trabalho, como a esperança do CME no IRB, E[KIRB], para uma população de bancos de tamanho n é tal que:

$\mathrm{E}\left[\mathrm{KIRB}_{\mathrm{n}}\right]=\mathrm{E}\left[\mathrm{KIRB}_{\mathrm{n}} *\right]=\mathrm{E}\left[\mathrm{KIRB}_{\mathrm{n} 1} *, \mathrm{KIRB}_{\mathrm{n} 2} *, \ldots . . \mathrm{KIRB}_{\mathrm{nB}}.\right]$

Em que

* representa que KIRB foi reamostrado a partir da população com amostras de tamanho n. ${ }^{24}$

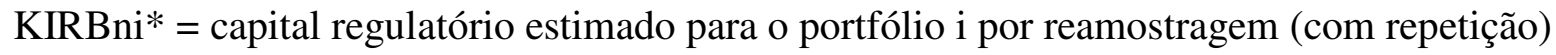
$\mathrm{E}[\mathrm{KIRBn} *]=$ esperança ou estimador da média de KIRB*

$\mathrm{E}[\mathrm{KIRBn}]=$ média populacional de KIRB para um portfólio de tamanho $\mathrm{n}$

Efron (1981) demonstra que uma média como E[KIRB*] converge para E[KIRB] após um número $b=\mathrm{B}$ grande de repetições e que esse procedimento é numericamente equivalente a jackknife delete-m. O autor demonstra que Jackknife delete-m é computacionalmente mais eficiente, já que o bootstrap estima toda a f.d.p para obter os estimadores de média e de variância. Todavia, nesse estudo explora-se também a f.d.p. em si. Além disso, o procedimento aqui desenvolvido estima diversos indicadores ao mesmo tempo para que a performance das diferentes abordagens seja perfeitamente comparável, tornando, no caso desse trabalho, boostrap preferível. 
Assim, nas seções seguintes, a simulação pode ser aproveitada para se tecer uma série de comentários que só são possíveis quando os estimadores são calculados em conjunto para cada portfólio. O intervalo de confiança para os estimadores será o de bootstrap por ser mais robusto.

Um único tipo de simulação é realizado: bootstraping (com repetição) em que as exposições ajustadas sempre pelas LGDs apropriadas são atribuídas sem obedecer nenhuma função de diversificação e sem restrição de saldo. Uma tentativa por simulação de Monte Carlo impondo restrições mais severas para replicar o SFN respeitando faixas de tamanho, modalidades etc foi implementada, mas foi computacionalmente muito pesada para ser reproduzida em todos os exercícios dessa tese (Ver Apêndice C).

No caso de Carey $(1998 ; 2002)$, a intervenção é necessária porque o autor não está utilizando o portfólio efetivo dos bancos e sim alocando debêntures de modo a replicar uma estratégia que contenha um certo percentual fixo de AAAs, BBBs etc. O procedimento é usado porque portfólios com operações bancárias estavam indisponíveis. Além disso, de certa forma, o primeiro objetivo deste trabalho é o de estimar uma distribuição empírica e não paramétrica para perdas do Sistema Bancário e não para um banco que persegue estratégias particulares.

Para o autor, se todas as estratégias de diversificação pudessem ser replicadas por um período longo, a f.d.p. empírica convergiria para a populacional não condicional. Na prática, as simulações são muito mais restritas, porque nem períodos suficientemente longos, nem todas as estratégias podem ser simuladas.

É importante frisar que não é possível impor uma estratégia de diversificação baseada em faixas de risco como em Carey (1998). Como as categorias da Resolução CMN n. 2.682/99 (CMN, 1999) usadas aqui são (ao menos parcialmente) backward-looking, uma função objetivo que visasse compor, por exemplo, um portfólio com um máximo de x As e y Bs estaria, na realidade, direcionando a inadimplência do exercício, o que o tornaria inútil. Além disso, por restrição dos dados, a classificação da Resolução CMN n. 2.682/99 (CMN, 1999) disponível nesse estudo é a do momento t da extração e não a inicial.

O modelo de Carey, conforme aplicado nesse estudo, equivale a um gestor que aloca as exposições disponíveis no Sistema Bancário à sua carteira aleatoriamente. De certo modo, essas operações já foram escolhidas por eles próprios ou seus concorrentes em algum 
momento e possíveis diferenças entre a forma como eles individualmente o fazem são consideradas conjuntamente desprezíves.

O resultado ex-post da inadimplência da carteira é sempre aleatório ( $C f$. CAREY, 1998) e esse é o momento $\mathrm{T}$ de estudo deste trabalho, em que independentemente do $\mathrm{t}$ em que foram colhidas, todas as exposições estão inadimplentes ou não em T, quando o portfólio é formado.

No entanto, o resultado ex-post no momento T é desconhecido. Essa é a principal premissa de Carey (2002) de que a inadimplência observada nos portfólios reamostrados é a realização de uma variável aleatória sob a qual os gestores não têm nenhum controle ex-ante. Ao usar exposições de momentos t distintos, assim como em Carey (1998; 2001; 2002), cria-se um cenário em que as condições econômicas de 2004 a 2010 são combinadas irrealmente. O objetivo, porém, é justamente o de aproximar a distribuição empírica da não condicionada (DUPOY, 2007; CAREY, 1998) o máximo possível e, portanto, essa combinação de ts é desejável (CAREY, 2001).

Neste trabalho, cada banco é, de fato, passivo e trata apenas de diversificar o portfólio com as operações disponíveis, na média, refletindo o SFN. Alternativamente, esse banco representa o Sistema Bancário em si e os pontos da curva, realizações possíveis de perdas de crédito (CAREY, 2002).

São propostas as estimações por modelo de Carey para: perdas totais de bancos grandes, pequenos e as observadas durante a crise de 2008/2009. Novamente, a perda total nesse exercício é a inadimplência observada no portfólio reamostrado ajustada pela LGD. A relação N/n será a sugerida por Carey (2001) de ao menos 5x.

\subsubsection{Creditrisk+}

Como salientado na revisão bibliográfica e acima, a abordagem CVaR não paramétrica impõe um grau de subjetividade elevado. Para Carey (2002), o melhor uso da técnica é para estimação de requerimentos absolutos de capital. Alternativamente, calibra-se um modelo de CVaR paramétrico com os mesmos dados para comparação dos resultados. 
$\mathrm{O}$ modelo que melhor se adequava à natureza dos dados disponíveis exigindo menos pressupostos sobre o comportamento dos fatores sistemáticos era Creditrisk+. O método de estimação foi o do CSFB (1997), isto é, o algoritmo recursivo de Panjer.

O modelo foi calibrado com as PDs estimadas por matrizes de migração, as mesmas do segundo objetivo, para preservar o comparabilidade. O modelo está sendo usado de modo peculiar, porque, conceitualmente, não se procura saber o capital econômico de um portfólio, e sim do Sistema Bancário. Nessa aplicação de Creditrisk+, toda a amostra foi usada de modo a representar uma carteira de aproximadamente R\$ 15 bilhões representativa do Sistema Bancário.

Carey (2002) aponta que duas interpretações são possíveis para seu modelo. A primeira é que, se cada portfólio representa um banco, o quantil de 99,9\% representa a probabilidade que 1 em cada 1000 bancos desse SFN tenha uma perda de crédito total superior àquela encontrada no quantil empírico. A segunda é que, se cada portfólio representa uma realização dos possíveis estados do SFN, o quantil representa a probabilidade de que o SFN colapse com uma inadimplência superior ao valor encontrado nesse quantil. Esta última interpretação é, na verdade, equivalente à dos modelos paramétricos, porque os fatores sistemáticos conduzem todas as exposições ao estado de default à medida que Y se eleva (CAREY, 2002). Se o risco idiossincrático é plenamente diversificável com respeito a $\mathrm{Y}$, toda a carteira se deteriora à medida que Y (normalmente distribuído em Creditmetrics ou como uma distribuição Gamma em Creditrisk+) se aproxima de valores extremos.

Para o desvio-padrão do default, usa-se o desvio-padrão das FDs observadas nas matrizes de migração de Yanaka e Holland (2010). ${ }^{25}$ Os resultados ficaram um pouco abaixo da estimação mais conservadora de Wilde (2000) ou do CSFB (1997) de que o desvio-padrão médio é da ordem da PD e acima da prática de países desenvolvidos de usar 0,5 desvio-padrão da PD como referência. Todas as exposições são ajustadas pelas LGDs do Edital n. 37 para maior comparabilidade com os resultados do objetivo 2. Foi apresentada apenas uma estimação de Creditrisk+ para o portfólio-base. Na verdade, essa aplicação de Creditrisk+ é uma estimativa exata do capital econômico da amostra completa.

\footnotetext{
${ }^{25} \mathrm{O}$ desvio calculado com base nas matrizes para o consolidado do SFN usados neste trabalho para a PD do SFN não puderam ser usados para estimar o desvio, porque não havia informação suficiente para estimá-lo de modo consistente. Por outro lado, estimadas banco a banco, como em Yanaka e Holland (2010), elas medem precisamente o que se deseja capturar, salvo por certas diferenças nas definições das categorias de risco entre os oito maiores bancos.
} 
Após centenas de especificações alternativas, apresenta-se como setores, as faixa de tamanho da exposição. Além disso, dois cestos foram criados, o primeiro para exposições abaixo de $\mathrm{R} \$ 5.000$ e o segundo para as demais. A razão disso é que o algoritmo usado é particularmente viesado para portfólios grandes e PDs elevadas. Para minimizar ao máximo o problema e tornar as médias e os desvio-padrão analíticos o mais próximo possível dos numéricos, buscase maior grau de homogeneidade entre tamanho de exposição e PDs.

Avesani et al (2006) destacam como o algoritmo de Panjer tende a superestimar VaR e minimizar esse efeito foi uma preocupação constante na calibração do modelo. A solução encontrada parece muito adequada. Ao adotar dois cestos e sete setores mais homogêneos, houve redução substantiva do problema de grandes carteiras destacado pelos autores. O tratamento para PDs elevadas também minimizou muito esse viés que também é mencionado pelos autores e por Schechtman et al. (2004). Ambas as soluções de contorno são frequentemente adotadas no mercado.

$\mathrm{O}$ primeiro cesto, que continha as exposições abaixo de $\mathrm{R} \$ 5$ mil, foi subdivido em dois setores, um entre R \$ 500 e R \$ 1.000 e outro até R \$ 5 mil. O segundo cesto, em 5 "setores": PF abaixo de $\mathrm{R} \$ 50$ mil, PF acima de $\mathrm{R} \$ 50$ mil, PJ abaixo de $\mathrm{R} \$ 100.000, \mathrm{PJ}$ abaixo de $\mathrm{R} \$$ 10 MM e PJ acima deste valor. Assim, como em Schechtman et al (2004), as PDs acima de 15\% são tratadas como determinísticas, pois tendem a viesar os resultados de Creditrisk+. As exposições abaixo de R \$ 500,00 também o são. Assume-se que EL(\%) nesses casos seja a própria PDxLGD e ela não contribui adicionalmente para perda não esperada (Ibidem).

\subsection{Premissas para as Abordagens de Basileia}

Nesta etapa, quer-se averiguar se o K ou o CME (\%) e a Provisão Mínima estimados nos bancos brasileiros no IRB e nas demais abordagens são mais ou menos adequados para fazer frente às perdas de crédito totais no Brasil, estimadas na etapa anterior. Para todas as abordagens estima-se a Perda Esperada (EL), Inesperada (UL) e Total (TL) na amostra total ou parcial. Para Basileia I e SSA, a perda esperada é a própria provisão mínima. Avalia-se ainda a relevância da Resolução CMN n. 2.682/99 (CMN, 1999) e as possíveis consequências de sua eliminação no contexto do IRB. 


\subsubsection{Basileia I}

Estimar os parâmetros de Provisão (PME), CME e CVaR para o risco de crédito sob Basileia I é bastante simples. A provisão é o mínimo exigido pela Resolução CMN n. 2.682/99 (CMN, 1999) para cada exposição no portfólio-base e em todos os portfólios reamostrados. Como na carteira de crédito, o APR era sempre 100\%. Após o efeito da provisão, o requerimento de capital para cada exposição é calculado da seguinte maneira (CME_B1):

CME_B1 $=0,11 *($ carteira ativa - provisão mínima $)$

\subsubsection{A abordagem padronizada simplificada (SSA)}

A abordagem de Basileia II, ora em vigor e implantada em 2008 pela Resolução CMN n. 3.490/07 (CMN, 2007) para os dados disponíveis publicamente, equivale a Basileia I, salvo por um FPR de $75 \%$ quando a exposição é considerada de varejo.

A bibliografia sobre o assunto permite afirmar que existem fatores de ponderação diferenciados quando certos tipo de colateral são utilizados. Na prática, não é possível estimar com precisão esses dados, porque a informação sobre o colateral não está disponível na base de dados. Consequentemente, por desconsiderar o benefício completo do colateral, superestima-se o CME para risco de crédito. Além disso, as exposições off-balance também passam a contribuir para o cálculo do CME a partir de 2008 e aumentam a necessidade de capital. O portfólio simulado não contém essas exposições, o que equivale a dizer que o banco simulado desse estudo não possui ativos off-balance. As estimativas de CME para a vertente de crédito da SSA está discretamente superestimada pela falta de informações precisas sobre colateral, mas subestimada pela falta dos fatores de conversão de crédito (FCC) que incidem sobre o montante off-balance. As vertentes de risco operacional e de mercado obviamente não estão incluídas.

\subsubsection{A abordagem IRB Fundamental}

A calibração do modelo IRB é bastante complexa e pode adquirir contornos distintos em cada país. No Brasil, o Edital Público N. 37 é, até aqui, a referência para o setor bancário. Diversas 
premissas e simplificações tiveram de ser adotadas devido à natureza e limitações dos dados disponíveis neste trabalho (Ver APÊNDICE A).

Os parâmetros mais importantes no modelo do IRB Fundamental são as PDs, as LGDs e o R para as famílias de Varejo, Corporate e Pequenas e médias empresas (SME) por faixa de risco. As Fórmulas específicas do IRB apresentadas na Revisão Bibliográfica são utilizadas. Para cada empréstimo da amostra, estimou-se o CME baseado na PD, LGD e EAD apropriada conforme as definições operacionais explicitadas abaixo.

\subsubsection{1. $\quad$ Probabilidades de Default no Brasil}

A inadimplência é a variável-chave no risco de crédito e é definida como a perda total da exposição decorrente de um atraso superior a 90 dias (Basel Committee in Banking Supervision, 2005; 2006). Como observado na revisão bibliográfica, não existe uma medida não viesada de inadimplência disponível ao usuário externo. Costa e Blum (2008) demonstram que a métrica carteira classificada de $\mathrm{E}$ a $\mathrm{H}$, denominada nesse trabalho de tloss, é superior ex-ante ao atraso de 90 dias - dloss - para estimar a inadimplência. Para Jackson (2001), métricas como tloss são mais coerentes com o conceito de perda econômica, porque medem (nesse caso com dados internos e não de mercado) a depreciação no valor do ativo, embora estes dois estejam de certa forma amarrados no Brasil pela Resolução CMN n. 2.682/99 (CMN, 1999).

A forma mais precisa para se estimar a inadimplência por faixa de risco é por meio de matrizes de migração, acompanhando os mesmos devedores, em cada banco individualmente, por um certo período usualmente de um ano. Após um ano, a percentagem original de exposições AA agora nos níveis E a H representa a Frequência de Default. Em geral, assumese que uma média suficientemente longa de FDs por categoria e família de risco é um bom estimador da inadimplência e pode ser usado como PD.

Yanaka e Holland (2010) realizam essa estimação individualmente para os oito maiores bancos brasileiros utilizando dados populacionais. Até onde se tem notícia, essa é a melhor estimação pública disponível para PDs no Brasil e parte dos dados do SCR. Neste trabalho, usa-se o mesmo critério. Entretanto, ao invés de utilizar as matrizes para os oito maiores 
bancos adotou-se a do SFN como um todo. Assume-se que a média dessas FDs para matrizes anuais coletadas semestralmente converge para a PD do Sistema Bancário brasileiro.

Nesta tese, esta última é a PD usada, em oposição à inadimplência observada, para calibrar a PD da fórmula do IRB. Acredita-se que esse procedimento seja superior a uma calibração com a inadimplência amostral ou populacional como em Antão e Lacerda (2011) e Vasquez et al (2011), embora inferior a Yanaka e Holland (2010), realizado banco a banco. Dada a natureza aleatória das exposições aqui utilizadas em cada data-base, construir uma matriz de migração assim como realizado por estes autores seria impossível. Deve-se ressalvar que as PDs foram estimadas entre 2005 e 2008 e estão sendo alocadas indistintamente desde 2004 a 2010. Idealmente, elas seriam utilizadas a partir de 2009, mas isso restringiria muito a amostra desse trabalho. De certa forma, aqui assume-se que, entre 2004 e 2010 e 2005 e 2008, existe um ciclo econômico comparável. Os dados são os da Tabela 18.

Tabela 18 - PDs estimadas por matrizes de migração para o SFN

\begin{tabular}{|l|c|c|c|c|c|c|}
\hline \multicolumn{1}{|c|}{ Categorias } & AA & A & B & C & D & Total \\
\hline Grupo PF - Aquisição de Bens & $3.03 \%$ & $3.13 \%$ & $7.86 \%$ & $11.87 \%$ & $21.04 \%$ & $9.38 \%$ \\
\hline Grupo PF - Consumo & $3.18 \%$ & $5.64 \%$ & $10.04 \%$ & $17.85 \%$ & $35.30 \%$ & $14.40 \%$ \\
\hline Grupo PF - Financ. Rural & $1.78 \%$ & $2.07 \%$ & $4.39 \%$ & $10.22 \%$ & $22.60 \%$ & $8.21 \%$ \\
\hline Grupo PF - Outros & $0.50 \%$ & $0.69 \%$ & $1.88 \%$ & $8.92 \%$ & $13.47 \%$ & $5.09 \%$ \\
\hline Grupo PJ - Aplic. Ativ. Específicas & $0.17 \%$ & $0.41 \%$ & $1.09 \%$ & $4.37 \%$ & $14.73 \%$ & $4.15 \%$ \\
\hline Grupo PJ - Capital de Giro & $0.64 \%$ & $2.95 \%$ & $5.89 \%$ & $14.89 \%$ & $30.64 \%$ & $11.00 \%$ \\
\hline Grupo PJ - Invest. e Aquis. Bens & $0.25 \%$ & $0.58 \%$ & $2.27 \%$ & $5.40 \%$ & $19.39 \%$ & $5.58 \%$ \\
\hline Grupo PJ - Outros & $0.09 \%$ & $0.45 \%$ & $1.75 \%$ & $2.47 \%$ & $2.65 \%$ & $1.48 \%$ \\
\hline Total & $1.21 \%$ & $1.99 \%$ & $4.40 \%$ & $9.50 \%$ & $19.98 \%$ & $7.41 \%$ \\
\hline
\end{tabular}

Conforme o Basel Committee in Banking Supervision (2005, p. 101), o Comitê da Basileia ainda recomenda que a base de dados para estimar a PD seja longa o suficiente para representar um ciclo econômico completo (mínimo de 5 anos) e que consequentemente seja menos sensível a informação mais recente (cíclica). Nesse estudo são usadas apenas três.

Dois outros pontos que merecem destaque são o critério de arrasto e a carteira usada na estimação. Para fins desse estudo, quando uma determinada parcela de uma operação de crédito entra em default, considera-se que toda a exposição entrou em default (arrasto), medida pela variável dloss. Na medida de inadimplência sugerida por Costa e Blum (2008): tloss a parcela vencida também arrasta todas as parcelas vincendas. 
É preciso salientar que, para default (dloss) ou classificações de E a H (tloss), a PD atribuída é $100 \%$. Esse critério pode parecer conservador se comparado ao mínimo exigido pela Resolução CMN n. 2.682/99 (CMN, 1999) entre E e G, mas reflete o espírito do modelo interno (BCB, 2011b, Art. 63).

\subsubsection{2. $\quad$ LGDs}

Como mencionado, na abordagem avançada, a LGD é estimada por cada banco por modalidade e para cada colateral com base em seu histórico de recuperação de perdas ajustado a valor presente em situação adversa (LGD de downturn). Neste trabalho, para cada simulação, as LGDs da abordagem fundamental - estimadas pelo regulador - são atribuídas a cada exposição dependendo da categoria em que se enquadrem conforme explicitado abaixo. De modo geral, no Brasil, as modalidades de crédito guardam relação com a natureza do colateral existente, levando às proxies ${ }^{26}$ abaixo:

- 45\% (quarenta e cinco por cento) para o Financiamento Imobiliário;

- 50\% (cinquenta por cento) para o Financiamento de Veículos;

- 70\% (setenta por cento) para o tipo Financiamento de Outros Bens;

- 60\% (sessenta por cento) para o tipo "recebíveis financeiros"; isto é, genericamente todas as categorias de Títulos Descontados mais Vendor e Compror, Adiantamento de Contrato de Exportação (ACE) e Adiantamento de Contrato de Câmbio (ACC);

- 70\% Corporate;

- $85 \%$ Outros (não varejo) e SME; ${ }^{27}$

$-90 \%$ para Varejo. ${ }^{28}$

Esses números são baseados nos parâmetros mínimos para a abordagem fundamental disponíveis no Edital Público n.37/11.

\footnotetext{
${ }^{26} \mathrm{Na}$ verdade, as LGDs são aplicadas aos colaterais. No entanto, como esses dados não estavam disponíveis no SCR à época ou não refletiam adequadamente a realidade, optou-se por associar àquelas categorias indissociáveis da garantia, a própria LGD da garantia. Implicitamente, assume-se que existe o grau de sobrecolaterização exigido pelo Edital (Art. 88 §6)

${ }^{27}$ Para SME, a LGD varia entre 70\% e $85 \%$ de acordo com o Faturamento da empresa (dado não disponível). Adotou-se $85 \%$ por conservadorismo.

${ }^{28} \mathrm{O}$ varejo deve ser estimado pelos bancos mesmo na abordagem fundamental. Para todas essas exposições adotou-se $90 \%$ igualmente por conservadorismo. Partindo do referencial mais conservador do Edital (o da abordagem PD/LGD - Art. $52 \S 1$ ).
} 


\subsubsection{3. $\quad$ Fator de Correlação $R$}

Para o fator R, foram adotadas as definições do Edital, iguais as de BCBS (2006a), como na Revisão Bibliográfica. Como premissa, assumiu-se o Faturamento intermediário de R\$ 25,5 $\mathrm{MM}^{29}$ para calibrar a Fórmula $\mathrm{R}$ de pequenas e médias empresas (SME) e assume-se ainda que a categoria de HCVRE era formada pelas modalidades de Financiamento de Carteira Hipotecária e Empreendimentos Imobiliários do SCR.

\subsubsection{Exposição no momento do descumprimento (EAD)}

Embora no modelo interno do banco, EAD seja uma variável estocástica, cujo valor máximo é o do empréstimo no momento da concessão. Para fins desse estudo, o saldo contábil a valor presente do contrato de dívida do devedor no momento de seu envio para o SCR representa a exposição no momento do default. Essa premissa é adequada, já que o resultado de cada simulação é a realização de uma variável aleatória que representa a inadimplência do portfólio no momento $\mathrm{T}$ em que todos os defaults aconteceram.

\subsubsection{Provisão Mínima Exigida (PME)}

No Brasil, existe uma PME devida pelos critérios mínimos da Resolução CMN n. 2682/99. Essa provisão ainda que deduzida do PR é um colchão de proteção para a absorção de perdas de crédito. Obviamente, o critério de atraso é apenas o mínimo exigido e espera-se que os bancos utilizem as faixas propostas no normativo de maneira mais conservadora refletindo seus modelos internos.

Os bancos grandes públicos e os estrangeiros tendem a usar a provisão próxima do mínimo regulatório e os demais, provisões maiores (YANAKA, 2009). De certo modo, a opção aparentemente apresentada no Edital N.37 valida essa discricionariedade da gestão na constituição da provisão. Se EL é superior à provisão, para qualquer empréstimo, o banco pode eleger a provisão em qualquer ponto entre o mínimo e EL. No entanto, se a provisão mínima para aquele crédito circunscrito a um certo nível de risco for superior a EL, a provisão terá de ser a exigida pela Resolução CMN n. 2.682/99 (CMN, 1999) e jamais menor.

\footnotetext{
${ }^{29}$ Variações nessa premissa têm impacto desprezível.
} 
A adoção dos modelos internos deve gerar maiores ELs e Provisões para carteiras mais arriscadas, o que tenderia a reduzir o resultado do banco. Eventuais diferenças entre a Provisão constituída e EL devem ser compensadas com capital regulatório. Por outro lado, se as carteiras forem de baixo risco, espera-se o fenômeno contrário. Considerando inexistente o risco moral e conflitos de interesse por parte da gestão; do ponto de vista exclusivamente da estabilidade do SFN, os dois casos se equivalem. As perdas totais são sempre supridas por capital ou provisão que são de qualidade equivalente (PR1). Contudo, a lucro contábil dos bancos é fortemente afetado pela adoção ou não de uma possível flexibilização da Resolução CMN n. 2.682/99 (CMN, 1999).

\subsubsection{Composição dos portfólios de Varejo, SME e Atacado.}

A atribuição de uma grande família de Basileia II a cada exposição de crédito é imprescindível, já que calibrações diferentes da Fórmula do IRB precisam ser utilizadas conforme apresentado na Revisão Bibliográfica. Embora a correlação R seja uma função decrescente da $\mathrm{PD}$, existem modalidades em que $\mathrm{R}$ é fixo, e.g. $\mathrm{R}=15 \%$ no crédito imobiliário. Além disso, R é mais elevado para SME e Atacado e a família de atacado tem um fator de maturidade M. Como mencionado acima, as LGDs variam também em função da alocação do empréstimo nessas famílias.

O Edital N. 37 trata da definição dessas famílias, mas ele permite bastante flexibilidade ao banco na definição de cada uma delas, em especial na de varejo. Como as informações cadastrais sobre os devedores necessárias para sua alocação precisa nessas famílias não está disponível, foi adotado o seguinte critério para classificação das exposições da amostra nas categorias do IRB:

Varejo:

- Todas as exposições PF nas modalidade de imobiliário (Edital BCB n.37 Art. $5^{\mathrm{O}}$ IIIa).

- Todas as modalidades com carteira ativa inferior a $\mathrm{R} \$ 400.000,00$ ( $C f$. Circular BCB n. 3360). O critério genérico do Edital N.37 é de faturamento inferior a R\$ 2,4 MM. (Edital N.37 Art. $5^{\circ}$ IIIa). Optou-se pela definição da 
Circular, porque este dado não está disponível e também para preservar a comparação entre os requerimentos de capital da SSA com os do IRB.

SME:

- Todas as exposições PJ com carteira ativa inferior a $\mathrm{R} \$ 4.000 .000,00$ não classificadas no Varejo. ${ }^{30} \mathrm{O}$ Edital N. 37 estabelece que o ponto de corte entre Varejo e SME é de R\$ 3 MM. Entre SME e atacado, de R\$ 48MM .

- Para o cálculo do R nessa família (que é função do faturamento), adotou-se o ponto do meio $S=25,5$ entre os faturamentos de $\mathrm{R} \$ 3$ e $\mathrm{R} \$ 48 \mathrm{MM}$.

Atacado:

- Todas as exposições não contempladas nas categorias anteriores, isto é, PF e PJ com carteira ativa superior a R \$ 4MM.

- Para a Fórmula do IRB assumiu-se o ponto do meio para $\mathrm{M}(\mathrm{M}=2,5$ anos $)$.

\subsubsection{Critério de Stress1 e Stress2}

O Basel Committee on Banking Supervision (2005, p. 220) recomenda que testes de estresse sejam utilizados para estimar o risco de mercado (Basel Committee in Banking Supervision, 2005, p. 165), o risco de contraparte e para estimar a adequação de capital. Entretanto, a metodologia e os pressupostos para os cenários são deixados inteiramente a critério dos bancos.

Um procedimento simples de stress de crédito, stress ad hoc, é realizado semestralmente no Relatório de Estabilidade Financeira do Banco Central do Brasil. ${ }^{31} \mathrm{O}$ procedimento avalia os impactos sobre a provisão e consequentemente sobre o Patrimônio de Referência (PR) de um downgrade de duas faixas de risco em todas as exposições de crédito de cada banco do SFN individualmente (BCB, 2011c).

De modo similar, neste trabalho foram criadas duas variáveis "stress1" e "stress2" que representam o downgrade de uma e duas faixas de risco respectivamente. Para cada portfólio simulado e para o portfólio-base, há variáveis que recalculam a provisão, EL, UL em todos os modelos sob stress 1 e $2 .^{32}$

\footnotetext{
${ }^{30} \mathrm{O}$ ponto de corte para o faturamento da SME em $\mathrm{R} \$ 4 \mathrm{MM}$ da carteira ativa é subjetivo, mas conservador baseado em sugestões de colegas da Supervisão Bancária. O impacto de alterá-lo foi simulado e é marginal.

${ }^{31}$ Disponível em: <www.bcb.gov.br/>

${ }^{32}$ Note-se que o código contém EL1, EL2, MProv1, MProv2 etc. (Apêndice A)
} 
O impacto de stress 1 e 2 nesse trabalho é maior do que no Relatório de Estabilidade, porque quando o downgrade dispara o default com uma classificação abaixo de E, a PD passa a ser de $100 \%$ com efeitos bem mais expressivos sobre a perda total. O Relatório está mais interessado no impacto da provisão sobre o PR quando stress2 acontece.

Finalmente, esta etapa permite convenientemente avaliar duas variantes possíveis do IRB. Uma a da ausência da Resolução CMN n. 2.682/99 (CMN, 1999), em que todas as provisões são calculadas como ELs do modelo interno e lançadas contabilmente, conforme idealizado pelo BCBS (2006a). A outra, mais viável no momento, como se depreende do Edital N.37, em que as provisões seguem sempre o padrão mínimo regulatório.

\subsection{A CRBA}

Nesta seção, apresenta-se detalhadamente o modelo CRBA desenvolvido para essa tese, sua lógica e seus fatores de ponderação. Novamente, para todos os portfólios simulados e o portfólio-base, cria-se uma estimativa de CME para todas as variantes dessa abordagem e que é uma alternativa à abordagem padroniza clássica (SA). Aqui são apresentadas as premissas dessa abordagem que é voltada para bancos pequenos e médios de modo a melhor refletir seu capital econômico no espírito de Basileia II. ${ }^{33}$

\subsubsection{Lógica}

A justificativa prática dessa tese apresentou diversos problemas que emergiram durante a crise pelo uso de ratings externos para a determinação do capital regulatório e a forma como Basileia II.5 e III lidam com o problema. Uma cuidadosa revisão do aparato regulatório e dos mecanismos de supervisão foi conduzida tanto na Europa, quanto nos EUA no sentido de minimizar possíveis conflitos de interesse envolvidos no uso da informação das ACRs. No entanto, além das mudanças de Basileia II.5, pouco foi feito para minimizar o problema da dependência regulatória nessas opiniões, sobretudo na abordagem padronizada de Basileia II (SA).

\footnotetext{
${ }^{33}$ Note-se que os códigos de simulação apresentados no Apêndice estimam todos os modelos ao mesmo tempo. Para maior clareza, procura-se separar esses modelos tanto aqui, quanto na etapa de análise de resultados.
} 
A proposta desse estudo é baseada na aplicação de uma classificação de risco padronizada para bancos pequenos e médios. $\mathrm{Na}$ abordagem padronizada dos ratings centralizados (CRBA), a classificação de risco viria do banco, mas seu desempenho seria controlado diretamente pelo organismo supervisor, que limitaria as FDs por faixas de risco padronizadas e fixaria uma Frequência de default (FD) para tracking error dos bancos.

No Brasil, o uso das informações geradas pelas ACRs tem pouca penetração no sistema bancário (Ver Capítulo 3.2), a proposta aqui desenvolvida sensibiliza o CME a risco de crédito no espírito de Basileia II e tende a corrigir incentivos e reduzir oportunidades para arbitragem regulatória, em especial o subprovisionamento e o incentivo à formação de carteiras de maior risco.

O modelo dos ratings centralizados (CRB) sugerido por Majnoni e Powell (2005) como alternativa ao IRB tinha o benefício de minimizar dois problemas presentes nos modelos internos. O primeiro é a falta de comparabilidade entre eles, que é minimizado na CRB na medida em que as FDs devem se conformar às bandas superior e inferior impostas pelo regulador para cada faixa de risco. O segundo é o da dificuldade de se fiscalizar a adequação do CME ao risco assumido por esses bancos (e.g. HALDANE, 2011; BENINK et al, 2009) minimizado quando todos os dados são consolidados em Centrais de Risco.

A proposta deste estudo é inspirada na CRB, mas diferente na operacionalização. O modelo sugerido aqui não utiliza a Fórmula do IRB e não permite tanta flexibilidade na alocação do CME. A ideia é reformular a abordagem padronizada para bancos pequenos e médios e sensibilizar o seu CME a risco de crédito (Pilar 1) com a contrapartida de maior transparência e controle do Supervisor sobre o modelo interno desses bancos (Pilares 2 e 3 ).

Adicionalmente, a exigência de monotocidade do modelo interno dos bancos pequenos e médios e tracking error com acompanhamento mensal da supervisão indireta poderia ser feito por meio de matrizes de migração, como na $\mathrm{CRB}$, e como realizado por diversos bancos centrais (MILLER, 2003).

\subsubsection{O Modelo proposto}

O Quadro 16, construído a partir de uma comparação entre o percentual de provisionamento mínimo da Resolução CMN n. 2.682/99 (Tabela 19) e das três maiores ACRs (Quadro 17), 
permite usar as categorias do regulador para sensibilizar também os Fatores de Ponderação de Risco (FPRs) e consequentemente o CME da carteira de crédito.

Quadro 16 - FPRs para o Modelo Proposto

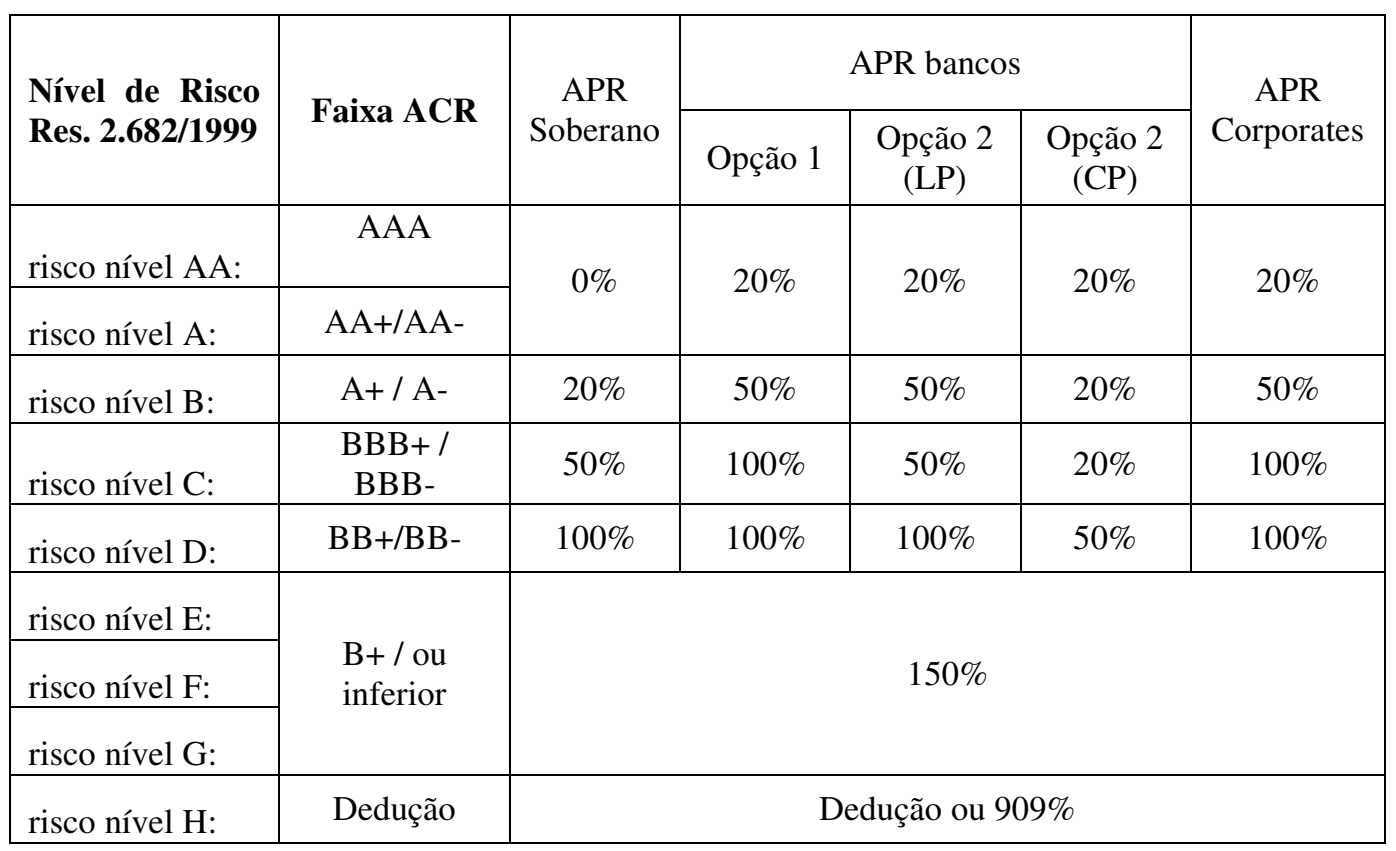

Suponha-se uma operação de crédito de atacado de R 1 milhão sem nenhum tipo de garantia. $\mathrm{Na}$ abordagem atual (SSA), o CME para essa exposição seria R \$ 107,8 mil (PD de 2\%, APR 100\% e índice de Basileia de 11\%). Na abordagem CRBA, esse valor seria diretamente ligado à faixa de risco da operação. Assim, se a mesma operação de R 1 milhão sem garantia fosse classificada como A, o CME seria de R \$21,56 mil (APR de 20\% - coluna da direita - Quadro 15). Se fosse uma operação $C, R \$ 106,7$ mil da operação não classificada. ${ }^{34}$

Tabela 19 - Critérios mínimos de Provisionamento

\begin{tabular}{|c|c|c|}
\hline Faixa de atraso & Nível de Risco & $\begin{array}{c}\text { Provisão Mínima } \\
\text { Requerida }\end{array}$ \\
\hline & risco nível AA: & $0 \%$ \\
\hline & risco nível A: & $0,5 \%$ \\
\hline-15 e 30 dias ............ & risco nível B: & $1 \%$ \\
\hline-31 e 60 dias.............: & risco nível C: & $3 \%$ \\
\hline-61 e 90 dias ............. & risco nível D: & $10 \%$ \\
\hline-91 e 120 dias ...........: & risco nível E: & $30 \%$ \\
\hline-121 e 150 dias ..........: & risco nível F: & $50 \%$ \\
\hline-151 e 180 dias ...........: & risco nível G: & $70 \%$ \\
\hline- superior a 181 dias ....: & risco nível $\mathrm{H}:$ & $100 \%$ \\
\hline
\end{tabular}

FONTE: CMN, 1999.

\footnotetext{
${ }^{34}$ A Provisão Mínima subiu de $2 \%$ para $3 \%$ no exemplo para obedecer o mínimo exigido pela Resolução CMN n. 2682/99 (CMN, 1999)
} 
Quadro 17 - Comparação de FDs nas 3 principais agências de Rating (Corporate) - 10 anos de inadimplência

\begin{tabular}{|l|r|l|r|l|r|}
\hline \multicolumn{2}{|c|}{ Moody's } & \multicolumn{2}{c|}{ S\&P } & \multicolumn{2}{c|}{ Fitch } \\
\hline Aaa & $0,19 \%$ & AAA AA & $0,82 \%$ & AAA & $0,00 \%$ \\
\hline Aa1 & $0,16 \%$ & AA+ A & $0,33 \%$ & AA+ & $0,00 \%$ \\
\hline Aa2 & $0,47 \%$ & AA & $0,66 \%$ & AA & $0,20 \%$ \\
\hline Aa3 & $0,47 \%$ & AA- B & $0,98 \%$ & AA- & $0,16 \%$ \\
\hline A1 & $1,47 \%$ & A+ & $1,55 \%$ & A+ & $0,88 \%$ \\
\hline A2 & $2,62 \%$ & A B1 & $1,98 \%$ & A & $2,04 \%$ \\
\hline A3 & $2,15 \%$ & A- C & $2,37 \%$ & A- & $2,93 \%$ \\
\hline Baa1 & $2,46 \%$ & BBB+ & $3,75 \%$ & BBB+ & $3,43 \%$ \\
\hline Baa2 & $5,04 \%$ & BBB C1 & $4,76 \%$ & BBB & $5,91 \%$ \\
\hline Baa3 & $7,54 \%$ & BBB- D & $8,96 \%$ & BBB- & $8,56 \%$ \\
\hline Ba1 & $13,79 \%$ & BB+ & $11,10 \%$ & BB+ & $12,30 \%$ \\
\hline Ba2 & $15,01 \%$ & BB & $16,43 \%$ & BB & $18,15 \%$ \\
\hline Ba3 & $31,87 \%$ & BB- & $22,03 \%$ & BB- & $13,18 \%$ \\
\hline B1 & $39,93 \%$ & B+ & $27,93 \%$ & B+ & $4,95 \%$ \\
\hline B2 & $42,71 \%$ & B & $32,26 \%$ & B & $22,12 \%$ \\
\hline B3 & $56,49 \%$ & B- & $37,45 \%$ & B- & $16,03 \%$ \\
\hline Caa a C & $77,84 \%$ & CCC a C & $53,41 \%$ & CCC+ & $48,78 \%$ \\
\hline Invst Grade & $2,37 \%$ & Invst Grade & $2,80 \%$ & Invst Grade & $2,34 \%$ \\
\hline Especulativo & $36,47 \%$ & Especulativo & $25,96 \%$ & Especulativo & $15,79 \%$ \\
\hline Todos & $11,46 \%$ & Todos & $10,45 \%$ & Todos & $4,14 \%$ \\
\hline
\end{tabular}

FONTE: ROBB (2010). Notas de aula. Columbia University, 12 de setembro de 2010.

A Tabela 20 propõe duas calibrações para a abordagem CRBA: uma típica, a mesma do Quadro 16, inspirada nos faixas das ACRs (Quadro 17) e no mínimo exigido pelo regulador (Tabela 19) e a outra mais conservadora.

Tabela 20 - Fatores FPR da CRBA e CRBAc

\begin{tabular}{|c|c|c|}
\hline Classificações & Fatores CRBA & Fatores CRBAc \\
\hline AA & $20 \%$ & $50 \%$ \\
\hline A & $50 \%$ & $75 \%$ \\
\hline B & $100 \%$ & $100 \%$ \\
\hline C & $100 \%$ & $150 \%$ \\
\hline D & $150 \%$ & $300 \%$ \\
\hline E & $150 \%$ & $300 \%$ \\
\hline F & $150 \%$ & $500 \%$ \\
\hline G & $150 \%$ & $700 \%$ \\
\hline H & $909 \%$ & $909 \%$ \\
\hline
\end{tabular}


São propostas, ao final, 4 versões da CRBA:

1- Conforme o Quadro 15, mas para todas as exposições de crédito com os fatores CRBA da Tabela 20 coluna do meio. Trata-se de CRBA.

2- Exatamente como o Quadro 15, apenas para exposições corporate. Este é o modelo mais próximo da SA. Trata-se de CRBA_CP (ou CRBA Corporate).

3- Para todas as exposições, utilizando os Fatores de Ponderação mais conservadores da Tabela 20 coluna da direita. Trata-se de CRBAc.

4- Para todas as exposições corporate, utilizando igualmente os Fatores de Ponderação mais conservadores da Tabela 20 coluna da direita. Trata-se de CRBAc_CP (ou CRBAc Corporate).

\subsection{Limitações}

A Resolução CMN n. 2.682/99 (CMN, 1999) especificamente dispõe que a classificação das exposições por risco de crédito nas categorias AA a H é de "responsabilidade da instituição financeira detentora do crédito" e deve envolver: "critérios consistentes e verificáveis" e ser "amparada por informações internas e externas", o que especificamente envolve:

Art. 2 - I) Contemplando pelo menos (em relação ao devedor e seus garantidores):
a) situação econômico-financeira;
b) grau de endividamento;
c) capacidade de geração de resultados;
d) fluxo de caixa;
e) administração e qualidade de controles;
f) pontualidade e atrasos nos pagamentos;
g) contingências;
h) setor de atividade econômica;
i) limite de crédito;

Adicionalmente, deveriam ser considerados natureza e finalidade da transação, características das garantias (em especial sua suficiência e liquidez e valor); situação patrimonial, renda e outras informações cadastrais do devedor, exposição e garantidores (Art. 2).

Apesar da clara natureza ex-ante sugerida no artigo 2, a existência de um critério mínimo de atraso (Tabela 19) implica em um tipo de arbitragem regulatória no uso das categorias. Em outras palavras, existem incentivos para a classificação do devedor nas categorias superiores e apenas migrá-los na existência de atrasos. A consequência disso é que os modelos internos de certas instituições, em especial das menores (ANNIBAL, 2008), podem não identificar apropriadamente o risco do tomador ou, se identificado, ele não é reportado ao supervisor. 
Entretanto, o supervisor é refém dessa situação, porque impõe um critério mínimo e claro expost e sugere um critério vago ex-ante sobre a mesma escala.

A instituição que classifica seus clientes apenas pelo atraso nunca terá uma matriz de migração cuja probabilidade de transição entre classes de risco seja monotônica. Se eles foram aleatoriamente classificados em AA e A, a probabilidade de migração de qualquer categoria para default nunca será consistente, pois a cada 30 dias uma proporção fixa de empréstimos salta para a categoria inferior.

A consequência desse fenômeno para esse trabalho é que as PDs estimadas para o SFN podem não refletir adequadamente a probabilidade de default e sim a discrepância entre os sistemas de classificação de todos os bancos. Esse último fenômeno é mais problemático nas exposições de bancos pequenos. Como a maioria das exposições são de instituições grandes, esse viés é reduzido.

Nas métricas de perda total do portfólio, variável-chave do objetivo 1, só existirão dois tipos de exposição: as que tiveram default total e as que não registraram atrasos superiores a 90 dias ou classificação abaixo de D até o momento da coleta. Nos segundo e terceiro objetivos, as categorias de risco da Resolução 2.682/09 são tratadas como não tendo qualquer caráter preditor sobre a inadimplência e são utilizadas para identificar point-in-time o rating do devedor, calcular sua provisão e alocar a PD apropriada para o cálculo do CME.

Em relação a Carey (2002), ao não impor restrições de saldo aos exercícios, o banco com "n" operações em carteira possui tamanho aleatório e ex-post carteiras maiores apresentam perdas menores. Uma regressão simples entre perdas e o tamanho das carteiras entre B portfólios apresentou sempre um coeficiente negativo e significante e, em média, o r quadrado ajustado foi de $61 \%$. Se as realizações representam um banco ou o SFN, isso é indesejável, pois, em geral, ele não se expande ou se retrai exageradamente em curto espaço de tempo.

Com respeito a Creditrisk+, existe o viés mencionado na literatura decorrente do uso do algoritmo de Panjer. Para o portfólio de mais de 675.000 exposições e PDs elevadas, buscouse minimizar esse problema conforme explicitado anteriormente. 


\subsection{Quadro Resumo}

O Quadro 18 sintetiza novamente esse trabalho, sua metodologia e resultados esperados.

Quadro 18 - Quadro Resumo

\begin{tabular}{|c|c|c|c|}
\hline $\begin{array}{l}\text { Pergunta } \\
\text { Problema }\end{array}$ & $\begin{array}{c}\text { Objetivo do } \\
\text { Trabalho }\end{array}$ & Metodologia & Resultados \\
\hline \multirow{3}{*}{$\begin{array}{c}\text { Quais as } \\
\text { consequências } \\
\text { sobre o } \\
\text { capital } \\
\text { regulatório } \\
\text { para risco de } \\
\text { crédito da } \\
\text { adoção de } \\
\text { diferentes } \\
\text { abordagens } \\
\text { de Basileia } \\
\text { II? }\end{array}$} & $\begin{array}{l}\text { 1) Estimar o } \\
\text { capital econômico } \\
\text { para um portfólio } \\
\text { que representa o } \\
\text { SFN. Para Carey } \\
\text { (2002), esse é o } \\
\text { requerimento } \\
\text { absoluto de } \\
\text { capital. }\end{array}$ & $\begin{array}{l}\text { 1.1) Estimar o VaR de } \\
\text { Crédito (CVaR) por } \\
\text { modelo de Carey } \\
\text { (2002) para bancos } \\
\text { pequenos e grandes } \\
\text { 1.2) Estimar CVaR } \\
\text { paramétrico por } \\
\text { Creditrisk+ }\end{array}$ & $\begin{array}{l}\text { 1. Baseado nos quantis da distribuição não } \\
\text { paramétrica de CVaR para bancos pequenos } \\
\text { na crise de 2008-2009, o capital econômico } \\
\text { seria de 9,05\% (95\%). } \\
\text { 2. Para o CVaR paramétrico de Creditrisk+, } \\
\text { tem-se no quantil de 99,9\%, 17,5\% (com } \\
\text { provisão) ou um CME de } 11,5 \% \text {. Para } \\
\text { CVaR(95\%), 13,55\% e CME de 7,55\%. } \\
\text { Ambos os CMEs próximos à exigência } \\
\text { regulatória atual, isto é, entre } 8.25 \% \text { e } 11 \% \text {. } \\
\text { Um intervalo de confiança (bootstrap) de } \\
\text { 99,9\% para CME mais provisão mínima } \\
\text { exigida (PME) na abordagem atual } \\
\text { apresentou valores entre [13,32\%:14,82\%], } \\
\text { situando CReq na zona de 95\% a 97.5\% de } \\
\text { Creditrisk+. }\end{array}$ \\
\hline & $\begin{array}{l}\text { 2) Avaliar a } \\
\text { performance do } \\
\text { IRB Fundamental } \\
\text { frente a } \\
\text { abordagem atual } \\
\text { (SSA) em dois } \\
\text { cenários de stress }\end{array}$ & $\begin{array}{l}\text { 2.1) Avaliar na } \\
\text { amostra a Provisão } \\
\text { Mínima e o CME nos } \\
\text { cenários-base nas } \\
\text { abordagens atual e } \\
\text { IRB, durante a crise, e } \\
\text { sob stress } 1 \text { e stress } 2 \\
\text { para: bancos pequenos } \\
\text { e grandes; e para } \\
\text { 2.2) as carteiras } \\
\text { teóricas de Basileia II: } \\
\text { varejo, atacado r } \\
\text { pequenas e médias } \\
\text { empresas (PME). }\end{array}$ & $\begin{array}{l}\text { 1. Durante a crise, o aumento da } \\
\text { inadimplência em bancos pequenos foi de } \\
56,16 \% \text { e nos grandes de } 28,93 \% \text {. No } \\
\text { entanto, apenas bancos pequenos tiveram } \\
\text { perdas médias superiores à PME. O IRB } \\
\text { Fundamental é mais conservador que todas } \\
\text { as demais abordagens e subsiste ao choque } \\
\text { aleatório mais severo stress } 2 \text {. Na } \\
\text { abordagem atual, o exigível mínimo não } \\
\text { subsiste stress2. } \\
\text { 2. O Varejo mostrou-se mais arriscado que } \\
\text { SME e o atacado. O IRB ajuda a corrigir } \\
\text { essa distorção reforçada pela abordagem } \\
\text { atual. }\end{array}$ \\
\hline & $\begin{array}{l}\text { 3) Avaliar a } \\
\text { proposição da } \\
\text { Abordagem } \\
\text { Padronizada dos } \\
\text { Ratings } \\
\text { Centralizados } \\
\text { (CRBA) }\end{array}$ & $\begin{array}{l}\text { 3.1) Avaliar o CME } \\
\text { para as diversas } \\
\text { CRBAs propostas em } \\
\text { bancos pequenos } \\
\text { frente a abordagem } \\
\text { atual e o IRB. }\end{array}$ & $\begin{array}{c}\text { 1. CRBAc para bancos pequenos é a } \\
\text { abordagem mais conservadora dentre as } \\
\text { quatro propostas para CME e representa } \\
\text { uma meia distância entre a abordagem } \\
\text { brasileira atual (SSA) e o IRB. Além disso, } \\
\text { é mais sensível ao risco de crédito } \\
\text { principalmente no Varejo e resiste ao } \\
\text { critério de stress } 2 \text {. }\end{array}$ \\
\hline
\end{tabular}




\section{ANÁLISE DE RESULTADOS}

Como mencionado, este trabalho possui três objetivos de pesquisa:

1- Estimar um capital econômico adequado ao sistema bancário para risco de crédito que seja referência para requerimentos absolutos de capital para bancos grandes e pequenos;

2- Analisar o CME, EL e a provisão mínima (PME) do IRB frente à SSA e a já extinta Basileia I para risco de crédito;

3- Analizar a abordagem padronizada CRBA e suas variantes para risco de crédito.

Este capítulo está subdivido em três seções: uma para cada objetivo acima.

\subsection{Requerimentos absolutos de Capital}

Nesta etapa, são apresentados os resultados para o Modelo de Carey (2002) em diversas simulações de reamostragens e os resultados de Creditrisk+.

\subsubsection{Reamostragens em carteiras de diversos tamanhos}

Em consonância com os dois conceitos de default mencionados, criam-se as medidas perda com default (dloss ajustada pela LGD) e perda econômica (tloss ajustada pela LGD). A Tabela 21 traz as perdas totais de um exercício de Carey para o portfólio-base, o mais representativo, pois contém toda a amostra e o ciclo econômico completo (2004-2010). Todas essas carteiras têm 300.000 empréstimos e em média R\$2.940 MM. Essa é a maior carteira formada nesse estudo.

Tabela 21 - Perdas Totais - Carteiras de 300.000 exposições ${ }^{35}$ - Todo o SFN entre 2004-2010 $(B=20000)$

\begin{tabular}{|l|c|c|c|c|c|c|c|c|c|}
\hline & Média & $\mathrm{DP} / \mathrm{R}$ & $\mathrm{As}$ & $\mathrm{Ku}$ & $95,0 \%$ & $97,5 \%$ & $99,0 \%$ & $99,50 \%$ & $99,90 \%$ \\
\hline Inadimplência & $4,19 \%$ & $0,65 \%$ & 0,9737 & 4,23 & $5,14 \%$ & $5,77 \%$ & $6,18 \%$ & $6,45 \%$ & $7,07 \%$ \\
\hline $\begin{array}{l}\text { Perda com } \\
\text { default }\end{array}$ & $\mathbf{3 , 2 9 \%}$ & $\mathbf{0 . 4 4 \%}$ & $\mathbf{0 , 9 1 5 7}$ & $\mathbf{4 , 2 4}$ & $\mathbf{4 , 1 2 \%}$ & $\mathbf{4 , 3 5 \%}$ & $\mathbf{4 , 6 0 \%}$ & $\mathbf{4 , 7 9 \%}$ & $\mathbf{5 , 2 1 \%}$ \\
\hline $\begin{array}{l}\text { Perda } \\
\text { econômica }\end{array}$ & $4,60 \%$ & $0,50 \%$ & 0,3730 & 3,73 & $5,48 \%$ & $5,68 \%$ & $5,91 \%$ & $6,06 \%$ & $6,39 \%$ \\
\hline
\end{tabular}

\footnotetext{
${ }^{35} \mathrm{~N}$ é de 1.582 .475 por causa da reponderação. A relação entre N/n é a sugerida por Carey (2002) de 5x para o SFN.
} 
Para essa carteira, que representa o SFN, a inadimplência média foi de 4,19\%. A variável de maior interesse é a perda com default (a mesma de Carey), pois representa a perda efetiva decorrente da inadimplência por atraso registrada em cada um dos B portfólios simulados, já considerando as LGDs apropriadas para cada exposição. Essa variável teve média de 3,29\% e seu quantil de 99,9\% era de 5,21\%. Isso significa que, se o ciclo econômico de 2004-2010 for longo e representativo o suficiente da realidade econômica brasileira, a probabilidade da inadimplência no SFN em um único ano (representativo do ciclo) exceder 7,07\% é de uma em mil e as perdas decorrentes disso 5,21\%. Se a perda econômica é a referência de interesse, $\operatorname{VaR}(99,9 \%)$ é de $6,39 \%$.

Os valores da Tabela 22 e de todas as demais não devem ser comparados com o referencial de $11 \%$ de Basileia, porque a referência para $\mathrm{VaR}$ de crédito é o colchão total para fazer frente às perdas de crédito e ele deve conter além do CME a provisão mínima, excluída do PR1 no Brasil. Desde 2008, o referencial para Basileia é de no máximo 11\%, já que um FPR de 75\% foi incluído na carteira dos bancos para o varejo. O CME de referência para a abordagem atual está entre $8,25 \%$ e $11 \%$ dependendo no peso do varejo na carteira dos bancos. Certo grau de provisão mínima exigida é sempre devido ainda que dependente da classificação que cada banco concede a seus tomadores. A média das provisões mínimas exigidas na amostra foi de $5,70 \%$.

Novamente, é importante ressaltar que os portfólios desse estudo não estão sujeitos a risco de mercado $(\mathrm{PRM})^{36}$, a risco operacional (POPR) e a risco de crédito fora do banking book. PRM e POPR representavam juntas em média 10\% do CME total em dezembro de 2010.

Na Tabela 22, CVaR para a carteira de crédito de um banco com 50.000 operações de crédito (R\$ 490 MM em média) é apresentado - Tabela 22. Ela representa em (Cf. Carey, 2002) as perdas de um bancos que atua reproduzindo passivamente a carteira do Sistema bancário.

Tabela 22 - Reamostragem 50.000 empréstimos

\begin{tabular}{|l|c|c|c|c|c|c|c|c|c|}
\hline & Média & $\mathrm{DP} / \mathrm{R}$ & $\mathrm{As}$ & $\mathrm{Ku}$ & $95,0 \%$ & $97,5 \%$ & $99,0 \%$ & $99,50 \%$ & $99,90 \%$ \\
\hline Inadimplência & $4,24 \%$ & $1,56 \%$ & 2,41 & 10,80 & $7,64 \%$ & $7,67 \%$ & $9,07 \%$ & $11,28 \%$ & $13,54 \%$ \\
\hline $\begin{array}{l}\text { Perda com } \\
\text { default }\end{array}$ & $3,32 \%$ & $1,05 \%$ & 2,25 & 10,71 & $5,37 \%$ & $6,42 \%$ & $7,62 \%$ & $8,21 \%$ & $9,31 \%$ \\
\hline $\begin{array}{l}\text { Perda } \\
\text { econômica }\end{array}$ & $4,69 \%$ & $1,21 \%$ & 0,99 & 4,67 & $7,01 \%$ & $7,67 \%$ & $8,37 \%$ & $8,92 \%$ & $10,22 \%$ \\
\hline
\end{tabular}

\footnotetext{
${ }^{36}$ PRM é formada por PCAM, PJUR, PCOM e PACS (Ver Quadro 10)
} 
Deve-se notar que no quantil de 99,9\% a perda por default é de 9,31\%. Esse dado é o mais próximo do pretendido por Carey (2002) antes de simular as crises, porque reflete as perdas possíveis em um banco e a probabilidade de que bancos desse tamanho experimentem as perdas da Tabela $22 \mathrm{em}$ um ano qualquer que represente a média das realizações macroeconômicas do ciclo compreendido entre 2004 e 2010.

Na Tabela 23, apresenta-se um banco menor. Ele é simulado com 10.000 empréstimos (R $\$ 98$ MM em média). As perdas em relação às do exercício anterior são bem maiores nas caudas de 99,0\% e superiores, porque nesses quantis observa-se ex-post uma concentração dos piores devedores e esse banco não é capaz de diversificar as perdas decorrentes desses choques adversos.

Tabela 23 - Reamostragem 10.000 empréstimos

\begin{tabular}{|l|c|c|c|c|c|c|c|c|c|}
\hline & Média & $\mathrm{DP} / \mathrm{R}$ & $\mathrm{As}$ & $\mathrm{Ku}$ & $95,0 \%$ & $97,5 \%$ & $99,0 \%$ & $99,50 \%$ & $99,90 \%$ \\
\hline Inadimplência & $4,42 \%$ & $3,11 \%$ & 4,95 & 35,65 & $7,95 \%$ & $12,83 \%$ & $20,26 \%$ & $25,99 \%$ & $32,46 \%$ \\
\hline $\begin{array}{l}\text { Perda com } \\
\text { default }\end{array}$ & $3,48 \%$ & $2,10 \%$ & 4,51 & 33,80 & $6,36 \%$ & $8,60 \%$ & $13,11 \%$ & $16,64 \%$ & $23,12 \%$ \\
\hline $\begin{array}{l}\text { Perda } \\
\text { econômica }\end{array}$ & $4,97 \%$ & $2,51 \%$ & 2,23 & 10,74 & $9,60 \%$ & $12,45 \%$ & $15,39 \%$ & $16,87 \%$ & $19,64 \%$ \\
\hline
\end{tabular}

É importante frisar que não existe um quantil exato para inadimplência ou perdas de crédito. Um quantil de $95 \%$ é coerente com uma probabilidade de 5\% de que uma concentração maior dos piores devedores estivesse nesse banco em particular, causando uma inadimplência nesse banco de 7,95\%. Carey (2001) esclarece que do ponto de vista do regulador, o número equivale a $5 \%$ ao ano de falências no Sistema Bancário em bancos com portfólio de 10.000 empréstimos e que têm capital econômico para risco de crédito exatamente igual ao valor apresentado nesse quantil. Alternativamente, se o regulador fixasse o requerimento absoluto de capital mínimo para risco de crédito no quantil, em média, seriam esperados $5 \%$ de falências em bancos de mesmo tamanho em condições econômicas similares e desconsiderando o risco de seus demais ativos.

Tanto em Carey (2002), como nos modelos paramétricos, os quantis também representam a elevação do risco sistêmico (Y) ou o agravamento dos "estados da economia". 


\subsubsection{Ciclo e Crise}

A Tabela 24, a ser comparada com a Tabela 21, apresenta os resultados obtidos por reamostragem do SFN apenas para o período de crise. Esse dado é importante, porque Carey (2002) sugere que a reamostragem com exposições de crises seja o procedimento mais adequado para se estimar requerimentos absolutos de capital.

Tabela 24 - Perdas Totais - SFN na Crise de 2008-2009

\begin{tabular}{|l|c|c|c|c|c|c|r|r|r|}
\hline & Média & $\mathrm{DP} / \mathrm{R}$ & $\mathrm{As}$ & $\mathrm{Ku}$ & $95,0 \%$ & $97,5 \%$ & $99,0 \%$ & $99,50 \%$ & $99,90 \%$ \\
\hline Inadimplência & $5,69 \%$ & $1,70 \%$ & 1,42 & 5,51 & $9,07 \%$ & $9,95 \%$ & $11,18 \%$ & $12,15 \%$ & $14,03 \%$ \\
\hline Perda default & $4,48 \%$ & $1,20 \%$ & 1,31 & 5,26 & $6,89 \%$ & $7,51 \%$ & $8,35 \%$ & $9,01 \%$ & $10,30 \%$ \\
\hline $\begin{array}{l}\text { Perda } \\
\text { econômica }\end{array}$ & $5,71 \%$ & $1,09 \%$ & 0.58 & 3,50 & $7,67 \%$ & $8,13 \%$ & $8,71 \%$ & $9,20 \%$ & $10,03 \%$ \\
\hline
\end{tabular}

Note-se que a inadimplência média e a perda por default se elevam em cerca de $35 \%$ entre o ciclo completo e o período de crise, mas o impacto na cauda implica na elevação do VaR de $99,9 \%$ de 5,20\% para 10,22\%. Apenas 1 vez em cada 1.000 anos de crises similares às do Subprime seria possível observar perdas superiores a 10,30\% no SFN como um todo, sugerindo que se o colchão total para absorção de perdas, PR1 mais provisão, fosse superior a $10,30 \%$, o Sistema Bancário estaria em tese bem capitalizado para crises desse porte.

\subsubsection{Carteira de bancos pequenos vs. grandes.}

Um exercício comparativo interessante e com o objetivo de verificar se bancos pequenos e grandes têm acesso a operações de crédito de qualidade distinta e quanto de suas perdas é fruto da granularidade da carteira e da qualidade de sua clientela é apresentado abaixo. Primeiramente, apresentam-se os resultados de um SFN composto apenas de bancos grandes com 270.000 empréstimos (Tabela 25) e o resultado para um banco de 50.000 empréstimos na Tabela 26. Para esses dois exercícios, restringiu-se o universo disponível de operações de crédito nas simulações às disponíveis exclusivamente nas carteiras desses bancos entre $2004 \mathrm{e}$ 2010.

Tabela 25 - SFN - Bancos Grandes (270.000 empréstimos)

\begin{tabular}{|l|c|c|c|c|c|c|c|c|r|}
\hline & Média & $\mathrm{DP} / \mathrm{R}$ & $\mathrm{As}$ & $\mathrm{Ku}$ & $95,0 \%$ & $97,5 \%$ & $99,0 \%$ & $99,50 \%$ & $99,90 \%$ \\
\hline Inadimplência & $3,95 \%$ & $0,37 \%$ & 0,28 & 3,25 & $4,60 \%$ & $4,74 \%$ & $4,92 \%$ & $5,05 \%$ & $5,37 \%$ \\
\hline $\begin{array}{l}\text { Perda por } \\
\text { default }\end{array}$ & $3,20 \%$ & $0,30 \%$ & 0,23 & 3,16 & $3,71 \%$ & $3,82 \%$ & $3,96 \%$ & $4,06 \%$ & $4,29 \%$ \\
\hline $\begin{array}{l}\text { Perda } \\
\text { econômica }\end{array}$ & $5,37 \%$ & $0,57 \%$ & 0.34 & 3,20 & $6,36 \%$ & $6,59 \%$ & $6,82 \%$ & $6,98 \%$ & $7,45 \%$ \\
\hline
\end{tabular}


Na Tabela 26, apresenta-se uma simulação para bancos de 50.000 empréstimos formados com operações de crédito disponíveis nas carteira de bancos grandes entre 2004 e 2010.

Tabela 26 - Bancos com carteiras formadas por empréstimos de bancos grandes (50.000 empréstimos)

\begin{tabular}{|l|c|c|c|c|c|c|r|r|r|}
\hline & Média & DP/R & As & $\mathrm{Ku}$ & $95,0 \%$ & $97,5 \%$ & $99,0 \%$ & $99,50 \%$ & $99,90 \%$ \\
\hline Inadimplencia & $4,23 \%$ & $1,56 \%$ & 2,41 & 10,80 & $7,64 \%$ & $9,07 \%$ & $10,40 \%$ & $11,28 \%$ & $13,54 \%$ \\
\hline Perda default & $3,32 \%$ & $1,05 \%$ & 2,25 & 10,72 & $5,38 \%$ & $6,43 \%$ & $7,63 \%$ & $8,21 \%$ & $9,32 \%$ \\
\hline $\begin{array}{l}\text { Perda } \\
\text { econômica }\end{array}$ & $4,69 \%$ & $1,22 \%$ & 1,00 & 4,67 & $7,01 \%$ & $7,67 \%$ & $8,38 \%$ & $8,92 \%$ & $10,23 \%$ \\
\hline
\end{tabular}

$\mathrm{Na}$ verdade, quanto maior a carteira de um banco, mais ela se aproxima da f.d.p. da esquerda do Gráfico 4. Esse é o efeito granularidade ASRF apontado como necessário para o IRB e descrito na Bibliografia.
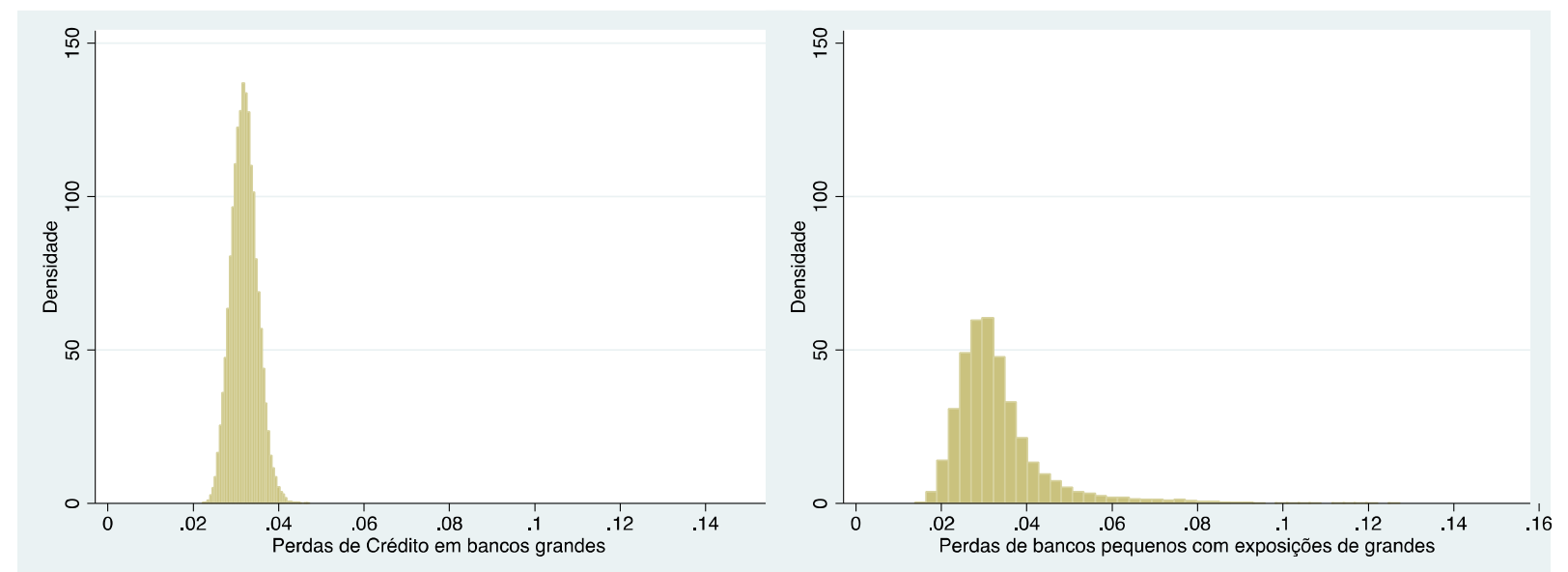

Gráfico 4 - Perdas de Crédito - Granularidade

A Tabela 27 apresenta uma simulação similar à da Tabela 26, no entanto as carteiras dos bancos são formadas apenas com exposições de crédito disponíveis nas carteiras de bancos pequenos entre 2004 e 2010.

Tabela 27 - Bancos com carteiras formadas por empréstimos de bancos Pequenos (50.000 empréstimos)

\begin{tabular}{|l|c|c|c|c|c|c|c|c|c|}
\hline & Média & $\mathrm{DP} / \mathrm{R}$ & $\mathrm{As}$ & $\mathrm{Ku}$ & $95,0 \%$ & $97,5 \%$ & $99,0 \%$ & $99,50 \%$ & $99,90 \%$ \\
\hline Inadimplência & $4,94 \%$ & $2,27 \%$ & 1,11 & 4,20 & $9,35 \%$ & $10,46 \%$ & $11,85 \%$ & $12,79 \%$ & $14,90 \%$ \\
\hline $\begin{array}{l}\text { Perda por } \\
\text { default }\end{array}$ & $3,53 \%$ & $1,47 \%$ & 1,19 & 4,54 & $6,40 \%$ & $7,13 \%$ & $8,07 \%$ & $8,72 \%$ & $10,15 \%$ \\
\hline $\begin{array}{l}\text { Perda } \\
\text { econômica }\end{array}$ & $3,69 \%$ & $0,90 \%$ & 0,87 & 4,02 & $5,36 \%$ & $5,79 \%$ & $6,29 \%$ & $6,66 \%$ & $7,47 \%$ \\
\hline
\end{tabular}


Ao analisar as três tabelas e o gráfico 4, fica claro que a granularidade (necessária para utilizar um modelo IRB) pesa bastante na distribuição de perdas. Os quantis extremos apresentam perdas quase duas vezes maiores entre a Tabela 25 e 26.

As perdas em bancos pequenos na Tabela 27 ainda são cerca de 10\% maiores na média em todos os quantis quando comparadas as da Tabela 26. O Gráfico 5 evidencia que a clientela dos bancos maiores é, em média, melhor. No entanto, como destacado no Gráfico 4, o efeito granularidade é mais expressivo que o efeito clientela.
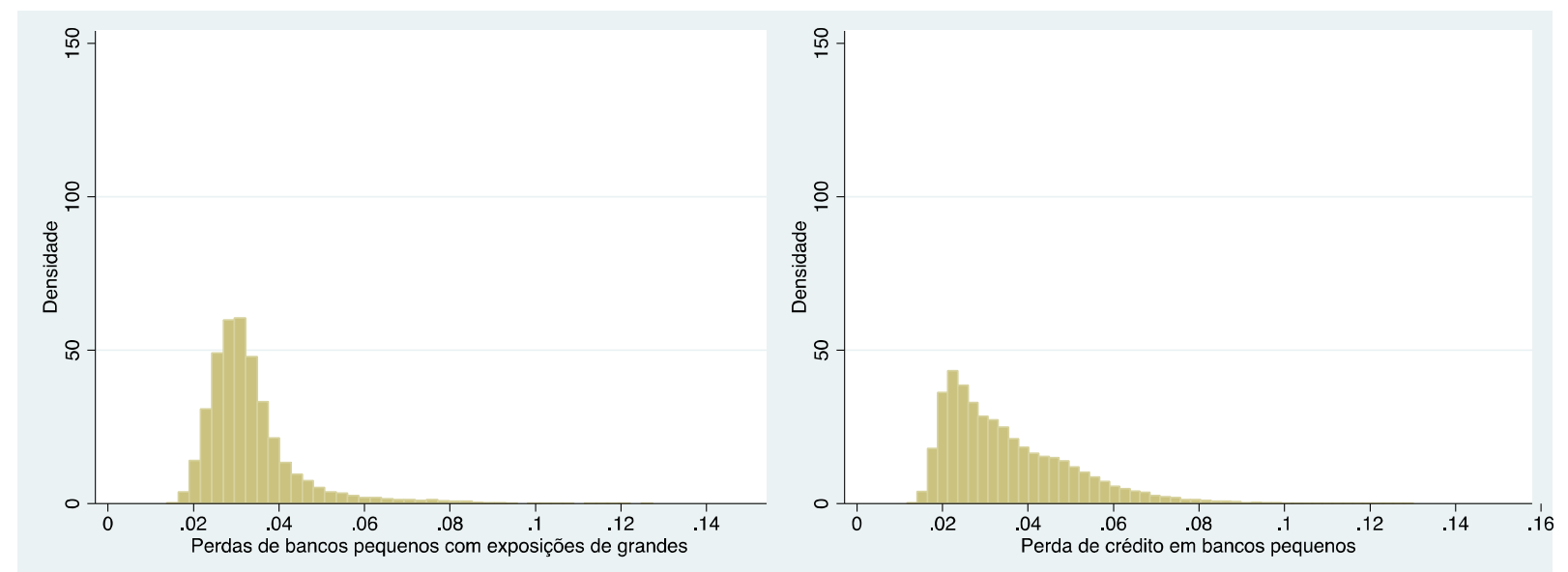

Gráfico 5 - Perdas de Crédito - Clientela

$\mathrm{Na}$ sequência, apresentam-se as perdas para bancos pequenos na Crise (Tabelas 28). As carteiras são menores para essas simulações (10.000 empréstimos). É importante observar como a perda por default é muito maior nos quantis de bancos pequenos. Nesse exercício, a quantidade mais abundante de defaults na população da crise e o menor poder de diversificação pesarão em conjunto. Para condições econômicas similares às da crise, por volta de cinco em cem bancos com 10.000 operações de crédito em carteira teriam dificuldades financeiras por perdas de crédito superiores a 9,05\% (Gráfico 6 e Tabela 28)

Tabela 28 - Bancos pequenos na Crise $(n=10.000)$

\begin{tabular}{|l|c|c|c|c|c|c|c|c|r|}
\hline & Média & $\mathrm{DP} / \mathrm{R}$ & $\mathrm{As}$ & $\mathrm{Ku}$ & $95,0 \%$ & $97,5 \%$ & $99,0 \%$ & $99,50 \%$ & $99,90 \%$ \\
\hline Inadimplência & $5,18 \%$ & $4,23 \%$ & 3,66 & 18,90 & $13,83 \%$ & $19,67 \%$ & $25,76 \%$ & $29,03 \%$ & $33,5 \%$ \\
\hline Perda default & $3,97 \%$ & $2,79 \%$ & 3,63 & 19,93 & $9,05 \%$ & $12,59 \%$ & $18,08 \%$ & $20,55 \%$ & $23,31 \%$ \\
\hline $\begin{array}{l}\text { Perda } \\
\text { econômica }\end{array}$ & $5,56 \%$ & $2,52 \%$ & 1,66 & 6,75 & $10,85 \%$ & $12,63 \%$ & $14,56 \%$ & $15,60 \%$ & $17,98 \%$ \\
\hline
\end{tabular}



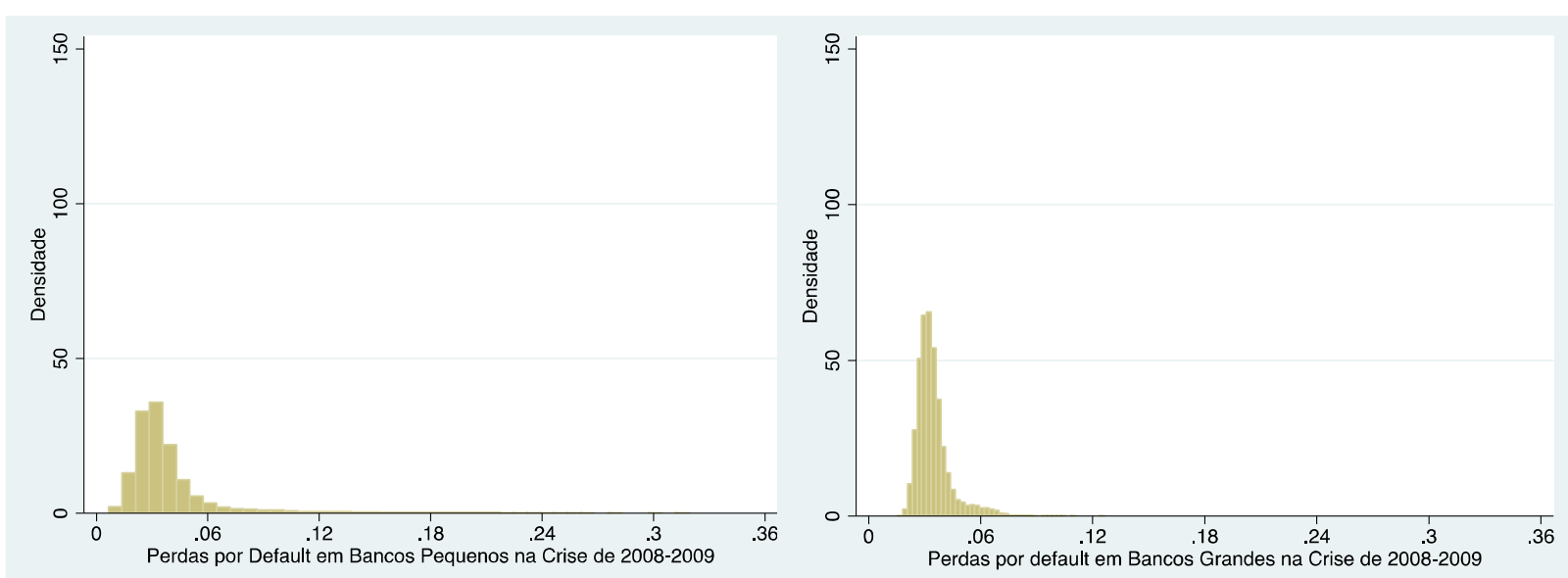

Gráfico 6 - Perdas na Crise (bancos peq e grandes)

É de certa forma subjetivo, com base nesses números, saber o capital econômico desejável para bancos pequenos. Do ponto de vista do regulador, cinco por cento de perdas expressivas em bancos de tamanho $\mathrm{n}$ em crises como a última, pode ser aceitável. O investidor, por sua vez, pode preferir bancos cujo total de provisão e capital econômico exceda 18,08\%, reduzindo sua própria probabilidade de perdas para $1 \%$ em caso de choques macroeconômicos como o da crise.

\subsubsection{Creditrisk+}

Como alternativa à abordagem $\mathrm{CVaR}$ não paramétrica, propõe-se uma solução paramétrica bastante utilizada para gestão de riscos de crédito. Creditrisk+ é o modelo de VaR paramétrico que efetivamente impõe menos pressupostos sobre a correlação entre os ativos e os fatores de risco da economia. Para Schechtman et al (2004), essas particularidades o tornam mais adequado à realidade brasileira. Vale mencionar, que Creditrisk+ é teoricamente pouco sensível ao tamanho dos bancos, ao contrário do procedimento anterior (SAUNDERS, 1999).

A calibração de Creditrisk+ para esse exercício foi feita de acordo com CSFB (1997), ou seja, com o algoritmo recursivo de Panjer. Para minimizar os dois tipos de viés mais comuns desse algoritmo: o de carteiras muito grandes, e o de PDs elevadas, foram adotados os procedimentos mencionados na metodologia. É importante reiterar que as PDs e LGDs utilizadas são as mesmas usadas para a estimação dos parâmetros do IRB do portfólio-base da próxima sessão, o que torna essa estimação de requerimento absoluto de capital extremamente útil para a etapa seguinte por sua elevada comparabilidade. 
As estimações de VaR são apresentadas para a amostra completa - Portfólio SFN (Tabela 29). Em todos os casos, o VaR representa o total dos dois cestos (abaixo e acima de $\mathrm{R} \$ 5$ mil) para cada quantil.

Tabela 29 - VaR de Creditrisk+

\begin{tabular}{|ccc|}
\hline Quantil & CVaR (\%) $^{37}$ & CME (\%) \\
Média & $11.01 \%$ & $5.01 \%$ \\
50.00 & $10.75 \%$ & $4.75 \%$ \\
75.00 & $11.71 \%$ & $5.71 \%$ \\
95.00 & $13.55 \%$ & $7.55 \%$ \\
97.50 & $14.29 \%$ & $8.29 \%$ \\
$\mathbf{9 9 . 0 0}$ & $15.23 \%$ & $9.23 \%$ \\
99.50 & $15.94 \%$ & $9.94 \%$ \\
99.75 & $16.63 \%$ & $10.63 \%$ \\
99.90 & $17.54 \%$ & $11.54 \%$ \\
\hline
\end{tabular}

Para Creditrisk+, o resultado do VaR no Quantil de 99,9\% foi 17,54\%. Como 6\% de perda esperada estão incluídos em todos os quantis, apresenta-se alternativamente o valor apenas para UL, que é a referência para CME (desconsiderando a provisão do modelo). Nesse caso, para o mesmo quantil, CME ficaria em 11,54\%. É necessário ressaltar que esse número está ligeiramente acima do referencial máximo de Basileia de $11 \%$. Por outro lado, as PDs estimadas com as faixas de classificação da Resolução CMN n. 2682/99 (CMN, 1999) para o SFN são elevadas, pelos motivos já mencionados.

Pode-se dizer que a estimativa paramétrica foi mais conservadora que a de Carey (2002) para a crise de 2008-2009. A referência regulatória entre 8,25\% e 11\%, para Creditrisk+, estaria entre o quantil de $95 \%$ e $99,75 \%$ de Creditrisk+. Em outras palavras, a probabilidade do portfólio SFN colapsar seria de menos de 5\% a.a. dado os requerimentos atuais quandos os "estados da economia" são os do quantil de 95\%. CVaR deve ser comparado com EL ou a provisão mínima exigida (PME) mais o CME. Para bancos pequenos, a PME média foi de $4,53 \%$ e para bancos grandes de $6,08 \%$ no período. A PME de bancos grandes ficou muito próxima da EL de $6 \%$ de Creditrisk+.

\section{Comparação com Modelo de Carey}

\footnotetext{
${ }^{37}$ A perda esperada inclui, além da estimação de EL de Creditrisk+, a EL das exposições com PDs elevadas e inferiores a $\mathrm{R} \$ 500,00$ e a totalidade das exposições em default, para as quais a provisão é de $6 \%$.

${ }^{38} \mathrm{CV}$ aR sem o efeito da Provisão para Devedores Duvidosos (PDD) sobre default.
} 
Não é possível estimar Creditrisk+ exatamente para bancos pequenos e grandes. No entanto, a probabilidade seria possivelmente superior com o procedimento paramétrico, porque ele não está condicionado nem aos estados da economia disponíveis na crise de 2008-2009, nem ao tamanho dos portfólios. Se se puder assumir que bancos grandes se comportam em linha com o SFN, já que representam cerca de $80 \%$ dele em saldo, um referencial importante para comparar com os resultados da etapa seguinte (no contexto do IRB) é o do quantil de 99,9\%, $17,54 \%$, e o CME de $11,5 \%$.

Para bancos pequenos, a perda total por default em condições similares às da Crise de 20082009, está entre CVaR (95\%) de 9,05\% e CVaR (99,9\%) de 23,31\% pelo modelo de Carey (Tabela 29). Se se puder considerar que esses bancos impõem menor risco sistêmico e que o quantil de 99\% é adequado, para Creditrisk+ ele é da ordem de 15,23\%.

Anteriormente, foi mencionado que a intensidade das perdas de crédito na faixa abaixo de $\mathrm{R} \$$ 5.000,00 é superior às observadas acima dessa faixa. A f.d.p. gerada por Creditrisk+ para esses dois cestos permite ilustrar melhor esse ponto (Gráficos 7 e 8). Note que a cauda no Gráfico 7 é bem mais pesada que a do Gráfico 8.

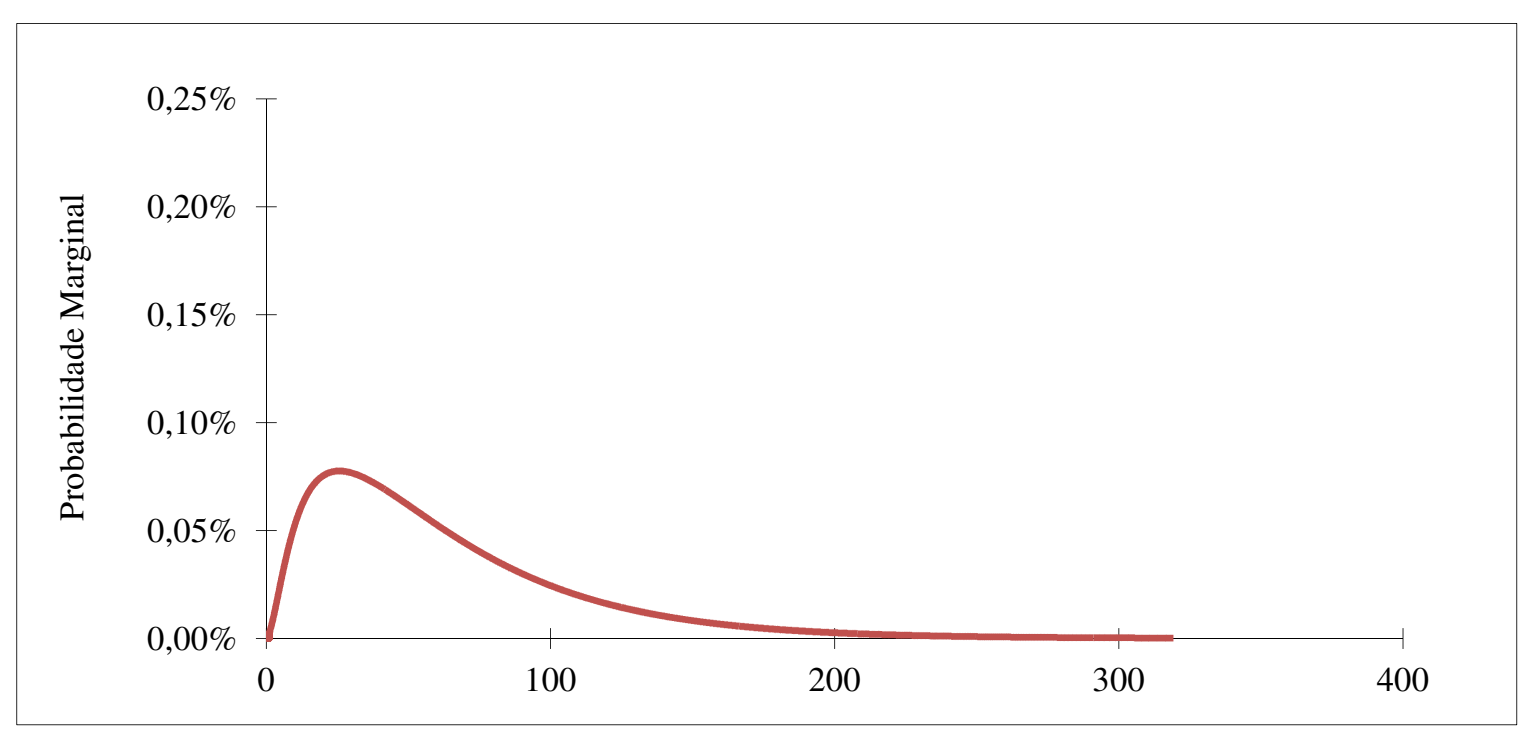

Gráfico 7 - f.d.p. de Creditrisk+ para perdas de crédito - Cesto 1 (R\$ MM) - exposições abaixo de R\$ 5 mil 


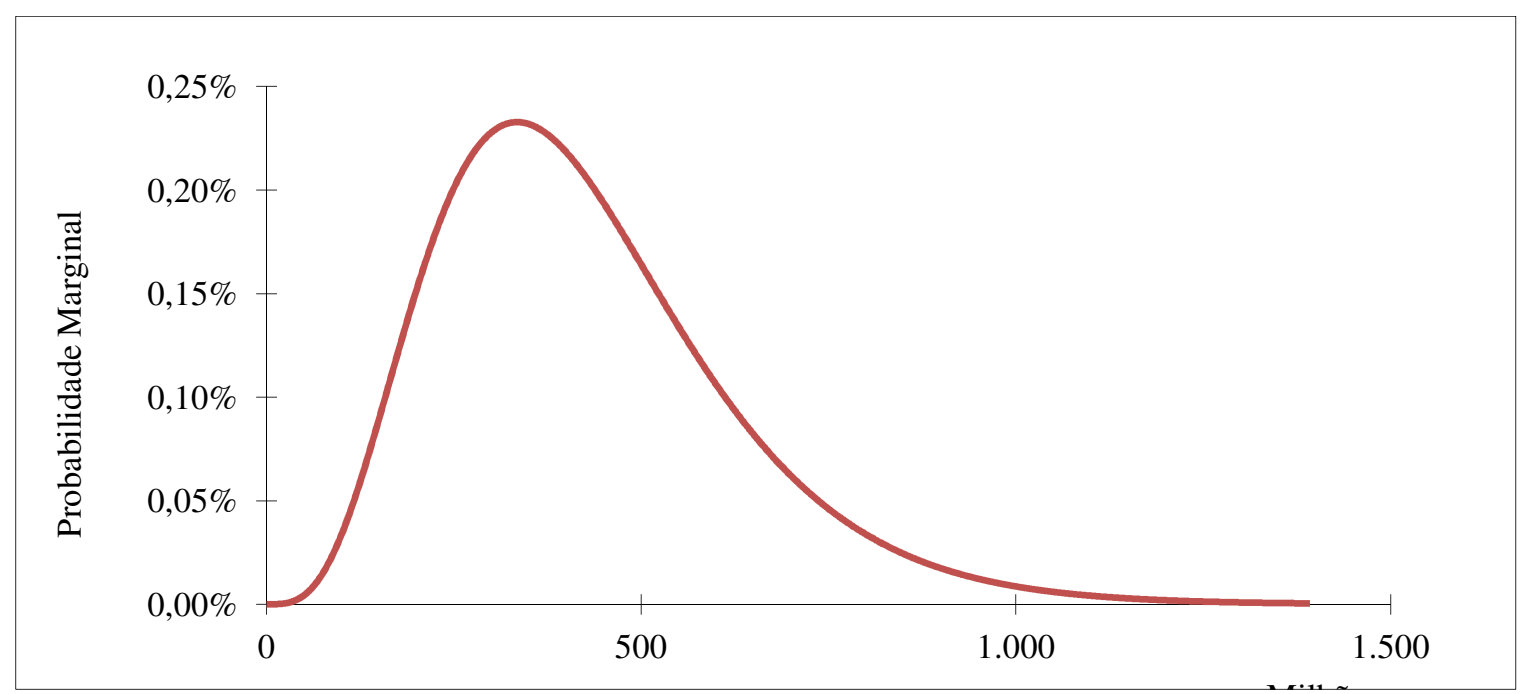

Gráfico 8 - f.d.p. de Creditrisk+ para perdas de Crédito - Cesto 2 (R\$ MM) - exposições acima de R\$ 5 mil

\subsection{Resultados para o IRB}

Para todos os portfólios gerados por reamostragem, o CME na IRB Fundamental foi calculado, o que permitiu gerar centenas de simulações com milhares de realizações ou carteiras de todos os tamanhos em diversas condições de stress. Além disso, para cada simulação uma estimativa do CME com downgrade de uma categoria (stress1 ad hoc) e duas categorias (stress2 ad hoc) em toda a carteira de crédito é realizado. As simulações foram feitas com a amostra reponderada para a faixa abaixo de $\mathrm{R} \$ 5.000$.

O portfólio tem uma carteira ativa de $\mathrm{R} \$ 14,17$ bilhões (antes de reponderação) e $\mathrm{R} \$ 15,15$ bi após. Este valor representa 1,81\% do universo de interesse no ciclo de 2004 a 2010. Por ser um portfólio reponderado para representar o SFN, e que contém exposições tanto de bancos pequenos, quanto grandes, este portfólio será denominado de Portfólio SFN.

As PDs para as categorias AA, A, B, C e D são as PDs do SFN, as mais robustas disponíveis para as oito modalidades da supervisão bancária, estimadas conforme Yanaka (2009). As LGDs são as do Edital N.37.

\subsubsection{Portfólio SFN}

Para este portfólio, a LGD média foi de 73,86\% (Tabela 30). 
Tabela 30 - Perdas Esperadas (EL) e Provisão Mínima para o Portfólio SFN Período total

\begin{tabular}{|c|c|c|cc|}
\hline & Razão & $\begin{array}{c}\text { Bootstrap } \\
\text { Std. Err. }\end{array}$ & $\begin{array}{c}\text { Intervalo } \\
\text { de }\end{array}$ & $\begin{array}{c}\text { Confiança } \\
\text { de 99,9\% }\end{array}$ \\
WLGD & $73.86 \%$ & $0.26 \%$ & $73.00 \%$ & $74.72 \%$ \\
inadimplência & $4.18 \%$ & $0.28 \%$ & $3.25 \%$ & $5.10 \%$ \\
tloss & $6.20 \%$ & $0.24 \%$ & $5.41 \%$ & $6.99 \%$ \\
tloss1 & $8.97 \%$ & $0.31 \%$ & $7.94 \%$ & $10.01 \%$ \\
tloss2 & $21.62 \%$ & $1.11 \%$ & $17.96 \%$ & $25.29 \%$ \\
perdas & $\mathbf{3 . 2 7 \%}$ & $\mathbf{0 . 1 9 \%}$ & $\mathbf{2 . 6 3 \%}$ & $\mathbf{3 . 9 1 \%}$ \\
pecon & $5.05 \%$ & $0.18 \%$ & $4.44 \%$ & $5.65 \%$ \\
pecon1 & $7.28 \%$ & $0.24 \%$ & $6.49 \%$ & $8.07 \%$ \\
pecon2 & $16.83 \%$ & $0.69 \%$ & $14.55 \%$ & $19.12 \%$ \\
MProv & $\mathbf{5 . 7 1 \%}$ & $\mathbf{0 . 2 2 \%}$ & $\mathbf{4 . 9 9 \%}$ & $\mathbf{6 . 4 3 \%}$ \\
MProv1 & $8.47 \%$ & $0.25 \%$ & $7.64 \%$ & $9.30 \%$ \\
MProv2 & $14.33 \%$ & $0.40 \%$ & $13.02 \%$ & $15.64 \%$ \\
EL & $9.15 \%$ & $0.28 \%$ & $8.22 \%$ & $10.08 \%$ \\
EL_2682 & $9.85 \%$ & $0.31 \%$ & $8.82 \%$ & $10.88 \%$ \\
ProvAjuste & $4.14 \%$ & $0.18 \%$ & $3.53 \%$ & $4.75 \%$ \\
Ajuste2682 & $0.70 \%$ & $0.06 \%$ & $0.51 \%$ & $0.89 \%$ \\
\hline
\end{tabular}

O verdadeiro valor da inadimplência com arrasto (dloss) com intervalo de confiança (bootstrap) de $99,9 \%$ está ente $3,25 \%$ e 5,10\%. A variável alternativa sugerida por Costa e Blum (2009), tloss, foi de 6,20\%. Naturalmente, o valor não deveria ser superior ao anterior, na média, por força da Resolução CMN n. 2.682/99 (CMN, 1999). O fato de tloss ser significativamente superior à inadimplência sugere que a maioria das exposições não foi classificada seguindo rigorosamente o critério mínimo de atraso da Resolução CMN n. 2.682/99 (CMN, 1999), mas critérios ex-ante mais conservadores. A variável tloss representa este indicador no cenário base, tloss 1 com stress 1 , tloss 2 com stress 2 . De modo similar, as variáveis pecon, pecon1 e pecon2 representam a perda econômica (tloss ajustada pela LGD) de cada exposição em default pelo critério de tloss.

A perda esperada (EL) estimada foi substancialmente superior aos demais indicadores por dois motivos:

1- porque efetivamente os modelos internos foram mais conservadores quando calibrados para a LGD fundamental. No Portfólio SFN, a média ponderada das PDs foi de $9,50 \%$;

2- porque default é desencadeado tanto por tloss quanto por dloss, e ambos sofrem o efeito denominador já explicitado na metodologia. 
É importante frisar que o nível de provisionamento requerido pela Resolução (PME) foi na média adequado para fazer frente à inadimplência entre 2004 e 2010 e às perdas tanto por default quanto econômicas.

Duas variáveis de controle foram criadas: ProvAjuste e Ajuste2682. ProvAjuste é computada sempre que EL excede a Provisão Mínima e registra a diferença entre ambas. Ajuste2682 registra o movimento oposto, quando a Provisão Mínima (PME) é superior a EL. Note-se que na maioria dos casos EL é superior a PME e a diferença é expressiva, o que é fruto das altas PDs estimadas nas matrizes de migração do SFN.

Uma vez que o regulador deve implementar IRB na presença da Resolução CMN n. 2682/99 (CMN, 1999), estima-se uma nova EL, EL_2682, que registra EL sempre com o maior valor possível. A existência da Resolução CMN n. 2682/99 (CMN, 1999) cria uma discricionariedade porque o verdadeiro valor da provisão pode estar entre $5,71 \%$ e $9,85 \%$. A diferença será alocada na forma de capital, mais precisamente, o Patrimônio de Referência Nível 1 (PR1). Na ausência dela, EL de 9,15\% (Tabela 30) seria o provisionamento sugerido pelo modelo interno.

Tabela 31 - VaR e CME para o portólio do SFN em todos os períodos

\begin{tabular}{|c|c|c|cc|}
\hline & Razão & $\begin{array}{c}\text { Bootstrap } \\
\text { Std. Err. }\end{array}$ & $\begin{array}{c}{[\mathbf{9 9 , 9 \%}} \\
\text { Intervalo }\end{array}$ & $\begin{array}{c}\text { de } \\
\text { Confiança] }\end{array}$ \\
perdas & $3.27 \%$ & $0.21 \%$ & $2.58 \%$ & $3.96 \%$ \\
pecon & $5.05 \%$ & $0.22 \%$ & $4.32 \%$ & $5.77 \%$ \\
pecon1 & $7.28 \%$ & $0.28 \%$ & $6.34 \%$ & $8.21 \%$ \\
pecon2 & $16.83 \%$ & $0.88 \%$ & $13.95 \%$ & $19.72 \%$ \\
VaR_IRB & $19.02 \%$ & $0.40 \%$ & $17.71 \%$ & $20.33 \%$ \\
VaR_2682 & $19.64 \%$ & $0.38 \%$ & $18.41 \%$ & $20.88 \%$ \\
CReq_b1 & $16.08 \%$ & $0.24 \%$ & $15.30 \%$ & $16.87 \%$ \\
CReq_SSA & $\mathbf{1 4 . 0 7 \%}$ & $\mathbf{0 . 2 3 \%}$ & $\mathbf{1 3 . 3 2 \%}$ & $\mathbf{1 4 . 8 2 \%}$ \\
KIRB & $10.50 \%$ & $0.16 \%$ & $9.98 \%$ & $11.02 \%$ \\
K2682 & $9.79 \%$ & $0.18 \%$ & $9.21 \%$ & $10.37 \%$ \\
K_b1 & $10.37 \%$ & $0.03 \%$ & $10.27 \%$ & $10.47 \%$ \\
K_3360 & $\mathbf{8 . 3 6 \%}$ & $\mathbf{0 . 0 7 \%}$ & $\mathbf{8 . 1 3 \%}$ & $\mathbf{8 . 5 8 \%}$ \\
\hline
\end{tabular}

Com respeito ao cenário de Stress 1, downgrade de 1 notch, observa-se que ele é equivalente a um choque de $44,1 \%$ na perda econômica medida por pecon1 em relação a pecon. Vale ressaltar que um choque de 35\% na inadimplência média é similar ao observado no ápice da crise de 2008 e 2009. Um exercício importante é saber se a provisão mínima (MProv) ou a 
perda esperada (EL) são capazes de absorver as perdas dos cenários de stress 1 e 2. Em caso negativo, deseja-se saber se o VaR_IRB é capaz. Neste exercício, EL_2682 conseguiria absorver as perdas de stress 1 . Stress 2 invariavelmente consumiria capital, mas não acima do mínimo exigido pelo modelo interno.

A Tabela 31 apresenta o VaR_IRB para o cenário base. VaR_IRB representa a soma de EL e o CME no IRB e representa o colchão total estimado pelo modelo interno para absorver as perdas de crédito do Portfólio SFN. Ele é apresentado para o IRB Fundamental (VaR_IRB) e para o modelo mais factível no Brasil (VaR_2682). Embora o CME em Basileia 1 e na SSA não seja estimado por $\mathrm{VaR}$, os números equivalentes ao colchão de capital (a Provisão mais o CME) em Basileia I (CReq_b1) e na abordagem atual (CReq_SSA) são também apresentados para comparação. $K I R B, K \_2682, K \_b 1$ e $K \_3360$ representam apenas o CME nas abordagem IRB fundamental, a brasileira na presença da Resolução CMN n. 2682/99 (CMN, 1999), Basileia I e a abordagem atual com os fatores de ponderação da Circular BCB n.3.360, respectivamente.

Da Tabela 31, depreende-se que VaR_IRB é da ordem de 19,02\% e VaR_2682 ligeiramente superior, 19,64\%, para o cenário base. Ambos superiores ao CVaR paramétrico $(99,9 \%)$ de $17,54 \%$ por Creditrisk+, o que representa um nível seguro para o colchão total contra perdas de crédito.

Vale ressaltar que metade desse colchão do IRB Fundamental (VaR_IRB) vem do CME, KIRB de 10,50\% ou de K_2682, 9,79\%. ${ }^{39}$ Sob Basileia I, o mesmo banco (ou SFN) teria uma colchão total de $16,08 \%$, a provisão mínima seria responsável por 5,71\% e os outros $10,37 \%$ viriam do CME (K_b1). ${ }^{40}$ Deve-se notar que o CME no IRB é parecido com o que seria observado sob Basileia I, mas a perda esperada é mais expressiva no IRB por causa das PDs elevadas observadas no Brasil. As PDs estimadas para esse estudo foram superiores a MProv1, a provisão sob stress1 (Tabela 30).

No modelo atual, o colchão regulatório foi de 14,07\% (CReq_SSA) dos quais 8,46\% vêm do CME (K_3360) - Tabela 31. O valor na abordagem atual (SSA) é menor do que o observado sob Basileia I, porque o fator de ponderação de $75 \%$ sobre o varejo é menor que o de $100 \%$ sob Basileia I. Não estão sendo consideradas exposições off-balance que têm peso relevante no cálculo da SSA como o Fator de Conversão de Crédito. É incorreto afirmar que a

\footnotetext{
${ }^{39}$ K_2682 é menor porque EL no modelo brasileiro é sempre maior que a EL típica do IRB.

${ }^{40}$ Esse valor é menor que $11 \%$, porque não existe recolhimento de capital sobre a parcela já provisionada.
} 
introdução da SSA reduziu o requerimento de capital no Brasil em relação ao observado em Basileia I com base nestes dados. ${ }^{41}$ Além disso, ressalta-se novamente que a amostra desse trabalho contém apenas exposições do banking book e ignora as vertentes de risco de mercado e operacional, introduzidos também com a SSA.

É possível observar na Tabela 30 que a perda de crédito de stress 2 é extremamente severa $(16,83 \%)$, mas os modelos interno calibrados conforme o Edital BCB n.37 subsistiriam com certa folga esse choque.

Deve-se ponderar, contudo, que se fossem as PDs e as LGDs estimadas de modo menos conservador, os modelos IRB facilmente teriam apresentado VaR abaixo do colchão (CReq) de Basileia I e da SSA. Na verdade, se apenas a LGD fosse ajustada para o nível da observada nos países desenvolvidos (45\%), EL seria de 4,64\% e VaR_IRB de 11,96\% inferior a 14,07\% da SSA ou $16 \%$ de Basileia I - Tabela 31, o que deve incentivar os bancos brasileiros a adotarem a abordagem avançada.

Vale ressaltar novamente que os resultados desse trabalho são condicionais às PDs estimadas por matrizes migração e elas consideram apenas as 9 categorias de Resolução CMN n. 2682/99 (CMN, 1999). Como os modelos internos possuem um número maior de categorias, é provável que os valores apresentados neste trabalho estejam superestimados, sobretudo para os cenários de stress adhoc. A existência de mais categorias (sobretudo entre A e B e entre B e C) deverá reduzir a exigência de capital principalmente nos cenários de stress ad hoc como o aqui desenvolvido e também exigido pelo Edital BCB n. 37. Note-se que a falta de categorias intermediárias na Resolução CMN n. 2682/99 (CMN, 1999) acaba tornando stress2 muito severo.

\subsubsection{O Portfólio SFN durante a crise}

A Crise de 2008 e 2009 teve impactos não negligenciáveis sobre a inadimplência no SFN. A inadimplência média salta de 4,17\% para 5,65\% (aumento de 35,5\%). No Quadro 19, apresentam-se as principais variáveis calculadas apenas para o período de crise. As linhas "indicador" apresentam o valor estimado do indicador para a crise, o "incremento", a

\footnotetext{
${ }^{41}$ A SSA marca o início de Basileia II no Brasil. Uma parcela de risco operacional passou a entrar no cálculo e as informações sobre colaterais e muitas outras não estão disponíveis e a aferição precisa desse número foge ao escopo desse trabalho. Acredita-se que a estimação apresentada está viesada para baixo.
} 
elevação ou retração de "indicador" em relação ao Portfólio SFN em todo o período e o "incremento S1", a relação entre o stress 1 e o cenário base com o ciclo completo de 2004 a 2010.

Quadro 19 - Portfólio SFN durante a crise de 2008 a 2009.

\begin{tabular}{|c|c|c|c|c|c|c|c|}
\hline & dloss & pecon & MProv & EL & EL_2682 & CReq_b1 & CReq_SSA \\
\hline indicador & $5,65 \%$ & $6,13 \%$ & $6,82 \%$ & $10,36 \%$ & $11,21 \%$ & $17,07 \%$ & $14,94 \%$ \\
incremento & $35,16 \%$ & $21,38 \%$ & $19,44 \%$ & $13,22 \%$ & $13,80 \%$ & $6,16 \%$ & $6,22 \%$ \\
incremento S 1 & $44,16 \%$ & $48,35 \%$ & $48,32 \%$ & $48,78 \%$ & $15,28 \%$ & $17,92 \%$ \\
\hline
\end{tabular}

\begin{tabular}{|c|c|c|c|c|c|c|c|}
\hline \multicolumn{2}{|c|}{ WLGD } & VaR_IRB & VaR_2682 & KIRB & K_2682 & K_b1 & K_3360 \\
\hline indicador & $74,80 \%$ & $19,92 \%$ & $20,48 \%$ & $10,13 \%$ & $9,27 \%$ & $10,25 \%$ & $8,12 \%$ \\
incremento & $1,28 \%$ & $4,73 \%$ & $4,28 \%$ & $-3,5 \%$ & $-5,31 \%$ & $-1,18 \%$ & $0,04 \%$ \\
\multicolumn{2}{|c|}{ incremento S1 } & $47,13 \%$ & $48,92 \%$ & $55 \%$ & $58,1 \%$ & $-1,85 \%$ & $0,00 \%$ \\
\hline
\end{tabular}

Para o SFN, o choque de 2008-2009 é menos severo que stress 1. Por outro lado, permite avaliar o que aconteceu com as estimativas das variáveis de interesse na crise. No exercício anterior, pecon de 5,05\% no cenário base era elevada para pecon1 de 7,28\%, um choque de $44,16 \%$, literalmente o dobro do choque observado na crise para pecon. Mas a perda por default (dloss) aumentou em 35\%, em parte porque boa parte das classificações de risco era conservadora. A reclassificação em decorrência da crise é da ordem de 21,38\%. Incremento S1 é a relação entre EL1 e EL, VaR_IRB1 e VaR_IRB etc (Quadro 18). Stress1 representa o que aconteceria se este choque ad hoc fosse perfeitamente conhecido ex-ante e afetasse a todas as exposições de crédito por igual e linearmente. Naturalmente, para S1, todas as estimativas reproduzem o choque linear de $44,16 \%$ representado por peconl (salvo por Basileia 1 e a SSA).

Na prática, o efeito (dloss) não é linear e nem poderia ser. Observe-se que o CME é consumido na crise, porque tanto EL, quanto a provisão precisam ser reforçadas apenas nas exposições problemáticas e UL (CME) é transferida para EL, consequentemente KIRB e K_2682 sofrem decréscimos. A exigência total do modelo interno VaR_IRB também aumentaria cerca de 4,28\% durante a crise, o que é indesejável pois reflete como o modelo reforça a prociclicidade durante a crise. Esse fenômeno é mais pronunciado no IRB do que nas demais abordagens (Gráfico 9). 


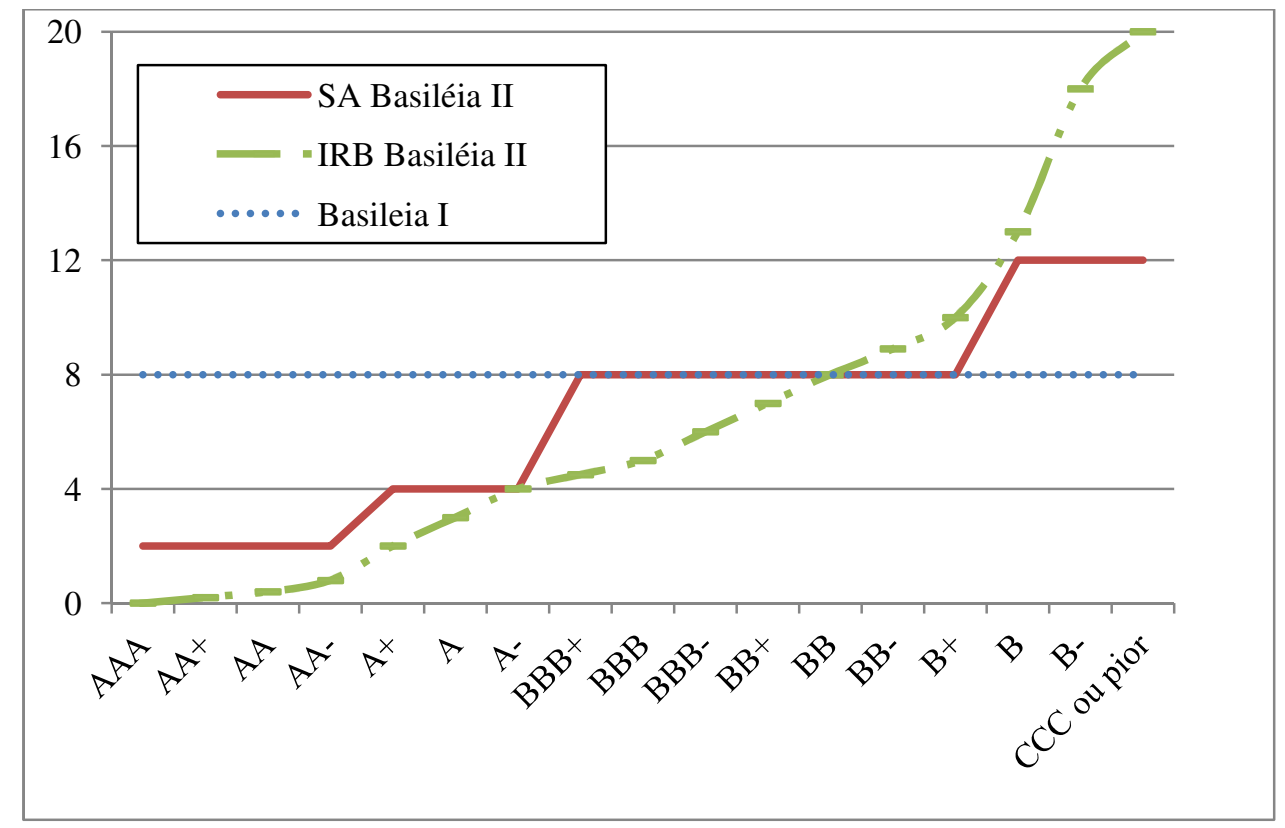

Gráfico 9 - Prociclidade do capital regulatório

FONTE: Gonzalez et al, 2011.

\subsubsection{Varejo, SME e Corporate}

Nesta etapa, procura-se apresentar as características dos portfólios específicos que compõem Basileia II. O Quadro 20 mostra os resultados obtidos no Portfólio SFN nas três famílias de referência.

Quadro 20 - Varejo, SME e Corporate

\begin{tabular}{|lccccccc|}
\hline & WLGD & inadimplência & pecon & PD & MProv & EL & EL2682 \\
Varejo & $78,01 \%$ & $5,78 \%$ & $7,10 \%$ & $14,96 \%$ & $7,66 \%$ & $11,89 \%$ & $13,16 \%$ \\
SME & $75,72 \%$ & $2,98 \%$ & $4,43 \%$ & $9,78 \%$ & $4,41 \%$ & $7,84 \%$ & $8,24 \%$ \\
Corporate & $65,45 \%$ & $1,74 \%$ & $1,54 \%$ & $5,87 \%$ & $2,68 \%$ & $3,87 \%$ & $4,45 \%$ \\
\hline \multicolumn{7}{r}{} & \multicolumn{7}{c}{ VaR_IRB } & VaR_2682 & R & CReq_b1 & CReq_SSA & K_b1 & K_3360 \\
Varejo & $21,67 \%$ & $21,67 \%$ & $6,43 \%$ & $17,82 \%$ & $14,68 \%$ & $10,16 \%$ & $7,02 \%$ \\
SME & $20,28 \%$ & $20,28 \%$ & $14,50 \%$ & $14,92 \%$ & $14,23 \%$ & $10,52 \%$ & $9,82 \%$ \\
Corporate & $13,61 \%$ & $15,63 \%$ & $18,30 \%$ & $13,38 \%$ & $12,88 \%$ & $10,71 \%$ & $10,20 \%$ \\
\hline
\end{tabular}

A LGD para o portfólio de varejo apresentou uma média de 78,01\%. A inadimplência foi a maior entre os três portfólios. Os dados médios ponderados para PD e EL refletem o mix de classificação de risco nessas carteiras. As ELs, especialmente as de varejo, são bem superiores à provisão mínima (PME), refletindo novamente a sua natureza mais forward looking e as PDs elevadas do varejo. Um detalhe importante é que a PME não é conceitualmente alinhada com PDs forward-looking. A Resolução CMN n. 2.682/99 (CMN, 1999) foi essencialmente 
criada para provisionar a inadimplência por atraso, medida no curto prazo e calibrada para tal fim (embora sempre admita maior conservadorismo). Como mencionado, as suas faixas não são adequadas para a estimação de PDs.

O requerimento absoluto de capital VaR_IRB é substancialmente mais elevado para o varejo, naturalmente refletindo seu maior risco. Neste ponto, é importante observar que os requerimentos das abordagens de Basileia I e sobretudo da SSA não refletem essa realidade. O CME em Basileia 1 (K_b1) é naturalmente neutro ao risco, e consequentemente CReq_b1 é mais elevado para o varejo apenas por causa da provisão mínima. K_3360 é efetivamente mais leniente com o varejo em consequência do FPR de 75\% introduzido em 2008. Por esse motivo, a abordagem atual, CReq_SSA, efetivamente negligencia o risco de crédito no varejo e demanda mais capital das modalidades de SME e Corporate onde ele é menos necessário. Esse fenômeno também foi observado em Yanaka (2009).

O atacado é onde se observa o menor risco de crédito. Ainda assim, o CME para corporate é mais elevado do que em Basileia I ou CReq_SSA para a mesma modalidade. A elevada correlação R e as LGDs fundamentais exigidas pelo Edital BCB n.37/11 são responsáveis por isso. Notadamente, o Comitê de Basileia entende que a correlação entre os episódios de default para corporate pode gerar perdas mais danosas do que as do varejo.

Durante a crise de 2008-2009 a elevação da inadimplência nas 3 categorias não foi linear. Ainda que a inadimplência do varejo tenha sido a maior entre as três famílias, o incremento da inadimplência no corporate durante a crise foi muito superior em relação ao observado no período completo - de 2004 a 2010 (Tabela 32).

Tabela 32 - Inadimplência na crise

\begin{tabular}{|c|c|c|c|c|}
\hline & inadimplência & $\begin{array}{c}\text { Aumento da } \\
\text { inadimplência }\end{array}$ & tloss & $\begin{array}{c}\text { Aumento de } \\
\text { tloss }\end{array}$ \\
\hline Varejo & $6,68 \%$ & $15,57 \%$ & $9,67 \%$ & $13,1 \%$ \\
\hline SME & $4,90 \%$ & $64,43 \%$ & $6,65 \%$ & $22,9 \%$ \\
\hline Corporate $^{42}$ & $3,89 \%$ & $123,5 \%$ & $3,62 \%$ & $63,09 \%$ \\
\hline
\end{tabular}

\footnotetext{
${ }^{42}$ A amostra corporate neste estudo é pequena: 330 observações no ciclo, e 92 , na crise.
} 
Com respeito ao SME, suas LGDs, tão elevadas quanto às do varejo, e a correlação R muito mais elevada, geram demandas de capital aparentemente desproporcionais, pois o comportamento da inadimplência no setor de SME é intermediário entre corporate e varejo.

O R do Edital n. 37 segue o referencial do BCBS (2006a), mas não se sabe ao certo o comportamento de $\mathrm{R}$ no Brasil. ANDRADE (2005) sugere que o $\mathrm{R}$ de Basileia seja exagerado. No varejo, o R estimado por eles está próximo de 2,5\% para a pessoa jurídica e $9,26 \%$ para a pessoa física.

\subsubsection{Bancos grandes vs. bancos pequenos}

O Quadro 21 apresenta algumas variáveis de interesse para bancos pequenos e grandes. Busca-se saber se as abordagens analisadas discriminam as diferenças de risco de crédito entre ambos.

Quadro 21 - Bancos Grandes vs. Bancos Pequenos

\begin{tabular}{|c|c|c|c|}
\hline \multicolumn{2}{|c|}{ Bancos Grandes } & \multicolumn{2}{|c|}{ Bancos Pequenos } \\
\hline WLGD & $74,80 \%$ & WLGD & $70,81 \%$ \\
\hline default & $3,94 \%$ & default & $4,95 \%$ \\
\hline tloss & $6,52 \%$ & tloss & $5,17 \%$ \\
\hline tloss1 & $9,37 \%$ & tloss 1 & $7,69 \%$ \\
\hline perdas & $3,19 \%$ & perdas & $3,54 \%$ \\
\hline pecon & $5,35 \%$ & pecon & $4,07 \%$ \\
\hline MProv & $6,07 \%$ & MProv & $4,53 \%$ \\
\hline EL2682 & $9,97 \%$ & EL2682 & $9,47 \%$ \\
\hline CVaR & $18,87 \%$ & CVaR & $19,51 \%$ \\
\hline CVaR_2682 & $19,44 \%$ & CVaR_2682 & $20,30 \%$ \\
\hline CVaR_b1 & $16,41 \%$ & CVaR_b1 & $15,03 \%$ \\
\hline CVaR_SSA & $14,37 \%$ & CVaR_SSA & $13,10 \%$ \\
\hline KIRB & $10,22 \%$ & KIRB & $11,41 \%$ \\
\hline K2682 & $9,47 \%$ & K2682 & $10,83 \%$ \\
\hline K_b1 & $10,33 \%$ & K_b1 & $10,50 \%$ \\
\hline K_b11 & $10,03 \%$ & K_b11 & $10,20 \%$ \\
\hline K_b12 & $9,39 \%$ & K_b12 & $9,52 \%$ \\
\hline K_3360 & $8,29 \%$ & K_3360 & $8,57 \%$ \\
\hline K_33601 & $8,05 \%$ & K_33601 & $8,31 \%$ \\
\hline K_33602 & $7,55 \%$ & K_33602 & $7,75 \%$ \\
\hline
\end{tabular}

Primeiramente, observa-se que a inadimplência é cerca de $26 \%$ maior nos bancos pequenos $(4,95 \%)$ em relação aos bancos grandes $(3,94 \%)$. Apesar disso, a provisão mínima nos bancos grandes $(6,07 \%)$ é $34 \%$ superior à dos bancos pequenos (4,53\%). A única explicação para isso é que os bancos pequenos são significantemente menos conservadores na estimação ou na 
comunicação do risco de crédito para o Banco Central Brasil. O fato de tloss e dloss estarem muito próximas sugere que estes bancos utilizam a aplicação menos conservadora da Resolução CMN n. 2.682/99 (CMN, 1999), isto é, usando quase que exclusivamente o critério mínimo de atraso para atribuir as classificações de risco à seus empréstimos.

A Tabela 33 compara bancos pequenos e grandes no período de crise.

Tabela 33 - Bancos grandes e pequenos na crise

\begin{tabular}{|c|c|c|c|c|c|}
\hline & $\begin{array}{c}\text { Inadimplência } \\
\text { dloss }\end{array}$ & $\begin{array}{c}\text { Aumento } \\
\text { de } \text { dloss }\end{array}$ & $\begin{array}{c}\text { Perdas por } \\
\text { default }\end{array}$ & tloss & Mprov \\
B grandes & $5,08 \%$ & $28,93 \%$ & $4,09 \%$ & $7,92 \%$ & $7,23 \%$ \\
B pequenos & $7,73 \%$ & $56,16 \%$ & $5,77 \%$ & $6,20 \%$ & $5,35 \%$ \\
\hline
\end{tabular}

A Tabela 33 ainda revela que os bancos pequenos foram mais afetados pelo aumento da inadimplência na crise e que a provisão mínima não seria suficiente, em média, para fazer frente às suas perdas de crédito. Portanto, os bancos pequenos, que constituem provisão próximo do mínimo, em média, teriam prejuízos contábeis durante a crise de 2008-2009. Os bancos grandes em média constituíram PME em nível superior ao necessário para suportar as perdas de crédito sem prejuízos contábeis.

Embora o exercício de stress 1 tenha sido duas vezes mais severo do que os efeitos da crise de 2008-2009 para o SFN como um todo, ao analisar independentemente bancos pequenos e grandes, a inadimplência efetiva nos pequenos foi da ordem de stress 1 . É preciso observar que a Tabela 33 traz tloss de 6,20\% e inadimplência de 7,73\%, excedendo tloss 1 de 7,69\% para esses bancos (Quadro 21) .

É importante ressaltar que as PDs desse estudo foram estimadas para o SFN em que a maioria das exposições é de bancos grandes. Ao usar as mesmas PDs, implicitamente, força-se KIRB e K2682 a um mesmo patamar para bancos pequenos (Quadro 21). Esse pressuposto traz um viés baixista para VaR_IRB e VaR_2682 nos bancos pequenos, que na prática são mais arriscados como se depreende da inadimplência.

A Revisão Bibliográfica apontou que bancos pequenos podem não obedecer ao pressuposto de granularidade necessário para que os modelos ASRF como o regulatório IRB sejam consistentes. Esses motivos sugerem a necessidade de um modelo mais rigoroso e ao mesmo tempo mais sensível a risco nesses bancos no espírito de Basileia II. 


\subsection{Abordagem CRBA e as alternativas}

Nesta etapa, apresenta-se e compara-se a performance dos modelos desenvolvidos para este projeto de pesquisa baseados na abordagem dos ratings centralizados. A CRBA atende um dos principais objetivos de Basileia II, que é tornar o CME mais sensível ao risco. Por outro lado, ela não se baseia no uso de informações de ACRs. Como sugerido na Revisão Bibliográfica, um modelo regulatório insensível a ratings externos é desejável porque reduz os incentivos a ratings externos de baixa qualidade. Além disso, as ACRs têm baixa penetração no Brasil. A insensibilidade do capital regulatório ao risco de crédito do tomador, conforme reza a SSA atualmente, também não parece adequada ao Brasil onde os agentes de maior risco (por hipótese os bancos pequenos) podem com facilidade apresentar perdas elevadas em choques não muito severos.

Os bancos pequenos ainda tendem a ser reacionários no que diz respeito ao provisionamento, o que leva a um nível de provisionamento ex ante insuficiente para fazer frente à inadimplência sobretudo durante crises de crédito como a de 2008 e 2009. Se estes modelos são reacionários à provisão, não há razões para crer que eles seriam menos conservadores ao estimar o CME. Assim, qualquer modelo regulatório para estes bancos demandará da Supervisão Bancária maior fiscalização sobre esse grupo. O modelo aqui proposto para bancos pequenos, se implementado, só será tão efetivo quanto for a fiscalização.

São apresentadas quatro versões da CRBA (Quadro 22). As duas primeiras CRBA e a conservadora, CRBAc; e outras duas que sensibilizam apenas as exposições corporate aos fatores de ponderação da CRBA e da CRBAc; a saber, CRBA_CP e CRBAc_CP, respectivamente. Todas essas abordagens cumprem o papel esperado: são tão ou menos conservadoras no cenário base, mas a medida que o risco do portfólio aumenta, tornam-se mais conservadoras que a atual SSA. 
Quadro 22 - Bancos Pequenos nas abordagens alternativas

\begin{tabular}{|c|c|c|c|c|c|c|c|c|}
\hline inadimplência & $4,95 \%$ & \multicolumn{7}{|c|}{ CReq de Crédito em diversas abordagens } \\
\hline & pecon & SSA & CRBA & CRBAc & CRBA_CP & CRBAc_CP & VaR_2682 \\
\hline Cenário base & $4,07 \%$ & $13,10 \%$ & $11,88 \%$ & $\mathbf{1 4 , 8 8 \%}$ & $12,86 \%$ & $\mathbf{1 3 , 7 0 \%}$ & $\mathbf{1 9 , 9 9 \%}$ \\
\hline Cenário S1 & $5,95 \%$ & $\mathbf{1 5 , 6 2 \%}$ & $\mathbf{1 7 , 5 3 \%}$ & $\mathbf{2 1 , 7 4 \%}$ & $\mathbf{1 7 , 5 2 \%}$ & $\mathbf{1 9 , 1 4 \%}$ & $\mathbf{2 8 , 5 0 \%}$ \\
\hline Cenário S2 & $\mathbf{1 3 , 8 7 \%}$ & $21,19 \%$ & $24,83 \%$ & $33,10 \%$ & $24,00 \%$ & $29,00 \%$ & $39,91 \%$ \\
\cline { 2 - 8 } & Mprov & SSA & CRBA & CRBAc & CRBA_CP & CRBAc_CP & K_2682 \\
\hline Cenário base & $4,53 \%$ & $8,57 \%$ & $7,35 \%$ & $10,35 \%$ & $8,33 \%$ & $9,18 \%$ & $10,62 \%$ \\
\hline Cenário S1 & $7,30 \%$ & $8,31 \%$ & $10,23 \%$ & $14,43 \%$ & $10,21 \%$ & $11,84 \%$ & $14,76 \%$ \\
\hline Cenário S2 & $13,44 \%$ & $7,75 \%$ & $11,38 \%$ & $19,66 \%$ & $10,56 \%$ & $15,56 \%$ & $15,97 \%$ \\
\hline
\end{tabular}

Idealmente, deseja-se que o colchão de capital seja capaz de absorver choques adversos sem necessidade de uma recapitalização do banco, porque a prociclidade do CME é indesejável. Se stress 1 é um choque suficientemente rigoroso, espera-se que CReq de CRBA calibrado para o cenário-base subsista completamente às perdas econômicas de stress1 (pecon1). Se stress 2 , é suficientemente rigoroso, espera-se que CRBA seja calibrada de modo a suportar pecon2.

Stress1 não é um stress muito rigoroso e, para os bancos pequenos, a última crise teve o efeito dele. Por outro lado, pecon2 é mais severa e apenas a especificação mais conservadora CRBAc e obviamente VaR_2682 subsistem. CRBAc_CP apenas para corporate chega muito perto, porque as exposições corporate são poucas, mas pesam muito no balanço dos bancos e na amostra (Quadro 22 - negrito).

Se pecon2 é um agravamento de peconl para o qual o SFN está em média capitalizado, isto é, se stress 1 fosse o cenário-base para esses bancos, que querem ex-ante precaver-se, todas as abordagens, inclusive a atual, são adequadas (Quadro 22 - negrito - segunda linha).

O principal objetivo de Basileia II é aproximar o CME do Capital econômico, de modo que bancos com portfólios mais arriscados efetivamente sejam consistentemente mais capitalizados.

A abordagem proposta aqui permite uma calibragem mais fina para episódios de stress, além de ser mais justa, corrigindo incentivos a atuação de bancos com comportamento mais agressivo. Além disso, a especificação mais conservadora (CRBAc) exigiria CReq de 14,88\% (Quadro 22) suficiente para reduzir as perdas às do quantil de 97,5\% de Creditrisk+. A abordagem atual com exposições de bancos pequenos na crise demandou CReq de 13,10\%, abaixo do VaR Paramétrico (95\%) de 13,55\% (Quadro 23). 
Quadro 23 - CVaR - Modelo de Carey (2002) para Bancos Pequenos na crise e Credirisk+

\begin{tabular}{|ccc|ccc|}
\hline Quantis & Creditrisk+ & Carey \\
média & $11,01 \%$ & $3,97 \%$ \\
$\operatorname{VaR}(95 \%)$ & $13,55 \%$ & $9,05 \%$ \\
$\operatorname{VaR}(97,5 \%)$ & $14,29 \%$ & $12,59 \%$
\end{tabular}$\quad$\begin{tabular}{ccc} 
Quantis & Creditrisk+ & Carey \\
$\operatorname{VaR}(99 \%)$ & $15,23 \%$ & $18,08 \%$ \\
$\operatorname{VaR}(99,5 \%)$ & $16,63 \%$ & $20,55 \%$ \\
$\operatorname{VaR}(99,9 \%)$ & $17,54 \%$ & $23,31 \%$ \\
\hline
\end{tabular}

Se os bancos pequenos adotassem o capital econômico e a provisão tendo em vista o requerimento (CReq) necessário sob stress1, a sua referência seria de 15,62\% na abordagem atual (SSA). Para Creditrisk+, haveria menos de $1 \%$ de probabilidade deles incorrerem em perdas superiores a esse valor. Se adotassem a CRBA sob stress 1 (valores superiores a $17,52 \%$ - Quadro 22), a probabilidade diminuiria para $1 \mathrm{em}$ mil.

Todas as CRBAs têm as propriedades desejadas do capital regulatório sob Basileia II. Em especial, permitem discriminar por meio do CME bancos mais e menos arriscados, minimizando incentivos para a arbitragem regulatória e incentivando a concessão de crédito a clientes menos arriscados. Mais importante, a abordagem permite ao Banco Central do Brasil o acompanhamento do portfólio desses bancos mês a mês por matrizes de migração, o que direciona a fiscalização para bancos com matrizes não monotônicas ou com Frequências de Default que excedam um limite predefinido.

O acompanhamento banco a banco pode ser realizado por longos Períodos de tempo, à semelhança do acompanhamento realizado pelas ACRs.

As abordagens conservadoras também poderiam ser usadas indistintamente por todos os bancos e apenas aqueles com matrizes monotônicas seriam certificados para usar os fatores reduzidos da CRBA.

Um detalhe importante é que foram utilizadas as categorias de Resolução CMN n. 2682/99 (CMN, 1999) para criar os Fatores de Ponderação de Risco desse exercício. Todavia, propõese uma escala distinta com mais categorias, por exemplo 11 como sugerido pelo BCBS (2006a), e que seja exclusivamente forward looking. Assim, as exposições com atraso superior a 90 dias já seriam consideradas em default nessas matrizes de migração e a provisão nesse caso (fora dessa matriz) seguiria a Resolução CMN n. 2682/99 (CMN, 1999). 


\section{CONCLUSÃO}

Essa pesquisa avaliou os requerimentos de capital para risco de crédito no Brasil e o impacto sobre bancos pequenos e grandes. Além disso, avalious-se a adoção do modelo IRB, como estipulado no Edital Público BCB n. 37 e propôs uma abordagem alternativa para cálculo do CME em bancos pequenos baseada na abordagem padronizada em vigor na Europa, mas voltada para dados disponíveis nas Centrais de Risco.

Foram propostos três objetivos primários:

1- Verificar qual o requerimento absoluto de capital para as carteiras de crédito bancárias no Brasil baseado na metodologia de CVaR não-paramétrico de Carey (2002) e o paramétrico Creditrisk+.

2- Avaliar o CME nas diferentes abordagens de Basileia: a extinta Basileia I, a SSA (em vigor) e, em especial, o IRB Fundamental (em fase de certificação para bancos grandes).

3- Avaliar a abordagem proposta, a CRBA, em diversas especificações como uma alternativa à SSA para bancos pequenos e médios.

Para Carey (2002), o nível adequado dos requerimentos absolutos de capital deve ser estabelecido sob condições de stress e, nesse estudo, adotou-se o mesmo critério. O VaR de Carey (2002) é consistente com a perda de crédito probabilística observada nos quantis de $95 \%$ a $99,9 \%$. Esses números devem ser interpretados como as piores perdas no SFN a cada $\mathrm{x}$ anos, como 5 em 100, ou em $\mathrm{x}$ bancos do SFN de tamanho $\mathrm{n}$ preestabelecido nas mesmas condições macroeconômicas vigentes nas condições usadas na estimação.

Para bancos pequenos, um número de referência no quantil de CVaR(95\%) foi $9,05 \%$ de perdas por default, consistente com cinco falências em 100 de tamanho similar por perdas de crédito superiores a 9,05\% em um ano de crise similar à de 2008-2009. Esse referencial deve ser comparado com o Requerimento absoluto de capital (CReq) representado pela soma de provisão mínima exigida (PME) e CME. Se o requerimento for fixado nesse nível, em média cinco bancos terão perdas superiores a essa, possivelmente levando à falências.

No espírito de Basileia III, considera-se que o risco sistêmico envolvido na falência de uma banco grande ou sistemicamente importante (SIFIs) é muito expressivo e, por isso mesmo, um quantil mais exigente deve ser estabelecido (Anexo 1). 
Uma estimação alternativa, paramétrica para o portfólio base, o portfólio-SFN, foi de VaR (95\%) de $13,55 \%, \operatorname{VaR}(99 \%)$ de $15,23 \%$ e $\operatorname{VaR}(99,9 \%)$ de $17,5 \%$.

O mínimo regulatório atual cuja adequação também desejava-se averiguar esteve entre [13,32\%;14,82\%] - Tabela 31 - em 99,9\% das simulações. Para bancos pequenos e grandes, ele pode ser diferente dependendo de como administram a classificação de suas operações de crédito no contexto da Resolução CMN n. 2682/99 (CMN, 1999).

Quanto ao IRB com os parâmetros do Edital BCB n. 37, observa-se que as estimativas obtidas para o cenário base são conservadoras o bastante para subsistir o muito severo stress 2 . O colchão de capital e PME estimado para o IRB (VaR_IRB ou VaR_2682) são superiores a 19\% em média e consistentes com menos de uma falência a cada mil anos.

A especificação do IRB na presença da Resolução CMN n. 2682/99 (CMN, 1999) é mais conservadora que a sugerida pelo comitê da Basileia, no entanto, gera certa discricionariedade sobre quanto deve ser a provisão contábil dado o resultado do modelo. Do ponto de vista do regulador, esse detalhe é menos relevante, porque tanto a provisão, quanto o CME viriam essencialmente do atual PR1 sob Basileia III.

Com respeito aos bancos pequenos, observou-se que eles têm perdas mais expressivas e numa crise como a de 2008-2009, se provisionassem o mínimo, em média teriam certas perdas contábeis. Dado o capital econômico necessário em bancos desse porte, o mínimo regulatório é consistente com pouco mais de cinco falências em anos de crises com perdas comparáveis. O IRB ofereceria proteção maior, mas não é adequado para esse tipo de banco.

Para as perdas econômicas esperadas sob stress 1, a abordagem atual (SSA) é consistente com cinco em cem falências em crises similares por ano. Por sua vez, para o mais rigoroso stress 2 , em média os bancos que mantêm o CME próximo do mínimo estariam descapitalizados para fazer frente às perdas de crédito.

No Brasil, as abordagens CRBA propostas oferecem a mesma proteção que a SSA no cenáriobase, mas são mais sensíveis a risco de crédito, discriminando melhor entre bancos pequenos mais e menos arriscados e, possivelmente, produzindo os incentivos para que a gestão dessas entidades escolhesse seu capital econômico de modo mais conservador. Além disso, um melhor acompanhamento desses bancos pela supervisão indireta seria possível, se esses bancos tivessem que informar suas PDs por operação e conformá-los ao tracking error do 
regulador. Aliada a uma fiscalização in loco rigorosa, com uma escala de ratings forwardlooking própria para bancos pequenos, esses modelos podem ser mais seguros que o atual.

Em relação ao requerimento no cenário-base, a abordagem CRBAc foi mais conservadora e resistiria a um choque aleatório da magnitude do proposto stress2. O colchão regulatório exigido nessa abordagem é de $14,88 \%$, e é consistente com uma probabilidade de falência de no máximo 2,5\% a.a nos quantis de Creditrisk+ ou Carey(2002).

Se o capital econômico escolhido pela gestão nesses bancos fosse em linha com as perdas em um não muito severo stress 1 , a probabilidade de perdas superiores às regulatórias seria de 1 em 1.000 na CRBA e de 1 em 100 na abordagem atual.

A CRBA pode teoricamente eliminar a dependência regulatória em ratings externos existente na abordagem padrão (SA) e que não pode ser eficazmente dirimida nas reformas regulatórias americana e europeia. A opção pode ser utilizada na maioria dos países da União Europeia que atualmente possuem Centrais de Risco e adotam a SA para bancos pequenos e médios. A opção pela CRBA pode finalmente cooperar com as atuais propostas regulatórias e minimizar substantivamente a oportunidade para conflitos de interesse na indústria de ratings, pois o interesse de alguns agentes em ratings externos inflacionados ou de baixa qualidade perde sua razão de ser.

Pode-se elencar duas limitações relevantes nesse estudo: a primeira diz respeito à inadequação teórica das faixas de classificação de risco da Resolução CMN n. 2682/99 (CMN, 1999) para a finalidade utilizada nesse trabalho e para a estimação de probabilidade de default. A consequência desse viés é possivelmente CMEs e ELs superestimados. A segunda limitação é inerente ao grau de subjetividade na calibragem do modelo de Carey (2002). Alternativamente, Creditrisk+ oferece uma estimação de capital econômico paramétrica com resultados comparáveis especialmente para bancos grandes.

Finalmente, cabe dizer que o Edital n. 37 foi, de modo geral, rigoroso e esse estudo procura examinar as consequências de seu uso. Maiores investigações são necessárias para a estimação de PDs e sobre o R. Uma replicação de Carey (2002) com amostras maiores também seria desejável.

O quadro final (Quadro 24) sumariza os resultados desse estudo. 
Quadro 24 - Quadro Final

\begin{tabular}{|c|c|c|c|}
\hline $\begin{array}{l}\text { Pergunta } \\
\text { Problema }\end{array}$ & $\begin{array}{c}\text { Objetivo do } \\
\text { Trabalho } \\
\end{array}$ & Metodologia & Resultados \\
\hline \multirow{3}{*}{$\begin{array}{c}\text { Quais as } \\
\text { consequências } \\
\text { sobre o } \\
\text { capital } \\
\text { regulatório } \\
\text { para risco de } \\
\text { crédito da } \\
\text { adoção de } \\
\text { diferentes } \\
\text { abordagens } \\
\text { de Basileia } \\
\text { II? }\end{array}$} & $\begin{array}{l}\text { 1) Estimar o } \\
\text { capital econômico } \\
\text { para um portfólio } \\
\text { que representa o } \\
\text { SFN. Para Carey } \\
\text { (2002), esse é o } \\
\text { requerimento } \\
\text { absoluto de } \\
\text { capital. }\end{array}$ & $\begin{array}{l}\text { 1.1) Estimar o VaR de } \\
\text { Crédito (CVaR) por } \\
\text { modelo de Carey } \\
\text { (2002) para bancos } \\
\text { pequenos e grandes } \\
\text { 1.2) Estimar CVaR } \\
\text { paramétrico por } \\
\text { Creditrisk+ }\end{array}$ & $\begin{array}{l}\text { 1. Baseado nos quantis da distribuição não } \\
\text { paramétrica de CVaR para bancos pequenos } \\
\text { na crise de 2008-2009, o capital econômico } \\
\text { seria de 9,05\% (95\%). } \\
\text { 2. Para o CVaR paramétrico de Creditrisk+, } \\
\text { tem-se no quantil de 99,9\%, 17,5\% (com } \\
\text { provisão) ou um CME de } 11,5 \% \text {. Para } \\
\text { CVaR(95\%), 13,55\% e CME de 7,55\%. } \\
\text { Ambos os CMEs próximos à exigência } \\
\text { regulatória atual, isto é, entre } 8.25 \% \text { e } 11 \% \text {. } \\
\text { Um intervalo de confiança (bootstrap) de } \\
\text { 99,9\% para CME mais provisão mínima } \\
\text { exigida (PME) na abordagem atual } \\
\text { apresentou valores entre [13,32\%:14,82\%], } \\
\text { situando CReq na zona de 95\% a 97.5\% de } \\
\text { Creditrisk+. }\end{array}$ \\
\hline & $\begin{array}{l}\text { 2) Avaliar a } \\
\text { performance do } \\
\text { IRB Fundamental } \\
\text { frente a } \\
\text { abordagem atual } \\
\text { (SSA) em dois } \\
\text { cenários de stress }\end{array}$ & $\begin{array}{l}\text { 2.1) Avaliar na } \\
\text { amostra a Provisão } \\
\text { Mínima e o CME nos } \\
\text { cenários-base nas } \\
\text { abordagens atual e } \\
\text { IRB, durante a crise, e } \\
\text { sob stress1 e stress } 2 \\
\text { para: bancos pequenos } \\
\text { e grandes; e para } \\
\text { 2.2) as carteiras } \\
\text { teóricas de Basileia II: } \\
\text { varejo, atacado r } \\
\text { pequenas e médias } \\
\text { empresas (PME). }\end{array}$ & $\begin{array}{l}\text { 1. Durante a crise, o aumento da } \\
\text { inadimplência em bancos pequenos foi de } \\
56,16 \% \text { e nos grandes de } 28,93 \% \text {. No } \\
\text { entanto, apenas bancos pequenos tiveram } \\
\text { perdas médias superiores à PME. O IRB } \\
\text { Fundamental é mais conservador que todas } \\
\text { as demais abordagens e subsiste ao choque } \\
\text { aleatório mais severo stress } 2 \text {. Na } \\
\text { abordagem atual, o exigível mínimo não } \\
\text { subsiste stress } 2 \text {. }\end{array}$ \\
\hline & $\begin{array}{l}\text { 3) Avaliar a } \\
\text { proposição da } \\
\text { Abordagem } \\
\text { Padronizada dos } \\
\text { Ratings } \\
\text { Centralizados } \\
\text { (CRBA) }\end{array}$ & $\begin{array}{l}\text { 3.1) Avaliar o CME } \\
\text { para as diversas } \\
\text { CRBAs propostas em } \\
\text { bancos pequenos } \\
\text { frente a abordagem } \\
\text { atual e o IRB. }\end{array}$ & $\begin{array}{c}\text { 1. CRBAc para bancos pequenos é a } \\
\text { abordagem mais conservadora dentre as } \\
\text { quatro propostas para CME e representa } \\
\text { uma meia distância entre a abordagem } \\
\text { brasileira atual (SSA) e o IRB. Além disso, } \\
\text { é mais sensível ao risco de crédito } \\
\text { principalmente no Varejo e resiste ao } \\
\text { critério de stress } 2 \text {. }\end{array}$ \\
\hline
\end{tabular}




\section{BIBLIOGRAFIA}

ADELINO, Manuel. Do Investors Rely Only on Ratings? The Case of Mortgage-Backed Securities (Working paper). MIT Sloan School of Management. 2009.

ADMATI, Anat R. et al. Fallacies, Irrelevant Facts, and Myths in the Discussion of Capital Regulation: Why Bank Equity is Not Expensive (Working paper). Stanford GSB Research Paper. n. 2063, 2010.

ALLEN, Linda et al. Understanding Market, Credit, and operational risk: the Value at Risk Approach. [S.1]: Blackwell Publiching, 2004.

ALTMAN, Edward I. et al. Regulation of Rating Agencies. In: ACHARYA, Viral et al. Regulating Wall Street.NJ: John Wiley \& Sons Inc, Hoboken, 2010.

ANDRADE, Fábio W. M. Análise Empírica de correlações no mercado brasileiro. In: SERASA, São Paulo, 2005. Anais eletrônicos, 2005. Disponível em: < http://www.serasaexperian.com.br/ftp2/palestra/7forum_p1-fabio.pdf>. Acesso em: 06/02/2012.

ANGELINI, Paolo et al. Pro-cyclicality of capital regulation: is it a problem? how to fix it? Bank of Italy. Occasional paper. [S.1.], n. 74, 2010.

ANNIBAL, Clodoaldo A. O poder discriminante das Operações de Crédito nas Instituições Financeiras Brasileiras. Trabalhos para Discussão do Bando Central do Brasil. [S.1.]: n.167, 07/2008.

ANTÃO, Paula; LACERDA, Ana. Capital requirements under the credit risk-based framework. Journal of Baking and Finance. [S.1.]: n. 35, p. 1350-1390, 2011.

ARAUJO, Gustavo; MOREIRA, João Maurício de Souza; CLEMENTE, Ricardo. Avaliação de métodos de Exigências de Capital de Risco de Ações no Brasil. Revista de Administração Contemporânea, v. 9, n.2, 2005

AVESANI, Renzo et al. Review and implementation of credit risk models of the financial sector assesment program (Working paper). IMF. [S.1.]: n. 6, v. 134, 06/2006.

BARTH, James et al. The regulation and supervision of banks around the world: a new database. In: LITAN, R; HERRING, R. (Eds). Brookings-Wharton Papers on Financial Services. Washington, D.C.: Brookings Institution Press, 2001. 
BARTH, James et al. Bank regulation and supervision: What works best? Journal of Financial Intermediation. [S.1.], n. 12, p. 205-248, 2004.

BARTH, James et al. Rethinking Bank Regulation: Till Angels Govern. New York: Cambridge University Press, 2006.

BANCO CENTRAL DO BRASIL - BCB. Circular n. 3.325, de 25/08/2006.

. Circular n. 3.360, de 12/09/2007.

. Circular n. 3.415, de 16/10/2008.

. Carta-circular n. 3.419, de 10/12/2009b

. Comunicado n. 12.746, de 09/12/2004.

. Comunicado n. 18.365, de 22/04/2009a.

. Comunicado n. 19.028, de 29/10/2009.

. Comunicado n. 20.615, de 17/02/2011.

. Edital de Audiência Pública n.37, de 2011.

. Relatório de estabilidade do Sistema financeiro nacional. Relatório, abril 2011b.

. Nova Central de Risco (SCR). Documento 3020.

BASEL COMMITTEE ON BANKING SUPERVISION - BCBS. A New Capital Adequacy Framework: First Consultative Paper. Basileia, 1988.

Amendment to the Capital Accord to incorporate market risks. Basileia, 1996.

. The new Basel Capital Accord: First Consultative Paper. Basileia: Janeiro, 1999. 
2001.

The new Basel Capital Accord: Second Consultative Paper. Basileia: Janeiro,

International Convergence of Capital Measurement and Capital Standards: $a$ Revised Framework: Basileia, 2005.

International Convergence of Capital Measurement and Capital Standards: $A$

Revised Framework (Comprehensive Version). Basileia, Junho, 2006a.

. Quantitative Impact Study n.5. Basileia, 2006b.

. Revisions to the Basel II market risk framework. Basileia, 06/2009a.

. Guidance for national authorities operating the countercyclical capital buffer. Basileia, 2010a.

. An Assessment of the Long-Term Impact of Stronger Capital and Liquidity Requirements (LEI Report). Basileia, 2010b.

. Results of the comprehensive quantitative impact study. Basileia, 2010c.

. The Basel Committee's response to the financial crisis, 11/2010. Basileia, 2010d.

. Revisions to the Basel II market risk framework. Updated as of 31 December 2010. Basileia, 2011.

. Stocktaking in the use of credit ratings. Basileia, 06/2009b.

BEAU, Denis et al. Macro-prudential policy and the conduct of monetary policy. Banque de France. Occasional papers. n. 8, 01/2011.

BECK, Thorsten et al. Law, endowments, and finance. Journal of Financial Economics. [S.1], n. 70, p. 137-181, 2003.

Bank supervision and corruption in lending. Journal of Monetary Economics. n. 53, p. 2131-2163, 2006. 
BENINK, Harrald et al. On the Role of Regulatory Banking Capital. Financial markets, institutions \& instruments. n. 17, v. 1, p. 85-96, 2009.

BERNANKE, Ben. The Crisis and the Policy Response. Stamp Lecture. London School of Economics. Proceedings... London, 2009. Disponível em:

$<$ http://www.federalreserve.gov/newsevents/speech/bernanke20090113a.htm>. Acesso em: $11 / 12 / 2010$.

BLACK, Fischer; SCHOLES, Myron. The Pricing of Options and Corporate Liabilities. Journal of Political Economy. University of Chicago Press, n. 81, v. 3, p. 637-654, 1973.

BLUM, Denis. O impacto do requerimento de capital na oferta de crédito bancário no Brasil. Dissertação (Mestrado em Economia) - Faculdade de Economia, Administração e Contabilidade da Universidade de São Paulo, 2005.

CALOMIRIS, Charles. Modern Banking. In: Joel Mokyr (Ed.). The Oxford Encyclopedia of Economic History. Nova York: Oxford University Press, 2003.

CALOMIRIS, Charles. A recipe for ratings reform. Economist's Voice. [S.1]: n. 11, v. 6, 2009a.

Prudential Bank Regulation: What's Broke and How To Fix It? (Working paper). Graduate School of Business Columbia University. [S.1.], 2009b. Disponível em: <http://www0.gsb.columbia.edu/faculty/ccalomiris/papers/PrudentialBankRegulation.pdf>.

Data de Acesso: 05/03/2010.

.The debasement of Ratings: What's Wrong and How We Can Fix It? (Working paper). Graduate School of Business Columbia University. [S.1.], 2010. Disponível em: <http://www0.gsb.columbia.edu/faculty/ccalomiris/RatingAgenciesE21.pdf>. Data de Acesso: 05/03/2010.

CANTOR, R; PARKER, F. The Credit Rating Industry. Federal Reserve Bank of New York. Quarterly Review. Summer-Fall, 1994.

CAREY, Mark. Credit Risk in Private Debt Portfólios. Journal of Finance. n. 53, v. 4, p. 1363-1387, 1998.

Dimensions of Credit Risk and Their Relationship to Economic Capital Requirements. In: MISHKIN, Frederic (Org). Prudential Supervision: What works and What Doesn't? [S.1.]: University of Chicago Press, 2001. 
A guide to choosing absolute bank capital requirements. Journal of Banking \&

Finance [S.1.]: Elsevier, n. 26, p. 929-951, 2002.

CARNEIRO, Fabio Lacerda et al. Novo Acordo da Basileia: estudo de caso para o contexto brasileiro. Resenha BM\&F. n. 163, 2005.

CHARTERED FINANCIAL ANALYST Institute -CFA Institute. Comparison of DoddFrank Act with IWG and CFA Institute views. Relatório, 12/08/2010. Disponível em: $<$ http://www.cfainstitute.org/ethics/Documents/comparison_of_financial_regulatory_proposal s.pdf>. Acesso em: 30/09/2011.

COMITÊ DE REGULAÇÃO E FISCALIZAÇÃO DOS MERCADOS FINANCEIRO, DE CAPITAIS, DE SEGUROS, DE PREVIDÊNCIA E CAPITALIZAÇÃO - COREMEC. Levantamento do uso regulatório de classificação de risco no Brasil, 2010. Disponível em: <www.bcb.gov.br>. Acesso em: 25/02/2011.

CONSELHO MONETÁRIO NACIONAL - CMN. Resolução n. 2.099 de 17 de agosto de 1994.

. Resolução n. 2.784 de 27 de novembro de 1997

. Resolução n. 2.682 de 22 de dezembro de 1999.

Resolução n. 3.490 de 29 de agosto de 2007.

Resolução n. 3.543 de 28 de fevereiro de 2008a.

Resolução 3.633 de 3 de novembro de 2008b.

Resolução 3.691 de 23 de março de 2009a.

Resolução 3.721 de 30 de abril de 2009b.

Resolução 3.790 de 24 de setembro de 2009c.

COSTA, Ana Carla; BLUM, Denis. Inadimplência do setor bancário brasileiro. Revista SERASA. n. 65, 2008. 
COVAL, Joshua et al. The economics os structured finance (Working paper). Harvard Business Scholl. [S.1.]: n. 60, 2009.

COVITZ, Daniel; HARRISON, Paul. Testing Conflicts of Interest at bond rating agencies with market anticipation: Evidence that reputation incentives dominate (Working paper). FEDS. [S.1.]: n. 68, 2003.

CREDIT SUISSE FIRST BOSTON - CSFB. Creditriskt: A Credit risk management framework. Technical document, 1997.

CRUZ, Marcelo. Operational risk modeling and analysis: theory and practice. Londres: Risk Books, 2004.

DANNHAUSER, Bob. CFA Charterholders to Credit Rating Firms: Vote of No Confidence, 2011. CFA Institute: Market integrity insights (Blog). Disponível em: $<$ http://blogs.cfainstitute.org/marketintegrity/2011/08/01/cfa-charterholders-to-credit-ratingfirms-vote-of-no-confidence/>. Acesso em: 10/09/2011.

DEMIRGUÇ-KUNT, Asli et al. Regulations, market structure, institutions, and the cost of financial intermediation. Journal of Money, Credit and Banking. n. 36, p. 593-622, 2004.

DUPOY, Rodrigues. Loan Loss Distribution (Working paper). Banco Central del Uruguay, 2007.

EFRON, Bradley. (1981). Nonparametric estimates of standard error: The jackknife, the bootstrap and other methods. Biometrika. n. 68, p. 589-591, 1981.

EICHENGREEN, Barry. International Financial Regulation After Crisis. Daedalus. [S.1], n.4, v. 139, p. 107-128, Fall 2010.

ELIZALDE, Abel. Credit Risk Models III: Reconciliation Reduced - Structural Models (Working paper). 2005. Disponível em: <http://www.abelelizalde.com/>. Acesso em: 20/10/2011.

EUROPEAN CENTRAL BANK - ECB. The use of portfólio credit risk models in Central Banks. Occasional Paper Series. n. 64, Julho de 2007.

Credit Rating Agencies: Developments and Policy Issues. ECB Monthly Bulletin. p. 107-117, Maio de 2009. 
EUROPEAN COMMISSION. Public Consultation on Credit Rating agencies. 5/11/2010. Disponívelem :

<http://ec.europa.eu/internal_market/consultations/docs/2010/cra/cpaper_en.pdf>

. European Commission's public consultation on Credit Rating Agencies Eurosystem reply. 23/02/2011. Disponível em:

$<$ http://www.ecb.int/pub/pdf/other/ecpublicconsultationcreditratingagencieseurosystemreplye n.pdf $>$. Acesso em: 10/05/2011.

EUROPEAN PARLIAMENT. Regulation (EC) No. 1060 of the European Parliament and of the Council on Credit Rating Agencies. Sep 16, 2009.

Draft report: on credit rating agencies: future perspectives. Relatório. Committee on Economic and Monetary Affairs. 24/10/2011.

FINANCIAL SERVICES AUTHORITY - FSA. Sovereign, Bank and Corporate. HPE Feedback, 2010. Disponível em: <http://www.fsa.gov.uk/pubs/international/sbc_hpe.pdf>

FINANCIAL STABILITY BOARD - FSB. Principles for Reducing reliance in CRA ratings. Outubro de 2010. Disponível em: <www.financialstabilityboard.org >

FREIXAS, Xavier; ROCHET, Jean-Claude. Microeconomics of Banking. Boston: MIT Press, 1997.

FRENCH, Kenneth R. et al. The Squam Lake Report: Fixing the financial system. Oxford: Princeton University Press, 2010.

GOODHART, Charles. Financial Regulation, Credit Risk and Financial Stability. National Institute Economic Review. n.19, 2005

GONZALEZ, Rodrigo et al. Why are CRAs so important to banking regulation? Understanding rating centered regulatory arbitrage. MONEY, ECONOMY and MANAGEMENT. Anais... Paris: Jul. 2011.

GORDY, Michael, B. A comparative anatomy of credit risk models. Journal of Banking \& Finance. Elsevier, n. 1-2, v. 24, p. 119-149, 2000.

.A risk-factor model foundation for ratings-based bank capital rules. Journal of Financial Intermediation. n. 12, p. 199-232, 2003. 
HALDANE. Capital Discipline, Bank of England Paper based on a Speech given at the American Economic Association, Denver, USA, 01/09/2011. Disponível em: <http://www.bankofengland.co.uk/publications/speeches/2011/speech484.pdf>

HENDRICKS, D; HIRTLE, B. Bank Capital Requirements for Market Risk: the internal model approach. FRBNY Economic Policy Review, dec, 2012

HULL, John; WHITE, Alan. The risk of tranches created from residential mortgages (Working paper). University of Toronto, 2009.

INTERNATIONAL MONETARY FUND. Global Financial Stability Report. Washington, DC: IMF, Outubro de 2008. Disponível em: < www.imf.org>

Global Financial Stability Report. Washington, DC: IMF, Outubro de 2009. Disponível em: <www.imf.org>

JACKSON, Patricia. Dimensions of Credit Risk and Their Relationship to Economic Capital Requirements. In: MISHKIN, Frederic (Org). Prudential Supervision: What works and What Doesn't? [S.1.]: University of Chicago Press, 2001.

JAPPELLI, Tullio; PAGANO, Marco. Information sharing, lending and defaults: crosscountry evidence. Journal of Banking and Finance. n. 10, v. 26, p. 2023-54, Outubro, 2001.

JORION, Phillipe et al. Informational Effects of Regulation FD: Evidence from Rating Agencies. Journal of Financial Economics. n. 76, p. 309-330, 2005.

KRETZCHNAR, Gavin. Integrated models of capital adequacy - Why banks are undercapitalised. Jornal of Banking and Finance. 2011

LAEVEN, Luc; LEVINE, Ross. Is there a diversification discount in financial conglomerates? Journal of Financial Economics. n. 85, p. 331-367, 2007.

MAJNONI, Giovanni; POWEL, Andrew. Reforming bank capital requirements implications of Basel II for Latin American Countries. Economia. 2005.

MEIRELLES, Anthero. Novo Sistema de Informações de Crédito. BCB. Disponível em:<http://www.bcb.gov.br/pec/appron/apres/Apresentacao_Diretor_Anthero_NovoSistemaC redito_SCR_12.12.2011.pdf>. Acesso em: 29/12/2011. 
MERTON, Robert. On the pricing of corporate dect: the risk structure of interest rates. Journal of Finance. v. 29, 1974.

MCNEIL, Alexander J. et al. Quantitative risk management: concepts, techniques, and tools. [S.1]: Princeton Series in Finance, 2005.

MELCHIORI, Mario R. CreditRisk+ by Fast Fourier Transform (July 2004). YieldCurve, August 2004.

MILLER, Margareth. Credit reporting system and the international economy. [S.1]: MIT Press, 2003.

NIER, Erlend; BAUMANN, Ursel. Market Discipline, Disclosure and Moral Hazard in Banking. EFA Annual Conference Paper. 2003

OLIVEIRA, Raquel de Freitas; SCHIOZER, R.F; BARROS, Lucas. Financial Crisis and Cross Border Too Big to Fail Perception. In: MIDWEST FINANCIAL ANNUAL MEETING 2012, New Orleans. Proceedings...New Orleans, 2012

PARTNOY, Frank. Sunlight shows cracks in crisis rescue story. Financial Times. Nova York, 4/12/2010. Disponível em: <www.ft.com>. Acesso em: 4/12/2010.

POWELL, Andrew. A Capital Accord for Emerging Markets (Working paper). World Bank, 2002.

Basel II and Developing Countries: Sailing through the Sea of Standards. World Bank Series. 2004.

PRICE WATERHOUSE COOPERS - PWC. Financial Services Institute. The New Basel III Framework: Navigating Changes in Bank Capital Management. PWC FSI Report. New York, 2010.

ROGOFF, Kenneth. The way forward for global financial policy. Project Syndicate. Disponível em: <http://www.project_syndicate.org/commentary/rogoff29>. Data: 13/4/2007

ROUBINI, Nouriel; MIHM, Stephen. Crisis Economics: a crash course in the future of finance. Nova York: Penguim Press HC, 2009. 
ROY, Patrick Van. Credit Ratings and the standardized approach to credit risk (Working paer). European Centre for Advanced Research in Economics and Statistics (ECARES). Université Libre de Bruxelles, 2005.

SAUNDERS, Anthony. Credit Risk Measurement: New Approaches to Value at Risk and Other Paradigms. 1. ed. Wiley: 1999.

SCHECHTMAN, Ricardo et al. Credir risk measurement and the regulation of bank capital and provision requirements in Brazil - a corporate analysis. Trabalho para discussão do Banco Central do Brasil. n. 91, 2004.

SCHECHTMAN, Ricardo. A Central de Risco de Crédito no Brasil: uma análise da utilidade da informação. Trabalho para discussão do Banco Central do Brasil. n. 119, 2006 a.

Uma investigação baseada em reamostragem sobre requerimentos de capital para risco de crédito no Brasil. Trabalho para discussão do Banco Central do Brasil. n. 127, $2006 b$.

; GAGLIANONE, Wagner P. 2011. Macro Stress Testing of Credit Risk Focused on the Tails. Central Bank of Brazil, Research Department. Working Papers Series. 241.

SILVA JR., Altamiro. Itaú usou linhas de crédito do FED durante a crise. Agência Estado. São Paulo, 3/12/2010. Disponível em:

$<$ http://economia.estadao.com.br/noticias/negocios+geral,itau-usou-linhas-de-credito-do-feddurante-a-crise,46070,0.htm>. Acesso em: 23/12/2010.

SILVA, Antonio C. M. da. et al. Correlação de default: uma investigação empírica de créditos de varejo no Brasil. Trabalho para discussão do Banco Central do Brasil. n. 208, 2010.

SMITH, Rot; WALTER, Ingo. Rating Agencies: Is There an Agency Issue? In: LEVICH, Richard $\mathrm{M}$ et al. (Orgs.). Ratings, Rating Agencies and the Global Financial System. Boston: Kluwer, 2002.

SONG, Inwon. Foreign Banking Supervision and challenges to emerging market supervisors (Working paper). IMF. Maio, 2004

STIGLITZ, Joseph. Freefall. Nova York: The New Press, 2010a.

The Stiglitz Report. Nova York: The New Press, 2010b. 
SY, Amadou. The Systemic Regulation of Credit Rating Agencies and Rated Markets (Working paper). IMF. 2009. Disponível em: <www.imf.org>

TETT, Gillian. Rating agencies in a bind as pressures mount. Financial Times, 15/12/2010. Disponível em: <www.ft.com>.

THAKOR, Anjan. The Economic consequences of proposed regulation on NRSRO regulation (Working paper). 2010.

TRUCHARTE, Carlos A. A Review of Credit Registers and their use for Basel II. FSI Award Paper. Financial Stability Institute, 2004. Disponível em: <www.bis.org>. Acesso em: 23/01/2011.

TRIANA, Pablo. Basel III still contains the seeds of chaos. Financial Times, 19/9/2010.

UNITED STATES OF AMERICA - USA. Congress. House of Representatives. The Federal Reserve Act, de 23 de dezembro de 1913.

.Congress. House of Representatives. Bill H.R 1424. Emergency Economic Stabilization Act of 2008, de 3 de outubro de 2008. Disponível em: <www.financialstability.gov>. Acesso em: 24/12/2010.

Congress. House of Representatives. Bill H.R 4173, de 5 de janeiro de 2010; sancionada pelo senado em 20/5/2010a. The Dodd-Frank Wall Street Reform and Consumer Protection Act of 2010.

Congress. Senate. The Credit Rating Agencies Reform of 2006, 2a Seção, 2006.

$-$ . Board of Governors of the Federal Reserve System. Credit and Liquidity Programs and the Balance Sheet, 2010b. Disponível em: $<\mathrm{http}: / / \mathrm{www}$. federalreserve.gov/monetarypolicy/bst_fedsbalancesheet.htm>. Acesso em: $11 / 12 / 2010$.

Board of Governors of the Federal Reserve System. Minutes of the Federal Open Market Committee November 2-3, 2010, de 23 de novembro de 2010d. Disponível em: <www.federalreserve.gov>. Acesso em: 27/01/2011.

. United States Department of the Treasury. Troubled Asset Relief Progam: Two Years retrospective, 2010c. Disponível em: <www.financialstability.gov>. Acesso em: 24/12/2010. 
UTZIG, Siegfried. The Financial Crisis and the Regulation of Credit Rating Agencies: A European Banking Perspective (Working paper). ADBI. Tokyo: Asian Development Bank Institute, n. 188, 2010. Disponível:

em:<http://www.adbi.org/workingpaper/2010/01/26/3446.credit.rating.agencies.european.ban king/>

VASICEK, Oldrich A. The probability of loss on loan portoflio. KMV Corporation Document. 1987.

The distribution of loans portfólio value. Risk. n.15, 2002.

VASQUEZ, Francisco et al. A macro stress test model of credit risk for the Brazilian banking sector. Journal of Financial Stability. 2011.

WILDE, Tom. CreditRisk+. In: DAS, S. (Ed.) Credit Derivatives and Credit Linked Notes. 2. ed., 2000.

VISCUSI, W. K. et al. Economics of regulation and antitrust. 4. ed. Cambridge: Massachussets Institute of Technology, 2005.

WYATT, Katherine. The Standardized Approach in the U.S.: Credit Risk Mitigation and other Options (Working paper). New York State banking department. 2007.

WOLF, Martin. A Reconstrução do Sistema Financeiro Global. Rio de Janeiro: Elsevier, 2009.

WHITE, Lawrence J. Markets: The Credit Rating Agencies. Journal of Economic Perspectives. n. 24, p. 211-226, 2010.

YANAKA, Guilherme M. Modelo interno de risco de crédito de Basileia II: Possíveis impactos no capital mínimo exigido dos bancos. Dissertação (Mestrado em Economia) Escola de Economia da Fundação Getúlio Vargas, São Paulo, 2009.

; HOLLAND, Márcio. Basileia II e Exigência de Capital para risco de crédito nos bancos no Brasil. Revista Brasileira de Finanças. n. 8, v. 2, p. 167-195, 2010. 


\section{ANEXO 1: OS ACORDOS DA BASILEIA}

\begin{tabular}{|c|c|c|c|c|}
\hline & Basileia I & $\begin{array}{l}\text { Basileia II - } \\
\text { Abordagem } \\
\text { Padronizada }\end{array}$ & $\begin{array}{c}\text { Basileia II - } \\
\text { Abordagem IRB }\end{array}$ & $\begin{array}{l}\text { Basileia III e } \\
\text { Basileia II.5 }\end{array}$ \\
\hline Ano & $\begin{array}{c}\text { Documento base de } \\
1988\end{array}$ & $\begin{array}{l}\text { Documento base de } \\
\text { junho de } 2004\end{array}$ & $\begin{array}{l}\text { Documento base de } \\
\text { junho de } 2004\end{array}$ & $\begin{array}{l}\text { Documento base de } \\
12 / 09 / 2010\end{array}$ \\
\hline Contexto Base & $\begin{array}{l}\text { Após a Crise de 1980, } \\
\text { principalmente por } \\
\text { causa das perdas em } \\
\text { países latino- } \\
\text { americanos e } \\
\text { intermináveis acordos } \\
\text { sobre descontos tanto } \\
\text { na Europa quanto nos } \\
\text { EUA culminando em } \\
\text { muitas perdas (Plano } \\
\text { Brady) }\end{array}$ & $\begin{array}{c}\text { Depois de muitas } \\
\text { crises como as de } \\
\text { México, Brasil, } \\
\text { Rússia e Leste } \\
\text { Asiático aliadas a } \\
\text { diversos escândalos } \\
\text { de corrupção, falta de } \\
\text { supervisão e de } \\
\text { controles internos } \\
\text { especialmente de } \\
\text { gestão risco de } \\
\text { mercado }\end{array}$ & $\begin{array}{l}\text { Depois de muitas } \\
\text { crises como as de } \\
\text { México, Brasil, } \\
\text { Rússia e Leste } \\
\text { Asiático aliadas a } \\
\text { diversos escândalos } \\
\text { de corrupção, falta de } \\
\text { supervisão e de } \\
\text { controles internos } \\
\text { especialmente de } \\
\text { gestão risco de } \\
\text { mercado }\end{array}$ & $\begin{array}{c}\text { Depois da Crise de } \\
\text { Crédito 2007-2009 } \\
\text { causando enormes } \\
\text { perdas no sistema } \\
\text { financeiro e recessão, } \\
\text { especialmente na } \\
\text { Europa e nos EUA às } \\
\text { custas dos } \\
\text { contribuintes. }\end{array}$ \\
\hline $\begin{array}{l}\text { Principal } \\
\text { Objetivo }\end{array}$ & $\begin{array}{l}\text { Criar Requerimentos } \\
\text { Mínimos de Capital } \\
\text { sensíveis ao risco de } \\
\text { crédito }\end{array}$ & $\begin{array}{c}\text { Criar requerimentos } \\
\text { de capital para risco } \\
\text { de mercado e } \\
\text { operacional, além de } \\
\text { estruturar práticas de } \\
\text { supervisão (Pilar 2) e } \\
\text { disciplina de mercado } \\
\text { (Pilar 3). }\end{array}$ & $\begin{array}{l}\text { Dar mais flexibilidade } \\
\text { aos bancos grandes } \\
\text { para obter maior } \\
\text { alavancagem } \\
\text { baseados nos seus } \\
\text { modelos de gestão de } \\
\text { risco superiores e a } \\
\text { sua habilidade de } \\
\text { obter financiamento } \\
\text { estável. }\end{array}$ & $\begin{array}{l}\text { Enfrentar o problema } \\
\text { de too-big-to-fail, } \\
\text { criar controles de } \\
\text { liquidez e } \\
\text { alavancagem e } \\
\text { reprimir a arbitragem } \\
\text { regulatória. O acordo } \\
\text { foi concebido com } \\
\text { compromisso dos } \\
\text { membros do G-20 e } \\
\text { implementação } \\
\text { esperada para janeiro } \\
\text { de } 2013 \text {. }\end{array}$ \\
\hline $\begin{array}{l}\text { Risco de } \\
\text { Crédito I }\end{array}$ & APR criado & $\begin{array}{l}\text { Novas categorias de } \\
\text { APR são criadas para } \\
\text { reconhecer a } \\
\text { existência de } \\
\text { colateral, items off- } \\
\text { balance passam a ser } \\
\text { considerados e as } \\
\text { opiniões das ECAIs } \\
\text { são usadas para } \\
\text { classificar as } \\
\text { exposições em faixas } \\
\text { de APRs. }\end{array}$ & $\begin{array}{c}\text { Os APRs são } \\
\text { substituídos por } \\
\text { modelos internos com } \\
\text { faixas de risco } \\
\text { definidas por cada } \\
\text { banco e para cada } \\
\text { exposição por meio } \\
\text { da calibração dos } \\
\text { parâmetros: PD, } \\
\text { LGD,EAD e M. }\end{array}$ & $\begin{array}{l}\text { No IRB; exceto pela } \\
\text { inclusão da } \\
\text { securitização } \\
\text { obrigatoriamente no } \\
\text { banking book, nada é } \\
\text { feito. Observe-se que } \\
\text { é muito difícil } \\
\text { modificar qualquer } \\
\text { coisa no IRB porque } \\
\text { os parâmetros não são } \\
\text { públicos e a } \\
\text { supervisão não tem } \\
\text { como controlá-los e } \\
\text { antecipá-los. }\end{array}$ \\
\hline
\end{tabular}




\begin{tabular}{|c|c|c|c|c|}
\hline & Basileia I & $\begin{array}{c}\text { Basileia II - } \\
\text { Abordagem } \\
\text { Padronizada }\end{array}$ & $\begin{array}{c}\text { Basileia II - } \\
\text { Abordagem IRB }\end{array}$ & $\begin{array}{l}\text { Basileia III e } \\
\text { Basileia II.5 }\end{array}$ \\
\hline $\begin{array}{l}\text { Risco de } \\
\text { Crédito II }\end{array}$ & $\begin{array}{l}\text { APRs criados } 0 \% \text {, } \\
20 \%, 50 \% \text { e } 100 \% \\
\text { (faixas de risco). }\end{array}$ & $\begin{array}{l}\text { Um Novo APR de } \\
\text { varejo }(75 \%) \text { é criado } \\
\text { e diversos colaterais } \\
\text { são reconhecidos. As } \\
\text { exposições podem } \\
\text { assumir APRs de } 0 \% \\
\text { a } 150 \% \text { baseados na } \\
\text { opinião das agências } \\
\text { de rating. }\end{array}$ & $\begin{array}{c}\text { A estimação do } \\
\text { capital econômico e } \\
\text { regulatório é feio pelo } \\
\text { banco com base em } \\
\text { suas estimativas dos } \\
\text { parâmetros acima. } \\
\text { Muitas categorias de } \\
\text { exposição são } \\
\text { desenvolvidas e as } \\
\text { faixas de risco são } \\
\text { criadas livremente } \\
\text { pelo banco. }\end{array}$ & $\begin{array}{c}\text { Na abordagem } \\
\text { padronizada, a } \\
\text { securitização também } \\
\text { é removida do trading } \\
\text { book. Note que o } \\
\text { principal driver é a } \\
\text { opinião das ECAIs } \\
\text { que também não pode } \\
\text { ser controlada ou } \\
\text { antecipada. }\end{array}$ \\
\hline $\begin{array}{l}\text { Risco de } \\
\text { Mercado }\end{array}$ & $\begin{array}{l}\text { Inexistente em 1988, } \\
\text { mas introduzido por } \\
\text { uma emenda de } 1996 \\
\text { - metodologia VAR. }\end{array}$ & Maturity Ladder & $\begin{array}{l}\text { VAR internamente } \\
\text { calibrado pelos } \\
\text { bancos. O modelo } \\
\text { geral do banco para } \\
\text { geração dessas cargas } \\
\text { deve ser certificado } \\
\text { pela supervisão. }\end{array}$ & $\begin{array}{l}\text { Os requerimentos de } \\
\text { capital para a } \\
\text { securitização } \\
\text { aumentam muito para } \\
\text { impedir a arbitragem } \\
\text { regulatória no uso do } \\
\text { trading book. } \\
\text { Também é criado um } \\
\text { Stressed value-at-risk } \\
\text { (sVaR) e a estimação } \\
\text { fica mais } \\
\text { conservadora com um } \\
\text { multiplicador. } \\
\text { Requerimentos de } \\
\text { capital para risco de } \\
\text { contraparte são } \\
\text { elevados e é criado o } \\
\text { CVA. }\end{array}$ \\
\hline $\begin{array}{l}\text { Risco } \\
\text { Operacional }\end{array}$ & NA & $\begin{array}{c}\text { Definido pelo } \\
\text { Supervisor em geral } \\
\text { como uma parcela do } \\
\text { faturamento. }\end{array}$ & $\begin{array}{l}\text { Os modelos devem } \\
\text { ser formulados pelos } \\
\text { bancos e validados } \\
\text { pelo supervisor. }\end{array}$ & $\begin{array}{c}\text { Nenhuma mudança } \\
\text { mencionada. }\end{array}$ \\
\hline $\begin{array}{l}\text { Risco de } \\
\text { Liquidez }\end{array}$ & NA & NA & NA & $\begin{array}{l}\text { Dois índices um de } \\
\text { curto e um de longo } \\
\text { prazo são sugeridos. }\end{array}$ \\
\hline
\end{tabular}




\begin{tabular}{|c|c|c|c|c|}
\hline & Basileia I & $\begin{array}{l}\text { Basileia II - } \\
\text { Abordagem } \\
\text { Padronizada }\end{array}$ & $\begin{array}{c}\text { Basileia II - } \\
\text { Abordagem IRB }\end{array}$ & $\begin{array}{l}\text { Basileia III e } \\
\text { Basileia II.5 }\end{array}$ \\
\hline $\begin{array}{l}\text { Definição de } \\
\text { Capital }\end{array}$ & $\begin{array}{c}\text { Capital é } \\
\text { principalmente PR1 } \\
\text { (em 1988) contendo } \\
\text { Ações ordinárias, } \\
\text { Lucros retidos e } \\
\text { reservas qualificadas. }\end{array}$ & $\begin{array}{l}\text { PR2 largamente } \\
\text { difundido }\end{array}$ & $\begin{array}{l}\text { PR2 largamente } \\
\text { difundido }\end{array}$ & $\begin{array}{l}\text { PR2 fica muito } \\
\text { reduzido, envolvendo } \\
\text { um plano de } 10 \text { anos } \\
\text { para remover do } \\
\text { banco instrumentos } \\
\text { que não sejam } \\
\text { conversíveis em } \\
\text { capital ou que não } \\
\text { possam ter dividendos } \\
\text { suspensos. }\end{array}$ \\
\hline $\begin{array}{l}\text { Índice de } \\
\text { Basileia }\end{array}$ & $\begin{array}{l}\text { Definido } \\
\text { individualmente pelo } \\
\text { regulador local (BIS } \\
\text { sugeriu } 8 \% \text { ou } \\
\text { superior) }\end{array}$ & $\begin{array}{c}\text { Definido } \\
\text { individualmente em } \\
\text { cada país. Basileia } \\
\text { sugeriu 2\% para ações } \\
\text { ordinárias, } 4 \% \text { para } \\
\text { PR1 e PR total de } 8 \% \text {. }\end{array}$ & $\begin{array}{c}\text { Definido } \\
\text { individualmente em } \\
\text { cada país. Basileia } \\
\text { sugeriu } 2 \% \text { para ações } \\
\text { ordinárias, } 4 \% \text { para } \\
\text { PR1 e PR total de } 8 \% \text {. }\end{array}$ & $\begin{array}{c}\text { Elevado para 10,5\% } \\
\text { (em 2019) já } \\
\text { incluindo um buffer } \\
\text { de conservação, mas } \\
\text { sem incluir o capital } \\
\text { contra-cíclico. A } \\
\text { composição no } \\
\text { entanto muda: 4\% } \\
\text { para ações ordinárias, } \\
\text { 7\% para PR1. }\end{array}$ \\
\hline $\begin{array}{l}\text { Colchões } \\
\text { Adicionais }\end{array}$ & NA & $\begin{array}{l}\text { Instrumentos híbridos } \\
\text { de Capital e Dívida se } \\
\text { expandiram muito e } \\
\text { foram largamente } \\
\text { usados. }\end{array}$ & $\begin{array}{l}\text { Instrumentos híbridos } \\
\text { de Capital e Dívida se } \\
\text { expandiram muito e } \\
\text { foram largamente } \\
\text { usados. }\end{array}$ & $\begin{array}{l}\text { Criado um colchão } \\
\text { contra-cíclico que } \\
\text { pode representar até } \\
\text { 2,5\%. Do PR1 e um } \\
\text { de conservação de } \\
\text { 2,5\% também. }\end{array}$ \\
\hline
\end{tabular}




\section{APÊNDICE A: CÓDIGOS STATA PARA OS ESTIMADORES}

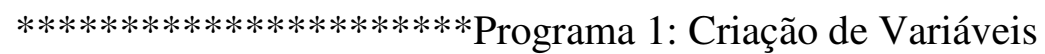

clear all

set memory $3000 \mathrm{~m}$

set matsize 11000 , permanently

use "SuperBase00.dta"

save "Simples.dta", replace

* Cria Default

gen default $=0$

replace default $=1$ if CAVencida90 $>0$

\section{* Cria Crise}

gen crisis $=0$

replace crisis $=1$ if data $==200812 \mid$ data $==200906 \mid$ dat $a==200912 \mid$ data $==201006$

*Cria Categorias DSIG: Consumo, Aq Bens, Rural, Outros-PF, CGiro, Invest, AESPEC, Outros-PJ

$$
\text { gen credit="pf" if } \mathrm{PF}==1
$$

replace credit $=" p j "$ if $\mathrm{PF}==2$

recode $\mathrm{PF}(2=1)$ if Type==202/Type==203 /// Corrige um erro na Base em que certas PJs estão ///

///classificadas nas categorias de emprésitmo pessoal

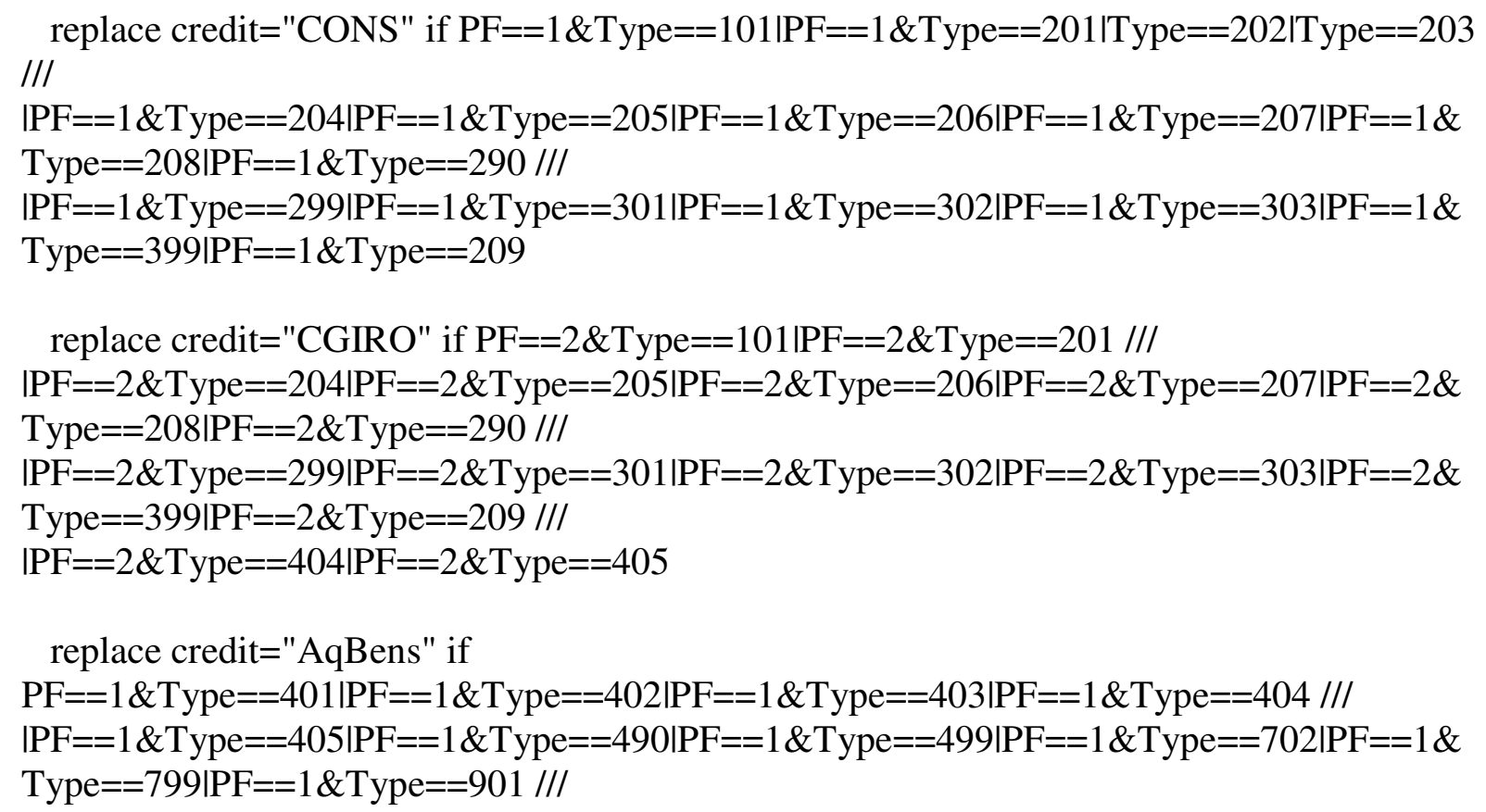




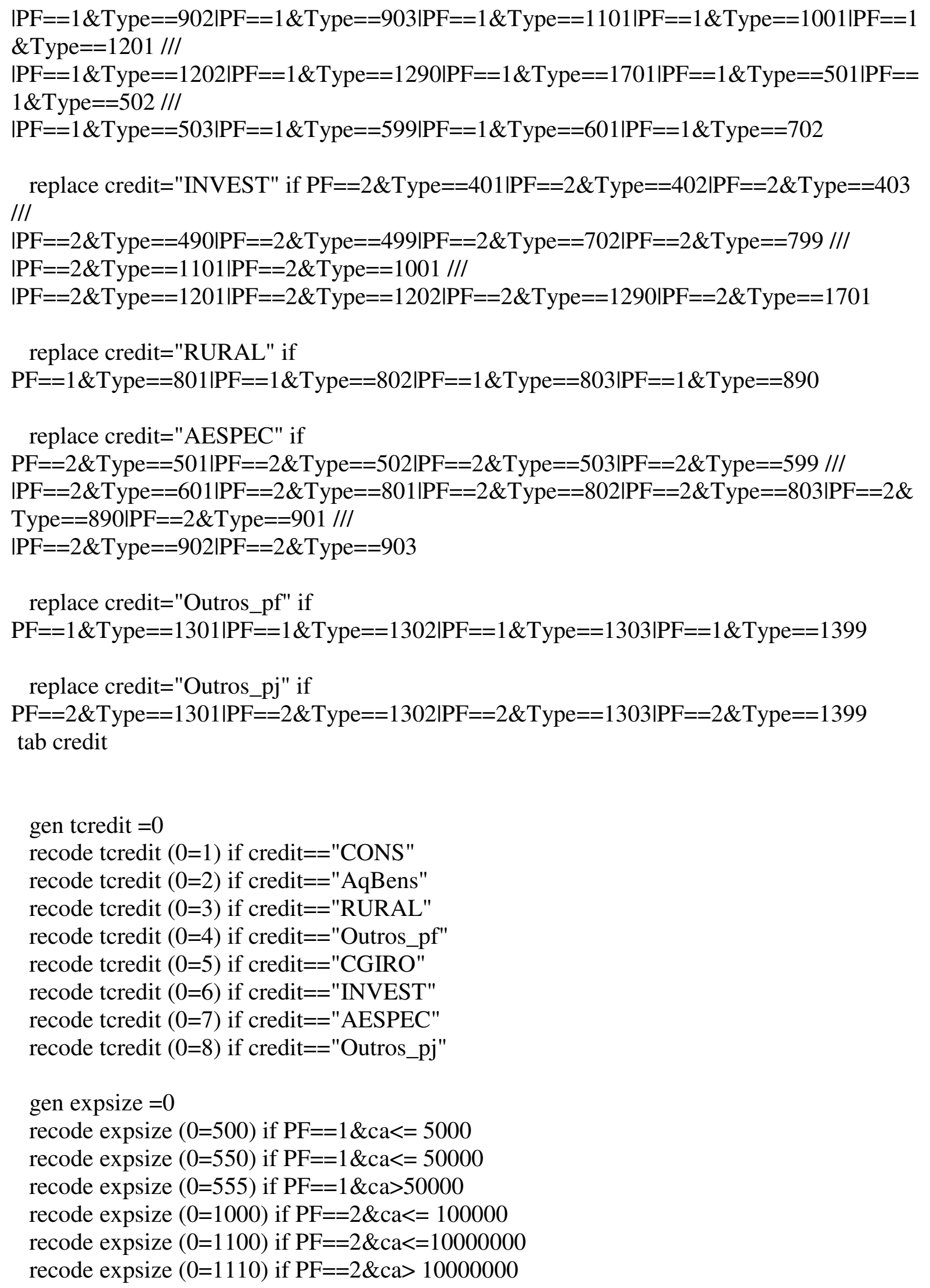

*Cria Categorias IRB ou Natu: Varejo, Atacado e SME 
gen natu $=5000$

* SME: PJ com carteira ativa $>\mathrm{R} \$ 400.000$ e $<\mathrm{R} \$ 4 \mathrm{MM}$

recode natu $(5000=4000)$ if $\mathrm{PF}==2 \& \mathrm{ca}>400000$

* Varejo: Todas as PFs e PJs inferiores a $\mathrm{R} \$ 400.000$

recode natu $(5000=3000)$ if $\mathrm{ca}<400000 \mid \mathrm{PF}==1$

* Atacdo: PJs superiores a R $\$ 4 \mathrm{MM}$

recode natu $(4000=5000)$ if $\mathrm{ca}>4000000$

recode natu $(3000=5000)$ if $\mathrm{ca}>4000000$

*Cria rating 1 para cenário stress de Política Monetária (rebaixamento de 1 nod) gen rating $1=$ rating

replace rating $1=" \mathrm{~A} "$ if rating $==" \mathrm{AA} "$

replace rating $1=" \mathrm{~B} "$ if rating $==" \mathrm{~A} "$

replace rating $1=" \mathrm{C} "$ if rating $==" \mathrm{~B} "$

replace rating $1=" \mathrm{D}$ " if rating $==" \mathrm{C} "$

replace rating $1=" \mathrm{E} "$ if rating $==" \mathrm{D} "$

replace rating $1=" \mathrm{~F}$ " if rating $==" \mathrm{E} "$

replace rating $1=" \mathrm{G}$ " if rating $==" \mathrm{~F} "$

replace rating $1=" \mathrm{H}$ " if rating $==" \mathrm{G}$ "

replace rating $1=" \mathrm{H}$ " if rating $==" \mathrm{H}$ "

*Cria rating 2 para cenário stress de Política Monetária (rebaixamento de 2 nods)

gen rating $2=$ rating

replace rating $2=" \mathrm{~B} "$ if rating $==" \mathrm{AA} "$

replace rating $2=" \mathrm{C} "$ if rating $==" \mathrm{~A} "$

replace rating $2=" \mathrm{D}$ " if rating $==" \mathrm{~B} "$

replace rating $2=" \mathrm{E} "$ if rating $==" \mathrm{C} "$

replace rating $2=" \mathrm{~F} "$ if rating $==" \mathrm{D} "$

replace rating $2=" \mathrm{G}$ " if rating $==" \mathrm{E} "$

replace rating $2=" \mathrm{H}$ " if rating $==" \mathrm{~F} "$

replace rating $2=" \mathrm{H}$ " if rating $==" \mathrm{G} "$

replace rating $2=" \mathrm{H}$ " if rating $==" \mathrm{H}$ "

* Cria Dloss, Tloss, Tloss1 e Tloss2 (downgrades)

gen dloss $=$ ca

replace dloss $=0$ if default $==0$

gen tloss $=0$

replace tloss=ca if rating =="E "|rating =="F "|rating =="G "|rating =="H "

gen tloss $1=0$

replace tloss $1=$ ca if rating $1==" \mathrm{E}$ "|rating 1 =="F "|rating $1==" \mathrm{G}$ "|rating $1==" \mathrm{H}$ "

gen tloss $2=0$

replace tloss2=ca if rating $2==" \mathrm{E}$ "|rating $2==" \mathrm{~F}$ "|rating $2==" \mathrm{G}$ "|rating2 =="H " 
*************Fase 2 - Calibra IRB

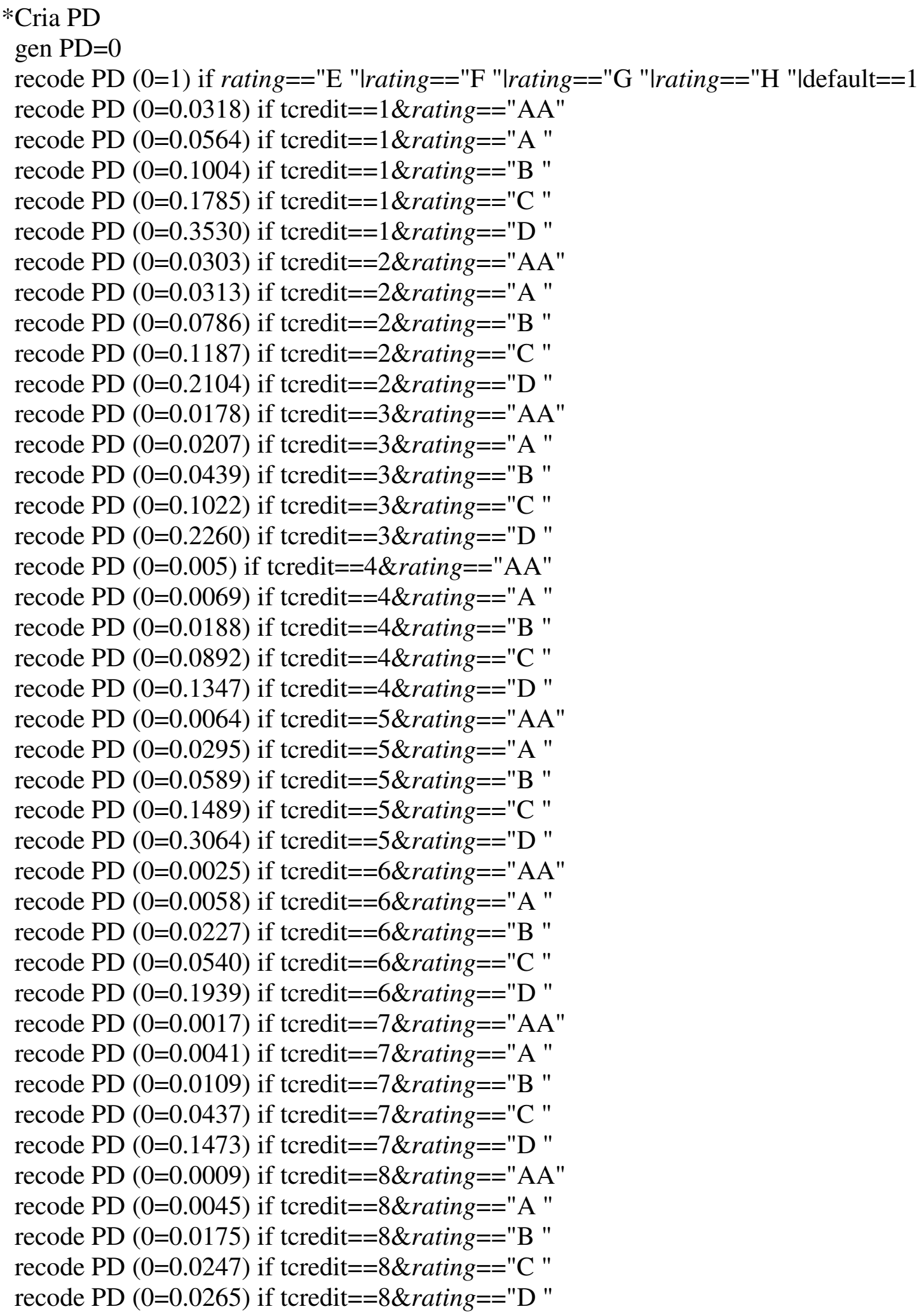

*Cria PD1 (Para stress de Política Monetária ) 
gen PD1 $=0$

recode $\mathrm{PD} 1(0=1)$ if rating $1==" \mathrm{E}$ "|rating $1==" \mathrm{~F}$ "|rating $1==" \mathrm{G}$ "|rating $1==" \mathrm{H}$ "|default==1

recode $\mathrm{PD} 1(0=0.0318)$ if tcredit $==1$ \& rating $1==" \mathrm{AA} "$

recode $\mathrm{PD} 1(0=0.0564)$ if tcredit $==1$ \& rating $1==" \mathrm{~A}$ "

recode $\mathrm{PD} 1(0=0.1004)$ if tcredit $==1$ \&rating $1==" \mathrm{~B}$ "

recode $\mathrm{PD} 1(0=0.1785)$ if tcredit $==1$ \& rating $1==" \mathrm{C}$ "

recode $\mathrm{PD} 1(0=0.3530)$ if tcredit $==1$ \& rating $1==" \mathrm{D}$ "

recode $\mathrm{PD} 1(0=0.0303)$ if tcredit==2\&rating $1==" \mathrm{AA} "$

recode $\mathrm{PD} 1(0=0.0313)$ if tcredit $==2$ \&rating $1==" \mathrm{~A}$ "

recode $\mathrm{PD} 1(0=0.0786)$ if tcredit==2\&rating $1==" \mathrm{~B}$ "

recode $\mathrm{PD} 1(0=0.1187)$ if tcredit $==2$ \& rating $1==" \mathrm{C}$ "

recode $\mathrm{PD} 1(0=0.2104)$ if tcredit $==2$ \& rating $1==" \mathrm{D}$ "

recode $\mathrm{PD} 1(0=0.0178)$ if tcredit $==3$ \& rating $1==" \mathrm{AA} "$

recode $\mathrm{PD} 1(0=0.0207)$ if tcredit $==3$ \& rating $1==" \mathrm{~A}$ "

recode $\mathrm{PD} 1(0=0.0439)$ if tcredit $==3$ \& rating $1==" \mathrm{~B}$ "

recode $\mathrm{PD} 1(0=0.1022)$ if tcredit $==3$ \& rating $1==" \mathrm{C}$ "

recode $\mathrm{PD} 1(0=0.2260)$ if tcredit $==3$ \& rating $1==" \mathrm{D}$ "

recode $\mathrm{PD} 1(0=0.005)$ if tcredit $==4 \&$ rating $1==" \mathrm{AA} "$

recode $\mathrm{PD} 1(0=0.0069)$ if tcredit $==4$ \& rating $1==" \mathrm{~A}$ "

recode $\mathrm{PD} 1(0=0.0188)$ if tcredit $==4$ \&rating $1==" \mathrm{~B}$ "

recode $\mathrm{PD} 1(0=0.0892)$ if tcredit $==4 \&$ rating $1==" \mathrm{C}$ "

recode $\mathrm{PD} 1(0=0.1347)$ if tcredit $==4$ \& rating $1==" \mathrm{D}$ "

recode $\mathrm{PD} 1(0=0.0064)$ if tcredit $==5$ \& rating $1==" \mathrm{AA} "$

recode $\mathrm{PD} 1(0=0.0295)$ if tcredit $==5$ \& rating $1==" \mathrm{~A}$ "

recode $\mathrm{PD} 1(0=0.0589)$ if tcredit $==5$ \& rating $1==" \mathrm{~B}$ "

recode $\mathrm{PD} 1(0=0.1489)$ if tcredit $==5$ \& rating $1==" \mathrm{C}$ "

recode $\mathrm{PD} 1(0=0.3064)$ if tcredit $==5$ \& rating $1==" \mathrm{D}$ "

recode $\mathrm{PD} 1(0=0.0025)$ if tcredit $=6$ $=6$ rating $1==" \mathrm{AA} "$

recode $\mathrm{PD} 1(0=0.0058)$ if tcredit $==6$ \& rating $1==" \mathrm{~A}$ "

recode $\mathrm{PD} 1(0=0.0227)$ if tcredit $==6 \&$ rating $1==" \mathrm{~B}$ "

recode $\mathrm{PD} 1(0=0.0540)$ if tcredit $==6$ \& rating $1==" \mathrm{C}$ "

recode $\mathrm{PD} 1(0=0.1939)$ if tcredit $==6$ \& rating $1==" \mathrm{D}$ "

recode $\mathrm{PD} 1(0=0.0017)$ if tcredit $==7$ \& rating $1==" \mathrm{AA} "$

recode $\mathrm{PD} 1(0=0.0041)$ if tcredit $==7$ \& rating $1==" \mathrm{~A}$ "

recode $\mathrm{PD} 1(0=0.0109)$ if tcredit $==7$ \& rating $1==" \mathrm{~B}$ "

recode $\mathrm{PD} 1(0=0.0437)$ if tcredit $==7$ \& rating $1==" \mathrm{C}$ "

recode $\mathrm{PD} 1(0=0.1473)$ if tcredit $==7$ \& rating $1==" \mathrm{D}$ "

recode $\mathrm{PD} 1(0=0.0009)$ if tcredit $==8 \&$ rating $1==" \mathrm{AA} "$

recode $\mathrm{PD} 1(0=0.0045)$ if tcredit $==8$ \& rating $1==" \mathrm{~A}$ "

recode $\mathrm{PD} 1(0=0.0175)$ if tcredit $==8$ \& rating $1==" \mathrm{~B}$ "

recode $\mathrm{PD} 1(0=0.0247)$ if tcredit $==8$ \& rating $1==" \mathrm{C}$ "

recode $\mathrm{PD} 1(0=0.0265)$ if tcredit==8\& rating $1==" \mathrm{D}$ "

*Cria PD2 para crise (Para stress de Política Monetária )

gen $\mathrm{PD} 2=0$

recode $\mathrm{PD} 2(0=1)$ if rating $2==" \mathrm{E}$ "|rating2=="F "|rating2=="G "|rating2=="H "|default==1

recode $\mathrm{PD} 2(0=0.0318)$ if tcredit $==1$ \& rating $2==" \mathrm{AA} "$

recode $\mathrm{PD} 2(0=0.0564)$ if tcredit $==1$ \& rating $2==" \mathrm{~A}$ "

recode $\mathrm{PD} 2(0=0.1004)$ if tcredit $==1$ \& rating $2==" \mathrm{~B}$ "

recode $\mathrm{PD} 2(0=0.1785)$ if tcredit $==1$ \& rating $2==" \mathrm{C} "$ 
recode $\mathrm{PD} 2(0=0.3530)$ if tcredit $==1$ \& rating $2==" \mathrm{D}$ " recode $\mathrm{PD} 2(0=0.0303)$ if tcredit $==2$ \& rating $2==" \mathrm{AA} "$ recode $\mathrm{PD} 2(0=0.0313)$ if tcredit $==2$ \& rating $2==" \mathrm{~A}$ " recode $\mathrm{PD} 2(0=0.0786)$ if tcredit $==2$ \& rating $2==" \mathrm{~B}$ " recode $\mathrm{PD} 2(0=0.1187)$ if tcredit $==2$ \& rating $2==" \mathrm{C}$ " recode $\mathrm{PD} 2(0=0.2104)$ if tcredit $==2$ \& rating $2==" \mathrm{D}$ " recode $\mathrm{PD} 2(0=0.0178)$ if tcredit $==3$ \& rating $2==" \mathrm{AA} "$ recode $\mathrm{PD} 2(0=0.0207)$ if tcredit $==3$ \& rating $2==" \mathrm{~A}$ " recode $\mathrm{PD} 2(0=0.0439)$ if tcredit $==3$ \& rating $2==" \mathrm{~B}$ " recode $\mathrm{PD} 2(0=0.1022)$ if tcredit $==3$ \& rating $2==" \mathrm{C}$ " recode $\mathrm{PD} 2(0=0.2260)$ if tcredit $==3$ \& rating $2==" \mathrm{D}$ " recode $\mathrm{PD} 2(0=0.005)$ if tcredit $==4 \&$ rating $2==" \mathrm{AA} "$ recode $\mathrm{PD} 2(0=0.0069)$ if tcredit $==4 \&$ rating $2==" \mathrm{~A}$ " recode $\mathrm{PD} 2(0=0.0188)$ if tcredit $==4$ \& rating $2==" \mathrm{~B}$ " recode $\mathrm{PD} 2(0=0.0892)$ if tcredit $==4$ \& rating $2==" \mathrm{C}$ " recode $\mathrm{PD} 2(0=0.1347)$ if tcredit $==4$ \& rating $2==" \mathrm{D}$ " recode $\mathrm{PD} 2(0=0.0064)$ if tcredit $==5$ \& rating $2==" \mathrm{AA} "$ recode $\mathrm{PD} 2(0=0.0295)$ if tcredit $==5$ \& rating $2==" \mathrm{~A}$ " recode $\mathrm{PD} 2(0=0.0589)$ if tcredit $==5$ \& rating $2==" \mathrm{~B}$ " recode $\mathrm{PD} 2(0=0.1489)$ if tcredit $==5$ \& rating $2==" \mathrm{C}$ " recode $\mathrm{PD} 2(0=0.3064)$ if tcredit $==5$ \& rating $2==" \mathrm{D}$ " recode $\mathrm{PD} 2(0=0.0025)$ if tcredit $==6 \&$ rating $2==" \mathrm{AA} "$ recode $\mathrm{PD} 2(0=0.0058)$ if tcredit $==6 \&$ rating $2==" \mathrm{~A}$ " recode $\mathrm{PD} 2(0=0.0227)$ if tcredit $==6$ \& rating $2==" \mathrm{~B}$ " recode $\mathrm{PD} 2(0=0.0540)$ if tcredit $==6 \&$ rating $2==" \mathrm{C} "$ recode $\mathrm{PD} 2(0=0.1939)$ if tcredit $==6 \&$ rating $2==" \mathrm{D}$ " recode $\mathrm{PD} 2(0=0.0017)$ if tcredit $==7$ \& rating $2==" \mathrm{AA} "$ recode $\mathrm{PD} 2(0=0.0041)$ if tcredit $==7$ \& rating $2==" \mathrm{~A}$ " recode $\mathrm{PD} 2(0=0.0109)$ if tcredit $==7$ \& rating $2==" \mathrm{~B}$ " recode $\mathrm{PD} 2(0=0.0437)$ if tcredit $==7$ \& rating $2==" \mathrm{C}$ " recode $\mathrm{PD} 2(0=0.1473)$ if tcredit $==7$ \& rating $2==" \mathrm{D}$ " recode $\mathrm{PD} 2(0=0.0009)$ if tcredit $==8$ \& rating $2==" \mathrm{AA} "$ recode $\mathrm{PD} 2(0=0.0045)$ if tcredit $==8$ \& rating $2==" \mathrm{~A}$ " recode $\mathrm{PD} 2(0=0.0175)$ if tcredit $==8$ \& rating $2==" \mathrm{~B}$ " recode $\mathrm{PD} 2(0=0.0247)$ if tcredit $==8$ \& rating $2==" \mathrm{C}$ " recode $\mathrm{PD} 2(0=0.0265)$ if tcredit $==8$ \& rating $2==" \mathrm{D}$ "

\footnotetext{
*Cria stPD gen $\mathrm{StPD}=0$ recode $\mathrm{stPD}(0=1)$ if rating=="E "|rating=="F "|rating=="G "Irating=="H "Idefault==1 recode $\mathrm{stPD}(0=0.0186)$ if tcredit $==1 \&$ rating $==" \mathrm{AA} "$ recode stPD $(0=0.0304)$ if tcredit $==1 \&$ rating $==" \mathrm{~A}$ " recode $\operatorname{stPD}(0=0.0962)$ if tcredit $==1$ \& rating $==" \mathrm{~B}$ " recode stPD $(0=0.1480)$ if tcredit $==1$ \& rating $==" \mathrm{C}$ " recode $\operatorname{stPD}(0=0.1675)$ if tcredit $==1$ \& rating $==" \mathrm{D}$ " recode $\mathrm{stPD}(0=0.0370)$ if tcredit $==2$ \& rating $==" \mathrm{AA} "$ recode $\operatorname{stPD}(0=0.0150)$ if tcredit $==2$ \& rating $==" \mathrm{~A}$ " recode $\operatorname{stPD}(0=0.0399)$ if tcredit $==2$ \& rating $==" \mathrm{~B}$ " recode $\mathrm{stPD}(0=0.0604)$ if tcredit $==2$ \& rating $==" \mathrm{C}$ " recode $\operatorname{stPD}(0=0.1084)$ if tcredit $==2$ \& rating $==" \mathrm{D}$ "
} 
recode stPD $(0=0.1204)$ if tcredit $==3 \&$ rating $==" \mathrm{AA} "$ recode $\mathrm{stPD}(0=0.0129)$ if tcredit $==3$ \& rating $==" \mathrm{~A}$ " recode $\mathrm{stPD}(0=0.0517)$ if tcredit $==3$ \& rating $==" \mathrm{~B}$ " recode stPD $(0=0.0996)$ if tcredit $==3$ \& rating $==" C$ " recode $\mathrm{stPD}(0=0.2531)$ if tcredit $==3$ \& rating $==" \mathrm{D}$ " recode $\operatorname{stPD}(0=0.0100)$ if tcredit $==4 \&$ rating $==" \mathrm{AA} "$ recode stPD $(0=0.0078)$ if tcredit $==4$ \& rating $==" \mathrm{~A}$ " recode $\mathrm{stPD}(0=0.0814)$ if tcredit $==4$ \& rating $==" \mathrm{~B}$ " recode stPD $(0=0.1256)$ if tcredit $==4$ \& rating $==" C$ " recode $\operatorname{stPD}(0=0.1627)$ if tcredit $==4$ \& rating $==" \mathrm{D}$ " recode stPD $(0=0.0096)$ if tcredit $==5 \&$ rating $==" A A "$ recode $\mathrm{stPD}(0=0.0285)$ if tcredit $==5$ \& rating $==" \mathrm{~A}$ " recode $\operatorname{stPD}(0=0.0586)$ if tcredit $==5$ \& rating $==" \mathrm{~B}$ " recode stPD $(0=0.1395)$ if tcredit $==5$ \& rating $==" C$ " recode $\mathrm{stPD}(0=0.1939)$ if tcredit $==5$ \& rating $==" \mathrm{D}$ " recode $\mathrm{stPD}(0=0.0051)$ if tcredit $==6$ \& rating $==" \mathrm{AA} "$ recode $\operatorname{stPD}(0=0.0098)$ if tcredit $==6 \&$ rating $==" \mathrm{~A}$ " recode $\mathrm{stPD}(0=0.0181)$ if tcredit $==6 \&$ rating $==" \mathrm{~B}$ " recode $\operatorname{stPD}(0=0.0757)$ if tcredit $==6$ \& rating $==" \mathrm{C} "$ recode $\operatorname{stPD}(0=0.1054)$ if tcredit $==6 \&$ rating $==" \mathrm{D}$ " recode stPD $(0=0.0096)$ if tcredit $==7 \&$ rating $==" A A "$ recode $\mathrm{stPD}(0=0.0285)$ if tcredit $==7$ \& rating $==" \mathrm{~A}$ " recode stPD $(0=0.0181)$ if tcredit $==7$ \& rating $==" \mathrm{~B}$ " recode $\mathrm{stPD}(0=0.0757)$ if tcredit $==7$ \& rating $==" \mathrm{C}$ " recode stPD $(0=0.1054)$ if tcredit $==7$ \& rating $==" \mathrm{D}$ " recode $\mathrm{stPD}(0=0.0013)$ if tcredit $==8$ \& rating $==" \mathrm{AA} "$ recode $\operatorname{stPD}(0=0.0244)$ if tcredit $==8$ \& rating $==" \mathrm{~A}$ " recode $\operatorname{stPD}(0=0.1429)$ if tcredit $==8 \&$ rating $==" \mathrm{~B}$ " recode $\operatorname{stPD}(0=0.1658)$ if tcredit $==8$ \& rating $==" \mathrm{C}$ " recode $\operatorname{stPD}(0=0.2607)$ if tcredit $==8$ \& rating $==" \mathrm{D}$ "

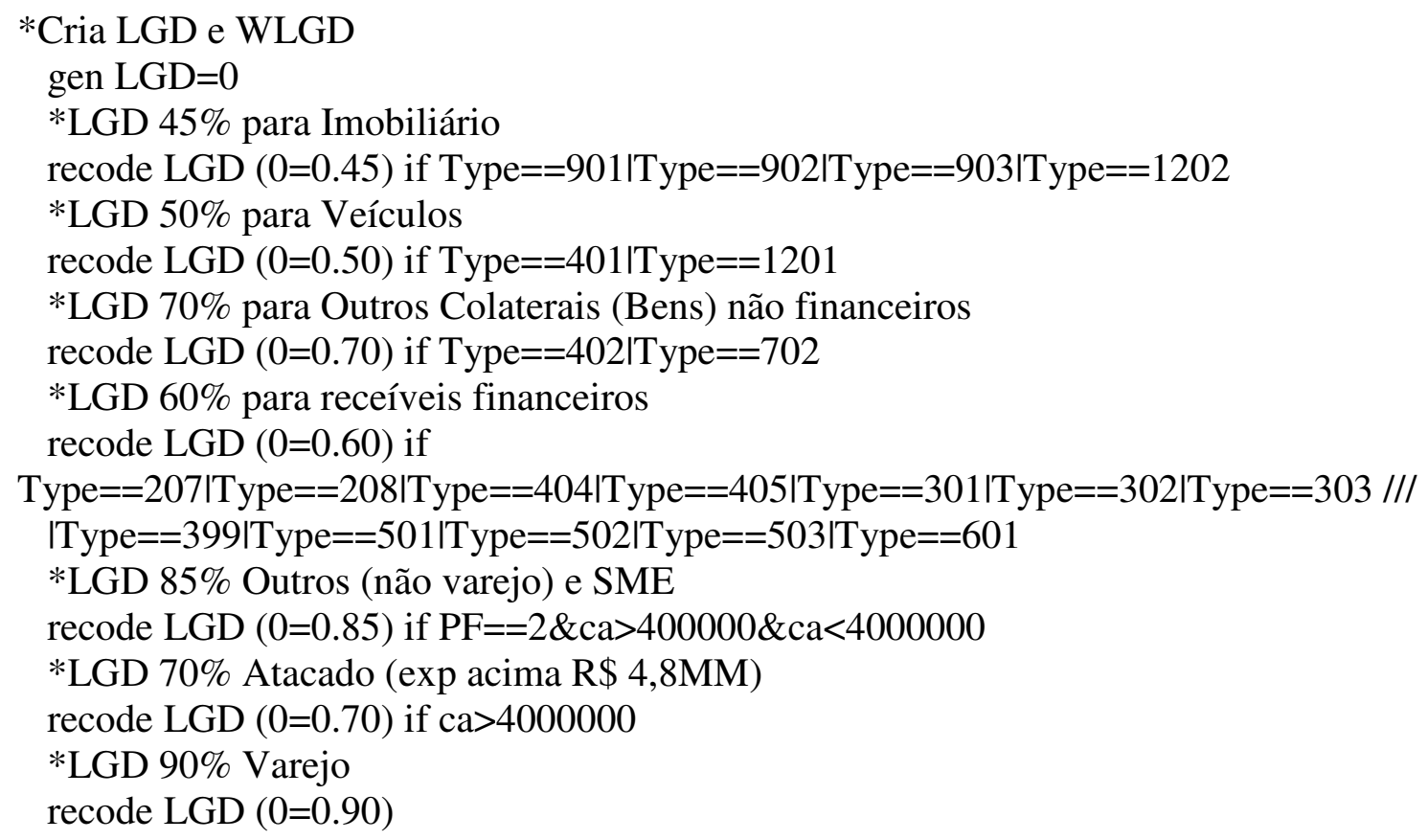


gen $\mathrm{WLGD}=\left(\mathrm{LGD}^{*} \mathrm{ca}\right)$

*Cria MProv, MProva1 e MProv2 (Com Downgrades) P.S MProv=0 se AA ... NÃO PODE HAVER RATING2 SUPERIOR A B.

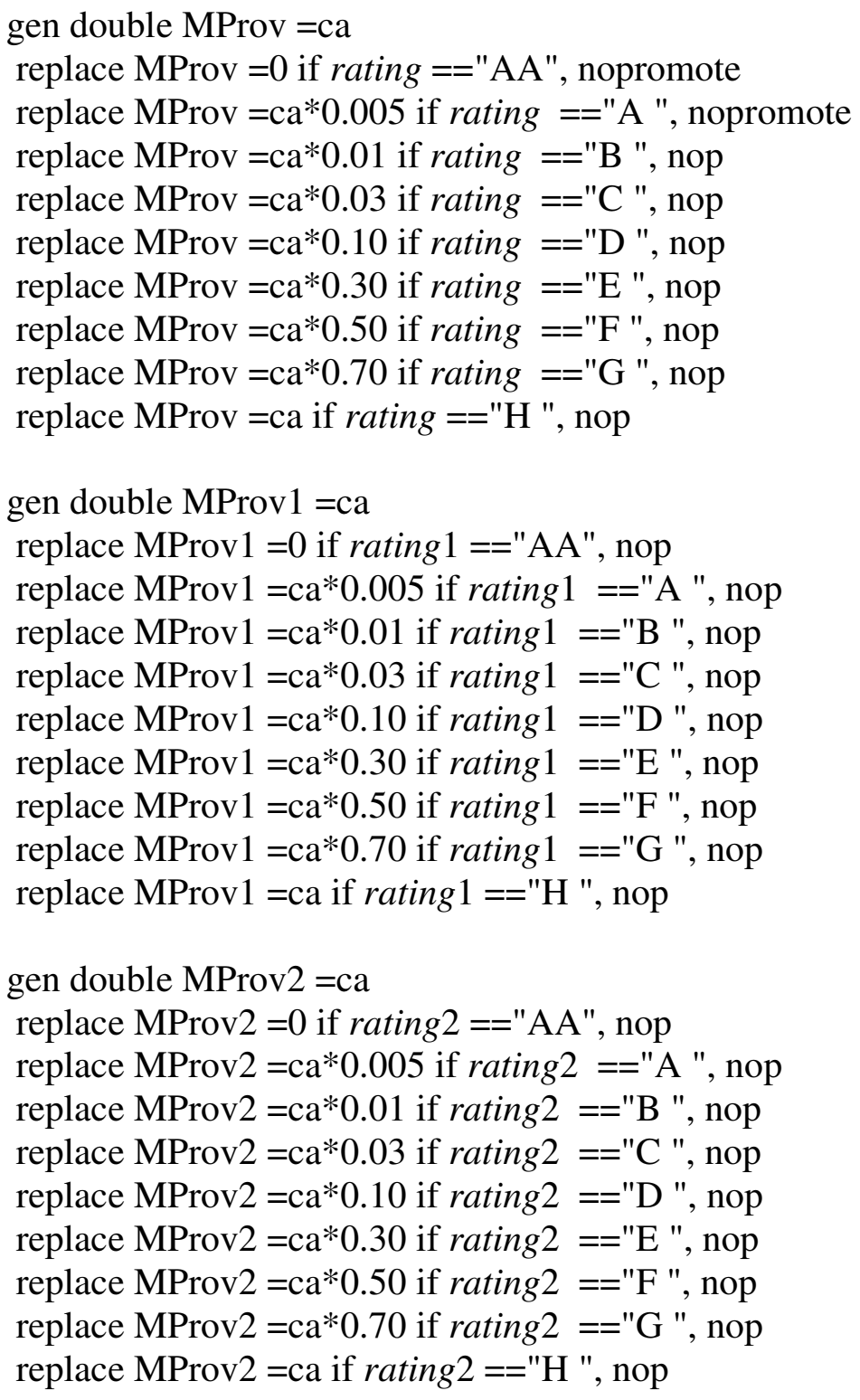

*Cria EL, EL1 e EL2 // Perdas Esperadas para cenário padrão (EL) e Stress de Política Monetária (EL2)

gen $\mathrm{EL}=\mathrm{PD} * \mathrm{LGD} * \mathrm{ca}$

gen EL1 $=$ PD $1 *$ LGD $*$ ca

gen EL2=PD2*LGD*ca

*Cria ProvAjuste e ProvAjuste2 (Downgrade) Necessário no preseça da Res. 2682

gen ProvAjuste $=0$

replace ProvAjuste $=($ EL-MProv $)$ if EL $>$ MProv 
gen ProvAjuste $1=0$

replace ProvAjuste1 =(EL1-MProv1 $)$ if EL1 $>$ MProv1

gen ProvAjuste $2=0$

replace ProvAjuste2 $=($ EL2-MProv2 $)$ if EL2 $>$ MProv2

gen Rigor2682 $=0$

replace Rigor2682 $=($ MProv-EL $)$ if MProv $>$ EL

gen Rigor $26821=0$

replace Rigor26821 $=($ MProv1-EL1) if MProv1 $>$ EL1

gen Rigor26822 $=0$

replace Rigor26822 $=($ MProv2-EL2) if MProv2 $>$ EL2

///Rigor2682 e as de stress são variáveis de controle, usadas apenas para melhor

///entender as condições em que a Res 2682 são mais rigorosas que os modelos internos

* Cria EL2682 e cenários de stress

gen EL2682=PD*LGD*ca

replace EL2682 $=$ MProv if ProvAjuste $==0$

gen EL26821=PD1*LGD*ca

replace EL26821 $=$ MProv1 if ProvAjuste $1==0$

gen EL26822=PD2*LGD*ca

replace EL26822=MProv2 if ProvAjuste2 $==0$

*Cria $\mathrm{R}$

gen $\mathrm{r}=0$

*Varejo geral

replace $\mathrm{r}=0.03 *((1-\exp (-35 *(\mathrm{PD}))) /(1-\exp (-35)))+/ / /$

$0.16 *(1-(1-\exp (-35 *(\mathrm{PD}))) /(1-\exp (-35)))$ if natu $==3000$

*SME: Faturamento de R $\$ 25.5 \mathrm{MM}$ assumido. O ponto do meio entre $\mathrm{R} \$ 3$ e $\mathrm{R} \$ 48 \mathrm{MM}$ replace $\mathrm{r}=0.12 *((1-\exp (-50 *(\mathrm{PD}))) /(1-\exp (-50)))+/ / /$

$0.24 *(1-(1-\exp (-50 *(\mathrm{PD}))) /(1-\exp (-50)))-0.04 *(1-((25.5-3) / 45))$ if natu==4000

*Corporate, IFs e Soberanos

replace $\mathrm{r}=0.12 *((1-\exp (-50 *(\mathrm{PD}))) /(1-\exp (-50)))+/ / /$

$0.24 *(1-(1-\exp (-50 *(\mathrm{PD}))) /(1-\exp (-50)))$ if natu $==5000$

*Varejo residencial

replace $r=0.15$ if Type $==901$

*HVCRE para PJ nas modalidades de Carteira Hipotecária ou outros Empreendimentos Imobiliários

replace $\mathrm{r}=0.12 *((1-\exp (-50 *(\mathrm{PD}))) /(1-\exp (-50)))+/ / /$

$0.30 *(1-(1-\exp (-50 *(\mathrm{PD}))) /(1-\exp (-50)))$ if $\mathrm{PF}==2 \& \mathrm{Type}==902 \mid \mathrm{PF}==2 \& \mathrm{Type}==903$

* Cria VaR e VaR2 (com downgrade)

gen $\mathrm{VaR}=1.06 * \mathrm{ca} * \mathrm{LGD} *$ normal $(\operatorname{sqrt}(1 /(1-\mathrm{r})) * \operatorname{invnormal}(\mathrm{PD})+\operatorname{sqrt}(\mathrm{r} /(1-$

r))*invnormal(0.999))

replace VaR=EL if rating=="E "|rating=="F "|rating=="G "|rating=="H "|default==1

gen VaR1 $=1.06 *$ ca*LGD*normal $(\operatorname{sqrt}(1 /(1-\mathrm{r})) * \operatorname{invnormal}(\mathrm{PD} 1)+\operatorname{sqrt}(\mathrm{r} /(1-$ 
r))*invnormal(0.999))

replace VaR1 =EL1 if rating $1==" \mathrm{E}$ "|rating $1==" \mathrm{~F}$ "|rating $1==" \mathrm{G}$ "|rating $1==" \mathrm{H}$

"Idefault $==1$

gen VaR2 $=1.06 * \mathrm{ca}^{*} \mathrm{LGD} * \operatorname{normal}(\operatorname{sqrt}(1 /(1-\mathrm{r})) *$ invnormal(PD2)+sqrt(r/(1-

r))*invnormal $(0.999))$

replace VaR2 =EL2 if rating2=="E "|rating2=="F "|rating2=="G "|rating2=="H

"Idefault==1

\section{*Cria CME}

* Cria KIRB para o capital apurado por VaR-EL e Corporate com M=2.5 gen $\mathrm{KIRB}=0$

replace KIRB $=$ VaR-EL if natu $==3000$ natu $==4000$

replace KIRB $=($ VaR-EL $) /\left(1-\left(1.5 *(0.11852-0.05478 * \ln (\mathrm{PD}))^{\wedge} 2\right)\right)$ if natu $==5000$

* Cria K2682 para o CME apurado por VaR-MProv e Corporate com M=2.5 gen $\mathrm{K} 2682=0$

replace $\mathrm{K} 2682=$ VaR-MProv-ProvAjuste if natu $==3000$ |natu $==4000$

replace K2682 $=($ VaR-MProv-ProvAjuste $) /\left(1-\left(1.5 *(0.11852-0.05478 * \ln (\mathrm{PD}))^{\wedge} 2\right)\right)$ if

natu $==5000$

/// Esta é a aplicação mais provável do IRB no Brasil

$/ / /$ Note que K2682 = VaR-MProv-EL+MProv = VaR - EL ou KIRB quando EL $>$ MProv

/// no entanto, quando MProv $>E L, K 2682$ = VaR-MProv, isto é, o regulador demanda que a

Provisão seja ///

/// sempre a maior entre o Mínimo da Res 2682 ou EL do modelo interno.

///Note que esta variável pode apresentar valores negativos sempre que a Provisao Minima da ///

///Resolução 2682 é maior do que VaR. Ainda que o impairment no IRB ocorra mais rápido (sempre ///

///que E a H ou atrasos existam, a Prov Min é mais rigorosa porque o efeito da Perda não é /// $/ / /$ mitigado pela LGD. Em outras palavras, a exigência de provisão para as categorias $\mathrm{F}$ e $\mathrm{G}$ podem ser ///

/// maiores pela aplicação explicita da Resolução 2682 do que EL e sempre serão mais rigorosos para $\mathrm{H}$.

* Cria KIRB1 para o capital apurado por VaR-EL com downgrade e Corporate com M=2.5 gen KIRB1=0

replace KIRB1 $=$ VaR1-EL1 if natu $==3000$ natu $==4000$

replace $\mathrm{KIRB} 1=(\mathrm{VaR} 1-\mathrm{EL} 1) /\left(1-\left(1.5 *(0.11852-0.05478 * \ln (\mathrm{PD} 2))^{\wedge} 2\right)\right)$ if natu $==5000$

* Cria KIRB2 para o capital apurado por VaR-EL com downgrade e Corporate com $\mathrm{M}=2.5$ gen KIRB2 $=0$

replace $\mathrm{KIRB} 2=\mathrm{VaR} 2-\mathrm{EL} 2$ if natu $==3000$ lnatu $==4000$

replace KIRB2 $=(\mathrm{VaR} 2-\mathrm{EL} 2) /\left(1-\left(1.5^{*}(0.11852-0.05478 * \ln (\mathrm{PD} 2))^{\wedge} 2\right)\right)$ if natu $==5000$

* Cria K26821 para o capital apurado por VaR-MProv2 com downgrade e Corporate com $\mathrm{M}=2.5$

gen $\mathrm{K} 26821=0$

replace $\mathrm{K} 26821=\mathrm{VaR} 1-\mathrm{MProv} 1-P r o v A j u s t e 1$ if natu $==3000$ natu $==4000$

replace K26821 = $($ VaR1-MProv1-ProvAjuste1 $) /\left(1-\left(1.5 *(0.11852-0.05478 * \ln (\mathrm{PD} 2))^{\wedge} 2\right)\right)$ 
* Cria K26822 para o capital apurado por VaR-MProv2 com downgrade e Corporate com $\mathrm{M}=2.5$

gen $\mathrm{K} 26822=0$

replace $\mathrm{K} 26822=$ VaR2-MProv2-ProvAjuste2 if natu $==3000$ natu $==4000$

replace K26822 $=($ VaR2-MProv2-ProvAjuste2 $) /\left(1-\left(1.5 *(0.11852-0.05478 * \ln (\mathrm{PD} 2))^{\wedge} 2\right)\right)$ if natu $==5000$

gen VaR_2682=K2682+MProv+ProvAjuste

gen VaR_26821=K26821+MProv1+ProvAjuste1

gen VaR_26822=K26822+MProv2+ProvAjuste2

$* * * * * * * * * * * * * * * * * \mathrm{FIM} \mathrm{FASE} 2-\operatorname{IRB}$

************Fase 3: Abordagem B1, SSA e Alternativas

$*^{*}$ Cria APR Circ 3360

* Crédito em geral gen APR_3360=1

* Imobiliário (assumindo critério conservador sobre sobrecolaterização de mais $125 \%$ e menos de $200 \%$ )

recode APR_3360 $(1=0.50)$ if Type $==401 \mid$ Type $==1201 \mid$ Type $==402 \mid$ Type $==702 \mid$

Type $==901 / / /$

IType $==902 \mid$ Type $==903 \mid$ Type $==1202$

* Varejo

recode APR_3360 $(1=0.75)$ if $\mathrm{ca}<400000$

*gera K_3360 e sob stress K_33601 e K_33602

gen K_3360=APR_3360*(ca-MProv)*0.11

gen VaR_SSA=K_3360+MProv

gen K_33601= APR_3360*(ca-MProv1)*0.11

gen VaR_SSA1=K_33601+MProv1

gen K_33602= APR_3360*(ca-MProv2 $) * 0.11$

gen VaR_SSA2=K_33602+MProv2

* Cria APR Basileia I

gen K_b1=(ca-MProv)*0.11

gen VaR_b1=K_b1+MProv

gen K_b11=(ca-MProv1)*0.11

gen VaR_b11=K_b11+MProv1

gen K_b12=(ca-MProv2 $) * 0.11$

gen VaR_b12=K_b12+MProv2

* Cria K e APR CRBA Padronizada(ACRBA), sob stres(ACRBA2),

Conservadora(ACRBAc) e sobr stress(ACRBAc2)

gen $\mathrm{ACRBA}=9.09$

/// Classificação H 
replace $\mathrm{ACRBA}=0.20$ if rating $==" \mathrm{AA} "$

replace $\mathrm{ACRBA}=0.50$ if rating=="A "

replace $\mathrm{ACRBA}=1$ if rating=="B "|rating=="C "

replace $\mathrm{ACRBA}=1.50$ if rating=="D "|rating=="E "|rating=="F "|rating=="G "

gen ACRBA1=9.09

/// Classificação H

recode ACRBA1 $(9.09=0.20)$ if rating $1==" A A "$

recode ACRBA1 $(9.09=0.50)$ if rating $1==" \mathrm{~A}$ "

recode ACRBA1 $(9.09=1)$ if rating $1==" \mathrm{~B}$ "|rating $1==" \mathrm{C}$ "

recode ACRBA1 (9.09=1.50) if rating1=="D "|rating1=="E "|rating $1==" F$ "|rating $1==" G$ "

gen ACRBA2 $=9.09$

/// Classificação H

recode ACRBA2 $(9.09=0.20)$ if rating $2==" \mathrm{AA} "$

recode ACRBA2 $(9.09=0.50)$ if rating $2==" \mathrm{~A}$ "

recode ACRBA2 $(9.09=1)$ if rating $2==" \mathrm{~B}$ "|rating $2==" \mathrm{C} "$

recode ACRBA2 (9.09=1.50) if rating2=="D "|rating2=="E "|rating2=="F "|rating2=="G "

gen K_CRBA $=$ ACRBA $*$ (ca-MProv)*0.11

gen VaR_CRBA=K_CRBA+MProv

gen K_CRBA1 $=$ ACRBA $1 *($ ca-MProv 1$) * 0.11$

gen VaR_CRBA1=K_CRBA1+MProv1

gen K_CRBA2 $=$ ACRBA2 $*($ ca-MProv2 $) * 0.11$

gen VaR_CRBA2=K_CRBA2+MProv2

gen ACRBAc=9.09

/// Classificação $\mathrm{H}$

recode ACRBAc $(9.09=0.50)$ if rating $==" \mathrm{AA} "$

recode ACRBAc $(9.09=0.75)$ if rating $==" \mathrm{~A}$ "

recode ACRBAc $(9.09=1)$ if rating $==" \mathrm{~B}$ "

recode ACRBAc $(9.09=1.50)$ if rating $==" \mathrm{C}$ "

recode ACRBAc (9.09=3) if rating=="D "|rating=="E "

recode ACRBAc $(9.09=5)$ if rating $==" F$ "

recode ACRBAc $(9.09=7)$ if rating $==" \mathrm{G}$ "

gen ACRBAc1=9.09

/// Classificação H

recode ACRBAc1 (9.09=0.50) if rating $1==" \mathrm{AA} "$

recode ACRBAc1 $(9.09=0.75)$ if rating $1==" \mathrm{~A}$ "

recode ACRBAc1 $(9.09=1)$ if rating $1==" \mathrm{~B}$ "

recode ACRBAc1 $(9.09=1.50)$ if rating $1==" \mathrm{C}$ "

recode ACRBAc1 $(9.09=3)$ if rating $1==" \mathrm{D}$ "|rating $1==" \mathrm{E}$ "

recode ACRBAc1 $(9.09=5)$ if rating $1==" F$ "

recode ACRBAc1 $(9.09=7)$ if rating $1==" \mathrm{G}$ "

gen ACRBAc2 $=9.09$

/// Classificação H

recode ACRBAc2 (9.09=0.50) if rating2=="AA" 
recode ACRBAc2 $(9.09=0.75)$ if rating $2==" \mathrm{~A}$ " recode ACRBAc2 $(9.09=1)$ if rating $2==" \mathrm{~B}$ " recode ACRBAc2 $(9.09=1.50)$ if rating $2==" \mathrm{C}$ " recode $\mathrm{ACRBAc} 2(9.09=3)$ if rating $2==" \mathrm{D}$ "|rating $2==" \mathrm{E}$ " recode $\mathrm{ACRBAc} 2(9.09=5)$ if rating $2==" \mathrm{~F} "$ recode ACRBAc2 (9.09=7) if rating $2==" \mathrm{G} "$

gen K_CRBAc $=$ ACRBAc $*($ ca-MProv $) * 0.11$ gen VaR_CRBAc $=$ K_CRBAc+MProv gen K_CRBAc1 $=$ ACRBAc1* $($ ca-MProv 1$) * 0.11$ gen VaR_CRBAc1=K_CRBAc1+MProv1 gen K_CRBAc2 $=$ ACRBAc2 $*($ ca-MProv 2$) * 0.11$ gen VaR_CRBAc2 $=$ K_CRBAc2+MProv2

*Cria K e APR CRBA Padronizada CORP (ACRBA_CORP), sob stress (ACRBA1_CORP) (ACRBA2_CORP) e Conservadoras

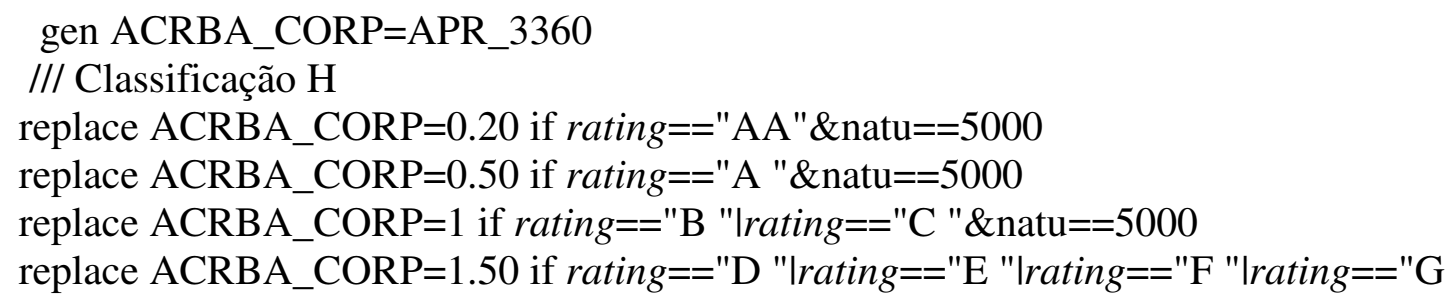


/// Classificação H

replace ACRBAc_CORP $=0.50$ if rating $==" A A " \&$ natu $==5000$

replace ACRBAc_CORP $=0.75$ if rating $==" A$ "\&natu $==5000$

replace ACRBAc_CORP $=1$ if rating $==" \mathrm{~B}$ "\&natu $==5000$

replace ACRBAc_CORP=1.50 if rating=="C "\&natu==5000

replace ACRBAc_CORP=3 if rating=="D "|rating=="E "\&natu==5000

replace ACRBAc_CORP $=5$ if rating $==" F$ "\&natu==5000

replace ACRBAc_CORP=7 if rating=="G "\&natu==5000

gen ACRBAc1_CORP=APR_3360

/// Classificação H

replace ACRBAc1_CORP $=0.50$ if rating $1=="$ AA" $\&$ natu $==5000$

replace ACRBAc1_CORP $=0.75$ if rating $1==" \mathrm{~A}$ "\&natu==5000

replace ACRBAc1_CORP $=1$ if rating $1==" B$ "\&natu==5000

replace ACRBAc1_CORP $=1.50$ if rating $1==" C$ "\&natu $==5000$

replace ACRBAc1_CORP=3 if rating $1==" \mathrm{D}$ "|rating $1==" \mathrm{E}$ "\&natu==5000

replace ACRBAc1_CORP $=5$ if rating $1==" F$ "\&natu==5000

replace ACRBAc1_CORP=7 if rating $1==" G$ "\&natu==5000

gen ACRBAc2_CORP=APR_3360

/// Classificação H

replace ACRBAc2_CORP $=0.50$ if rating $2==" \mathrm{AA} " \&$ natu $==5000$

replace ACRBAc2_CORP $=0.75$ if rating $2==" A$ "\&natu $==5000$

replace ACRBAc2_CORP $=1$ if rating $2==" \mathrm{~B}$ "\&natu $==5000$

replace ACRBAc2_CORP $=1.50$ if rating $2==" \mathrm{C}$ "\&natu $==5000$

replace ACRBAc2_CORP=3 if rating2=="D "|rating2=="E "\&natu==5000

replace ACRBAc2_CORP $=5$ if rating $2==" F$ "\&natu $==5000$

replace ACRBAc2_CORP=7 if rating2=="G "\&natu==5000

gen K_CRBAc_CORP $=$ ACRBAc_CORP*(ca-MProv) ${ }^{*} 0.11$

gen VaR_CRBAc_CORP $=$ K_CRBAc_CORP+MProv

gen K_CRBAc1_CORP= ACRBAc1_CORP*(ca-MProv1)*0.11

gen VaR_CRBAc1_CORP=K_CRBAc1_CORP+MProv1

gen K_CRBAc2_CORP=ACRBAc2_CORP*(ca-MProv2)*0.11

gen VaR_CRBAc2_CORP $=\mathrm{K} \_C R B A c 2 \_C O R P+M P r o v 2$

$* * * * * * * * * * * * * * * * * * * * * * *$ Ajustes amostrais $* * * * * * * * * * * * * * * * * * *$

local expsize $1=0.13895$

///até R $\$ 5.000,00(\mathrm{PF})$ expsize $=500$

local expsize $2=0.21147$

///entre R \$5 mil e R $\$ 50$ mil (PF) expsize $=550$

local expsize $3=0.09393$

///acima de $\mathrm{R} \$ 50 \mathrm{mil}(\mathrm{PF})$ expsize $=555$ 
local expsize $4=0.09613$

/// até $\mathrm{R} \$ 100$ mil $(\mathrm{PJ})$ expsize $=1000$

local expsize $5=0.22558$

/// entre $\mathrm{R} \$ 100$ mil e $\mathrm{R} \$ 10 \mathrm{MM}$ expsize $=1100$

local expsize $6=0.23392$

/// acima de $\mathrm{R} \$ 10 \mathrm{MM}$ expsize $=1110$

sum ca

local $b=r($ sum $)$

sum ca if expsize $==500$

local $\mathrm{a} 1=\mathrm{r}(\mathrm{sum}) / \mathrm{b}^{\prime}$

sum ca if expsize $==550$

local $\mathrm{a} 2=\mathrm{r}(\mathrm{sum}) / \mathrm{hb}^{\prime}$

sum ca if expsize $==555$

local a3 $=\mathrm{r}(\mathrm{sum}) / \mathrm{h}^{\prime}$

sum ca if expsize $==1000$

local $\mathrm{a} 4=\mathrm{r}(\mathrm{sum}) / \mathrm{h}^{\prime}$

sum ca if expsize $==1100$

local a5=r(sum)/ ` $\mathrm{b}$ '

sum ca if expsize $==1110$

local $\mathrm{a} 6=\mathrm{r}(\mathrm{sum}) / \mathrm{Cb}^{\prime}$

gen weights $=1$

replace weights=round ('expsize1'/ a a1') if expsize $==500$

replace weights=round ('expsize2' $/$ ' a2') if expsize $==550$

replace weights=round ('expsize 3 ' $/$ a 3 ') if expsize $==555$

replace weights=round ('expsize 4 ' $/$ a 4 ') if expsize $==1000$

replace weights=round ('expsize5' $/$ a5') if expsize $==1100$

replace weights=round('expsize6 6 ' ${ }^{\circ}$ a6') if expsize $==1110$

expand weights if expsize $==500 / / /$ repondera a base de dados

gen perdas $=$ LGD*dloss

gen pecon $=$ LGD $*$ tloss

gen $w R=c a * r$

gen $\mathrm{mPD}=\mathrm{ca} * \mathrm{PD}$

save "Simples.dta", replace 
10. APÊNDICE B: CÓDIGOS STATA PARA BOOTSTRAPPING

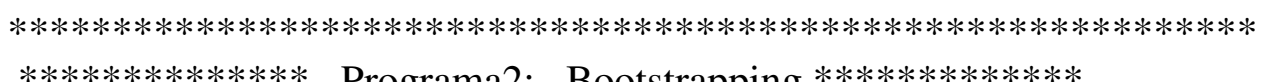

**************** Programa2: Bootstrapping $* * * * * * * * * * * * *$

program simu, rclass

version 11

summarize dloss

local dloss $=\mathrm{r}($ sum $)$

summarize ca

local ca $=\mathrm{r}($ sum $)$

return scalar carteira $=$ 'ca'

return scalar inadimplencia $=` d l o s s ' / \mathrm{ca}^{\prime}$

summarize tloss

local tloss $=\mathrm{r}(\mathrm{sum})$

return scalar Tloss $={ }^{\prime}$ tloss' $/{ }^{\prime} \mathrm{ca}^{\prime}$

summarize EL

local $\mathrm{EL}=\mathrm{r}(\mathrm{sum})$

return scalar Eloss $={ }^{`} \mathrm{EL}^{\prime} / \mathrm{ca}^{\prime}$

summarize MProv

local MProv $=r($ sum $)$

return scalar MinProv $=`$ MProv'/ $\mathrm{ca}^{\prime}$

summarize WLGD

local WLGD = r(sum)

return scalar wLGD $={ }^{\prime}$ WLGD' $/ \mathrm{ca}^{\prime}$

summarize VaR

local $\mathrm{VaR}=\mathrm{r}(\mathrm{sum})$

return scalar VAR $=$ 'VaR'/ ca'

summarize VaR_2682

local VaR_2682 = r(sum)

return scalar VAR2682 = 'VaR_2682' $/ \mathrm{ca}^{\prime}$

summarize VaR_SSA

local VaR_SSA =r(sum)

return scalar VAR_SSA $=$ 'VaR_SSA'/ $\mathrm{ca}^{\prime}$

summarize VaR_b1 


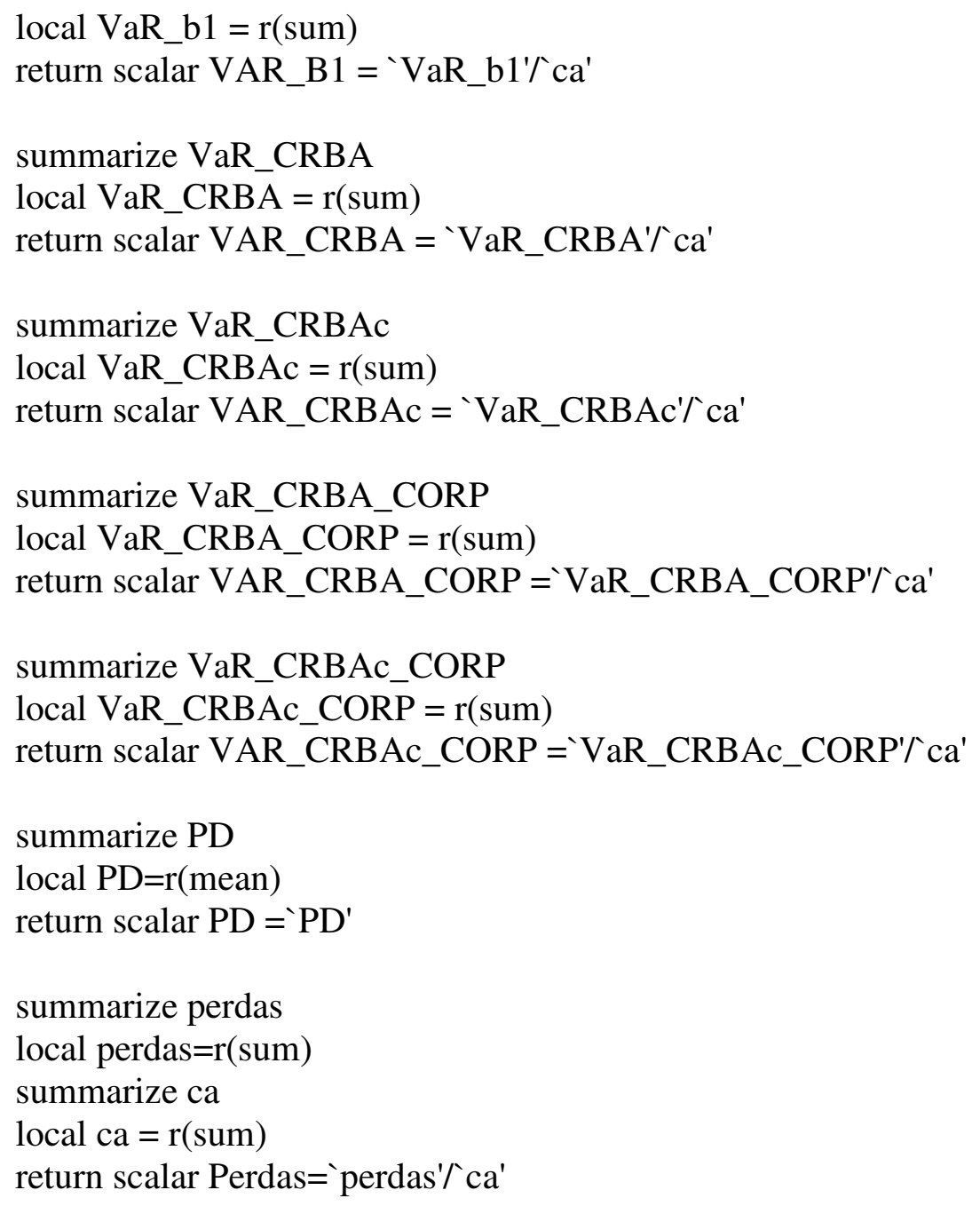




\section{APÊNDICE C: CÓDIGOS STATA PARA SIMULAÇÃo DE MONTE CARLO}

***********************Programa 3: Simulação de Monte Carlo

* Set-up inserir TAMANHO LIMITE

local size $2=500000000$

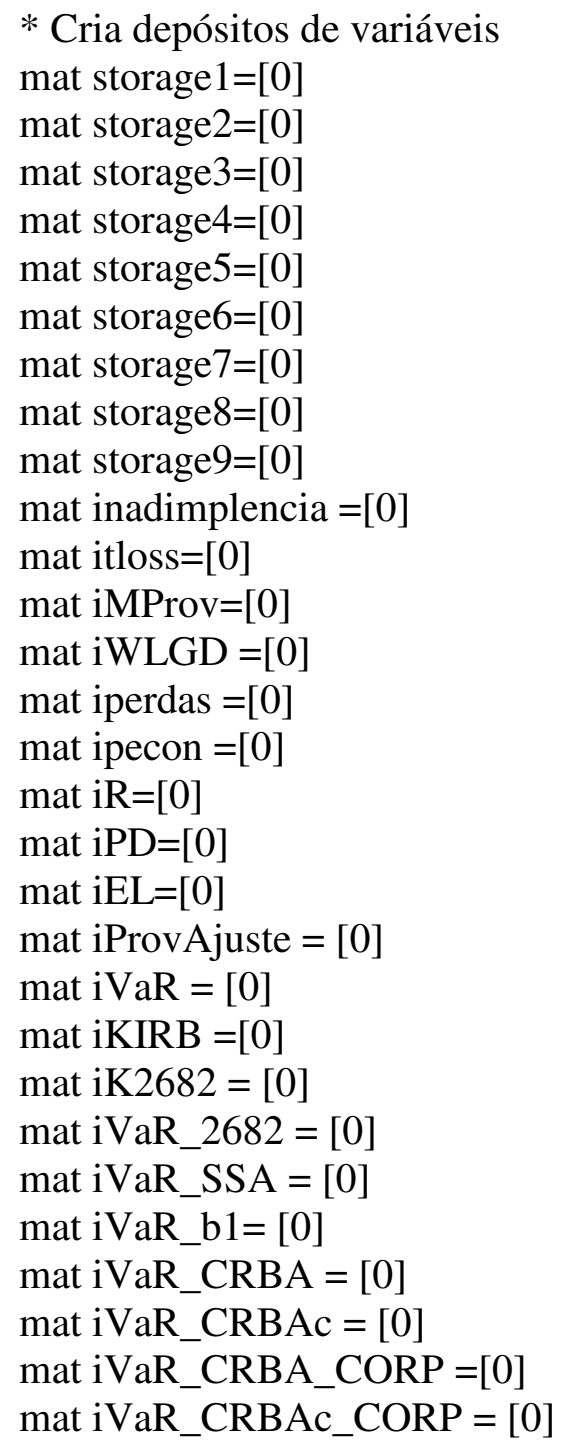

*Distribuição populacional do SFN em saldo por modalidades em dezembro de 2010. local Stype $1=0.15398$

local Stype $2=0.19801$

local Stype $3=0.05084$

local Stype $4=0.04153$

local Stype $5=0.22035$ 
local Stype $6=0.24792$

local Stype $7=0.08010$

local Stype $8=0.00727$

sum tcredit if tcredit $==1$

local Type $1=r(\mathrm{~N})+1$

sum tcredit if tcredit==2

local Type $2=r(N)+1$

sum tcredit if tcredit $==3$

local Type $3=r(\mathrm{~N})+1$

sum tcredit if tcredit $==4$

local Type $4=r(N)+1$

sum tcredit if tcredit $==5$

local Type $5=\mathrm{r}(\mathrm{N})+1$

sum tcredit if tcredit $==6$

local Type $6=r(N)+1$

sum tcredit if tcredit $==7$

local Type $7=\mathrm{r}(\mathrm{N})+1$

sum tcredit if tcredit $==8$

local Type $8=r(\mathrm{~N})+1$

* Impor o número 'b' de repetições (ex.3) Sugere-se ao menos 10.000.

set more off

forvalues $\mathrm{i}=1(1) 10000\{$

********** Sorteio para reproduzir a ponderação populacional do SFN

*Tamanho da amostra por modalidade em n exposições

gen group $=0$

* 15,398\% Type 1

gen drawer $=$ runiform ()

gen trash $=-1$ if tcredit==1

recode trash $(.=0)$

sort trash drawer

gen cum_ca=sum(ca)

sum cum_ca if cum_ca<'size 2'*'Stype1'

recode $\operatorname{group}(0=1)$ if _n<'Type 1 '\&_n $<\mathrm{r}(\mathrm{N})$

drop drawer trash cum_ca

* Observe que a amostra é ponderada para refletir o perfil do SFN: $15,398 \%$ representa a parcela///

/// do Consumo PF em R\$MM de dezembro de 2010

* $19,801 \%$ Type 2 
gen drawer $=$ runiform ()

gen $\operatorname{trash}=-1$ if tcredit==2

recode trash $(.=0)$

sort trash drawer

gen cum_ca=sum(ca)

sum cum_ca if cum_ca<'size2'*'Stype 2'

recode group $(0=1)$ if _n $<{ }^{\prime}$ Type $2 ' \& \_n<r(N)$

drop drawer trash cum_ca

* 5,084\% Type 3

gen drawer $=$ runiform ()

gen trash $=-1$ if tcredit==3

recode trash $(.=0)$

sort trash drawer

gen cum_ca=sum(ca)

sum cum_ca if cum_ca<'size 2'*'Stype 3 '

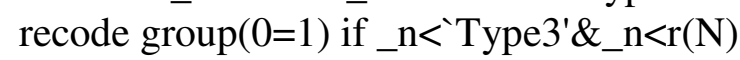

drop drawer trash cum_ca

* 4,153\% Type 4

gen drawer $=$ runiform ()

gen trash $=-1$ if tcredit==4

recode trash $(.=0)$

sort trash drawer

gen cum_ca=sum(ca)

sum cum_ca if cum_ca<'size 2'*'Stype 4'

recode group $(0=1)$ if _n $<$ 'Type4'\&_n $<\mathrm{r}(\mathrm{N})$

drop drawer trash cum_ca

\section{* 22,035\% Type 5}

gen drawer $=$ runiform ()

gen trash $=-1$ if tcredit $==5$

recode trash $(.=0)$

sort trash drawer

gen cum_ca=sum(ca)

sum cum_ca if cum_ca<'size $2{ }^{\prime *}$ 'Stype 5'

recode group $(0=1)$ if _n $<{ }^{\prime}$ Type 5 ' $\& \_n<r(N)$

drop drawer trash cum_ca

\section{* 24,792\% Type 6}

gen drawer $=$ runiform ()

gen trash $=-1$ if tcredit $==6$

recode trash $(.=0)$

sort trash drawer

gen cum_ca=sum(ca)

sum cum_ca if cum_ca<`size2'*'Stype6'

recode group $(0=1)$ if _n $<{ }^{\prime}$ Type6' $\& \_n<r(N)$

drop drawer trash cum_ca 
* 8,010\% Type 7

gen drawer $=$ runiform ()

gen trash $=-1$ if tcredit $==7$

recode trash $(.=0)$

sort trash drawer

gen cum_ca=sum(ca)

sum cum_ca if cum_ca<'size2'*'Stype7'

recode group $(0=1)$ if _n<'Type7'\&_n<r(N)

drop drawer trash cum_ca

* $0,727 \%$ Type 8

gen drawer $=$ runiform ()

gen $\operatorname{trash}=-1$ if tcredit $==8$

recode trash $(.=0)$

sort trash drawer

gen cum_ca=sum(ca)

sum cum_ca if cum_ca<'size 2'*'Stype 8 '

recode group $(0=1)$ if _n<'Type 8 ' $\& \_n<r(N)$

drop drawer trash cum_ca

*Criando ' $v$ ' variáveis para os portfólios simulados

sum group if group $==1$

mat storage $1=$ storage $1 \backslash \mathrm{r}$ (sum)

sum ca if group $==1$

local ca $=r($ sum $)$

mat storage $2=$ storage $2 \backslash \mathrm{r}($ sum $)$

sum dloss if group $==1$

local dloss $=\mathrm{r}($ sum $)$

mat storage $3=$ storage $3 \backslash \mathrm{r}($ sum $)$

sum tloss if group $==1$

mat storage $4=$ storage $4 \backslash \mathrm{r}(\mathrm{sum})$

local tloss $=r($ sum $)$

sum WLGD if group==1

local WLGD = r(sum)

sum MProv if group $==1$

mat storage $7=$ storage $7 \backslash \mathrm{r}($ sum $)$

local MProv $=r($ sum $)$

sum perdas if group $==1$

mat storage $8=$ storage $8 \backslash \mathrm{r}($ sum $)$

local perdas $=r($ sum $)$

sum pecon if group $==1$ 


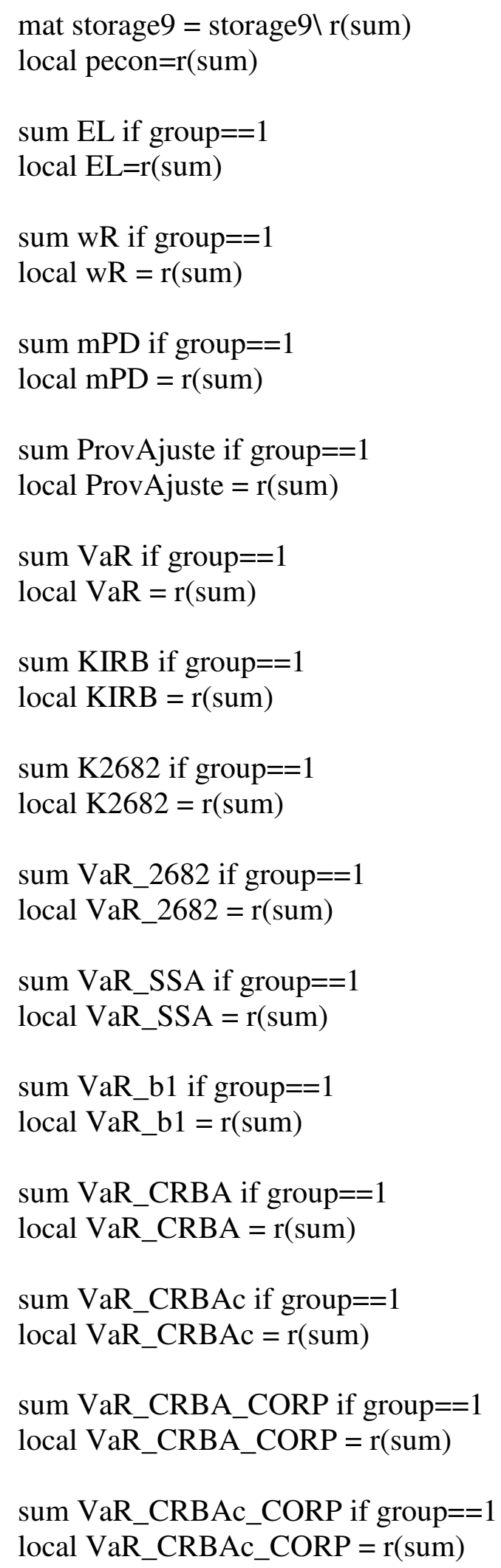




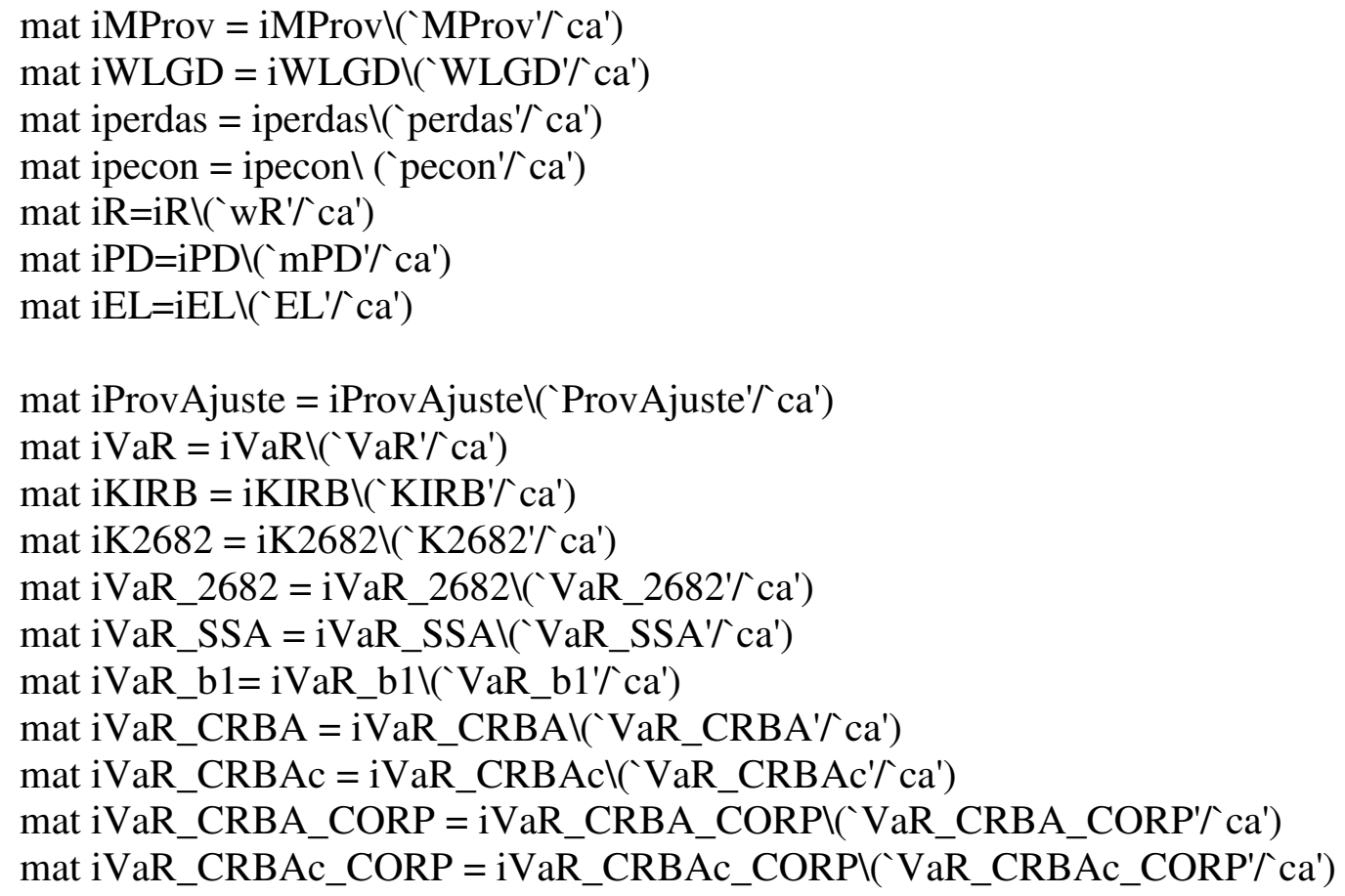

drop group

noisily: di 'i'

\}

$* * * * * * * * * * * * * * * * * * * * * * * * * * * *$

$* * * * * * * * * * * * * * * * * * * * * * * * * * * *$

$* * * * * * * * * * * * * * * * * * * * * * * * * * *$

$* * * * * * * * * * * * * * * * * * * * * * * * * * *$

clear

set more off

mat istorage $=$ storage 1 , storage 2 , storage9, inadimplencia, itloss, iMProv, ///

iWLGD, iperdas, ipecon, iR, iPD, iEL, iProvAjuste, iVaR, iKIRB, iK2682,iVaR_2682, ///

iVaR_SSA,iVaR_b1,iVaR_CRBA,iVaR_CRBAc,iVaR_CRBA_CORP,

iVaR_CRBAc_CORP

* Transforma matrizes em variáveis

svmat istorage

gen id = _n

sum id

drop if $\mathrm{id}==1$

format istorage 1 - istorage $23 \% 15.0 \mathrm{~g}$

rename istorage $1 \mathrm{~N}$ 
rename istorage $2 \mathrm{ca}$

rename istorage 3 pecon

rename istorage 4 inadimplencia

rename istorage 5 tloss

rename istorage6 iMProv

rename istorage $7 \mathrm{iWLGD}$

rename istorage 8 iperdas

rename istorage9 ipecon

rename istorage $10 \mathrm{iR}$

rename istorage $11 \mathrm{iPD}$

rename istorage $12 \mathrm{iEL}$

rename istorage 13 iProvAjuste

rename istorage $14 \mathrm{iVaR}$

rename istorage $15 \mathrm{iKIRB}$

rename istorage $16 \mathrm{iK} 2682$

rename istorage17 $\mathrm{iVaR} \_2682$

rename istorage $18 \mathrm{iVaR} \_S S A$

rename istorage $19 \mathrm{iVaR \_ b1}$

rename istorage $20 \mathrm{iVaR}$ _CRBA

rename istorage $21 \mathrm{iVaR}$ CRBAc

rename istorage22 iVaR_CRBA_CORP

rename istorage23 iVaR_CRBAc_CORP

save "500Msimples_totalexpand.dta", replace 